\title{
Marcos teóricos de PISA 2003
}

Conocimientos y destrezas en Matemáticas, Lectura, Ciencias y Solución de problemas 



\section{inecse}

\section{Marcos teóricos de PISA 2003}

Conocimientos y destrezas en Matemáticas, Lectura, Ciencias y Solución de problemas 
Marcos teóricos de PISA 2003 : la medida de los conocimientos y destrezas en matemáticas, lectura, ciencias y resolución de problemas / OCDE. - Madrid : Ministerio de Educación y Ciencia, Instituto Nacional de Evaluación y Calidad del Sistema Educativo, 2004

226 p. : il., gráf., tablas

1. Evaluación. 2. Medida del rendimiento. 3. Alumno. 4. Matemáticas. 5. Lectura. 6. Ciencias de la naturaleza. 8. Solución de problemas. 9. Enseñanza secundaria. 10. Investigación transnacional. I. OCDE. II. INECSE (España). III. Proyecto Pisa

371.27 Evaluación

Publicado originalmente por la OCDE en Inglés y Francés con los títulos:

PISA

The PISA 2003 Assessment Framework: Mathematicas, Reading, Science and Problem Solving Knowledge and Skills

PISA

Cadre d'évaluation de PISA 2003: connaissances et compétences en mathématiques, lecture, science et résolution de problèmes

(C) 2003, Organisation for Economic Co-operation and Development (OECD), Paris.

Todos los derechos reservados

Para la edición en castellano:

(C) 2004, Organisation for Economic Co-operation and Development (OECD) e Instituto Nacional de Evaluación y Calidad del Sistema Educativo (INECSE).

Publicado por acuerdo con la OCDE, París.

La calidad de la traducción al castellano y de su correspondencia con el texto original es responsabilidad del Instituto Nacional de Evaluación y Calidad del Sistema Educativo (INECSE)

Traducción: Encarnación Belmonte

Revisión: Ramón Pajares Box

Maquetación: Sonia García Rincón

\section{螋鼓}

MINISTERIO DE EDUCACIÓN Y CIENCIA

SECRETARÍA GENERAL DE EDUCACIÓN

Instituto Nacional de Evaluación y Calidad del Sistema Educativo (I.N.E.C.S.E.)

Edita:

(C) SECRETARÍA GENERAL TÉCNICA

Subdirección General de Información y Publicaciones

N.I.P.O.:

I.S.B.N.

Depósito Legal:

Imprime: 


\section{LA ORGANIZACIÓN PARA LA COOPERACIÓN Y EL DESARROLLO ECONÓMICOS}

De acuerdo con el Artículo 1 de la Convención firmada en París, el 14 de diciembre de 1960, que entró en vigor el 30 de septiembre de 1961, la Organización para la Cooperación y el Desarrollo Económicos (OCDE) deberá promover políticas diseñadas para:

- Alcanzar el empleo y el crecimiento económico sostenible más alto y un nivel de vida creciente en los países miembros, a la vez que se mantenga la estabilidad financiera, contribuyéndose de ese modo al desarrollo de la economía mundial;

- Contribuir a la expansión económica sólidamente fundamentada en el proceso de desarrollo económico, tanto en los países miembros como en los países que no son miembros;

- Contribuir a la expansión del comercio internacional de modo multilateral y no discriminatorio de acuerdo con las obligaciones internacionales.

Los países miembros originales de la OCDE son Alemania, Austria, Bélgica, Canadá, Dinamarca, España, Estados Unidos de Norteamérica, Francia, Grecia, Holanda, Irlanda, Islandia, Italia, Luxemburgo, Noruega, Portugal, Reino Unido, Suecia, Suiza y Turquía. Los siguientes países han llegado a ser miembros posteriormente mediante su acceso en las fechas indicadas a continuación: Japón (18 de abril de 1964), Finlandia (28 de enero de 1969), Australia (17 de junio de 1971), Nueva Zelanda (29 de mayo de 1973), México (18 de mayo de 1994), República Checa (21 de diciembre de 1995), Hungría (7 de mayo de 1996), Polonia (22 de noviembre de 1996), Corea (12 de diciembre de 1996) y República Eslovaca (14 de diciembre de 2000). La Comisión de las Comunidades Europeas toma parte en el trabajo de la OCDE (Artículo 13 de la Convención de la OCDE). 



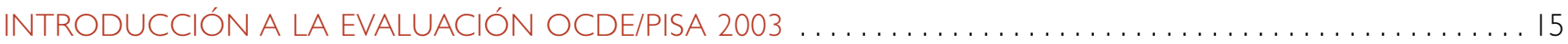

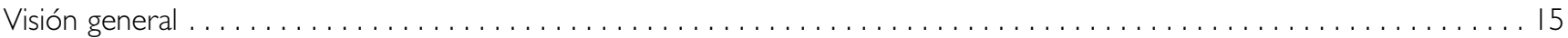

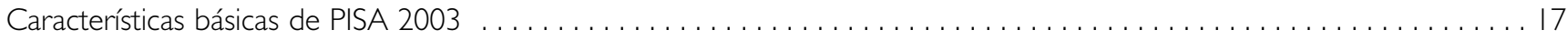

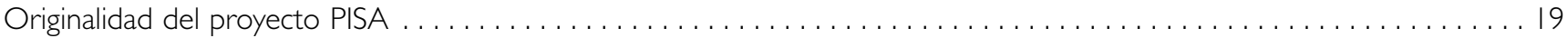

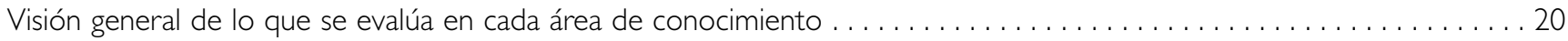

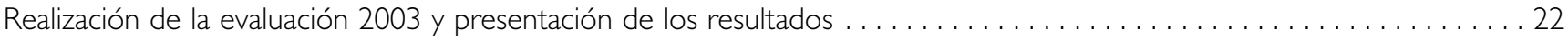

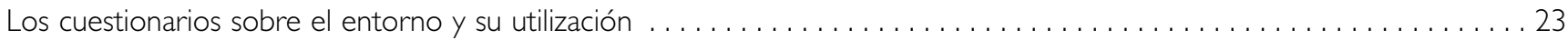

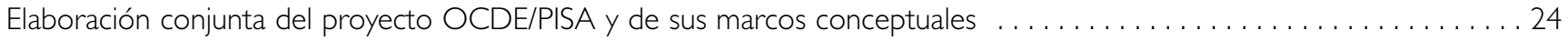

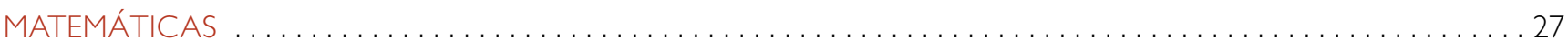

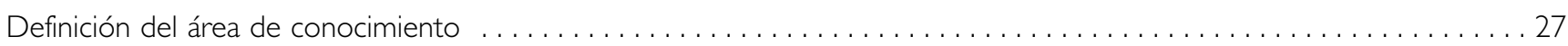

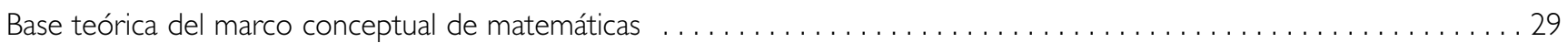

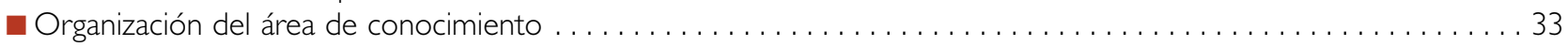

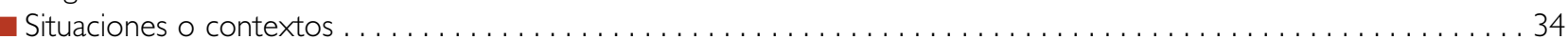

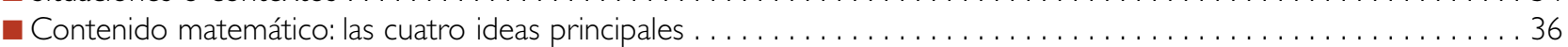

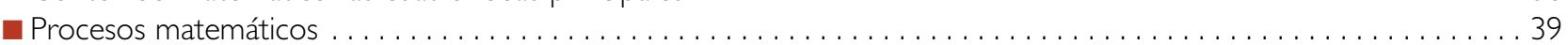

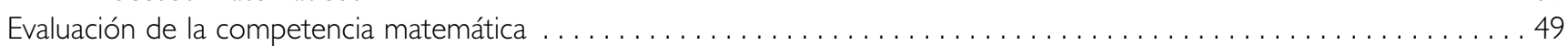

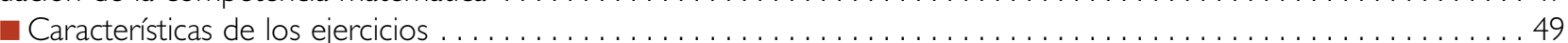

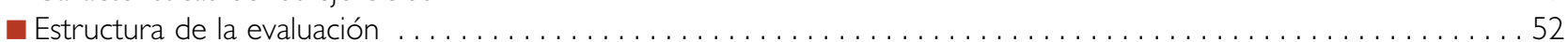

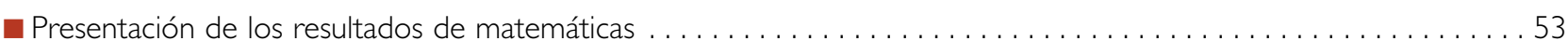

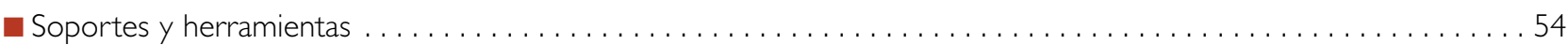

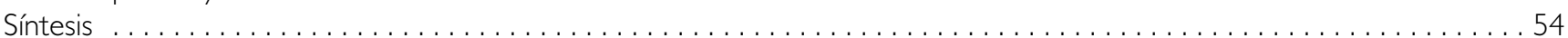




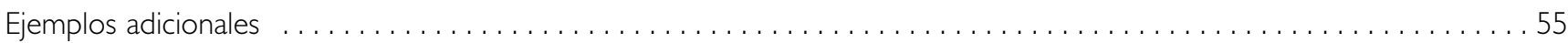

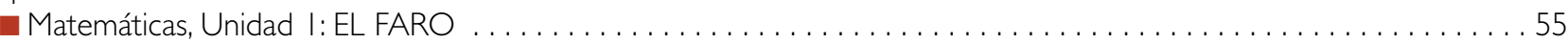

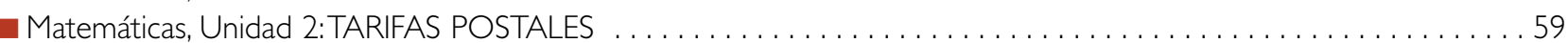

- Matemáticas, Unidad 3: LATIDOS DEL CORAZÓN . . . . . . . . . . . . . . . . . . . . . . . . . . . . . . . . . . . 62

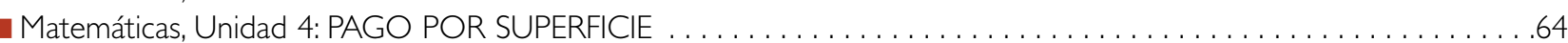

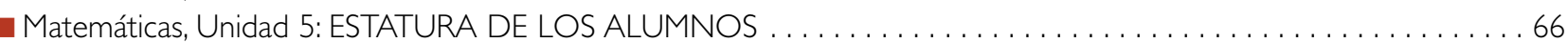

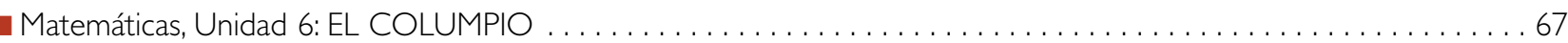

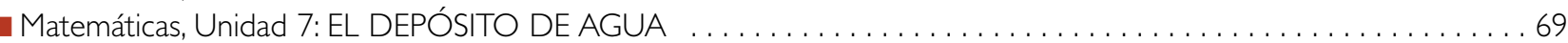

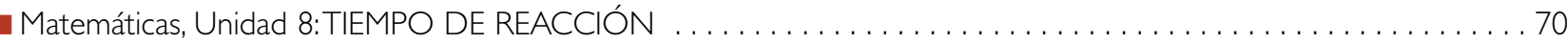

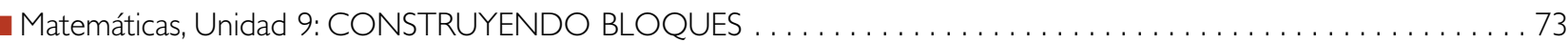

Matemáticas, Unidad I0: CONCENTRACIÓN DE UN FÁRMACO $\ldots \ldots \ldots \ldots \ldots \ldots \ldots \ldots \ldots \ldots \ldots \ldots$

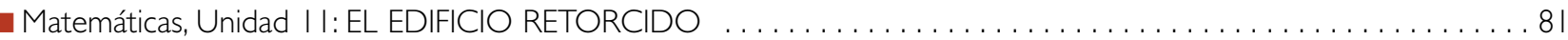

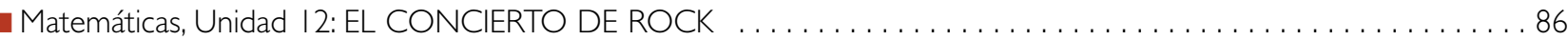

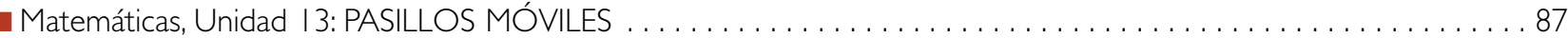

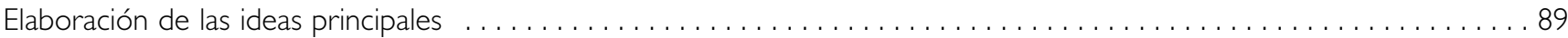

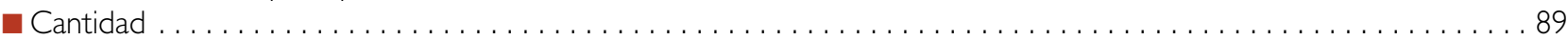

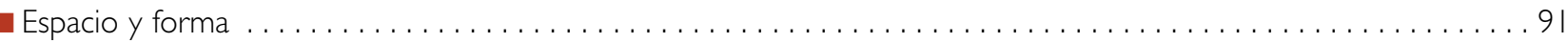

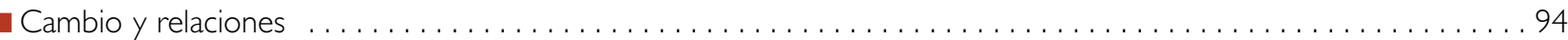

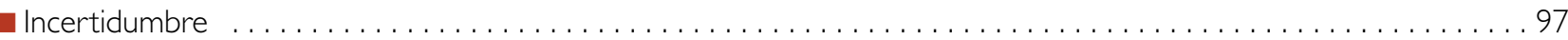

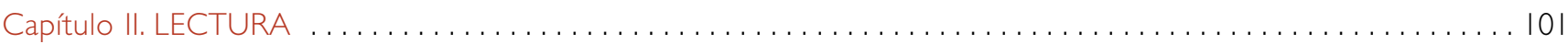

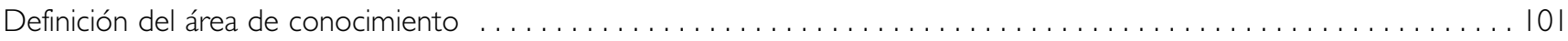

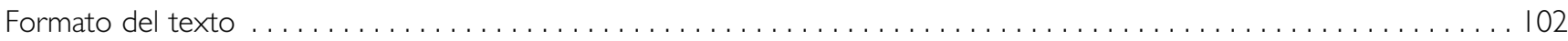

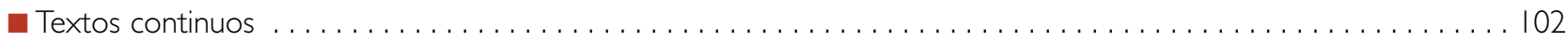

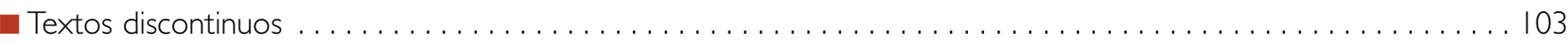

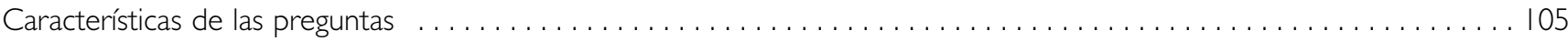

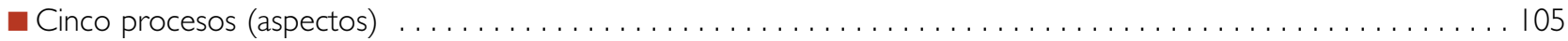

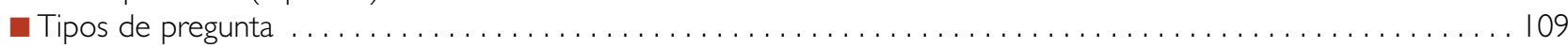

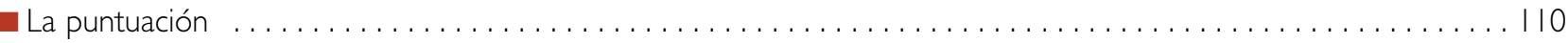

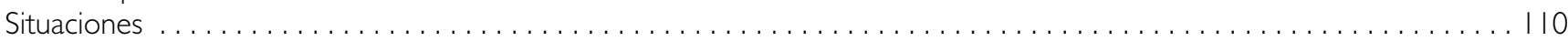

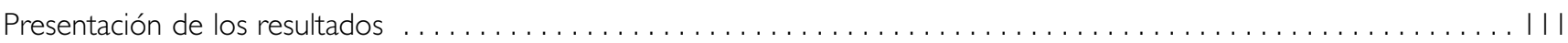

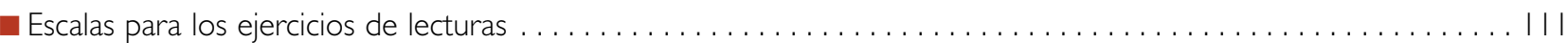

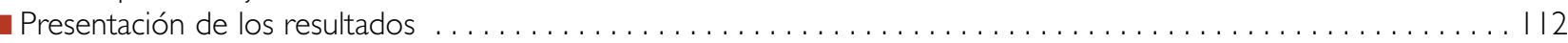

Elaboración de una planificación de preguntas .................................... 14

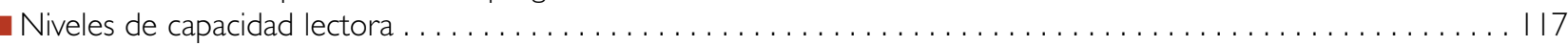

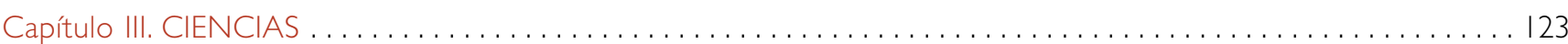

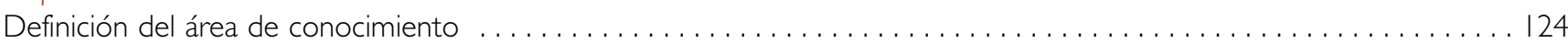

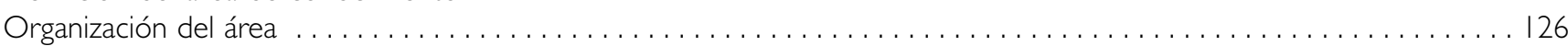

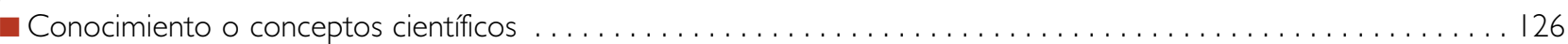

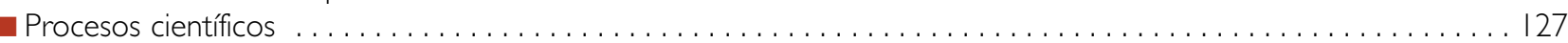

- Situaciones o contexto: áreas de aplicación . . . . . . . . . . . . . . . . . . . . . . . . . . . . . . . . . . . . . I29

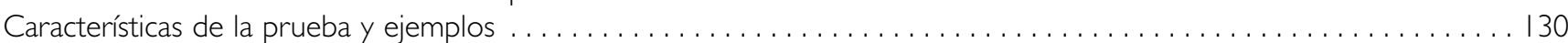

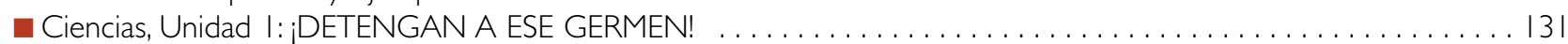

- Ciencias, Unidad 2: PETER CAIRNEY . . . . . . . . . . . . . . . . . . . . . . . . . . . . . . . . . . . . 133

- Ciencias, Unidad 3: MAílZ . . . . . . . . . . . . . . . . . . . . . . . . . . . . . . . . . . . . . . . . . . . . . . . . . . . . . . 137 


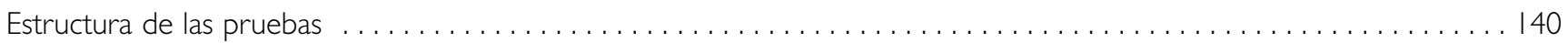

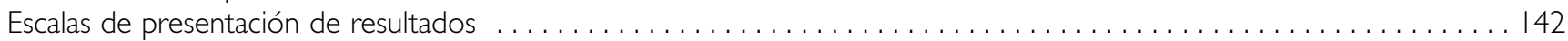

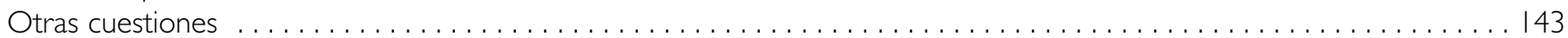

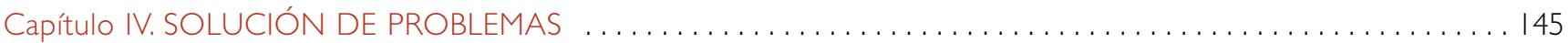

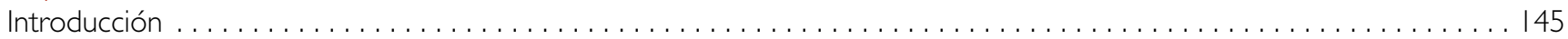

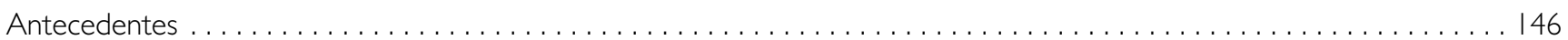

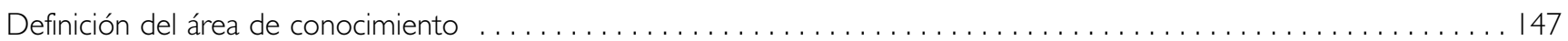

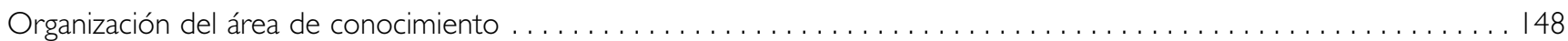

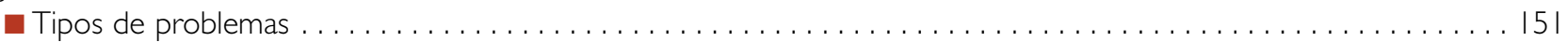

- Solución de problemas, Unidad I: NO AL DOLOR ............................. 52

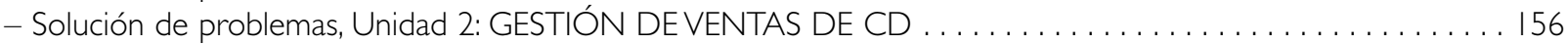

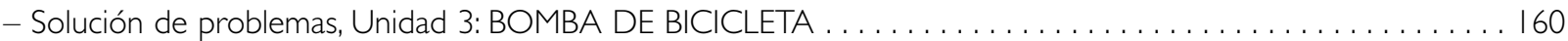

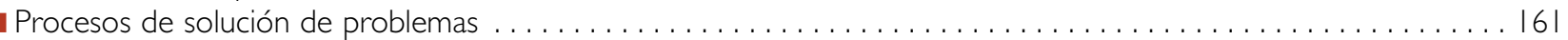

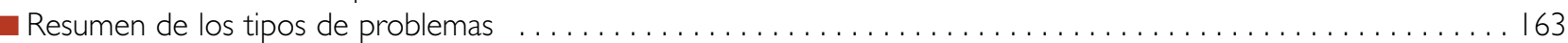

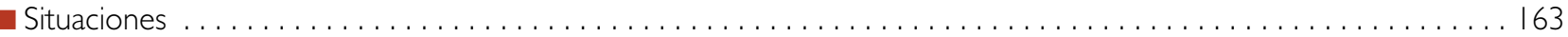

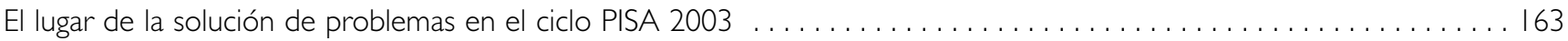

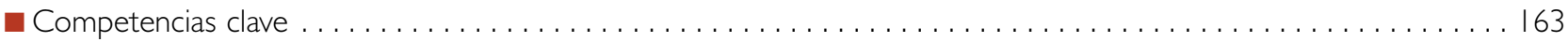

El papel de la solución de problemas en las tendencias del empleo y en la demanda de destrezas ........... I64

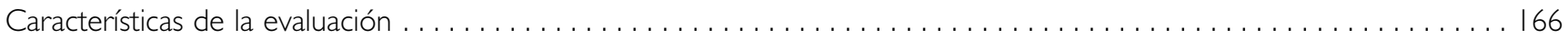

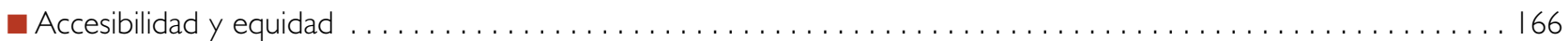

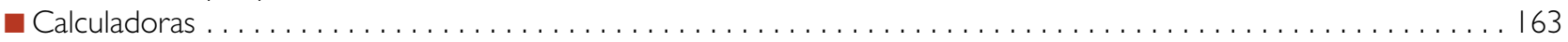

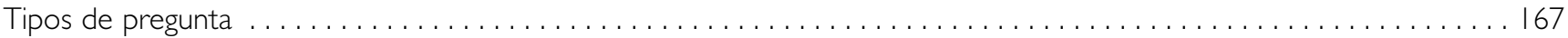

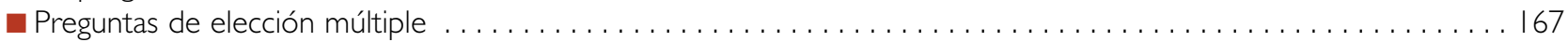

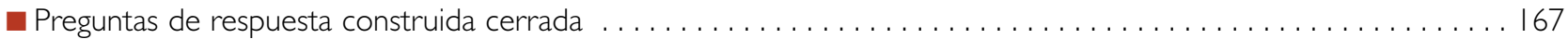

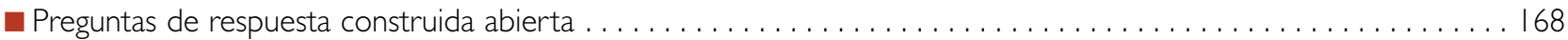

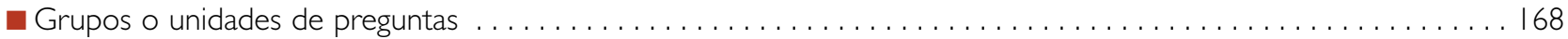

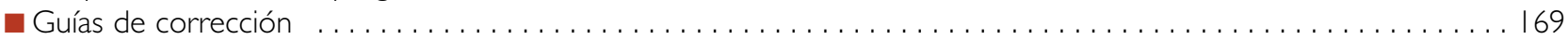

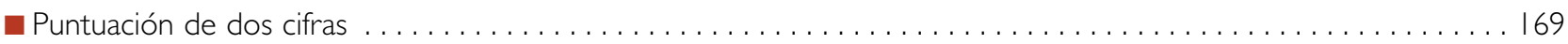

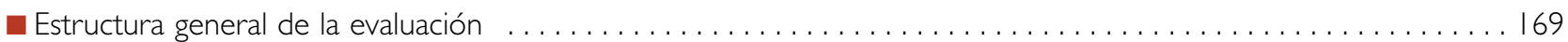

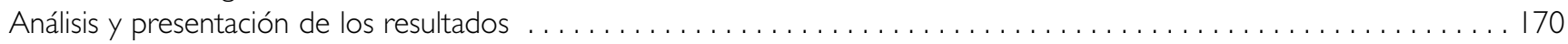

Ampliaciones potenciales del marco conceptual para futuros ciclos OCDE/PISA . . . . . . . . . . . . . . . . I70

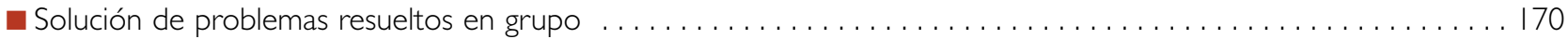

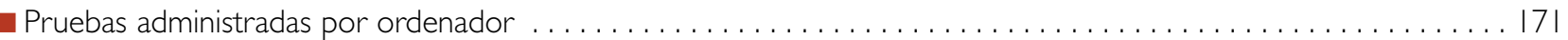

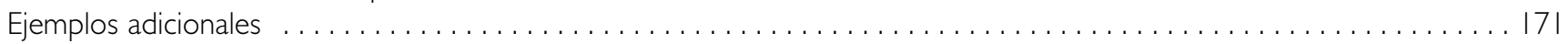

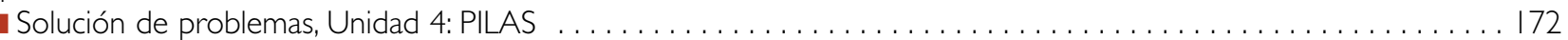

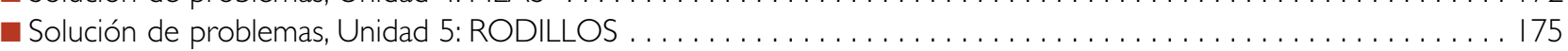

- Solución de problemas, Unidad 6:VENTA DE LIBROS ........................... 80

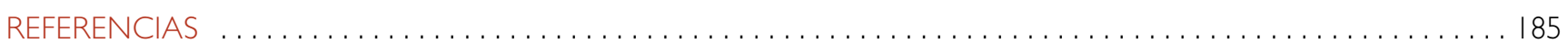

APÉNDICE $\ldots \ldots \ldots \ldots \ldots \ldots \ldots \ldots \ldots \ldots \ldots \ldots \ldots \ldots \ldots \ldots \ldots \ldots \ldots \ldots \ldots \ldots \ldots \ldots \ldots \ldots$ 



\section{ᄀ PRÓLOGO}

El Proyecto Internacional para la Producción de Indicadores de Rendimiento de los Alumnos (PISA), creado en 1997, constituye un compromiso por parte de los gobiernos de los países miembros de la OCDE para establecer un seguimiento de los resultados de los sistemas educativos en cuanto al rendimiento de los alumnos, dentro de un marco internacional común. El proyecto OCDE/PISA constituye, ante todo, un esfuerzo de colaboración que aúna los conocimientos científicos de los países participantes y que está dirigido de manera conjunta por los gobiernos respectivos, a partir de intereses políticos comunes. Los países participantes se encargan de los aspectos del proyecto relacionados con la política educativa. Además, los expertos de los países participantes colaboran también en grupos de trabajo encargados de aunar los objetivos políticos del proyecto PISA con los conocimientos técnicos y de contenido más avanzados en el campo de las evaluaciones comparativas a escala internacional. A través de la participación en estos grupos de expertos, los países garantizan que los instrumentos de evaluación del proyecto OCDE/PISA adquieran validez internacional y tengan en cuenta el contexto cultural y curricular de cada uno de los países miembros de la OCDE, además de poseer propiedades métricas sólidas y de poner de relieve su autenticidad y validez educativas.

El proyecto PISA 2003 constituye la continuación del plan de obtención de datos de rendimiento de los alumnos adoptado en 1997 por los países de la OCDE. Las áreas de conocimiento evaluadas parten de las ya consideradas en 
el proyecto PISA 2000. No obstante, mientras que en PISA 2000 se hizo hincapié en la evaluación de la lectura, en PISA 2003 se incide en la competencia matemática, definida como la capacidad de los estudiantes para reconocer, comprender y participar en las matemáticas y opinar con fundamento sobre el papel que desempeñan las matemáticas en la vida diaria. Además, como nuevo elemento del proyecto PISA, se ha añadido la evaluación de la capacidad de resolución de problemas, definida como la competencia de los estudiantes a la hora de utilizar procesos cognitivos para resolver problemas interdisciplinarios sin una solución obvia.

Esta publicación presenta los principios que guían la evaluación PISA 2003, descrita en términos de los contenidos que los estudiantes necesitan adquirir, los procesos que deben realizar y el contexto en que se aplican los conocimientos y destrezas. También ilustra los campos de evaluación mediante diferentes ejercicios de ejemplo. Éstos han sido desarrollados por comités de expertos bajo la dirección de Raymond Adams, Barry McCrae, Ross
Turner y Margaret Wu, miembros del Australian Council for Educational Research (ACER, Consejo Australiano de Investigación Educativa). El comité de matemáticas lo dirigió Jan de Lange, de la Universidad de Utrecht (Países Bajos); el comité de expertos en lectura estuvo dirigido por Irwin Kirsch, del Educational Testing Service (ETS, Servicio de Evaluación Educativa de los Estados Unidos); Wynne Harlen, del Reino Unido, dirigió el comité de expertos en ciencias; y el comité de expertos en resolución de problemas estuvo dirigido por John Dossey, de la Illinois State University (Universidad del Estado de Illinois, Estados Unidos). En el Apéndice de esta publicación se mencionan los nombres de los miembros de los grupos de expertos. Los marcos conceptuales han sido examinados también por comités de expertos de cada uno de los países participantes.

Esta publicación ha sido preparada por la Dirección de Educación de la OCDE, bajo la dirección de Andreas Schleicher y Claudia Tamassia. Se publica bajo la responsabilidad del secretario general de la OCDE. 


\section{ᄀ INTRODUCCIÓN A LA EVALUACIÓN OCDE/PISA 2003}

\section{Visión general}

El Proyecto Internacional para la Producción de Indicadores de Rendimiento de los Alumnos (PISA) de la OCDE representa un esfuerzo de colaboración entre los países miembros de la OCDE para medir el grado en que los estudiantes de 15 años — por tanto, aproximándose al final de la escolaridad obligatoria - están preparados para enfrentarse a los desafíos de las sociedades de hoy en día. La evaluación OCDE/PISA adopta un enfoque amplio para evaluar el conocimiento y las destrezas que reflejan los cambios actuales de los currículos, superando el enfoque basado en la escuela y teniendo en cuenta la utilización del conocimiento en las tareas y desafíos de cada día. Estas destrezas reflejan la capacidad de los estudiantes para continuar aprendiendo a lo largo de su vida al aplicar a contextos no escolares lo que han aprendido en la escuela, al valorar sus elecciones y al tomar sus decisiones. La evaluación, dirigida conjuntamente por los gobiernos participantes, aúna las preocupaciones de política educativa de los países participantes con las competencias científicas disponibles en el ámbito nacional e internacional. 
El proyecto OCDE/PISA combina la evaluación de áreas de conocimiento específicas como la lectura, las matemáticas y las ciencias con la de determinadas áreas transcurriculares que también constituyen una prioridad en los países de la OCDE. Estas áreas se estudian mediante una evaluación del aprendizaje autorregulado y las tecnologías de la información, que se complementa en el año 2003 con una evaluación de la competencia para solucionar problemas. Los resultados se asocian posteriormente con la información de contexto de los estudiantes, familias e instituciones, recogida a través de los cuestionarios. El proyecto OCDE/PISA se basa en: i) mecanismos sólidos para garantizar la calidad de la traducción, del muestreo y de la recogida de datos; ii) medidas para conseguir una amplia representatividad cultural y lingüística en los materiales de la evaluación, especialmente a través de la participación de los países en los procesos de elaboración y puesta a punto y en las comisiones de revisión cultural; y iii) la metodología más reciente para el análisis de datos. La combinación de estas medidas produce instrumentos de alta calidad y resultados con altos niveles de validez y fiabilidad, que mejoran la comprensión de los sistemas educativos y de las características de los estudiantes.

El proyecto OCDE/PISA se basa en un modelo dinámico de aprendizaje en el que los nuevos conocimientos y las destrezas necesarios para adaptarse con éxito a un mundo cambiante se van adquiriendo a lo largo de toda la vida. El proyecto OCDE/PISA se centra en las cosas que los estudiantes de 15 años necesitarán en el futuro y pretende valorar lo que son capaces de hacer con lo que han aprendido. La evaluación tiene en cuenta el denominador común de los currículos nacionales —aunque no está limitada por él一. Así, al tiempo que evalúa los conoci- mientos de los estudiantes, el proyecto OCDE/PISA también examina su capacidad para reflejar y aplicar su conocimiento y experiencia a los asuntos del mundo real. Por ejemplo, para entender y evaluar los consejos científicos sobre seguridad de la alimentación, un adulto no sólo necesitará conocer algunos datos básicos sobre la composición de los nutrientes, sino que también deberá ser capaz de aplicar esa información. Se utiliza el término competencia para condensar esta concepción amplia de los conocimientos y destrezas.

El proyecto OCDE/PISA fue ideado para recoger información de una manera rápida y eficiente mediante ciclos de tres años. Presenta datos sobre la competencia lectora, matemática y científica de los estudiantes, las escuelas y los países, proporciona nuevas perspectivas sobre los factores que influyen en el desarrollo de estas destrezas en el hogar y en la escuela, y examina cómo interactúan estos factores y cuáles son las implicaciones para el desarrollo de las políticas educativas.

Esta publicación presenta el marco conceptual que sirve de base para las evaluaciones del proyecto PISA 2003. Está constituido por el marco conceptual para la evaluación de la competencia lectora y científica del ciclo PISA 2000, un marco conceptual ampliado para la evaluación en profundidad de la competencia matemática y el marco conceptual para la nueva evaluación de la solución de problemas como competencia transcurricular. Dentro de cada área de conocimiento, el marco conceptual define los contenidos que los estudiantes necesitan adquirir, los procesos que deben realizarse y el contexto en que se aplican los conocimientos y las destrezas. Por último, ilustra las áreas de conocimiento y sus facetas mediante ejercicios de ejemplo.

\section{Cuadro 1. ¿Qué es el proyecto OCDE/PISA? \\ Características básicas}

\section{Principios}

- Una evaluación estandarizada desarrollada internacionalmente y de manera conjunta por los países participantes y aplicada a los alumnos de 15 años escolarizados en sus centros educativos.

- Un estudio aplicado en 43 países en el primer ciclo (32 en 2000 y 11 en 2002) y en 42 países en el segundo ciclo (2003).

- Por regla general se examinan entre 4.500 y 10.000 estudiantes en cada país. 


\section{Contenido}

- El proyecto OCDE/PISA 2003 engloba las áreas de lectura, matemáticas y ciencias no sólo en lo relativo al dominio del currículo escolar, sino también en lo referente a las destrezas y conocimientos necesarios en la vida adulta. El examen de las competencias transcurriculares sigue siendo parte integral del proyecto OCDE/PISA a través de la evaluación de una nueva área de conocimiento: la solución de problemas.

- Se presta especial atención al dominio de los procedimientos, a la comprensión de los conceptos y a la capacidad para actuar en diferentes situaciones dentro de cada área deconocimiento.

\section{Métodos}

- Para realizar la evaluación de cada estudiante, que dura un total de dos horas, se emplean las pruebas por escrito, de lápiz y papel.

- Las pruebas utilizan una combinación de preguntas de elección múltiple y preguntas que exigen a los alumnos la elaboración de sus propias respuestas. Las preguntas se organizan en grupos en torno a un texto que describe una situación de la vida real.

- Se han elaborado preguntas para un total de 7 horas de prueba, pero cada alumno sólo tiene que contestar a un conjunto parcial de preguntas.

- Los alumnos responden a un cuestionario sobre su entorno y características, que tardan unos 20-30 minutos en contestar, mediante el cual aportan información sobre sí mismos y su familia. Los directores de los centros reciben un cuestionario de 20 minutos con preguntas sobre su centro.

\section{Ciclo de evaluación}

- La evaluación tiene lugar cada tres años: 2000, 2003 y 2006.

- Cada uno de estos ciclos estudia en profundidad un área de contenido «principal» a la que se dedican dos ter-cios del tiempo de las pruebas, mientras que las otras áreas proporcionan un perfil resumido de las capacidades. Las áreas de conocimiento principales son en 2000 la lectura, en 2003 las matemáticas y en 2006 las ciencias.

\section{Resultados}

- Un perfil básico de los conocimientos y destrezas de los alumnos de 15 años.

- Indicadores contextuales que relacionan los resultados con las características de los alumnos y de los centros educativos.

- Indicadores de tendencias que muestran los cambios en los resultados a lo largo del tiempo.

- Una valiosa base de conocimientos para el análisis y la investigación de las políticas educativas.

\section{Características básicas de PISA 2003}

El proyecto PISA 2003 es el segundo ciclo del plan de recogida de datos definido en 1997 por los países participantes. La publicación Measuring Student Knowledge and Skills - A New Framework for Assessment (OCDE, 1999), editada en España bajo el título La medida de los conocimientos y destrezas de los alumnos: un nuevo marco de evaluación1, presentó el marco conceptual que sirvió de base para el primer ciclo, conocido como PISA 2000. Los resultados de ese primer ciclo, presentados en diciembre de 2001 en la publicación Knowledge and
Skills for Life - First Results from PISA 2000 (OCDE, 2001) $)^{1}$, cuyo resumen ha sido editado en España bajo el título Conocimientos y destrezas para la vida: Primeros resultados del Proyecto Pisa 2000, permiten que los creadores de políticas educativas nacionales comparen el funcionamiento de sus sistemas educativos con los de otros países. De manera similar al ciclo PISA 2000, el ciclo 2003 engloba las áreas de lectura, matemáticas y ciencias, pero cambia su centro de atención de la lectura a las matemáticas. Además, examina la capacidad de

\footnotetext{
${ }^{1}$ Esta publicación está también disponible en la dirección de Internet www.pisa.oecd.org. La versión en castellano se encuentra en el apartado de publicaciones del sitio web del Instituto Nacional de Evaluación y Calidad del Sistema Educativo, www.ince.mec.es
} 
los alumnos para resolver problemas en escenarios de la vida real a través de la evaluación de la solución de problemas. Los alumnos tienen que contestar también a un cuestionario sobre su entorno y sus características, y las autoridades del centro proporcionan información adicional. En la evaluación PISA 2003 participan 42 países, de los que 30 son miembros de la OCDE.

Dado que el objetivo del proyecto OCDE/PISA consiste en la evaluación del rendimiento acumulado de los sistemas educativos en una edad en la que la escolarización es obligatoria, la prueba se centra en jóvenes de 15 años matriculados en enseñanzas académicas o profesionales. Entre 5.000 y 10.000 alumnos de al menos 150 centros docentes realizan las pruebas en cada país, lo que aporta una muestra suficiente a partir de la cual se puedan desglosar los resultados de acuerdo a una serie de características de los alumnos.

El objetivo primordial de la evaluación OCDE/PISA es determinar en qué grado los jóvenes han adquirido las destrezas y los conocimientos generales de lectura, matemáticas y ciencias que necesitarán en la vida adulta. Además, la evaluación de las competencias transcurriculares se ha incluido como parte integral del proyecto PISA 2003 a través de la evaluación de la capacidad de solución de problemas. Los motivos principales para utilizar este tipo de enfoque amplio son los siguientes:

- Aunque la adquisición de conocimientos específicos es importante durante el período de aprendizaje escolar, la aplicación de este conocimiento en la vida adulta depende de manera decisiva de la adquisición de unas destrezas y nociones más amplias. En matemáticas, cuando se trata de aplicarlas a las situaciones de la vida diaria, es más importante la capacidad del alumno para establecer un razonamiento cuantitativo y repre sentar relaciones o interdependencias que saber res ponder a las preguntas típicas de los libros de texto. En lectura, una de las destrezas principales es la capacidad para desarrollar interpretaciones del material escrito y reflejar el contenido y las características de los textos. En ciencias, a la hora de reflexionar sobre las cuestiones de debate en la comunidad adulta, los conocimientos específicos, por ejemplo los nombres de plantas y animales, resultan de menor valor que la comprensión de temas más amplios, como el consumo de energía, la biodiversidad y la salud de los seres humanos. En solución de problemas, constituyen destrezas básicas para el aprendizaje futuro la capacidad para reconocer un problema, formular su naturaleza exacta, utilizar este conocimiento para plantear una estrategia de resolución, afinar la solución para que se adapte mejor al problema original y comunicar la solución a otras personas.

- En un contexto internacional, centrarse en los contenidos del currículum obligaría a centrar la atención en los elementos curriculares comunes a todos o la mayoría de los países. Ello implicaría hacer muchas concesiones y daría como resultado una evaluación demasiado limitada, que no sería provechosa para unos gobiernos que desean conocer la solidez e innovación de los sistemas educativos de otros países.

- Los alumnos necesitan desarrollar ciertas destrezas amplias y generales. Entre ellas se cuentan la comunicación, la adaptabilidad, la flexibilidad, la capacidad para solucionar problemas y la utilización de las tecnologías de la información. Estas destrezas se desarrollan a lo largo del currículum y su evaluación precisa una perspectiva transcurricular.

Los alumnos no pueden aprender en la escuela todo aquello que necesitarán saber en su vida adulta. Por tanto, lo que necesitan adquirir son los requisitos previos para un aprendizaje futuro provechoso. Los estudiantes deben ser capaces de organizar y regular su propio aprendizaje, de aprender en solitario o en grupo y de superar dificultades en el proceso de aprendizaje. Y para ello tendrán que ser conscientes de sus procesos de pensamiento, de sus métodos y estrategias de aprendizaje. Además, la necesidad de continuar aprendiendo se presenta cada vez más en situaciones en que las personas tienen que trabajar en grupo y depender unas de otras. Para evaluar estos aspectos, en el ciclo PISA 2000 se incluyó como componente opcional un instrumento para obtener información sobre el autoaprendizaje. En el ciclo PISA 2003 será un componente central.

El proyecto OCDE/PISA no es únicamente una evaluación internacional de las destrezas en lectura, matemáticas y 
ciencias de los estudiantes de 15 años. Es también un proyecto permanente que, a largo plazo, conducirá al desarrollo de un corpus de información útil para controlar la evolución de los conocimientos y destrezas de los estudiantes de varios países, así como de los diferentes subgrupos demográficos de cada país. En cada ciclo se evaluará en profundidad una de las áreas de conocimiento, a la que se le dedicarán dos terceras partes del tiempo de la prueba. En 2000, el área de conocimiento principal fue la lectura; en 2003 serán las matemáticas, y en 2006, las ciencias. Esto proporcionará en cada área un análisis detallado del rendimiento de los alumnos cada nueve años y un análisis más somero de su evolución en el tiempo cada tres.

Al igual que en el ciclo PISA 2000, el tiempo total con el que cuentan los estudiantes en PISA 2003 para realizar las pruebas es de dos horas; sin embargo, la información se obtiene a partir de casi siete horas de preguntas de evaluación. El conjunto total de preguntas se presenta en diferentes cuadernillos de evaluación. Cada cuadernillo debe contestarlo un número suficiente de estudiantes para poder estimar los niveles de rendimiento en todas las preguntas por parte de los estudiantes de cada país y de los subgrupos de interés dentro de cada país (como hombres y mujeres, y estudiantes de diferentes estratos sociales y económicos). Los estudiantes deberán dedicar también 30 minutos a contestar un cuestionario sobre su contexto personal.

La evaluación OCDE/PISA proporciona tres grandes tipos de resultados:

- indicadores básicos, que ofrecen un perfil básico de los conocimientos y las destrezas de los alumnos;

- indicadores contextuales, que muestran la relación existente entre tales destrezas y determinadas variables demográficas, sociales, económicas y educativas;

- indicadores de tendencias, que surgen de la naturaleza continua de la recogida de datos y que muestran los cambios producidos en el tiempo en la distribución, en los niveles de los resultados y en las relaciones entre los resultados y las variables del entorno de los alumnos y del centro escolar.

Si bien los indicadores representan un medio adecuado para llamar la atención sobre temas relevantes, no suelen ser útiles para responder a las cuestiones que se plantean los poderes públicos. Por eso, el proyecto OCDE/PISA ha desarrollado también un plan de análisis orientado a temas de política educativa, que irá más allá de la información proporcionada por los indicadores.

\section{Originalidad del proyecto PISA}

El proyecto OCDE/PISA no es el primer estudio comparativo internacional del rendimiento de los alumnos. Durante los últimos 40 años se han realizado otros estudios, dirigidos principalmente por la International Association for the Evaluation of Educational Achievement (IEA, Asociación Internacional para la Evaluación del Rendimiento Académico) y la Education Testing Service's International Assessment of Educational Progress (IAEP, Asociación Internacional para la Evaluación del Progreso Educativo del ETS, Servicio de Evaluación Educativa). Aunque la calidad y el alcance de estos estudios han mejorado considerablemente a lo largo de los años, continúan aportando solamente una visión parcial y aislada del rendimiento académico, centrada sólo en determinadas áreas de conocimiento.

Aún más importante resulta el hecho de que estos estudios se hayan centrado en resultados vinculados directamente con el currículum y, por lo tanto, sólo en aquellas partes del currículum comunes a todos los países participantes. Ello implica que, por lo general, no se hayan tenido en cuenta los aspectos curriculares específicos de un país o de un número reducido de países, independientemente de la importancia de esa parte del currículum para los países en cuestión.

El proyecto OCDE/PISA adopta un enfoque distinto en diferentes aspectos:

- Su origen: la iniciativa la han tomado los gobiernos, y los resultados se dirigen a sus preocupaciones en materia de política educativa

- Su regularidad: el compromiso de abarcar múltiples áreas de evaluación con actualizaciones cada tres años permite que los países efectúen un seguimiento regular y previsible de sus progresos para alcanzar las principales metas académicas. 
- El grupo de edad estudiado: la evaluación de los jóvenes que están acabando el período de escolarización obligatoria aporta un indicador muy útil acerca del rendimiento de los sistemas educativos. Aunque la mayor parte de los jóvenes de los países de la OCDE continúa su educación después de los 15 años, esta edad se encuentra generalmente próxima al final del período de escolarización obligatoria en que los alumnos siguen un currículum prácticamente común. En este punto de su formación, resulta útil determinar el grado en que los alumnos han adquirido los conocimientos y las destrezas que les ayudarán en el futuro, entre ellos las opciones específicas de aprendizaje que pueden elegir más tarde.

- Los conocimientos y destrezas evaluados: éstos no se definen a partir de un denominador común de los currículos nacionales, sino a partir de las destrezas que se consideran esenciales para la vida futura. Ésta es la característica más importante del proyecto OCDE/PISA. Tradicionalmente, los currículos se han estructurado en gran medida en bloques de información y de dominio de técnicas concretas, de modo que se han centrado menos en las destrezas que deben desarrollarse en cada área para su aplicación futura en la vida adulta y menos aún en otras competencias más generales, que se desarrollan a través del conjunto del currículum, para resolver problemas y aplicar ideas y razona mientos en las situaciones cotidianas. El proyecto OCDE/PISA no excluye los conocimientos y la comprensión basados en el currículum, pero los evalúa sobre todo en términos de la adquisición de destrezas y conceptos más amplios que permiten su aplicación cotidiana. En cualquier caso, el proyecto OCDE/PISA no está limitado por el denominador común de lo que se ha enseñado específicamente en cada país participante.

Este énfasis en la evaluación en términos de dominio funcional y de conceptos amplios resulta especialmente significativo si se tiene en cuenta el interés de los países en cuanto al desarrollo de capital humano, que la OCDE define como:

«los conocimientos, destrezas, competencias y otros atributos de los individuos que son importantes para el bienestar personal, social y económico».
Las estimaciones de capital humano han sido obtenidas habitualmente, en el mejor de los casos, mediante indicadores indirectos como el nivel de educación alcanzado. Estos indicadores se muestran aún más inadecuados cuando el interés en el capital humano se amplía para incluir atributos que permitan una plena participación social y democrática en la vida adulta y que doten a los alumnos de la preparación necesaria para seguir aprendiendo a lo largo de toda la vida.

La evaluación directa de los conocimientos y destrezas al final del período de escolarización básica permite que el proyecto OCDE/PISA examine el grado de preparación de los jóvenes para la vida adulta y, hasta cierto punto, analice la efectividad de los sistemas educativos. La meta del proyecto consiste en evaluar el rendimiento de los sistemas educativos en relación con sus objetivos de base (tal como los define la sociedad) y no en relación con la enseñanza y aprendizaje de un conjunto de conocimientos. Este modo de considerar los productos de la educación es necesario si se pretende animar a los centros y a los sistemas educativos a centrarse en los retos actuales.

\section{Visión general de lo que se evalúa en cada área de conocimiento}

La figura A presenta una definición de las cuatro áreas de conocimiento evaluadas en el proyecto PISA 2003. Todas las definiciones enfatizan los conocimientos y destrezas funcionales que hacen que una persona pueda participar en la sociedad de manera activa. Esta participación requiere algo más que el simple hecho de ser capaz de llevar a cabo tareas impuestas por terceros, por ejemplo por un patrón. También implica tener la preparación necesaria para participar en los procesos de toma de decisiones. En los ejercicios más complejos del proyecto OCDE/PISA se pedirá a los alumnos una reflexión y evaluación sobre el material en lugar de plantearles preguntas con una única respuesta «correcta».

Las matemáticas (que se tratan en el Capítulo I) tienen que ver con la capacidad de los estudiantes para analizar, razonar y transmitir ideas de un modo efectivo al plantear, resolver e interpretar problemas matemáticos en diferentes situaciones. Las matemáticas se evalúan teniendo en cuenta los puntos siguientes: 
Figura A. DEFINICIÓN DE LAS ÁREAS DE CONOCIMIENTO

\begin{tabular}{|c|c|c|c|}
\hline Matemáticas & Lectura & Ciencias & $\begin{array}{l}\text { Resolución } \\
\text { de problemas }\end{array}$ \\
\hline $\begin{array}{l}\text { Capacidad de un individuo } \\
\text { para identificar y compren- } \\
\text { der el papel que las matemá- } \\
\text { ticas desempeñan en el } \\
\text { mundo, realizar razonamien- } \\
\text { tos bien fundados y utilizar e } \\
\text { involucrarse en las matemá- } \\
\text { ticas de manera que se satis- } \\
\text { fagan las necesidades de la } \\
\text { vida del individuo como ciu- } \\
\text { dadano constructivo, com- } \\
\text { prometido y reflexivo. }\end{array}$ & $\begin{array}{l}\text { Comprender, utilizar y refle- } \\
\text { xionar sobre los textos escri- } \\
\text { tos para alcanzar los propios } \\
\text { objetivos, desarrollar el co- } \\
\text { nocimiento y el potencial } \\
\text { personales y participar en la } \\
\text { sociedad. }\end{array}$ & $\begin{array}{l}\text { La capacidad para utilizar el } \\
\text { conocimiento científico, iden- } \\
\text { tificar preguntas y extraer } \\
\text { conclusiones basadas en los } \\
\text { hechos para entender y poder } \\
\text { tomar decisiones sobre el } \\
\text { mundo natural y los cambios } \\
\text { que la actividad humana ha } \\
\text { provocado en él. }\end{array}$ & $\begin{array}{l}\text { Habilidad del individuo de } \\
\text { valerse de procesos cogniti- } \\
\text { vos para comparar y resolver } \\
\text { situaciones transdisciplina- } \\
\text { rias en las que el camino } \\
\text { hacia la solución no resulta } \\
\text { obvio de modo inmediato, y } \\
\text { donde las áreas de conoci- } \\
\text { miento o curriculares que } \\
\text { podrían aplicarse no perte- } \\
\text { necen a una única área de } \\
\text { conocimiento de matemáti- } \\
\text { cas, de ciencias o de lectura. }\end{array}$ \\
\hline
\end{tabular}

- El contenido matemático, definido principalmente en términos de cuatro ideas principales (cantidad, espacio y forma, cambio y relaciones e incertidumbre) y definido sólo de modo secundario en relación a los "contenidos curriculares" (como los números, el álgebra y la geometría).

- El proceso matemático, definido mediante las competencias matemáticas generales. Éstas incluyen el empleo del lenguaje matemático, la construcción de modelos matemáticos y las destrezas de solución de problemas. No obstante, dichas destrezas no se evalúan mediante preguntas distintas, ya que se presume que se necesitará un conjunto de competencias diversas para realizar cualquier ejercicio matemático propuesto. Por el contrario, las preguntas se organizan de acuerdo a "grupos de competencia" que definen el tipo de razonamiento necesario para resolverlas.

- Las situaciones en que se utilizan las matemáticas, determinadas a partir de la distancia a la que se encuentran de los estudiantes. El marco identifica cinco situa ciones: personal, educativa, profesional, pública y científica.

La lectura (que se trata en el Capítulo II) se define en relación con la capacidad de los estudiantes para comprender un texto escrito, utilizarlo y reflexionar sobre él con la finalidad de lograr sus objetivos. Este enfoque de la lectura ya ha sido utilizado por estudios comparativos anteriores, como el International Adult Literacy Survey
(IALS, Estudio Internacional de la Competencia de la Población Adulta), pero el proyecto OCDE/PISA lo lleva aún más lejos con la introducción de un elemento "activo": la capacidad no sólo de comprender un texto sino de reflexionar sobre el mismo a partir de las ideas y experiencias propias. La lectura se evalúa teniendo en cuenta los puntos siguientes:

- El formato del texto. A menudo las evaluaciones sobre la lectura de los alumnos se han centrado en textos continuos, es decir, prosa organizada en oraciones y párrafos. El proyecto OCDE/PISA introduce además los textos discontinuos, que presentan la información estructurada diferentemente, por ejemplo como listas, formularios, gráficos o diagramas. También distingue entre diferentes formas de prosa, como la narración, la exposición y la argumentación. Estas distinciones se basan en el principio de que en la vida adulta los individuos se encontrarán con una gran variedad de textos, de modo que no será suficiente con saber leer el limitado número de tipos de texto que se presentan habitualmente en los centros educativos.

- El proceso de lectura (aspectos). No se evaluarán las capacidades de lectura más básicas de los alumnos, puesto que se presupone que los estudiantes de 15 años ya deben haberlas adquirido. En su lugar, se espera que los estudiantes demuestren su capacidad 
para extraer la información, desarrollar una comprensión general del texto, interpretarlo y reflexionar sobre su contenido y sobre su forma y características.

- La situación, definida a través del uso al cual está des tinado el texto. Por ejemplo, una novela, una carta personal o una biografía se escriben para un uso privado; los anuncios o documentos oficiales, para un uso público; un manual o informe, para un uso profesional; y un libro de texto o una hoja de ejercicios, para un uso educativo. Dado que algunos grupos de alumnos pueden tener un mejor rendimiento en una situación de lectura que en otra, es conveniente incluir una amplia variedad de tipos de lectura en las preguntas de la evaluación.

Las ciencias (que se tratan en el Capítulo III) se definen como la capacidad para emplear los conocimientos y los procesos científicos no sólo para comprender el mundo natural, sino para participar en las decisiones que repercuten en él. Las ciencias se evalúan teniendo en cuenta los puntos siguientes:

- Los conocimientos o conceptos científicos, que constituyen los eslabones que ayudan a entender fenómenos relacionados. En el proyecto OCDE/PISA, los conceptos son los habituales en la física, la química, la biología y las ciencias de la Tierra y el espacio, pero no deberán únicamente memorizarse, sino que deberán aplicarse al contenido de las preguntas.

- Los procesos científicos, centrados en la capacidad para adquirir e interpretar los hechos y actuar de acuerdo a ellos. Tres de estos procesos incluidos en el proyecto OCDE/PISA están relacionados con: i) la descripción, la explicación y la predicción de hechos científicos; ii) la comprensión de la investigación científica; y iii) la interpretación de las pruebas y conclusiones científicas.

- Las situaciones o contextos científicos en los que se aplica el conocimiento científico y se emplean los procesos científicos. El marco conceptual identifica tres ámbitos principales: ciencias de la vida y la salud, ciencias de la Tierra y el medio ambiente y ciencias relacionadas con la tecnología.

La solución de problemas (que se trata en el Capítulo IV) se define como la capacidad de utilizar procesos cognitivos para resolver problemas reales interdisciplinares cuando no resultan inmediatamente obvios ni la vía de solución ni las áreas curriculares o de conocimiento aplicables. La solución de problemas se evalúa teniendo en cuenta los puntos siguientes:

- El tipo de problema, que engloba los procesos de solución de problemas, entre ellos la toma de decisiones, el análisis y diseño de sistemas y la detección y solución de problemas, aplicados en un contexto de problema específico, normalmente alejado del escenario de la clase y del currículum escolar y que se adentra en la vida personal, el trabajo y el ocio, o la comunidad y la sociedad.

- Los procesos de solución de problemas, que conllevan la comprensión de la naturaleza del problema, su descripción, representación, resolución, reflexión y comunicación de los resultados.

- Las situaciones o contextos de problemas, extraídos de escenarios de la vida real de los alumnos y en los que se inscriben los distintos tipos de problemas.

\section{Realización de la evaluación 2003 y presentación de los resultados}

De manera análoga al ciclo PISA 2002, las pruebas del ciclo PISA 2003 consisten en instrumentos tradicionales de papel y lápiz por razones de índole práctica. Se están estudiando otros mecanismos de evaluación para futuros ciclos. Las pruebas contienen preguntas de diferentes tipos. Algunas requieren que los alumnos seleccionen o elaboren respuestas simples que pueden ser comparadas directamente con una respuesta correcta única, como preguntas de respuesta múltiple o preguntas de respuesta cerrada. Estas preguntas tienen una respuesta claramente correcta o incorrecta y a menudo evalúan destrezas de orden inferior. Otras preguntas son más constructivas y requieren que los alumnos elaboren su propia respuesta, y han sido ideadas para poder medir aspectos más generales que los que suelen recoger otros estudios más tradicionales. Permiten una gama de respuestas aceptables más amplia y necesitan guías de corrección más complejas ya que está previsto aceptar respuestas que sólo son parcialmente correctas.

En el proyecto OCDE/PISA la competencia se evalúa a través de unidades formadas por un estímulo (p. ej., un texto, 
una tabla, un diagrama, un cuadro, etc.) al que le siguen cierto número de ejercicios asociados a él. Se trata de una característica importante porque abre la posibilidad de utilizar preguntas que profundizan más en el tema, al contrario de lo que ocurriría si cada pregunta introdujera un contexto totalmente nuevo. De este modo, el alumno tiene más tiempo para asimilar el material, que puede ser utilizado para evaluar múltiples aspectos de su rendimiento.

Los resultados del ciclo PISA 2000 se presentaron a través de unas escalas de puntuación con una media de 500 y una desviación típica de 100 para cada una de las tres áreas de conocimiento; esto significa que dos terceras partes de los estudiantes de los países de la OCDE obtuvieron una puntuación de entre 400 y 600 puntos. Estas puntuaciones representan grados de competencia en una determinada área de conocimiento. La lectura constituyó el área de conocimiento principal en PISA 2000 y las puntuaciones de lectura se repartieron en cinco niveles de conocimiento y destrezas. La principal ventaja de esta aproximación consiste en que describe lo que los estudiantes saben hacer, asociando distintos ejercicios a diferentes niveles de dificultad. Además, los resultados se presentaron también en tres subescalas de lectura: recuperación de la información, interpretación de los textos, y reflexión y evaluación. Se dispusieron también sendas escalas de competencia matemática y de competencia científica, aunque sin ser divididas en niveles de dificultad, debido al menor volumen de datos recogidos en las áreas de conocimiento menores. El ciclo PISA 2003 sigue este mismo planteamiento al especificar niveles en la escala de matemáticas tal como se había hecho con la lectura en el ciclo anterior. Además trata de presentar resultados de tendencia para la lectura, las matemáticas y las ciencias, así como una nueva escala de resultados para la solución de problemas como competencia transcurricular. De manera similar al procedimiento usado en el ciclo PISA 2000 para presentar los resultados de lectura, el ciclo PISA 2003 presentará probablemente los resultados de matemáticas a través de varias subescalas.

\section{Los cuestionarios sobre el entorno y su utilización}

Con el objeto de recopilar información contextual, el proyecto OCDE/PISA pregunta una serie de cuestiones sobre su entorno a los alumnos y directores de los centros educativos, agrupados en cuestionarios de entre 20 y 30 minutos de duración. Estos cuestionarios ${ }^{2}$ resultan de vital importancia en el análisis de los resultados redimiento al permitir relacionarlos con las características del centro educativo y de los alumnos.

Los cuestionarios recopilan información sobre:

- el entorno y las características de los alumnos y sus familias, incluyendo su nivel económico, social y cultural;

- las características de la vida de los alumnos, tales como sus actitudes ante el aprendizaje, sus hábitos y su estilo de vida en el centro educativo y en el entorno familiar:

- las características de los centros educativos, en particular la calidad de sus recursos humanos y materiales, la financiación y la gestión (pública o privada), los procesos de toma de decisión y las políticas de dotación de personal;

- el contexto educativo, tal como las modalidades y estructuras institucionales, el tamaño de las clases y el grado de implicación de los padres;

- las estrategias de aprendizaje auto-regulado de los alumnos, las preferencias de motivación y las orientaciones que se persiguen, los mecanismos cognitivos relacionados con su auto-concepto, las estrategias de control de las actividades, las preferencias por diferentes tipos de situaciones de aprendizaje, los estilos de aprendizaje y las destrezas sociales necesarias para el aprendizaje en grupo;

- las características de la enseñanza y del aprendizaje en el ámbito de las matemáticas, entre ellas la motivación de los estudiantes, su grado de participación y confianza en relación a las matemáticas, el impacto de las estrategias de aprendizaje sobre su rendimiento.

Se ofrecen además, como opciones internacionales, dos cuestionarios adicionales:

- Un cuestionario sobre la familiaridad con la informática, centrado en: i) la disponibilidad y utilización de la tecnología de la información (TI), lo cual requiere determinar dónde se emplea más la TI y el tipo de uso que se hace de ella; ii) la confianza y las actitudes respecto a la TI, entre ellas la autoeficacia y la

\footnotetext{
${ }^{2}$ Los cuestionarios del ciclo PISA 2000 pueden consultarse a través de la dirección de Internet www.pisa.oecd.org.
} 
actitud hacia los ordenadores; y iii) la formación en TI, con especial atención en saber dónde han aprendido los alumnos a utilizar los ordenadores y la Internet.

- Un cuestionario de formación educativa para recopilar datos en tres áreas: i) la formación recibida en el pasado, incluyendo las repeticiones de curso, las interrupciones de la escolarización, los cambios de centro y los cambios de modalidad educativa; ii) la formación actual de los alumnos en matemáticas, con especial atención al tipo de clases de matemáticas y a las puntuaciones de los profesores; y iii) la formación y el trabajo futuros de los alumnos, con especial atención al nivel de formación alcanzado y al puesto de trabajo previsto a la edad de 30 años.

La información contextual recogida mediante los cuestionarios del alumno y del centro educativo comprende sólo una parte del total de la información disponible en el proyecto OCDE/PISA. La OCDE desarrolla y actualiza regularmente indicadores que describen la estructura general de los sistemas educativos (su contexto demográfico y económico, por ejemplo costes, matrículas, características de los centros educativos y del profesorado, y algunos procesos de las clases) y su influencia sobre el mercado laboral.

\section{Elaboración conjunta del proyecto OCDE/PISA y de sus marcos conceptuales}

El proyecto OCDE/PISA supone un esfuerzo de colaboración entre los gobiernos miembros de la OCDE para ofrecer un nuevo modelo de evaluación del rendimiento de los alumnos de manera regular. Las evaluaciones se desarrollan conjuntamente por los países participantes y son las organizaciones nacionales las que se encargan de aplicarlas. La cooperación constructiva de los profesores y directores de los centros participantes ha sido crucial para el éxito del proyecto OCDE/PISA en todos los estadios de su desarrollo y aplicación.

El Consejo de Países Participantes, que representa a todos los países, determina las prioridades en materia de política educativa del proyecto OCDE/PISA dentro el marco de objetivos de la OCDE y vigila el cumplimiento de estas prioridades durante el desarrollo del proyecto. Se encarga de establecer las prioridades para el desarrollo de indicadores, para la preparación de los instrumentos de evaluación y para la presentación de los resultados. Los expertos de los países participantes colaboran también en grupos de trabajo encargados de aunar los objetivos de política educativa del proyecto PISA con los conocimientos técnicos más avanzados internacionalmente sobre las diferentes áreas de conocimiento a evaluar. Al participar en estos grupos de expertos, los países se aseguran de que los instrumentos sean válidos internacionalmente y tengan en cuenta los contextos culturales y educativos de los países miembros de la OCDE. También garantizan que los materiales de evaluación tengan unas cualidades de medición sólidas y que los instrumentos pongan énfasis en la autenticidad y validez educativa.

Los países participantes llevan a la práctica el proyecto OCDE/PISA a escala nacional a través de los Coordinadores Nacionales del Proyecto de acuerdo los procedimientos acordados. Los coordinadores nacionales desempeñan un papel fundamental a la hora de garantizar la máxima calidad en la aplicación del proyecto y verifican y evalúan los resultados de los estudios, análisis, informes y publicaciones.

El diseño y la realización del estudio, dentro del marco establecido por el Consejo de Países Participantes, se encarga a un consorcio internacional dirigido por el Australian Council for Educational Research (ACER, Consejo Australiano de Investigación Educativa). Otros socios de este consorcio son el Instituto Nacional Holandés de Investigación Educativa (CITO), la empresa estadounidense WESTAT y el Educational Testing Service (ETS, Servicio de Evaluación Educativa, de Estados Unidos) y el Instituto de Investigación sobre Política Educativa de Japón (NIER).

El Secretariado de la OCDE es el encargado general de la gestión del programa, controla su realización día a día, actúa como secretariado del Consejo de Países Participantes, acerca las posturas entre los países y ejerce de interlocutor entre el Consejo de Países Participantes y el consorcio internacional encargado de la realización práctica del proyecto. El Secretariado de la OCDE se encarga también de la elaboración 
de los indicadores y del análisis y preparación de las publicaciones e informes internacionales en colaboración con el consorcio OCDE/PISA y en contacto directo con los países miembros, tanto en lo referente a política educativa (Consejo de Países Participantes) como en lo relativo a la realización (coordinadores nacionales del proyecto).

El desarrollo de los marcos conceptuales del proyecto OCDE/PISA se ha llevado a cabo de forma continuada desde que se creó el programa en 1997 y puede describirse como la sucesión de los siguientes pasos:

- elaboración de una definición de trabajo para el área de conocimiento junto con la descripción de los supuestos en que se basa dicha definición;

- valoración del modo de organizar los ejercicios para poder informar a los investigadores y a los encargados de las políticas educativas sobre el rendimiento de los alumnos en cada una de las áreas de conocimiento evaluadas, junto con la identificación de las características clave que deben tenerse en cuenta al elaborar los ejercicios de evaluación destinados a un uso internacional;

- determinación de las características básicas que se emplearán en la elaboración de las pruebas, con definiciones basadas en la bibliografía existente y en la experiencia en la realización de otras evaluaciones a gran escala;

- validación de estas variables y valoración de la contribución de cada una de ellas en la dificultad del ejercicio en los diferentes países participantes;

- preparación de un esquema de interpretación de los resultados.

Aunque la ventaja principal que aporta elaborar y validar un marco conceptual para cada una de las áreas de conocimiento es una mejora de la medición, se dan además otras ventajas potenciales:

- Un marco conceptual proporciona un vehículo y un lenguaje comunes para debatir el propósito de la evaluación y lo que se pretende medir. Este debate fomenta el desarrollo de un consenso sobre el marco conceptual y los objetivos de la medición.

- Un análisis de las destrezas y de los tipos de conocimiento asociados a un rendimiento positivo aporta la base necesaria para establecer estándares o niveles de rendimiento. Conforme avanza la comprensión de lo que se está evaluando y la capacidad para interpretar los resultados sobre una escala concreta, se puede desarrollar una base empírica para transmitir un conjunto más rico de información a los diferentes tipos de público a los que se dirige el proyecto.

- La identificación y comprensión de las variables concretas que constituyen la base de un rendimiento positivo incrementa la capacidad para evaluar lo que se está midiendo y realizar cambios en la evaluación a lo largo del tiempo.

- La comprensión de lo que se está midiendo y su conexión con lo que decimos sobre los estudiantes proporciona un importante vínculo entre la política educativa pública, la evaluación y la investigación, lo cual, a su vez, refuerza la utilidad de los datos recogidos. 



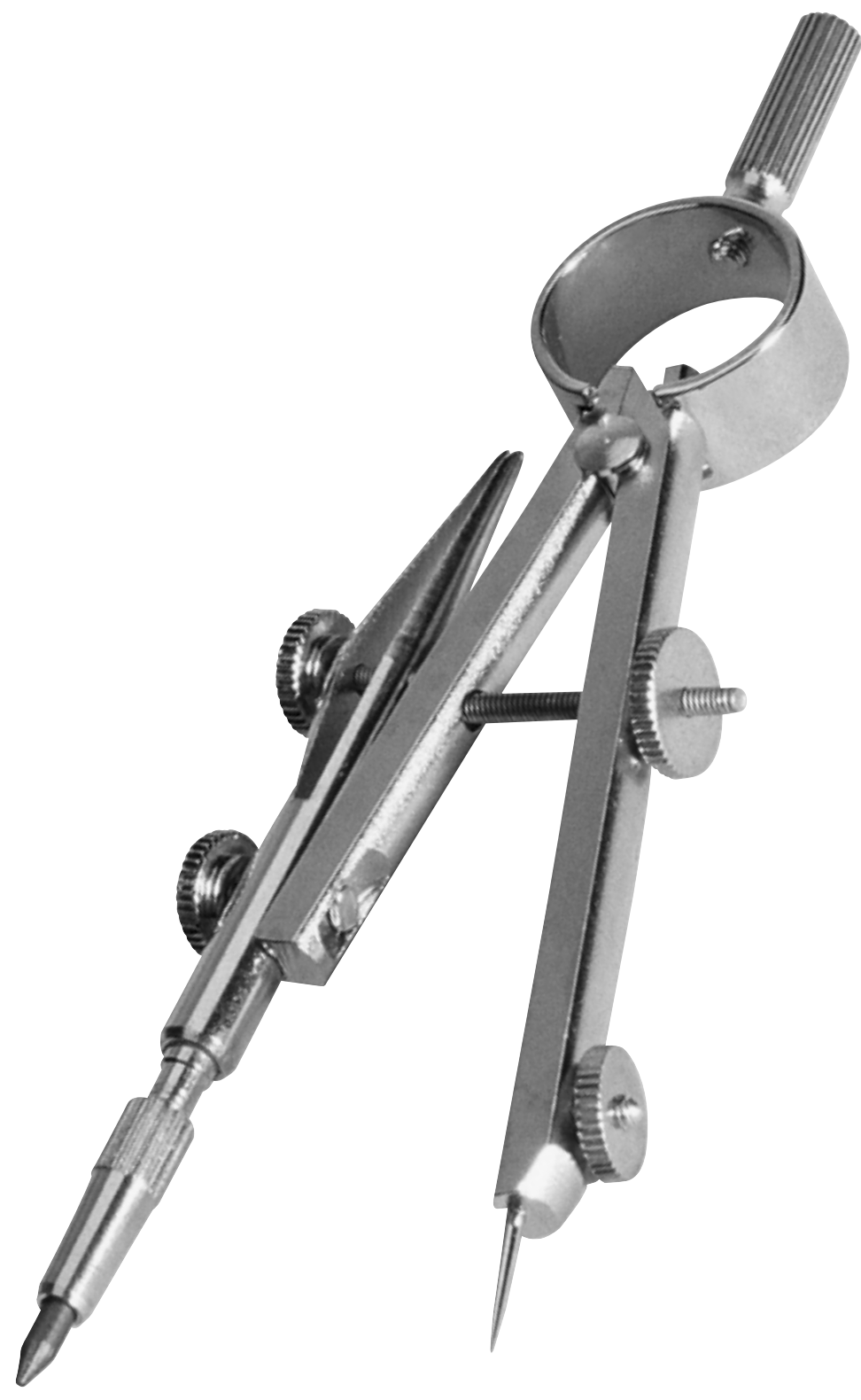

ᄀ MATEMÁTICAS

El objetivo de la evaluación OCDE/PISA es el desarrollo de indicadores que permitan determinar en qué medida los diferentes sistemas educativos de los países participantes han preparado a los estudiantes de 15 años para desempeñar un papel constructivo como ciudadanos dentro de la sociedad. En lugar de limitarse al contenido curricular que puedan haber aprendido los estudiantes, la evaluación se centra en determinar si los estudiantes son capaces de utilizar lo que han estudiado en situaciones similares a las que probablemente se tendrán que enfrentar en su vida diaria.

\section{Definición del área de conocimiento}

El área de matemáticas se ocupa de la capacidad de los estudiantes para analizar, razonar y comunicar ideas de un modo efectivo, al plantear, formular, resolver e interpretar problemas matemáticos en diferentes situaciones. La evaluación OCDE/PISA se centra en problemas del mundo real, de modo que va más allá de los casos y problemas que se plantean generalmente en las aulas. En el contexto del mundo real, a la hora de comprar, viajar, 
cocinar, gestionar su economía doméstica o valorar cuestiones políticas entre otras cosas, los ciudadanos se enfrentan con frecuencia a situaciones en las que el utilizar un razonamiento cuantitativo o espacial u otras aptitudes matemáticas les ayuda a aclarar, formular o resolver un problema. Este tipo de utilización de las matemáticas se basa en las destrezas que se han adquirido y practicado a través de los problemas que se presentan generalmente en los libros de texto y en las clases. Sin embargo, estas destrezas requieren la capacidad de saber aplicarlas en un contexto menos estructurado donde no hay indicaciones tan claras y donde el estudiante debe decidir qué datos son los importantes y cómo aplicarlos para que resulten útiles.

La competencia matemática de acuerdo al proyecto OCDE/PISA se ocupa de establecer en qué grado los estudiantes de 15 años pueden considerarse ciudadanos informados y reflexivos y consumidores inteligentes. Los ciudadanos de todos los países se tienen que enfrentar cada vez más con una miríada de tareas que comprenden conceptos matemáticos, cuantitativos, espaciales, de probabilidad o de otro tipo. Sin ir más lejos, los medios de comunicación (periódicos, revistas, televisión e Internet) están plagados de información en forma de tablas, diagramas y gráficos sobre cuestiones como el tiempo, la economía, la medicina y el deporte, por nombrar sólo unas pocas. Los ciudadanos se ven bombardeados con información sobre temas como el calentamiento global y el efecto invernadero, el crecimiento de la población, las mareas negras y la contaminación de los mares, la desaparición del campo. Y, por último, pero no por ello menos importante, los ciudadanos hacen frente a la necesidad de leer formularios, interpretar horarios de autobuses y trenes, realizar correctamente operaciones bancarias, decidir cuál es la mejor compra en el mercado, etcétera. La competencia matemática del proyecto OCDE/PISA se centra en la capacidad de los estudiantes de 15 años (la edad en que muchos están terminando su aprendizaje formal obligatorio de matemáticas) para utilizar su conocimiento y comprensión matemáticos para dilucidar estas cuestiones y llevar a cabo las acciones pertinentes.

Dentro del proyecto OCDE/PISA la definición de competencia matemática es la siguiente:
La competencia matemática es la aptitud de un indi-
viduo para identificar y comprender el papel que
desempeñan las matemáticas en el mundo, alcanzar
razonamientos bien fundados y utilizar y participar
en las matemáticas en función de las necesidades de
su vida como ciudadano constructivo, comprometido
y reflexivo.

A continuación se presentan algunas explicaciones para esclarecer la definición de esta área de conocimiento.

\section{Competencia matemática}

El término competencia matemática se ha escogido para enfatizar el uso funcional del conocimiento matemático en numerosas y diversas situaciones y de manera variada, reflexiva y basada en una comprensión profunda. Por descontado, para que este uso sea posible y viable, se requieren una gran cantidad de conocimientos y de destrezas matemáticas básicas, y tales destrezas forman parte de nuestra definición de competencia. En el sentido lingüístico, la competencia presupone, entre otras cosas, un amplio vocabulario y un conocimiento sustancial de las reglas gramaticales, la fonética, la ortografía, etc. A la hora de comunicarse, los seres humanos combinan estos elementos de una manera creativa en respuesta a las diferentes situaciones del mundo real en las que se ven envueltos. Del mismo modo, la competencia matemática no debe limitarse al conocimiento de la terminología, datos y procedimientos matemáticos, aunque, lógicamente, debe incluirlos, ni a las destrezas para realizar ciertas operaciones y cumplir con determinados métodos. La competencia matemática comporta la combinación creativa de estos elementos en respuesta a las condiciones que imponga una situación externa.

\section{el mundo}

El término mundo significa el entorno natural, social y cultural en que habita el individuo. Como postuló Freudenthal (1983): «Nuestros conceptos, estructuras e ideas matemáticas se han inventado como herramientas para organizar los fenómenos del mundo físico, social y mental» (pág. IX). 


\section{utilizar y participar}

La expresión utilizar y participar se aplica para abarcar el uso de las matemáticas y la resolución de problemas matemáticos. Conlleva también una implicación personal al comunicar, relacionar, evaluar e incluso apreciar las matemáticas y disfrutar con ellas. De este modo, la definición de competencia matemática engloba el uso funcional de las matemáticas en sentido estricto, así como la preparación para poder seguir estudiándolas, y los elementos estéticos y de esparcimiento de las matemáticas.

\section{su vida}

La expresión "su vida" incluye su vida privada, laboral y social con sus compañeros y familiares, así como su vida como ciudadano dentro de una comunidad.

Una capacidad fundamental que comporta esta noción de competencia matemática es la aptitud para plantear, formular, resolver e interpretar problemas a través de las matemáticas en diferentes situaciones y contextos. Los contextos varían de los puramente matemáticos a aquellos en los que no se presenta ninguna estructura matemática o ésta no es evidente de entrada: la persona que plantee o resuelva el problema deberá introducir correctamente la estructura matemática. También es importante destacar que la definición no hace exclusivamente referencia a los conocimientos matemáticos mínimos exigibles, sino también a la realización y utilización de las matemáticas en situaciones que varían entre lo diario y lo inusual, entre lo simple y lo complejo.

Las actitudes y emociones relacionadas con las matemáticas, tales como la confianza en uno mismo, la curiosidad, la percepción de su interés e importancia y el deseo de hacer o comprender las cosas, no forman parte de la definición de competencia matemática, pero, no obstante, contribuyen a ella. En principio, se puede tener competencia matemática sin necesidad de albergar tales actitudes y emociones. No obstante, en la práctica, no es probable que alguien pueda ejercer y llevar a la práctica tal competencia si no cuenta con cierto grado de confianza en sí mismo, curiosidad, percepción de su interés e importancia y el deseo de hacer o comprender cosas que incluyan componentes matemáticos. Se reconoce la importancia de estas actitudes y sentimientos en relación con la competencia matemática. No forman parte de la evaluación de la competencia matemática, pero se tratarán en otras partes del proyecto OCDE/PISA.

\section{Base teórica del marco conceptual de matemáticas}

La definición de competencia matemática del proyecto OCDE/PISA es coherente con la teoría amplia e integradora sobre la estructura y uso del lenguaje que aparece en recientes estudios sobre la competencia sociocultural. En el trabajo de James Gee Preamble to a Literacy Program (1998), el término "competencia" se refiere a la utilización que hacen las personas del lenguaje. La capacidad de leer, escribir, escuchar y hablar una lengua constituye la herramienta más importante de entre las que median en la actividad social humana. De hecho, cada lengua y cada utilización de la lengua posee un intrincado diseño que está vinculado de manera compleja a diferentes funciones. Que una persona sea competente en una lengua implica que conoce muchos de los recursos de diseño de la lengua y que sabe utilizar dichos recursos en muchas y variadas funciones sociales. De manera análoga, el considerar las matemáticas como un lenguaje implica que los estudiantes deben aprender los elementos característicos del discurso matemático (términos, hechos, signos, símbolos, procedimientos y destrezas para realizar ciertas operaciones de subáreas matemáticas específicas, además de la estructura de tales ideas en cada subárea) y también que deben aprender a utilizar tales ideas para resolver problemas no rutinarios en una variedad de situaciones definidas en términos de funciones sociales. Hay que tener en cuenta que entre los elementos característicos de las matemáticas se cuentan el reconocimiento de los términos, procedimientos y conceptos básicos que se enseñan normalmente en los colegios y también el saber cómo se utilizan y se estructuran estos elementos característicos. Por desgracia, una persona puede conocer muy bien estos elementos característicos de las matemáticas y no entender su estructura ni saber cómo utilizarlos para resolver problemas. Estas nociones teóricas de la interacción de los "elementos característicos" y las "funciones" que fundamentan el marco conceptual de las matemáticas dentro del proyecto OCDE/PISA se ilustran mediante el ejemplo siguiente. 
Matemáticas, ejemplo 1: LA FAROLA

El ayuntamiento ha decidido colocar una farola en un pequeño jardín triangular para que alumbre este jardín en su totalidad. ¿Dónde debería colocarse?

Este problema de tipo social puede resolverse mediante la estrategia general utilizada por los matemáticos y que dentro de este marco conceptual se denomina matematizar. La actividad de matematizar se puede describir a partir de cinco aspectos que la componen:

1. Comenzar con un problema enmarcado en la realidad: Localizar en qué lugar del jardín debe ubicarse la farola.

2. Sistematizar el problema según conceptos matemáticos: El jardín puede representarse como un triángulo y la iluminación producida como una circunferencia en cuyo centro se encuentra la farola.

3. Gradualmente reducir la realidad mediante procedimientos como la consideración de cuáles son los rasgos importantes del problema, la generalización y formalización (y con ello se potencian los rasgos matemáticos de la situación y se transforma el problema real en un problema matemático que representa fielmente la situación):

El problema queda reducido a localizar el centro de una circunferencia que circunscribe un triángulo.

4. Resolver el problema matemático:

Partiendo del hecho de que el centro de la circunferencia circunscrita al triángulo se encuentra en el punto de intersección de las mediatrices, traza las mediatrices de dos lados cualesquiera del triángulo. El punto de intersección de las mediatrices constituye el centro de la circunferencia.

5. Dar sentido a la solución matemática en términos de la situación real:

Relacionar la solución con la situación real del jardín. Reflexionar sobre la solución y reconocer, por ejemplo, que si una de las tres esquinas del jardín fuera un ángulo obtuso, esta solución no sería correcta, puesto que la ubicación de la farola quedaría fuera del jardín. Reconocer que la situación y el tamaño de los árboles del parque son otros factores que afectan a la posibilidad de aplicación de la solución matemática.

Son ésos los procedimientos que describen, en un sentido amplio, cómo, a menudo, los matemáticos «hacen matemáticas», cómo la gente utiliza las matemáticas en gran número de tareas reales y potenciales y cómo los ciudadanos bien informados y reflexivos utilizan las matemáticas para participar en el mundo real de manera total y competente. De hecho, aprender a matematizar debería constituir uno de los objetivos educativos más importantes para todos los alumnos.

En la actualidad y en el futuro inmediato, todos los países necesitan ciudadanos competentes en matemáticas, capaces de enfrentarse a una sociedad compleja y rápidamente cambiante. La información accesible ha ido creciendo de manera exponencial y los ciudadanos tienen que ser capaces de decidir cómo tratar esta información. Los debates sociales hacen uso, cada vez más, de información cuantitativa para apoyar las afirmaciones. Un ejemplo de la necesidad de la competencia matemática se observa en que, a menudo, a las personas se les pide en encuestas y estudios que den opiniones y valoraciones sobre la exactitud de diferentes conclusiones y afirmaciones. El ser capaz de juzgar la solidez de las afirmaciones de tales argumentos es, e irá siendo cada vez más, una característica crucial del ciudadano responsable. Los pasos del proceso de matematización tratados en este marco ceonceptual constituyen elementos fundamentales a la hora de utilizar las matemáticas en este tipo de situaciones complejas. El no saber utilizar las nociones matemáticas puede llevar a adoptar decisiones confusas en la vida personal, a creer más fácilmente en las pseudociencias y a tomar decisiones poco informadas en la vida profesional y social.

Un ciudadano con competencia matemática se da cuenta de lo rápido que se producen los cambios y de la consiguiente necesidad de ir aprendiendo a lo largo de toda la vida. 
Adaptarse a estos cambios de una manera creativa, flexible y práctica es una condición necesaria para tener éxito como ciudadano. Las destrezas aprendidas en la escuela probablemente no serán suficientes para cubrir las necesidades de los ciudadanos en la mayor parte de la vida adulta.

Los requisitos para una ciudadanía competente y reflexiva afectan también al mundo del trabajo. A los trabajadores se les pide cada vez menos que realicen trabajos físicos repetitivos en su vida laboral. Por el contrario, participan activamente en el control de la producción de un gran número de máquinas de alta tecnología al tiempo que tratan con un gran flujo de información y participan en la solución de problemas en grupo. La tendencia es que cada vez más trabajos exigirán la capacidad de saber comprender, comuni-car, utilizar y explicar conceptos y procedimientos basados en el pensamiento matemático. Los pasos del proceso de matematización constituyen los fundamentos de este tipo de pensamiento matemático.
Por último, los ciudadanos con competencia matemática tienden a apreciar las matemáticas como una disciplina dinámica, cambiante e importante que, a menudo, les resulta útil para sus necesidades.

El problema práctico al que se enfrenta el proyecto OCDE/PISA reside en cómo evaluar si los estudiantes de 15 años poseen o no una competencia matemática en términos de su habilidad para matematizar. Lamentablemente, esto resulta difícil en una prueba cronometrada puesto que, para las situaciones reales más complejas, el proceso de abstracción de la realidad a las matemáticas y a la inversa a menudo implica trabajar en grupo y saber hallar los recursos apropiados, y ello necesita un tiempo considerable.

Para ilustrar el proceso de la matematización en un ejercicio complejo de solución de problemas, vea el Ejemplo 2, Tablero de feria, un ejercicio realizado por estudiantes de octavo curso (segundo de Educación Secundaria Obligatoria en España) (Romberg, 1994):

\section{Matemáticas, ejemplo 2: TABLERO DE FERIA}

En una feria, los jugadores lanzan monedas sobre un tablero a cuadros. Si la moneda cae tocando una línea divisoria, el jugador la pierde. Si rueda y cae fuera del tablero, la recupera. Pero si la moneda queda totalmente dentro de un cuadrado, el jugador recupera la moneda y se lleva un premio.

\section{¿Cuál es la probabilidad de ganar en este juego?}

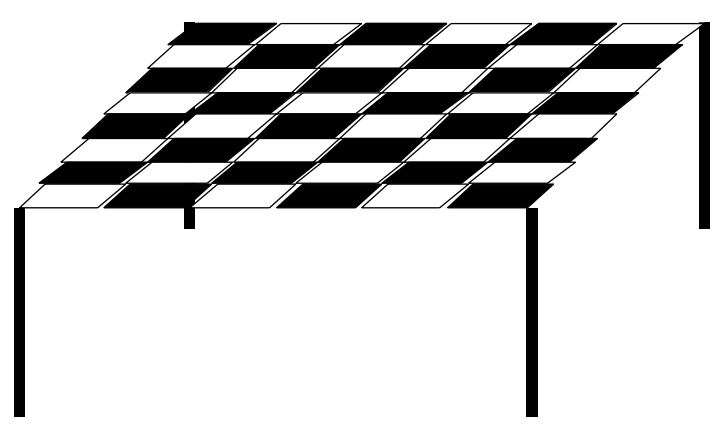


Este es un ejercicio que se enmarca claramente en la realidad. En primer lugar los estudiantes se dieron cuenta de que la probabilidad de ganar dependía del tamaño relativo de los cuadrados y de la moneda (identificando así las variables importantes). Acto seguido, para transformar el problema real en uno matemático, se dieron cuenta de que podía ser más fácil resolverlo si investigaban la relación de un único cuadrado y un círculo más pequeño que éste (reduciendo la realidad). A continuación decidieron elaborar un ejemplo específico (utilizando un método heurístico de resolución de problemas: «si no sabes resolver el problema que se pre- senta, resuelve uno que puedas»). Hay que tener en cuenta que lo que viene a continuación se realizó a raíz de este ejemplo específico, no del tablero, el premio, etc. En el ejemplo, hicieron que el radio de la moneda fuera de $3 \mathrm{~cm}$ y el lado de los cuadrados de $10 \mathrm{~cm}$. Se dieron cuenta de que, para ganar, el centro de la moneda debía estar al menos a tres centímetros de cada lado, porque, de otro modo, la moneda tocaría alguna línea. El espacio del ensayo era un cuadrado de $10 \mathrm{~cm}$ de lado y el espacio del suceso ganador era un cuadrado de 4 $\mathrm{cm}$ de lado. Las relaciones se muestran en el siguiente diagrama (Cuadro 1.1).

\section{Cuadro 1.1. Un lanzamiento ganador y otro perdedor (a la izquierda) y los espacios de ejemplo y de suceso (a la derecha)}

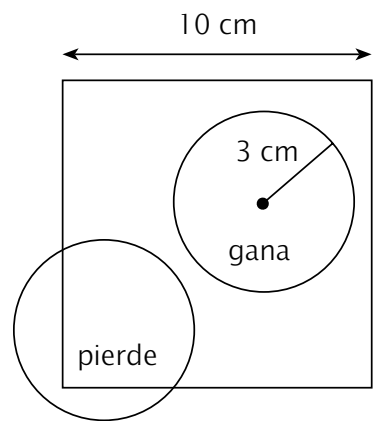

La probabilidad de ganar se obtuvo a partir de la relación entre las áreas de ensayo y de suceso (en el ejemplo, $\mathrm{p}=$ 16/100). Los estudiantes examinaron monedas de otros tamaños y generalizaron el problema exponiendo la solución en términos algebraicos. Por último, los estudiantes extrapolaron esta solución para averiguar los tamaños relativos de la moneda y los cuadrados en diferentes situaciones prácticas, construyeron tableros y comprobaron empíricamente los resultados (dando así sentido a la solución matemática en una situación real).

Obsérvese que en esta solución están presentes los cinco aspectos de la matematización. Aunque el problema es complejo, todo estudiante de 15 años debería comprender los conceptos matemáticas necesarios para resolver el problema. No obstante, hay que tener en cuenta que en

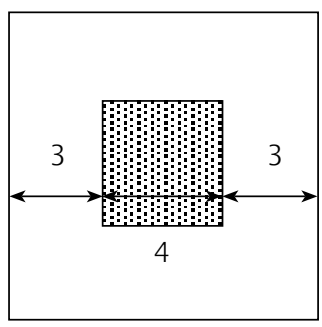

esta clase los estudiantes trabajaron juntos durante tres días para realizar este ejercicio.

Lo ideal para juzgar si los estudiantes de 15 años son capaces de utilizar los conocimientos matemáticos adquiridos para resolver problemas matemáticos que puedan encontrarse en la vida real sería recopilar información sobre su capacidad para matematizar dichas situaciones complejas. Obviamente, esto no es factible. En su lugar, el proyecto OCDE/PISA ha decidido elaborar preguntas para evaluar los diferentes estadios de este proceso. El apartado siguiente describe la estrategia seleccionada para crear un juego de preguntas de evaluación de modo equilibrado, de manera que el conjunto seleccionado de preguntas englobe los cinco aspectos del matematizar. El objetivo es utilizar las respuestas a dichas preguntas para ubicar a los estudiantes 
dentro de una escala de dominio en el constructo de la competencia matemática del proyecto OCDE/PISA.

\section{ORGANIZACIÓN DEL ÁREA DE CONOCIMIENTO}

El marco conceptual de matemáticas del proyecto OCDE/PISA proporciona la base y la descripción de una evaluación que determine en qué medida los estudiantes de 15 años son capaces de manejar las matemáticas de una manera bien fundada al hacer frente a problemas del mundo real. O, en términos más generales, una evaluación del grado de competencia matemática de los estudiantes de 15 años. Para describir más claramente el área de conocimiento evaluada deben distinguirse tres elementos:
- las situaciones o contextos en que se sitúan los problemas;

- el contenido matemático del que hay que valerse para resolver los problemas, organizado según ciertas ideas principales; y, sobre todo,

- las competencias que deben activarse para vincular el mundo real en el que se generan los problemas con las matemáticas, y, por tanto, para resolver los problemas.

Estos elementos están representados de manera gráfica en el Cuadro 1.2. A continuación aparece una explicación de cada uno de ellos.

Cuadro 1.2. Los elementos del área de conocimiento de matemáticas

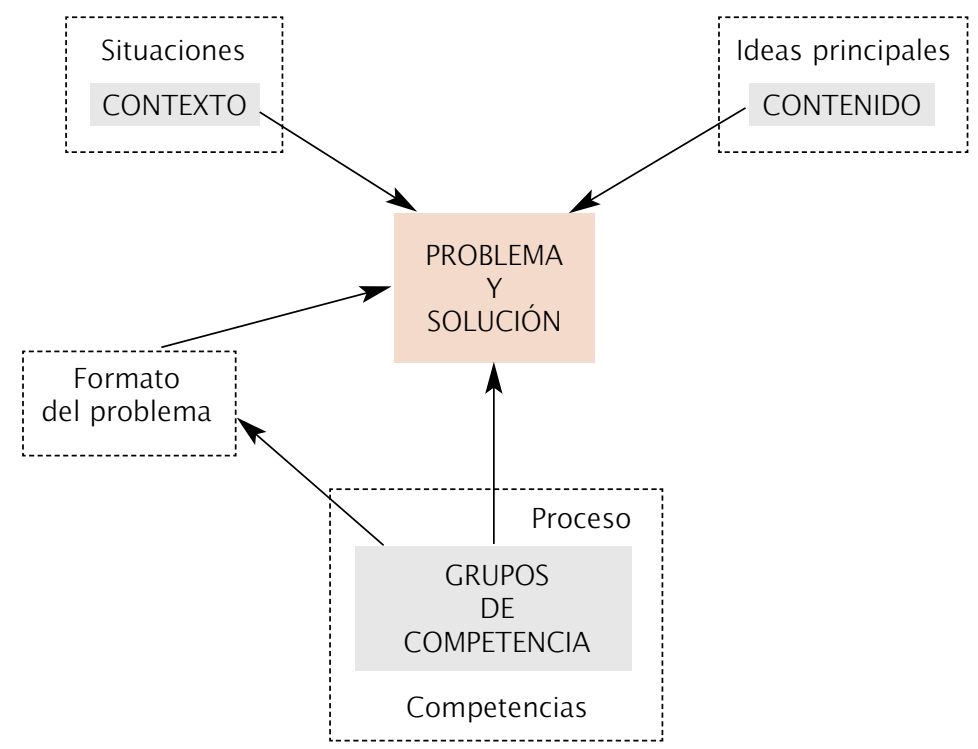


El grado de competencia matemática de una persona se observa en el modo en que utiliza sus destrezas y conocimientos matemáticos al resolver problemas. Los problemas (y su resolución) pueden presentarse en una gran variedad de situaciones o contextos en la experiencia de una persona. Los problemas del proyecto OCDE/PISA surgen del mundo real de dos maneras. En primer lugar, los problemas se dan en situaciones genéricas que son importantes en la vida del estudiante. Estas situaciones forman parte del mundo real y están indicadas mediante un cuadrado grande en la parte superior izquierda del gráfico. En segundo lugar, dentro de dicha situación, los problemas presentan un contexto más específico. Esto se representa mediante un cuadrado pequeño dentro del cuadrado de la situación.

\section{En los ejemplos anteriores, la situación la consti- tuye la comunidad local, y los contextos son el alumbrado de un jardín (Ejemplo 1) y el tablero de un juego de feria (Ejemplo 2).}

El siguiente elemento del mundo real que debe tenerse en cuenta al considerar la competencia matemática es el contenido matemático al que una persona recurre a la hora de resolver un problema. El contenido matemático puede explicarse mediante cuatro categorías que engloban los tipos de problemas que surgen de la interacción con los hechos del día a día y que se basan en una concepción del modo en que el contenido matemático se presenta ante la gente. Dentro de la evaluación PISA se les llama "ideas principales": cantidad, espacio y forma, cambio y relaciones $e$ incertidumbre. Se trata de un enfoque algo diferente al que resultaría familiar desde la perspectiva de la enseñanza de las matemáticas y las tendencias curriculares típicas de las escuelas. Sin embargo, las ideas principales engloban ampliamente toda la gama de temas matemáticos que se espera que hayan aprendido los estudiantes. Las ideas principales se representan mediante el cuadrado grande de la parte superior derecha del diagrama del Cuadro 1.2. De las ideas principales se extrae el contenido utilizado en la resolución de un problema. Esto se representa mediante el rectángulo sombreado situado en el interior del correspondiente a las ideas principales.

Las flechas que van de los rectángulos CONTEXTO y CONTENIDO al del PROBLEMA muestran cómo el mundo real (incluyendo las matemáticas) da lugar a un problema.

\begin{abstract}
El problema del jardín (Ejemplo 1) supone un conocimiento geométrico asociado a las ideas de espacio y forma, y el problema del tablero (Ejemplo 2) implica, al menos en sus estadios iniciales, tratar con la incertidumbre y aplicar conocimientos de probabilidad.
\end{abstract}

Los procesos matemáticos que los estudiantes aplican al tratar de resolver los problemas se conocen como competencias matemáticas. Tres grupos de competencia condensan los diferentes procesos cognitivos necesarios para resolver diferentes tipos de problemas. Estos grupos reflejan el modo en que los estudiantes utilizan normalmente los procesos matemáticos al resolver los problemas que surgen mientras se relacionan con su mundo. Éstos se explicarán con mayor detalle en los siguientes apartados.

Así, el elemento de proceso de este marco conceptual está representado primeramente por el rectángulo grande, que representa las competencias matemáticas, y por uno más pequeño, que representa los tres grupos de competencia. Las competencias específicas necesarias para resolver un problema irán en función de la naturaleza del problema y se verán reflejadas en la solución hallada. Esta interacción se representa mediante la flecha que va de los grupos de competencia al problema y su solución.

La flecha restante va de los grupos de competencia al formato del problema. Las competencias utilizadas para resolver un problema están relacionadas con la forma del problema y con lo que el problema exige.

Debe hacerse hincapié en que los tres elementos descritos son de naturaleza diferente. Mientras que las situaciones o contextos definen los ámbitos de problemas del mundo real, las ideas principales reflejan el modo en que observamos el mundo a través de un cristal matemático, y las competencias son el núcleo de la competencia matemática. Sólo cuando los estudiantes dispongan de ciertas competencias serán capaces de resolver acertadamente los problemas que se planteen. Evaluar la competencia matemática implica también valorar qué grado de competencias matemáticas son capaces de aplicar los estudiantes en situaciones de problemas. 
En los apartados siguientes se describen estos elementos con más detalle.

\section{SITUACIONES O CONTEXTOS}

Un aspecto importante de la competencia matemática lo constituye el involucrarse en las matemáticas, es decir, ejercitar y utilizar las matemáticas en una amplia variedad de situaciones. Se ha reconocido, en efecto, que al resolver un individuo asuntos susceptibles de tratamiento matemático, las representaciones y los métodos que escoge a menudo dependen de las situaciones en las que se presentan los problemas.

La situación es la parte del mundo del estudiante en la que se localizan los ejercicios que se le plantean. Se sitúa a una distancia diversa del estudiante mismo. Dentro de la evaluación OCDE/PISA, la situación más cercana es la vida personal del estudiante. Luego se sitúan la vida escolar, la vida laboral y el ocio, seguidas de la vida en la comunidad local y la sociedad tal y como se presentan en la vida diaria. A mucha distancia de todas ellas están las situaciones de tipo científico. Para los problemas que se van a presentar, se definen y utilizan cuatro tipos de situaciones: personal, educacional/profesional, pública y científica.

El contexto de un ejercicio lo constituye el modo concreto en que ésta se presenta dentro de una situación. Engloba los elementos específicos utilizados en el enunciado del problema que el ejercicio plantea.

Observe el siguiente ejemplo:

\section{Matemáticas, ejemplo 3: CUENTA DE AHORRO}

Se ingresan 1.000 zeds en una cuenta de ahorro en un banco. Existen dos opciones: o bien obtener un interés anual del 4\%, o bien obtener una prima inmediata de 10 zeds y un interés anual del 3\%. ¿Qué opción es mejor al cabo de un año? ¿Y al cabo de dos años?

La situación de esta pregunta es "finanzas y bancos", una situación de la comunidad local y la sociedad que en el proyecto OCDE/PISA se designa como "pública". El contexto de esta pregunta se refiere al dinero (zeds) y a los tipos de interés que ofrece una cuenta bancaria.

Observe que este tipo de problema podría ser parte de la práctica o experiencia del joven en su vida real. Proporciona un contexto auténtico de utilización de las matemáticas, ya que su aplicación en este contexto se dirigiría de manera directa a la resolución del proble$\mathrm{ma}^{1}$. Esto se puede contrastar con los problemas que se observan con frecuencia en los textos escolares de matemáticas, en los que el objetivo principal consiste más en practicar las matemáticas que en resolver un problema real. Esta autenticidad en la utilización de las matemáticas resulta un aspecto relevante del diseño y el análisis de las preguntas del proyecto OCDE/PISA y está estrechamente relacionada con la definición de la competencia matemática.
Debe tenerse en cuenta que algunos elementos de los problemas son inventados, por ejemplo, la moneda es ficticia. Este elemento ficticio se introduce para evitar que los estudiantes de algún país estén en una posición aventajada, algo que no sería justo para los demás.

La situación y el contexto de un problema también puede considerarse en términos de la distancia entre el problema y las matemáticas implicadas. Si un ejercicio hace referencia únicamente a estructuras, símbolos y objetos matemáticos y no alude a cuestiones ajenas al universo matemático, el contexto del ejercicio se considera intramatemático y dicho ejercicio se clasifica dentro de la clase de situación "científica". El proyecto OCDE/PISA incluye una variedad limitada de este tipo de ejercicios y en ellos se hace explícito el estrecho vínculo entre el problema y las matemáticas que subyacen en él. De manera más típica, los problemas que aparecen en la experiencia del día a día del estudiante no se plantean en términos matemáticos explícitos, sino que hacen referencia a objetos del mundo real. Los contenidos de

\footnotetext{
${ }^{1}$ Observe que esta utilización del término auténtico no quiere decir que las preguntas de matemáticas sean verdaderas y reales. Se utiliza el término auténtico para indicar que la utilización de las matemáticas se dirige directamente a la resolución del problema, en contraposición a que el problema sea únicamente un pretexto para hacer prácticas de operaciones matemáticas.
} 
estos ejercicios se denominan extramatemáticos y, entonces, el estudiante debe traducir estos contextos de los problemas a una formulación matemática. Por lo general, el proyecto OCDE/PISA hace hincapié en las tareas que pueden encontrarse en una situación real y que poseen un contexto auténtico para el uso de las matemáticas de un modo que influya en la solución y en su interpretación. Téngase en cuenta que esto no descarta la utilización de ejercicios con un contexto hipotético, siempre y cuando el contexto presente algunos elementos reales, no se encuentre demasiado alejado de una situación del mundo real y en el cual la utilización de las matemáticas pueda resultar auténtica para resolver el problema. El Ejemplo 4 muestra un problema con un contexto hipotético que es "extramatemático":

\section{Matemáticas, ejemplo 4: SISTEMA MONETARIO}

Se podría crear un sistema monetario basado únicamente en los valores 3 y 5 ? Concretamente, ¿qué cantidades podrían obtenerse a partir de esta base? ¿Resultaría conveniente un sistema de este tipo?

El carácter de este problema no se deriva de su cercanía respecto al mundo real, sino del hecho de que es matemáticamente interesante y alude a competencias relacionadas con la competencia matemática. El uso de las matemáticas para explicar escenarios hipotéticos y explorar sistemas o situaciones potenciales, incluso cuando éstos difícilmente vayan a llevarse a cabo en la realidad, es una de sus características más impactantes. Un problema de este tipo se clasifica dentro del tipo de situación "científica".

En resumen, el proyecto OCDE/PISA otorga la mayor importancia a aquellas tareas que podrían encontrarse en diferentes situaciones reales y que poseen un contexto en el que el uso de las matemáticas para resolver el problema sería auténtico. Los problemas con contextos extramatemáticos que influyen en la solución y en la interpretación se consideran preferentemente como un vehículo para evaluar la competencia matemática, porque estos problemas se asemejan mayoritariamente a los que se presentan en la vida diaria.

\section{CONTENIDO MATEMÁTICO: LAS CUATRO IDEAS PRINCIPALES}

Los conceptos, estructuras e ideas matemáticos se han inventado como herramientas para organizar los fenómenos del mundo natural, social y mental. En las escuelas, el currículum de matemáticas se ha organizado de una ma-nera lógica alrededor de las diferentes líneas de contenido (p. ej., aritmética, álgebra, geometría) y sus temas subordinados, que reflejan las ramas históricamente establecidas del pensamiento matemático y que facilitan el desarrollo de un plan de estudios estructurado. No obstante, en el mundo real, los fenómenos susceptibles de un tratamiento matemático no aparecen organizados de un modo tan lógico. Por lo general, los problemas no aparecen en contextos y maneras que permitan su comprensión y solución a través de la aplicación del conocimiento de una única área. El problema del tablero de feria descrito en el Ejemplo 2 constituye un ejemplo de problema que recurre a diversas áreas matemáticas.

Dado que el objetivo del proyecto OCDE/PISA es evaluar la capacidad de los estudiantes para resolver problemas reales, la estrategia ha consistido en definir el ámbito de los contenidos que se iban a evaluar utilizando un enfoque fenomenológico para describir los conceptos, estructuras e ideas matemáticas. Ello significa describir los contenidos en relación a los fenómenos y los tipos de problemas para los que se han creado. Este enfoque garantiza una atención de la evaluación que concuerda con la definición del área de conocimiento y que abarca un ámbito de contenidos que incluye todo aquello que normalmente aparece en otras evaluaciones matemáticas y en los currículos de matemáticas de los diferentes países.

La organización fenomenológica del contenido matemático no es nueva. Dos publicaciones muy conocidas, On the shoulders of giants: New approaches to numeracy (Steen, 1990) y Mathematics: The science of patterns (Devlin, 1994) han descrito las matemáticas de este modo. Sin embargo, 
se han utilizado diferentes maneras para etiquetar este enfoque y denominar las diferentes categorías fenomenológicas. Entre las diferentes propuestas de etiquetado se encuentran ideas profundas, grandes ideas, ideas fundamentales, conceptos principales, ideas principales, conceptos subyacentes, áreas principales o problemática. En el marco de matemáticas del proyecto OCDE/PISA se utiliza la etiqueta ideas principales.

Existen muchas ideas principales posibles. Las publicaciones mencionadas arriba, por sí solas, ya hacen referencia al modelo, la dimensión, la cantidad, la incertidumbre, la forma, el cambio, el cómputo, el razonamiento y la comunicación, el movimiento y el cambio, la simetría y la regularidad, y la posición. ¿Cuáles de estas ideas deberían utilizarse dentro del marco de matemáticas del proyecto OCDE/PISA? Con el objeto de centrar el área de conocimiento matemática, es importante seleccionar un conjunto de problemáticas surgidas de la evolución histórica de las matemáticas que englobe una variedad y profundidad suficiente para dejar ver los elementos esenciales de las matemáticas y que represente o incluya también los contenidos curriculares convencionales de las matemáticas de manera satisfactoria.

Durante siglos, las matemáticas consistieron preferentemente en la ciencia de los números, junto a una geometría relativamente concreta. Antes del año 500 a.C., Mesopotamia, Egipto y China vieron el origen del concepto de número. Se desarrollaron operaciones con números y cantidades, entre ellas cantidades resultantes de mediciones geométricas. Entre los años 500 a.C. y 300 d.C. tuvo lugar la era de la matemática griega, que se centraba fundamentalmente en el estudio de la geometría como teoría axiomática. Los griegos se encargaron de redefinir las matemáticas como una ciencia unificada a partir de los números y las formas. El siguiente cambio importante tuvo lugar entre los años 500 y 1300 d.C. en el mundo islámico, India y China, cuando el álgebra pasó a constituir una rama de las matemáticas. Con ello se estableció el estudio de las relaciones. Con las invenciones independientes del cálculo diferencial (el estudio del cambio, el crecimiento y el límite) por parte de Newton y Leibniz en el siglo XVII, las matemáticas se convirtieron en un estudio integrado del número, la forma, el cambio y las relaciones.
Los siglos XIX y XX vivieron diferentes explosiones del conocimiento matemático y del alcance de los fenómenos y problemas que podían tratarse mediante las matemáticas, especialmente los aspectos relacionados con la aleatoriedad y la indeterminación. Este desarrollo comportó que cada vez fuera más difícil hallar respuestas sencillas a la pregunta ¿qué son las matemáticas? En este nuevo milenio, mucha gente considera las matemáticas como la ciencia de las regularidades (en un sentido general). De esta manera, puede realizarse una elección de ideas principales que refleje este desarrollo: regularidades en el dominio de la cantidad, del espacio y la forma, y del cambio y las relaciones, constituyen los conceptos centrales y esenciales de cualquier descripción de las matemáticas y conforman el núcleo de cualquier currículum, ya sea de educación secundaria o universitaria. No obstante, ser competente en matemáticas significa algo más. Resulta esencial tratar con la incertidumbre desde una perspectiva matemática y científica. Por esta razón, los elementos de la teoría de la probabilidad y la estadística dan paso a la cuarta idea principal: la incertidumbre.

Por tanto, en el proyecto OCDE/PISA 2003 se utiliza la siguiente lista de ideas principales para adaptarse a los requisitos del desarrollo histórico, la cobertura del área y la plasmación de las líneas principales del currículum escolar:

- cantidad

- espacio y forma

- cambio y relaciones

- incertidumbre

A través de estas ideas, el contenido matemático se organiza en un número suficiente de áreas para garantizar que las preguntas de la prueba cubran el conjunto del currículo pero, al mismo tiempo, en un número suficientemente pequeño para evitar una división demasiado detallada que resultase perjudicial a la hora de atender los problemas basados en situaciones reales.

La concepción básica de una idea principal es un conjunto que engloba hechos y conceptos y que cobra sentido y puede encontrarse a lo largo de un gran número de situaciones diferentes. Debido a su misma naturaleza, cada idea principal puede percibirse como una especie de noción 
general que trata algún tipo de dimensión de contenido matemático. Esto implica que las ideas principales no pueden definirse de manera exacta en función de otra existente, porque no se puede trazar una línea de separación clara entre unas y otras ${ }^{2}$. Por el contrario, cada una de ellas representa una perspectiva o punto de vista que puede concebirse como poseedora de un núcleo, un centro de gravedad y, de algún modo, un área circundante difusa que permite la intersección con otras ideas principales. En principio, una idea principal posee una intersección con cualquier otra idea principal. Las cuatro ideas principales se resumen en el apartado siguiente y se tratan con mayor profundidad más adelante.

\section{Cantidad}

Esta idea principal se centra en la necesidad de cuantificar para organizar el mundo. Las características importantes engloban la comprensión del tamaño relativo, el reconocimiento de las regularidades numéricas y la utilización de los números para representar cantidades y atributos cuantificables de los objetos del mundo real (recuentos y medidas). Además, la cantidad tiene que ver con el procesamiento y comprensión de los números que de diferentes maneras se nos presentan.

Un aspecto importante al tratar con la cantidad es el razonamiento cuantitativo. Los componentes esenciales del razonamiento cuantitativo son el sentido para los números, la representación de los números de diferentes maneras, la comprensión del significado de las operaciones, la percepción de la magnitud de los números, los cálculos matemáticamente elegantes, la estimación y el cálculo mental.

\section{Espacio y forma}

Las regularidades se encuentran en todas partes: en el habla, la música, los vídeos, el tráfico, las construcciones y el arte. Las formas pueden considerarse como regularidades: casas, edificios de oficinas, puentes, estrellas de mar, copos de nieve, callejeros, hojas de trébol, cristales y sombras. Las regularidades geométricas pueden servir como unos modelos relativamente simples de muchas clases de hechos, y su estudio resulta posible y deseable en todos los niveles (Grünbaum, 1985).

El estudio de la forma y las construcciones exige buscar similitudes y diferencias al analizar los componentes formales y al reconocer las formas en diferentes representaciones y diferentes dimensiones. El estudio de las formas está estrechamente vinculado al concepto de percepción espacial. Esto comporta aprender a reconocer, explorar y conquistar, para vivir, respirar y movernos con mayor conocimiento en el espacio en que vivimos (Freudenthal, 1973).

Para conseguirlo es preciso comprender las propiedades de los objetos y sus posiciones relativas. Debemos ser conscientes de cómo vemos las cosas y de por qué las vemos de ese modo. Debemos aprender a orientarnos por el espacio y a través de las construcciones y formas. Ello significa entender la relación entre formas e imágenes, o representaciones visuales, tales como la relación entre una ciudad real y las fotografías y callejeros de esa ciudad. También presupone entender la representación en dos dimensiones de los objetos tridimensionales, la formación de las sombras y cómo interpretarlas, qué es la perspectiva y cómo funciona.

\section{Cambio y relaciones}

Cualquier fenómeno natural constituye una manifestación de cambio; el mundo que nos rodea presenta una gran cantidad de relaciones temporales y permanentes entre los diferentes fenómenos. Son ejemplo de ello los organismos, que cambian a medida que crecen, el ciclo de las estaciones, el flujo y reflujo de las mareas, los ciclos de desempleo, los cambios climatológicos y los índices bursátiles. Algunos de estos procesos de cambio comportan funciones matemáticas simples y pueden describirse o modelarse mediante ellas: funciones lineales, exponenciales, periódicas o logarítmicas, tanto discretas como continuas. No obstante, muchas relaciones pertenecen a categorías diferentes y, a menudo, el análisis de los datos resulta esencial para determinar qué tipo de relación se produce. A menudo las relaciones matemáticas adoptan la forma de ecuaciones o desigualdades, pero también pueden darse relaciones de una naturaleza más general (p. ej., equivalencia, divisibilidad o inclusión, entre otras).

El pensamiento funcional —es decir, el pensar sobre y en términos de relaciones- es uno de los objetivos disciplinarios más importantes de la enseñanza de las matemáticas (MAA, 1923). La relaciones pueden darse en una gran variedad de representaciones diferentes, entre ellas

${ }^{2}$ Y, por supuesto, tampoco pueden hacerlo las líneas de contenido matemático tradicionales. 
la simbólica, la algebraica, la tabular y la geométrica. Las diferentes representaciones sirven a propósitos diferentes y poseen propiedades diferentes. Por esta razón, la traducción entre las diferentes representaciones tiene a menudo una importancia fundamental a la hora de ocuparse de diversas situaciones y tareas.

\section{Incertidumbre}

La actual "sociedad de la información" proporciona un gran número de informaciones que a menudo se presentan como precisas, científicas y en diverso grado ciertas. No obstante, en la vida diaria nos enfrentamos a resultados de elecciones inciertos, puentes que desmoronan, caídas de la bolsa, predicciones del tiempo poco fidedignas, predicciones desafortunadas del crecimiento de la población, modelos económicos que no funcionan bien y muchas otras demostraciones de la incertidumbre del mundo en que vivimos.

La incertidumbre está pensada para sugerir dos temas relacionados: los datos y el azar. Estos dos fenóme-nos son objeto de estudio matemático por parte de la estadística y de la probabilidad, respectivamente. Las recientes recomendaciones relativas a los currículos escolares son unánimes al sugerir que la estadística y la probabilidad deberían ocupar un lugar mucho más importante que el que han tenido en el pasado (Committee of Inquiry into the Teaching of Mathematics in Schools, 1982; LOGSE, 1990; MSEB, 1990; NCTM, 1989; NCTM, 2000).

Actividades y conceptos matemáticos importantes de esta área son la recogida de datos, el análisis y la presentación /visualización de los mismos, la probabilidad y la deducción.

Ahora abordaremos el aspecto más importante del marco conceptual de las matemáticas: las competencias que los alumnos deben movilizar para tratar de resolver problemas. Éstas competencias se tratan bajo el título genérico de procesos matemáticos.

\section{PROCESOS MATEMÁTICOS}

\section{Introducción: la matematización}

El proyecto OCDE/PISA examina la capacidad de los estudiantes para analizar, razonar y transmitir ideas matemáticas de un modo efectivo al plantear, resolver e interpretar problemas matemáticos en diferentes situaciones. Este tipo de resolución de problemas exige a los estudiantes que se valgan de las destrezas y competencias que han adquirido a lo largo de su escolarización y sus experiencias vitales. En el proyecto OCDE/PISA, el proceso fundamental que los estudiantes emplean para resolver problemas de la vida real se denomina matematización.

Newton podría haber descrito la matematiza-
ción en su magna obra "Principios matemáticos
de la filosofía natural" cuando escribió: "Pero
nuestro objetivo consiste sólo en localizar la
cantidad y propiedades de esta fuerza a partir
de los fenómenos y en aplicar lo que descubra-
mos a algunos casos sencillos mediante los cua-
les, de manera matemática, podamos estimar los
efectos en otros casos más complejos» (Newton,
1687).

El debate anterior sobre la base teórica del marco conceptual de Matemáticas del proyecto OCDE/PISA trazó una descripción de la matematización en cinco pasos. Estos pasos se presentan en el Cuadro 1.3.

(1) Se inicia con un problema enmarcado en la realidad.

(2) Se organiza de acuerdo a conceptos matemáticos que identifican las matemáticas aplicables.

(3) Gradualmente se va reduciendo la realidad mediante procedimientos como la formulación de hipótesis, la generalización y la formalización. Ello potencia los rasgos matemáticos de la situación y transforma el problema real en un problema matemático que la representa fielmente.

(4) Se resuelve el problema matemático.

(5) Se da sentido a la solución matemática en términos de la situación real, a la vez que se identifican las limitaciones de la solución.

Como sugiere el diagrama del Cuadro 1.3, los cinco aspectos se tratan en tres fases. 
Cuadro 1.3. El ciclo de la matematización

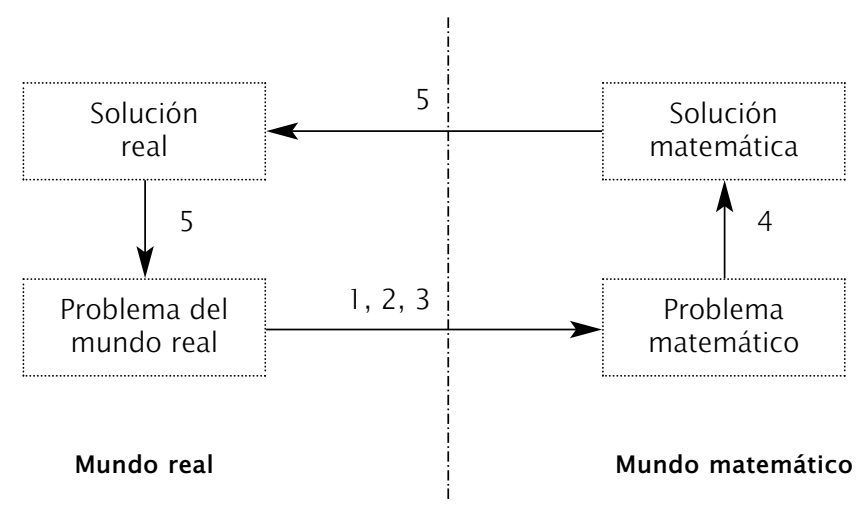

En primer lugar, la matematización implica traducir el problema de la «realidad» a las matemáticas. Este proceso engloba actividades como:

- identificar lo elementos matemáticos pertinentes en relación a un problema situado en la realidad;

- representar el problema de un modo diferente, organizándolo entre otras cosas de acuerdo a conceptos matemáticos y realizando suposiciones apropiadas;

- comprender las relaciones entre el lenguaje utilizado para describir el problema y el lenguaje simbólico y formal necesario para entenderlo matemáticamente;

- localizar regularidades, relaciones y recurrencias;

- reconocer aspectos que son isomórficos con relación a problemas conocidos;

- traducir el problema en términos matemáticos, es decir, en términos de un modelo matemático (De Lange, 1987, pág. 43).

Cuando el alumno ha traducido el problema a una forma matemática, el procedimiento continúa ya dentro de las matemáticas. Los estudiantes formularán preguntas como: «iHay...?», «En ese caso, ¿cuántos?» o «Cómo puedo hallar...» utilizando destrezas y conceptos matemáticos conocidos. Intentarán trabajar en su modelo de problema, adaptarlo, establecer regularidades, identificar conexiones y crear una buena argumentación matemática. A esta parte del proceso de matematización se la conoce normalmente como la parte deductiva del ciclo de construcción de modelos (Blum, 1996; Schupp, 1988). No obstante, en este estadio pueden desempeñar un papel otros procesos que no sean estrictamente deductivos. Esta parte del proceso de matematización incluye:

- utilizar diferentes representaciones e ir cambiando entre ellas;

- utilizar operaciones y lenguaje simbólico, formal y técnico;

- pulir y adaptar los modelos matemáticos, combinando e integrando modelos;

- argumentar;

- generalizar.

El último o los últimos pasos a la hora de resolver un problema conllevan una reflexión sobre todo el pro-ceso matemático y los resultados obtenidos. En este punto los estudiantes deben interpretar los resultados con una actitud crítica y validar todo el proceso. Esta reflexión tiene lugar en todas las fases del proceso, pero resulta de especial importancia en la fase final. Este proceso de reflexión y validación incluye: 
- la comprensión del alcance y los límites de los conceptos matemáticos;

- la reflexión sobre los argumentos matemáticos y la explicación y justificación de los resultados;

- la comunicación del proceso y de la solución;

- la crítica del modelo y de sus límites.

Esta fase viene indicada en dos puntos del Cuadro 1.3 mediante la etiqueta "5", donde el proceso de matematización pasa de la solución matemática a la solución real, y donde vuelve a relacionarse con el problema original perteneciente a la realidad.

\section{Las competencias}

El apartado anterior se centraba en los procesos y conceptos principales asociados a la matematización. Un individuo que deba participar con éxito en la matematización en una gran variedad de situaciones, contextos intra y extramatemáticos e ideas principales necesita poseer un número suficiente de competencias matemáticas que, juntas, puedan ser consideradas como una competencia matemática comprensiva. Cada una de estas competencias puede dominarse a diferentes niveles. Las distintas partes de la matematización se sirven de manera diferente de estas competencias, tanto en lo que se refiere a las competencias individuales como en relación con el nivel de dominio necesario. Para identificar y examinar estas competencias, el proyecto OCDE/PISA ha decidido utilizar ocho competencias matemáticas características que se basan en su forma actual en el trabajo de Niss (1999) y sus colegas daneses. Otras formulaciones similares se encuentran en las obras de muchos otros autores (tal y como se indica en Neubrand et al., 2001). No obstante, algunos de los términos utilizados tienen una acepción diferente entre los distintos autores.

1. Pensar y razonar. Formular preguntas características de las matemáticas («Hay...?», «En ese caso, ¿cuántos?», «Cómo puedo hallar...»); conocer los tipos de respuestas que dan las matemáticas a esas preguntas; diferenciar entre los diferentes tipos de afirmaciones (definiciones, teoremas, conjeturas, hipótesis, ejemplos, aseveraciones condicionadas); y entender y tratar la amplitud y los límites de los conceptos matemáticos dados.

2. Argumentación. Saber lo que son las demostraciones matemáticas y en qué se diferencian de otros tipos de razonamiento matemático; seguir y valorar el encadenamiento de argumentos matemáticos de diferentes tipos; tener un sentido heurístico ( «iQué puede o no puede pasar y por qué?»); y crear y plasmar argumentos matemáticos.

3. Comunicación. Esto comporta saber expresarse de diferentes maneras, tanto oralmente como por escrito, sobre temas de contenido matemático y entender las afirmaciones orales y escritas de terceras personas sobre dichos temas.

4. Construcción de modelos. Estructurar el campo o situación que se quiere modelar; traducir la realidad a estructuras matemáticas; interpretar los modelos matemáticos en términos de "realidad"; trabajar con un modelo matemático; validar el modelo; reflexionar, analizar y criticar un modelo y sus resultados; comunicar opiniones sobre el modelo y sus resultados (incluyendo las limitaciones de tales resultados); y supervisar y controlar el proceso de construcción de modelos.

5. Formulación y resolución de problemas. Representar, formular y definir diferentes tipos de problemas matemáticos (por ejemplo, "puro", "aplicado", "abierto" y "cerrado"); y la resolución de diferentes tipos de problemas matemáticos de diversas maneras.

6. Representación. Descodificar y codificar, traducir, interpretar y diferenciar entre las diversas formas de representación de las situaciones y objetos matemáticos y las interrelaciones entre las varias representaciones; seleccionar y cambiar entre diferentes formas de representación dependiendo de la situación y el propósito.

7. Empleo de operaciones y de un lenguaje simbólico, formal y técnico. Descodificar e interpretar el lenguaje formal y simbólico y comprender su relación con el lenguaje natural; traducir del lenguaje natural al lenguaje simbólico/formal; manejar afirmaciones y expresiones con 
símbolos y formulas; utilizar variables, resolver ecuaciones y realizar cálculos.

8. Empleo de soportes y herramientas. Tener conocimientos y ser capaz de utilizar diferentes soportes y herramientas (entre ellas, herramientas de las tecnologías de la información) que pueden ayudar en la actividad matemática; y conocer sus limitaciones.

La intención del proyecto OCDE/PISA no consiste en desarrollar preguntas de prueba que evalúen las competencias arriba mencionadas por separado. Dichas competencias se entremezclan y a menudo es necesario, al ejercitar las matemáticas, recurrir al mismo tiempo a muchas competencias, de manera que el intentar evaluar las competencias por separado resultaría por lo general una tarea artificial y una compartimentación innecesaria del área. Las diferentes competencias que presenten los alumnos variarán considerablemente de una persona a otra. Esto es en parte así debido a que todo el aprendizaje tiene lugar a través de experiencias, y «la elaboración del conocimiento propio tiene lugar a través de los procesos de interacción, negociación y colaboración» (De Corte, Greer y Verschaffel, 1996, pág. 510). El proyecto OCDE/PISA parte del hecho de que gran parte de las matemáticas que saben los estudiantes la han aprendido en la escuela. La comprensión de un área de conocimiento es algo que se va adquiriendo gradualmente. Con el tiempo van apareciendo maneras más formales y abstractas de representación y razonamiento como resultado de ir participando en actividades diseñadas para desarrollar ideas informales. La competencia matemática también se adquiere a través de experimentar interrelaciones asociadas en diferentes situaciones o contextos sociales.

Para describir y transmitir de manera productiva las capacidades de los estudiantes, así como sus puntos fuertes y sus puntos débiles desde una perspectiva internacional, es necesaria cierta estructura. Un modo de ofrecerla de una manera comprensible y manejable es describir grupos de competencias a partir de los tipos de requisitos cognitivos necesarios para resolver diferentes problemas matemáticos.

\section{Grupos de competencia}

El proyecto OCDE/PISA ha elegido describir las acciones cognitivas que estas competencias engloban de acuerdo a tres grupos de competencia: el grupo de reproducción, el grupo de conexión y el grupo de reflexión. En las secciones siguientes se definen los tres grupos y se tratan las maneras en que se interpretan cada una de las competencias dentro de cada grupo.

\section{El grupo de reproducción}

Las competencias de este grupo implican esencialmente a la reproducción del conocimiento estudiado. Incluyen aquellas que se emplean más frecuentemente en las pruebas estandarizadas y en los libros de texto: conocimiento de hechos, representaciones de problemas comunes, reconocimiento de equivalentes, recopilación de propiedades y objetos matemáticos familiares, ejecución de procedimientos rutinarios, aplicación de destrezas técnicas y de algoritmos habituales, el manejo de expresiones con símbolos y fórmulas establecidas y realización de cálculos.

1. Pensar y razonar. Formular las preguntas más simples («icuántos...?», «icuánto es...?») y comprender los consiguientes tipos de respuesta («tantos», «tanto»); distinguir entre definiciones y afirmaciones; comprender y emplear conceptos matemáticos en el mismo contexto en el que se introdujeron por primera vez o en el que se han practicado subsiguientemente.

2. Argumentación. Seguir y justificar los procesos cuantitativos estándar, entre ellos los procesos de cálculo, los enunciados y los resultados.

3. Comunicación. Comprender y saber expresarse oralmen te y por escrito sobre cuestiones matemáticas sencillas, tales como reproducir los nombres y las propiedades básicas de objetos familiares, mencionando cálculos y resultados, normalmente de una única manera.

4. Construcción de modelos. Reconocer, recopilar, activar y aprovechar modelos familiares bien estructurados; pasar sucesivamente de los diferentes modelos (y sus resultados) a la realidad y viceversa para lograr una interpretación; comunicar de manera elemental los resultados del modelo.

5. Formulación y resolución de problemas. Exponer y formular problemas reconociendo y reproduciendo problemas ya practicados puros y aplicados de manera cerrada; 
resolver problemas utilizando enfoques y procedimientos estándar, normalmente de una única manera.

6. Representación. Descodificar, codificar e interpretar representaciones de objetos matemáticos previamente conocidos de un modo estándar que ya ha sido practicado. El paso de una representación a otra sólo se exige cuando ese paso mismo es una parte establecida de la representación.

7. Empleo de operaciones y de un lenguaje simbólico, formal y técnico. Descodificar e interpretar el lenguaje formal y simbólico rutinario que ya se ha practicado en situaciones y contextos sobradamente conocidos; manejar afirmaciones sencillas y expresiones con símbolos y fórmulas, tales como utilizar variables, resolver ecuaciones y realizar cálculos mediante procedimientos rutinarios.

8. Empleo de soportes y herramientas. Conocer y ser capaz de emplear soportes y herramientas familiares en con textos, situaciones y procedimientos similares a los ya conocidos y practicados a lo largo del aprendizaje.

Las preguntas que miden las competencias del grupo de reproducción se pueden describir mediante los siguientes descriptores clave: reproducir material practicado y realizar operaciones rutinarias.

\section{Ejemplos de preguntas del grupo de reproducción}

\section{Matemáticas, ejemplo 5:}

Resuelve la ecuación $7 x-3=13 x+15$

\section{Matemáticas, ejemplo 6:}

¿Cuál es la media de 7, 12, 8, 14, 15, 9?

\section{Matemáticas, ejemplo 7:}

Escribe 69\% en forma de fracción

\section{Matemáticas, ejemplo 8:}

La línea $m$ se denomina de la circunferencia.

\section{Matemáticas, ejemplo 9:}

Se ingresan 1.000 zeds en una cuenta de ahorro en un banco con un tipo de interés del 4\%. ¿Cuántos zeds habrá en la cuenta al cabo de un año? 
Para clarificar los límites de las preguntas del grupo de reproducción hay que hacer notar que el problema presentado como Ejemplo 3 "Cuenta de ahorro" NO pertenece al grupo de reproducción. Este problema lleva a los alumnos más allá de la simple aplicación de un procedimiento de rutina, puesto que requiere la aplicación de un hilo de razonamiento y de una secuencia de pasos de cálculo que no son característicos de las competencias del grupo de reproducción.

\section{El grupo de conexión}

Las competencias del grupo de conexión se apoyan sobre las del grupo de reproducción, conduciendo a situaciones de solución de problemas que ya no son de mera rutina, pero que aún incluyen escenarios familiares o casi familiares.

1. Además de las competencias descritas para el grupo de reproducción, las competencias del grupo de conexión comprenden las siguientes:

1. Pensar y razonar. Formular preguntas («icómo hallamos...?», «¿qué tratamiento matemático damos...?») y comprender los consiguientes tipos de respuesta (plasmadas mediante tablas, gráficos, álgebra, cifras, etc.); distinguir entre definiciones y afirmaciones y entre distintos tipos de éstas; comprender y emplear conceptos matemáticos en contextos que difieren ligeramente de aquellos en los que se introdujeron por primera vez o en los que se han practicado después.

2. Argumentación. Razonar matemáticamente de manera simple sin distinguir entre pruebas y formas más amplias de argumentación y razonamiento; seguir y evaluar el encadenamiento de los argumentos matemáticos de diferentes tipos; tener sentido de la heurística (p. ej., «¿qué puede o no puede pasar y por qué?», «¿qué sabemos y qué queremos obtener?»).

3. Comunicación. Comprender y saber expresarse oralmente y por escrito sobre cuestiones matemáticas que engloban desde cómo reproducir los nombres y las propiedades básicas de objetos familiares o cómo explicar los cálculos y sus resultados (normalmente de más de una manera) hasta explicar asuntos que implican relaciones. También comporta entender las afirmaciones orales o escritas de terceros sobre este tipo de asuntos.
4. Construcción de modelos. Estructurar el campo o situación del que hay que realizar el mo-delo; traducir la «realidad» a estructuras matemáticas en contextos que no son demasiado complejos pero que son diferentes a los que están acostumbrados los estudiantes. Comporta también saber interpretar alternando los modelos (y de sus resultados) y la realidad), y sabiendo también comunicar los resultados del modelo.

5. Formulación y resolución de problemas. Plantear y formular problemas más allá de la reproducción de los problemas ya practicados de forma cerrada; resolver tales problemas mediante la utilización de procedimientos y aplicaciones estándar pero también de procedimientos de resolución de problemas más independientes que implican establecer conexiones entre distintas áreas matemáticas y distintas formas de representación y comunicación (esquemas, tablas, gráficos, palabras e ilustraciones).

6. Representación. Descodificar, codificar e interpretar formas de representación más o menos familiares de los objetos matemáticos; seleccionar y cambiar entre diferentes formas de representación de las situaciones y objetos matemáticos, y traducir y diferenciar entre diferentes formas de representación.

7. Empleo de operaciones y de un lenguaje simbólico, formal y técnico. Descodificar e interpretar el lenguaje formal y simbólico básico en situaciones y contextos menos conocidos y manejar afirmaciones sencillas y expresiones con símbolos y fórmulas, tales como utilizar variables, resolver ecuaciones y realizar cálculos mediante procedimientos familiares.

8. Empleo de soportes y herramientas. Conocer y ser capaz de emplear soportes y herramientas familiares en con textos, situaciones y maneras diferentes a las introducidas y practicadas a lo largo del aprendizaje.

Las preguntas de este grupo normalmente exigen alguna prueba de la integración y vinculación del material derivado de las diferentes ideas principales, de las diversas líneas curriculares matemáticas o de la conexión de las varias representaciones de un problema. 
Las preguntas que miden las competencias del grupo de conexión se pueden describir mediante los siguientes des- criptores clave: integración, conexión y ampliación moderada del material practicado.

\section{Ejemplos de preguntas del grupo de conexión}

Un primer ejemplo del grupo de conexión es el del Ejemplo 3, Cuenta de ahorro, aparecido anteriormente. A continuación se presentan otros.

\section{Matemáticas, ejemplo 10: DISTANCIA}

María vive a dos kilómetros de su colegio y Martín a cinco. ¿A qué distancia viven el uno del otro?

Cuando se mostró este problema a los profesores, muchos de ellos lo rechazaron por considerarlo demasiado fácil (se ve rápidamente que la respuesta es 3). Otro grupo de profesores argumentaron que no era una pregunta adecuada, porque no había respuesta (querían decir que no hay una única respuesta numérica). Otros argumentaron que no era adecuado porque había varias respuestas posibles, dado que, sin más información, la mayoría de alumnos podían concluir que vivían a entre 3 y 7 kilómetros de distancia (una respuesta que no es deseable para una pregunta de evaluación). Unos pocos pensaron por el contrario que se trataba de una pregunta excelente, porque exige entender la pregunta, porque es un problema real dado que no incluye una estrategia conocida por el estudiante, y porque es una cuestión matemática preciosa aunque no se sepa cómo van a resolverla los estudiantes. Esta última interpretación es la que vincula el problema con el grupo de competencias de conexión.

\section{Matemáticas, ejemplo 11: ALQUILER DE OFICINAS}

Los dos siguientes anuncios aparecieron en un diario de un país cuya unidad monetaria es el zed.

EDIFICIO A
Se alquilan oficinas
$58-95$ metros cuadrados
475 zeds al mes
$100-120$ metros cuadrados
800 zeds al mes

\begin{tabular}{l|} 
EDIFICIO B \\
Se alquilan oficinas \\
35-260 metros cuadrados \\
90 zeds por metro \\
cuadrado al año
\end{tabular}

Si una empresa está interesada en alquilar una oficina de 110 metros cuadrados en ese país durante un año, ¿en qué edificio de oficinas, A o B, deberá alquilar la oficina para conseguir el precio más bajo? Escribe tus cálculos. [๑ IEA/TIMSS] 
Matemáticas, ejemplo 12: LA PIZZA

Una pizzería ofrece dos pizzas redondas del mismo grosor pero de diferentes tamaños. La pequeña tiene un diámetro de $30 \mathrm{~cm}$ y cuesta 30 zeds. La grande tiene un diámetro de $40 \mathrm{~cm}$ y cuesta 40 zeds. [@ PRIM, Stockholm Institute of Education]

¿Qué pizza es la mejor opción en relación a lo que cuesta? Escribe tu razonamiento.

En estos dos problemas los estudiantes deben traducir una situación del mundo real a lenguaje matemático, desarrollar un modelo matemático que les permita establecer una comparación adecuada, comprobar que la solución se ajusta al contexto de la pregunta inicial y comunicar el resultado. Todas estas actividades se incluyen dentro del grupo de conexión.

\section{El grupo de reflexión}

Las competencias de este grupo incluyen un elemento de reflexión por parte del estudiante sobre los procesos necesarios o empleados para resolver un problema. Relacionan las capacidades de los alumnos para planificar estrategias de resolución y aplicarlas en escenarios de problema que contienen más elementos y pueden ser más «originales» (o inusuales) que los del grupo de conexión. Además de las competencias descritas para el grupo de conexión, entre las competencias del grupo de reflexión se encuentran las siguientes:

1. Pensar y razonar. Formular preguntas («icómo hallamos...?», «iqué tratamiento matemático damos...?», «¿cuáles son los aspectos esenciales del problema o situación...?») y comprender los consiguientes tipos de respuesta (plasmadas mediante tablas, gráficos, álgebra, cifras, especificación de los puntos clave, etc.); distinguir entre definiciones, teoremas, conjeturas, hipótesis y afirmaciones sobre casos especiales y articular de modo activo o reflexionar sobre estas distinciones; comprender y emplear conceptos matemáticos en contextos nuevos o complejos; comprender y tratar la amplitud y los límites de los conceptos matemáticos dados y generalizar los resultados.

2. Argumentación. Razonar matemáticamente de manera sencilla, distinguiendo entre pruebas y formas más amplias de argumentación y razonamiento; seguir, evaluar y elaborar encadenamientos de argumentos matemáticos de diferentes tipos; emplear la heurística (p. ej., «qué puede o no puede pasar y por qué?», «¿qué sabemos y qué queremos obtener?», «¿cuáles son las propiedades esenciales?», «¿cómo están relacionados los diferentes objetos?»).

3. Comunicación. Comprender y saber expresarse oralmente y por escrito sobre cuestiones matemáticas que engloban desde cómo reproducir los nombres y las propiedades básicas de objetos familiares o explicar cálculos y resultados (normalmente de más de una manera) a explicar asuntos que implican relaciones complejas, entre ellas relaciones lógicas. También comporta entender las afirmaciones orales o escritas de terceros sobre este tipo de asuntos.

4. Construcción de modelos. Estructurar el campo o situación del que hay que realizar el modelo, traducir la realidad a estructuras matemáticas en contextos complejos o muy diferentes a los que están acostumbrados los estudiantes y pasar alternando de los diferentes modelos (y sus resultados) a la «realidad», incluyendo aquí aspectos de la comunicación de los resultados del modelo: recopilar información y datos, supervisar el proceso de construcción de modelos y validar el modelo resultante. Conlleva también reflexionar analizando, realizando críticas y llevando a cabo una comunicación más compleja sobre los modelos y su construcción.

5. Formulación y resolución de problemas. Exponer y formular problemas mucho más allá de la reproducción de los problemas ya practicados de forma cerrada; resolver tales problemas mediante la utilización de procedimientos y aplicaciones estándar pero también de procedimientos de resolución de problemas más originales que implican establecer conexiones entre distintas áreas matemáticas y formas de representación y 
comunicación (esquemas, tablas, gráficos, palabras e ilustraciones). También conlleva reflexionar sobre las estrategias y las soluciones.

6. Representación. Descodificar, codificar e interpretar formas de representación más o menos familiares de los objetos matemáticos; seleccionar y cambiar entre diferentes formas de representación de las situaciones y objetos matemáticos y traducir y diferenciar entre ellas. También conlleva combinar representaciones de manera creativa e inventar nuevas.

7. Empleo de operaciones y de un lenguaje simbólico, formal y técnico. Descodificar e interpretar el lenguaje formal y simbólico ya practicado en situaciones y contextos desconocidos y manejar afirmaciones y expresiones con símbolos y fórmulas, tales como utilizar variables, resolver ecuaciones y realizar cálculos. También conlleva la habilidad de saber tratar con expresiones y afirmaciones complejas y con lenguaje simbólico o formal inusual, y realizar traducciones entre este lenguaje y el lenguaje natural.

8. Empleo de soportes y herramientas. Conocer y ser capaz de emplear soportes y herramientas familiares o inusuales en contextos, situaciones y formas bastante diferentes a las ya introducidas y practicadas. También conlleva reconocer las limitaciones de tales soportes y herramientas.

Las preguntas de evaluación que miden las competencias del grupo de reflexión se pueden describir mediante los siguientes descriptores clave: razonamiento avanzado, argumentación, abstracción, generalización y construcción de modelos aplicados a contextos nuevos.

\section{Ejemplos de preguntas del grupo de reflexión}

\section{Matemáticas, ejemplo 13: CRECIMIENTO DE LA POBLACIÓN DE PECES}

Se repobló con peces un canal fluvial. El gráfico muestra un modelo de cómo ha crecido el peso total de los peces en el canal fluvial.

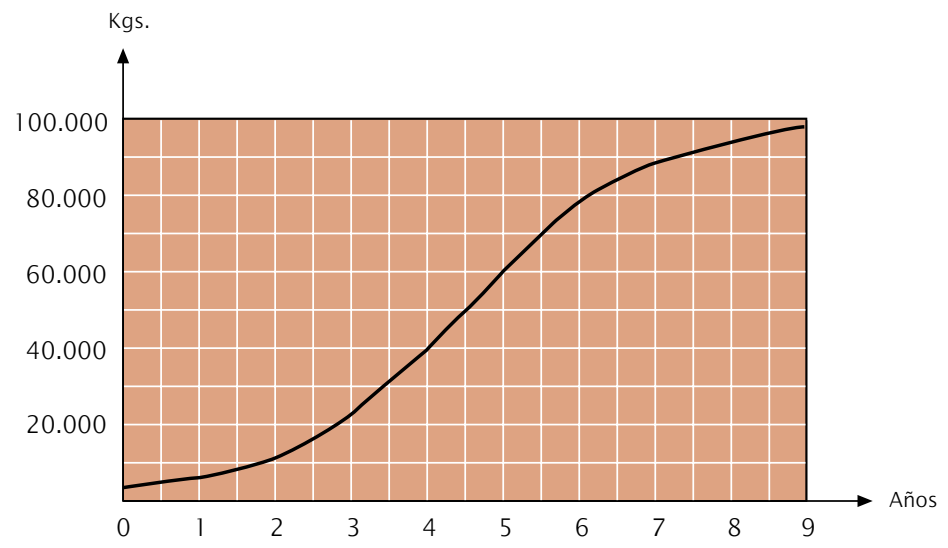

Supón que un pescador decide esperar unos años antes de empezar a pescar los peces del canal fluvial. ¿Cuántos años deberá esperar si desea maximizar el número de peces que pueda coger anualmente a partir de ese año? Razona tu respuesta. 


\section{Matemáticas, ejemplo 14: PRESUPUESTO}

En un determinado país, el presupuesto nacional de defensa fue de 30 millones (en la moneda del país) en 1980. El presupuesto total de ese año fue de 500 millones. Al año siguiente, el presupuesto de defensa pasó a 35 millones, mientras que el presupuesto total fue de 605 millones. La inflación del período comprendido entre los dos presupuestos alcanzó el 10 por ciento.

a) Te invitan a dar una conferencia en una asociación pacifista. Intentas explicar que el presupuesto de defensa ha disminuido en este período. Explica cómo lo harías.

b) Te invitan a dar una conferencia en una academia militar. Intentas explicar que el presupuesto de defensa ha aumentado en este período. Explica cómo lo harías.

Fuente: De Lange y Verhage (1992). Reproducción autorizada.

Está claro que el Ejemplo 13 se ajusta a la definición de resolución de problemas de matemáticas en un contexto auténtico. Los estudiantes tendrán que encontrar sus propias estrategias y argumentación en un problema algo complejo e inusual. La complejidad radica en parte en la necesidad de combinar con esmero la información presentada de manera gráfica o textual. Además, la respuesta no resulta obvia para los estudiantes. Necesitarán interpretar el gráfico y darse cuenta, por ejemplo, de que la tasa de crecimiento alcanza su nivel máximo al cabo de unos cinco años. Para realizar el problema de manera satisfactoria, los estudiantes tienen que reflexionar sobre la solución a medida que la elaboran y considerar la adecuación de su estrategia. Además, el problema exige una explicación y una indicación de la «prueba». Una posibilidad es emplear el método de ensayo-error: ver qué pasa si sólo se espera 3 años, por ejemplo, y seguir a partir de ahí. Si se espera hasta finales del quinto año, se obtiene la mayor recolección: $20.000 \mathrm{~kg}$ de pescado. Si no se puede esperar tanto y se inicia la pesca un año antes, sólo se consiguen $17.000 \mathrm{~kg}$, y, si se espera demasiado (seis años), sólo se pescarán $18.000 \mathrm{~kg}$ al año. Por tanto, los mejores resultados se obtienen cuando la recolección se inicia al cabo de cinco años.

El Ejemplo 14 se ha estudiando en profundidad con estudiantes de 16 años e ilustra muy bien los problemas del grupo de reflexión: los estudiantes reconocieron inmediatamente el aspecto matemático y con frecuencia supieron hacer algún tipo de generalización, puesto que el punto central de la solución radica en reconocer que los conceptos matemáticos clave aquí son el crecimiento absoluto y el crecimiento relativo. Por supuesto, la inflación podría dejarse a un lado para que el problema fuera más accesible para los estudiantes más jóvenes sin que por ello se perdieran las ideas conceptuales clave del problema, pero entonces se perdería complejidad y, de ese modo, parte de la matematización necesaria. Otra manera de facilitar la pregunta sería presentando los datos en una tabla o esquema. Estos aspectos de la matematización ya no son necesarios; los alumnos pueden empezar directamente por el punto central del asunto.

Resumen de los procesos matemáticos en la evaluación OCDE/PISA de matemáticas

El Cuadro 1.4 ofrece una representación gráfica de los grupos de competencia y resume las diferencias entre ellos. Las descripciones de competencia de las páginas anteriores podrían utilizarse para clasificar las preguntas de matemáticas y asignarlas así a uno de los grupos de competencia. Una manera de hacerlo sería analizar los requisitos de cada pregunta y luego considerar cada una de las competencias para la pregunta en cuestión: uno de los tres grupos proporcionará la descripción más ajustada de los requisitos de la pregunta en relación a esa competencia. Si se considera que alguna de las competencias se ajusta a la descripción del grupo de reflexión, entonces la pregunta se asigna a ese grupo de competencia. Si no ocurre eso, pero se considera que alguna de las competencias se ajusta a la descripción del grupo de 
Cuadro 1.4. Representación sintética

de los grupos de competencia

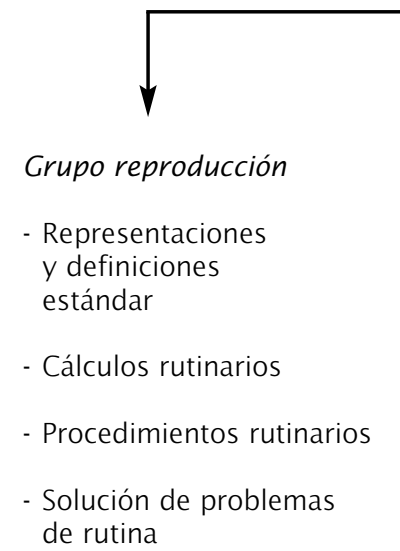

Grupo conexión

- Construcción de modelos

- Traducción, Interpretación y solución de problemas estándar

- Métodos múltiples bien definidos

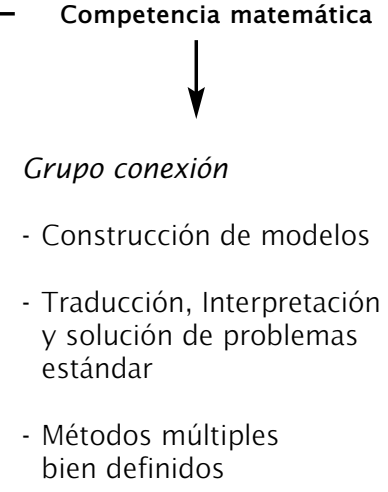

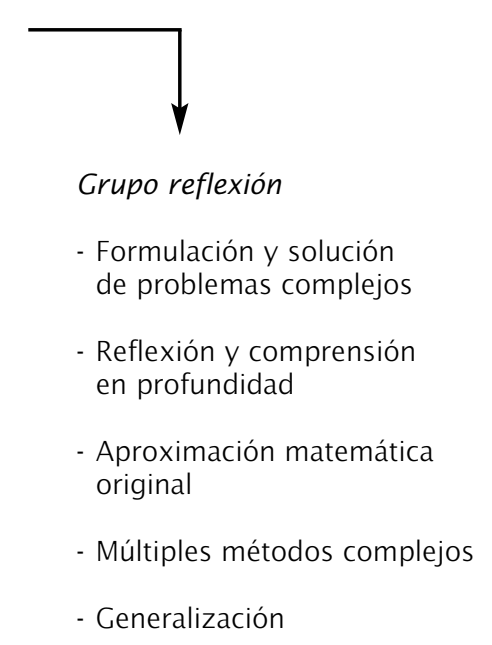

conexión, entonces la pregunta se asigna a ese grupo. Si no se da ninguno de estos casos, la pregunta se asignaría al grupo de reproducción, puesto que se consideraría que todas las competencias que moviliza se ajustarían a la descripción de las competencias de ese grupo.

\section{Evaluación de la competencia matemática}

\section{CARACTERÍSTICAS DE LOS EJERCICIOS}

En las secciones anteriores se ha definido la competencia matemática del proyecto OCDE/PISA y la estructura del marco conceptual de su evaluación. En este apartado se presentan con más detalle las características de los ejercicios que se utilizarán para evaluar a los estudiantes. Aquí se describen la naturaleza de los ejercicios y los tipos de formato de pregunta.

\section{La naturaleza de los ejercicios de matemáticas}

El proyecto OCDE/PISA es una evaluación internacional de las destrezas de los alumnos de 15 años. Todas las preguntas utilizadas deben ser las adecuadas para la población de estudiantes de 15 años de los países de la OCDE.
En general, las preguntas consisten en información o material de estímulo, una presentación, la pregunta propiamente dicha y la solución que se precisa. Además, para las preguntas cuyas respuestas no pueden puntuarse automáticamente se elaboran unos criterios de corrección para que correctores de los diferentes países especialmente formados puedan puntuar las respuestas de los alumnos de un modo consistente y fiable.

En un apartado anterior de este marco conceptual se han tratado detalladamente los tipos de situaciones que hay que utilizar para las preguntas de matemáticas del proyecto OCDE/PISA. En el ciclo 2003 cada pregunta se encuentra dentro de uno de los cuatro tipos de situación: personal, educacional/profesional, pública y científica. Las preguntas seleccionadas como instrumentos de matemáticas se distribuyen entre estos tipos de situación.

Además, se da preferencia a preguntas cuyos contextos que se consideren auténticos. Es decir, el proyecto OCDE/PISA otorga la mayor importancia a aquellos ejercicios que podrían encontrarse en situaciones reales y que poseen un contexto en el que el uso de las matemáticas para resolver el problema podría considerarse auténtico. Los problemas con contextos extramatemáticos que 
influyen en la solución y su interpretación se prefieren como vehículos de evaluación de la competencia matemática.

Las preguntas deben tener relación en su mayoría con una de las ideas principales (o categorías fenomenológicas de problemas) descritas en este marco conceptual. La elección de las preguntas de matemáticas en el proyecto OCDE/PISA garantiza una representación suficiente de las cuatro ideas principales.

Las preguntas deben incorporar uno o varios de los procesos matemáticos descritos en el marco conceptual y deben identificarse predominantemente con uno de los grupos de competencia.

En el desarrollo y elección de las preguntas que se incluyen como instrumento de evaluación del proyecto OCDE/PISA 2003, se considera detenidamente el nivel de lectura necesario para comprender una pregunta. La formulación de las preguntas debe ser lo más sencilla y directa posible. También se procura evitar contextos que pudieran comportar un sesgo cultural.

Las preguntas seleccionadas como instrumentos de evaluación del proyecto OCDE/PISA presenta una amplia gama de dificultad para así ajustarse a la amplia gama de habilidad de los estudiantes esperada. Además, las categorías principales del marco conceptual (en especial los grupos de competencias y las ideas principales) deben hallarse representadas en la mayor medida posible mediante preguntas de muy variada dificultad. El grado de dificultad de las preguntas se determina en una exten- sa prueba piloto que se realiza con anterioridad a la selección de las preguntas para la prueba principal.

\section{Tipos de pregunta}

Una vez creados los instrumentos de evaluación, deberá examinarse detenidamente el impacto de cada tipo de pregunta en el rendimiento del alumno y, por tanto, en la definición del constructo que se evalúa. Este punto es especialmente pertinente en un proyecto como PISA en el que el vasto contexto internacional plantea serias limitaciones a los de tipos de formato que pueden adoptar las preguntas.

El proyecto OCDE/PISA evaluará la competencia matemática mediante una combinación de preguntas de respuesta abierta, de respuesta cerrada y de elección múltiple. Se utiliza una cantidad más o menos igual de cada uno de estos formatos a la hora de elaborar los instrumentos de prueba del ciclo 2003.

La experiencia en la elaboración y administración de preguntas en el ciclo OCDE/PISA 2000 indica que el tipo de elección múltiple es generalmente el más adecuado para evaluar las preguntas asociadas a los grupos de competencia de reproducción y conexión. Un ejemplo de este tipo de pregunta es el Ejemplo 15, que plantea una pregunta asociada al grupo de conexión y que tiene un número limitado de respuestas pre-definidas. Para resolver este problema, los estudiantes deben traducir el problema a términos matemáticos, crear un modelo para representar la naturaleza periódica del contexto descrito y prolongar la secuencia para encontrar el resultado correspondiente a una de las opciones planteadas.

\section{Matemáticas, ejemplo 15: LA FOCA}

Una foca debe subir a la superficie para respirar incluso cuando duerme. Martín ha observado a una foca durante una hora. Al empezar la observación, la foca se sumergió hasta el fondo y comenzó a dormir. A los 8 minutos subió flotando lentamente hasta la superficie y respiró.

3 minutos más tarde estaba de nuevo en el fondo y todo el proceso empezó de nuevo de un modo regular.

Después de una hora la foca estaba:
a) en el fondo
b) saliendo hacia la superficie
c) respirando
d) volviendo al fondo 
Para objetivos de orden superior o para procesos más complejos se han de elegir preferentemente otros tipos de pregunta. Las preguntas de respuesta construida cerrada formulan tareas o ejercicios parecidos a las preguntas de elección múltiple, pero en ellas se pide a los estudiantes que produzcan una respuesta que pueda ser juzgada fácil- mente como correcta o incorrecta. El acertar por casualidad no es algo que preocupe en las preguntas de este tipo y no resulta necesario ofrecer distractores (que pueden además sesgar el constructo evaluado). Así, en el Ejemplo 16 sólo hay una respuesta correcta pero existen muchas respuestas incorrectas posibles.

\section{Matemáticas, ejemplo 16: EL MARATÓN DE ROTTERDAM}

Tepla Loroupe ganó el maratón de Rotterdam en 1998. «Ha sido fácil», dijo ella, «el recorrido era bastante llano». He aquí un gráfico de los desniveles del recorrido del maratón de Rotterdam:

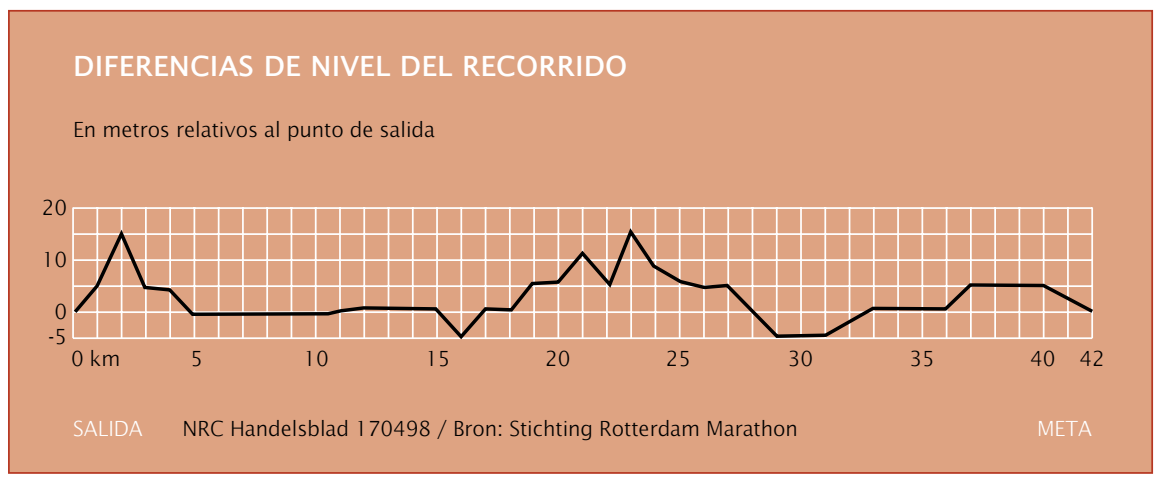

\section{¿Cuál fue la diferencia entre el punto más elevado y el más bajo de la carrera?}

m

Las preguntas de respuesta construida abierta requieren una contestación más amplia por parte del alumno y el proceso de elaboración de dicha respuesta normalmente comporta actividades cognitivas de orden más elevado. Con frecuencia tales preguntas no requieren únicamente que el alumno elabore una respuesta, sino que muestre también los pasos seguidos o explique cómo llegó a tal respuesta. La característica clave de las preguntas de respuesta construida abierta es que permiten que los alumnos demuestren su competencia al proporcionar soluciones que pueden estar situadas en diferentes niveles de complejidad matemática (véase el Ejemplo 17).
Alrededor de un tercio de las preguntas de matemáticas del proyecto OCDE/PISA son preguntas de respuesta construida abierta. Las respuestas a estas preguntan deben puntuarlas personas formadas que aplican unos criterios de puntuación que requieren un cierto grado de valoración profesional. Puesto que puede producirse un desacuerdo entre los correctores de estas preguntas, el proyecto OCDE/PISA realiza estudios de fiabilidad para controlar el grado de desacuerdo. La experiencia con este tipo de estudios demuestra que pueden elaborarse unos criterios de puntuación claros y conseguir así unas puntuaciones fiables. 


\section{Matemáticas, ejemplo 17: INDONESIA}

Indonesia se encuentra entre Malasia y Australia. En la siguiente tabla se muestran algunos datos de la población de Indonesia y su distribución a lo largo de sus islas.

\begin{tabular}{lcccc} 
Región & $\begin{array}{c}\text { Superficie } \\
(\mathrm{km} 2)\end{array}$ & $\begin{array}{c}\text { Porcentaje sobre } \\
\text { la superficie total }\end{array}$ & $\begin{array}{c}\text { Población en } 1980 \\
\text { (millones) }\end{array}$ & $\begin{array}{c}\text { Porcentaje sobre } \\
\text { la población total }\end{array}$ \\
\hline Java/Madura & 132.187 & 6,95 & 91.281 & 61,87 \\
Sumatra & 473.606 & 24,86 & 27.981 & 18,99 \\
Kalimantan (Borneo) & 539.460 & 28,32 & 6.721 & 4,56 \\
Sulawesi (Célebes) & 189.216 & 9,93 & 10.377 & 7,04 \\
Bali & 5.561 & 0,30 & 2.470 & 1,68 \\
Irían Jaya & 421.981 & 22,16 & 1.145 & 5,02 \\
& & & 147.384 & 100,00 \\
TOTAL & 1.905 .569 & 100,00 & &
\end{tabular}

Uno de los principales problemas de Indonesia es la desigual distribución de la población a lo largo de sus islas. En la tabla se puede observar que Java, que tiene menos del $7 \%$ del total de la superficie, tiene casi el $62 \%$ del total de la población.

Diseña un gráfico (o gráficos) que muestre la desigual distribución de la población de Indonesia.

Fuente: De Lange y Verhage (1992). Reproducción autorizada.

El proyecto OCDE/PISA utiliza con frecuencia un formato de ejercicio que engloba diversas preguntas bajo un estímulo común. Los ejercicios en este formato ofrecen a los estudiantes la oportunidad de implicarse en el contexto o problema cuando se les plantea una serie de preguntas que van aumentando en complejidad. Las primeras preguntas son normalmente de elección múltiple o preguntas de respuesta construida cerrada, mientras que las siguientes suelen ser preguntas de respuesta construida abierta. Este formato puede utilizarse para evaluar cualquiera de los grupos de competencia.

Una razón para el empleo de formatos de ejercicio con un estímulo común es que permite plantear tareas realistas que reflejen la complejidad propia de las situaciones de la vida real. Otra razón tiene que ver con una utilización eficiente del tiempo de examen, puesto que reduce el tiempo necesario para que el estudiante se introduzca en la situación. No obstante, en el diseño de los ejercicios, de la puntuación de la respuesta y de los criterios de puntuación se reconoce y tiene en cuenta la necesidad de que cada elemento presente en el ejercicio sea puntuado con independencia de los demás. Se reconoce también la importancia de minimizar el sesgo que puede producir la utilización de un número reducido de situaciones.

\section{ESTRUCTURA DE LA EVALUACIÓN}

Los instrumentos de prueba del ciclo 2003 totalizan 210 minutos de tiempo de examen. Las preguntas seleccionadas se agrupan en siete grupos y a cada uno de estos grupos le corresponden 30 minutos de examen. Los grupos de preguntas se distribuyen en los cuadernillos de prueba según un diseño de rotación.

El tiempo total de la prueba de matemáticas se distribuye lo más uniformemente posible entre las cuatro ideas principales (cantidad, espacio y forma, cambio y relaciones 
e incertidumbre) y las cuatro situaciones (personal, educacional/profesional, pública y científica). La proporción de preguntas asociadas a los tres grupos de competencia (reproducción, conexión y reflexión) es aproximadamente de 1:2:1. Alrededor de un tercio de las preguntas serán de elección múltiple, otro tercio de respuesta construida cerrada y otro tercio de respuesta construida abierta.

\section{PRESENTACIÓN DE LOS RESULTADOS DE MATEMÁTICAS}

Para sintetizar los resultados de las respuestas a los instrumentos de evaluación OCDE/PISA se crea una escala descriptiva de rendimiento de cinco niveles (Masters y Forster, 1996; Masters, Adams y Wilson, 1999). La escala se elabora con ayuda de un modelo estadístico TRI (Teoría de Respuesta al Item) que permite tener en cuenta respuestas de tipo ordinal. La escala general se utiliza para describir la naturaleza del rendimiento, clasificando los resultados de los estudiantes de diferentes países en términos de los cinco niveles de rendimiento descritos, y, de este modo, proporciona un marco de referencia para las comparaciones internacionales.

Se considera la elaboración de un cierto número de subescalas, que se basarían probablemente en los tres grupos de competencia o en las cuatro ideas principales. Las decisiones sobre la elaboración de estas sub-escalas separadas se tomarán de acuerdo a diferentes criterios, especialmente de tipo psicométrico, tras el análisis de los datos obtenidos arrojados por las pruebas OCDE/PISA. Para facilitar estas opciones hay que garantizar que se selecciona un número suficiente de preguntas para cubrir cada categoría susceptible de generar una subescala. Además, las preguntas de cada categoría deben ofrecer una amplia gama de dificultad.

Los grupos de competencia descritos anteriormente en este documento reflejan categorías conceptuales de una complejidad y exigencia cognitiva crecientes, pero no reflejan una jerarquía estricta del rendimiento de los alumnos según la dificultad de las preguntas. La complejidad conceptual es sólo uno de los componentes de la dificultad de las preguntas que influye en el nivel de rendimiento. Otros son la familiaridad con la tarea, la cercanía o lejanía del momento del aprendizaje, el grado de entrenamiento y de práctica en dicha tarea, etc. Así, una pregunta de elección múltiple que movilice competencias del grupo de reproducción (por ejemplo, la pregunta: «icuál de los siguientes objetos es un rectángulo paralelepípedo?», acompañada de las imágenes de una pelota, una lata, una caja y un cuadrado) puede resultar muy fácil para un estudiante al que se le haya enseñado el significado de estos términos, pero será muy complicada para los que no estén familiarizados con la terminología utilizada. Aunque resulta posible imaginar preguntas relativamente difíciles del grupo de reproducción y preguntas relativamente fáciles del grupo de reflexión, y aunque se deban incluir en cada grupo preguntas de diferente grado de dificultad, es esperable que exista una relación positiva entre el grupo de competencia al que pertenece la pregunta y su grado de dificultad.

Entre los factores que sustentan los niveles de dificultad creciente de las preguntas y de la competencia matemática de los alumnos se cuentan los siguientes:

- El tipo y grado de interpretación y reflexión necesarios. Ello incluye la naturaleza de los requisitos derivados del contexto del problema, el grado de visibilidad de los requisitos matemáticos del problema, el grado en que los alumnos deben aplicar su propia construcción matemática al problema y el grado necesario de perspicacia, razonamiento complejo y generalización.

- El tipo de destrezas de representación necesarias, desde los problemas en que sólo se emplea una clase de representación a los problemas en que los estudiantes deben moverse entre diferentes modos de representación para hallar por sí mismos el apropiado.

- El tipo y nivel de destreza matemática necesario, desde los problemas de un solo paso que piden a los estudiantes reproducir hechos matemáticos básicos y realizar cálculos sencillos, a los problemas de varios pasos que implican un conocimiento matemático más avanzado, y habilidades más complejas de toma de decisión, procesamiento de información, resolución de problemas y construcción de modelos.

- El tipo y grado de argumentación matemática necesario, desde problemas en que no se precisa argumentación, pasando por problemas en que los alumnos deben 
aplicar argumentos bien conocidos, a problemas en que éstos deben elaborar argumentos matemáticos o entender la argumentación de terceros o juzgar la corrección de los argumentos o pruebas que se presentan.

En el nivel de competencia más bajo, por lo general los estudiantes realizan procesos de un paso que implican reconocer contextos familiares y problemas matemáticos bien formulados, reproducen procesos o hechos ampliamente conocidos y aplican destrezas de cálculo simples.

En el siguiente nivel de competencia, los estudiantes realizan generalmente ejercicios más complejos de más de un paso de procesamiento. También combinan diferentes elementos de información o interpretan diversas representaciones de in-formación o de conceptos matemáticos identificando los elementos importantes y la relación entre ellos. Por lo general, trabajan con formulaciones o modelos matemáticos dados, presentados con frecuencia de forma algebraica, para identificar soluciones, o realizan una pequeña secuencia de pasos de procesamiento o cálculo para alcanzar una solución.

En el nivel de competencia más alto, los estudiantes desempeñan un papel más creativo y activo al tratar los problemas matemáticos. Normalmente interpretan información más compleja y gestionan diversos pasos de procesamiento. Elaboran la formulación de un problema y, a menudo, crean un modelo adecuado que facilita su solución. Los estudiantes con este nivel generalmente identifican y aplican herramientas y conocimientos importantes en un contexto que no les resulta familiar. Asimismo, demuestran perspicacia para identificar una estrategia de solución adecuada y otros procesos cognitivos de orden superior, como capacidad de generalización, razonamiento y argumentación para explicar o comunicar los resultados.

\section{SOPORTES Y HERRAMIENTAS}

La norma OCDE/PISA relativa al empleo de calculadoras $y$ otras herramientas es que los estudiantes pueden utilizarlas si las utilizan normalmente en el centro.

Así se conseguirá evaluar de la forma más verosímil el rendimiento de los estudiantes y se obtendrá la comparación más informativa del rendimiento de los diversos sistemas educativos. La elección de permitir a los estudiantes utilizar las calculadoras no difiere, en principio, de otras decisiones de política formativa de los propios sistemas que quedan fuera del control de OCDE/PISA.

Los estudiantes acostumbrados a disponer de una calculadora para ayudarse a resolver preguntas se verían en desventaja si se les privara de este aparato.

\section{Síntesis}

El objetivo del estudio OCDE/PISA es el desarrollo de indicadores que demuestren el grado de efectividad conseguida por diferentes países en la preparación de sus alumnos de 15 años para convertirlos en ciudadanos activos, reflexivos e inteligentes desde el punto de vista del empleo de las matemáticas. Para lograrlo, el proyecto OCDE/PISA ha desarrollado evaluaciones que se centran en determinar el grado en que los estudiantes son capaces de utilizar lo que han aprendido.

Este marco conceptual ofrece una definición de la competencia matemática y determina el contexto para su evaluación en el año 2003, de manera que los países de la OCDE puedan controlar algunos resultados importantes de sus sistemas educativos. La definición de competencia matemática seleccionada para este marco es coherente con las definiciones adoptadas para la competencia de lectura y de ciencias y con la orientación de OCDE/PISA de evaluar las capacidades de los alumnos para convertirse en miembros activos y participativos de la sociedad.

Los principales componentes del marco conceptual de matemáticas, que son coherentes con otros marcos del proyecto OCDE/PISA, incluyen contextos para el empleo de las matemáticas, contenido matemático y procesos matemáticos derivados de la definición de competencia. Los desarrollos sobre el contexto y el contenido hacen hincapié en los rasgos de los problemas a los que los estudiantes se enfrentan como ciudadanos, mientras que los desarrollos de los procesos hacen hincapié en las competencias a las que deben recurrir los alumnos para resolver estos problemas. Las competencias se han agrupado en 
tres grupos llamados "grupos de competencia" para facilitar un tratamiento racional del modo en que se interpretan los procesos cognitivos complejos dentro de un programa de evaluación estructurado.

El énfasis que hacen las evaluaciones de matemáticas OCDE/PISA en la utilización del conocimiento matemático para resolver los problemas del día a día representa la plasmación de un ideal que ya ha sido puesto en marcha, en grados diversos, en diferentes sistemas educativos a lo largo del mundo. Las evaluaciones OCDE/PISA intentan ofrecer una variedad de problemas matemáticos que incluyen diferentes grados de estructura y orientación, pero promoviendo problemas de tipo auténtico en que los estudiantes deben elaborar el razonamiento por sí mismos.

\section{Ejemplos adicionales}

En este apartado se presentan nuevas preguntas de matemáticas para ilustrar determinados aspectos del marco conceptual. Las preguntas van acompañadas de comentarios que relacionan aspectos de las preguntas con diversas categorías del marco conceptual.

Éste es el tercer conjunto de ejemplos de preguntas de matemáticas publicado por la OCDE. Siete unidades (un total de 14 preguntas) fueron publicadas en Measuring Student Knowledge and Skills (OCDE, 2000), y otras cinco unidades (un total de 11 preguntas) fueron publicadas en Sample Tasks from the PISA 2000 Assessment (OCDE, 2002a).

Aquí se incluyen trece unidades completas, con un total de 27 preguntas. Todas estas preguntas se emplearon en la prueba piloto del año 2002 como parte del proceso de elaboración de pruebas para el ciclo PISA 2003. Estas preguntas no fueron incluidas en la prueba final por diversas razones, relacionadas en buena parte con la necesidad de obtener un complejo equilibrio de características al estructurar los instrumentos definitivos de la prueba. Algunas de ellas tienen propiedades psicométricas que las convierten en poco apropiadas para una evaluación internacional; no obstante, resultan útiles a modo ilustrativo y, probablemente, para su empleo en clase.

Matemáticas, Unidad 1: EL FARO

Los faros son torres con un foco luminoso en la parte superior. Los faros ayudan a los barcos a seguir su rumbo durante la noche cuando navegan cerca de la costa. Un faro emite destellos de luz según una secuencia regular fija. Cada faro tiene su propia secuencia.

En el diagrama de abajo se puede ver la secuencia de un faro concreto. Los destellos de luz alternan con períodos de oscuridad.
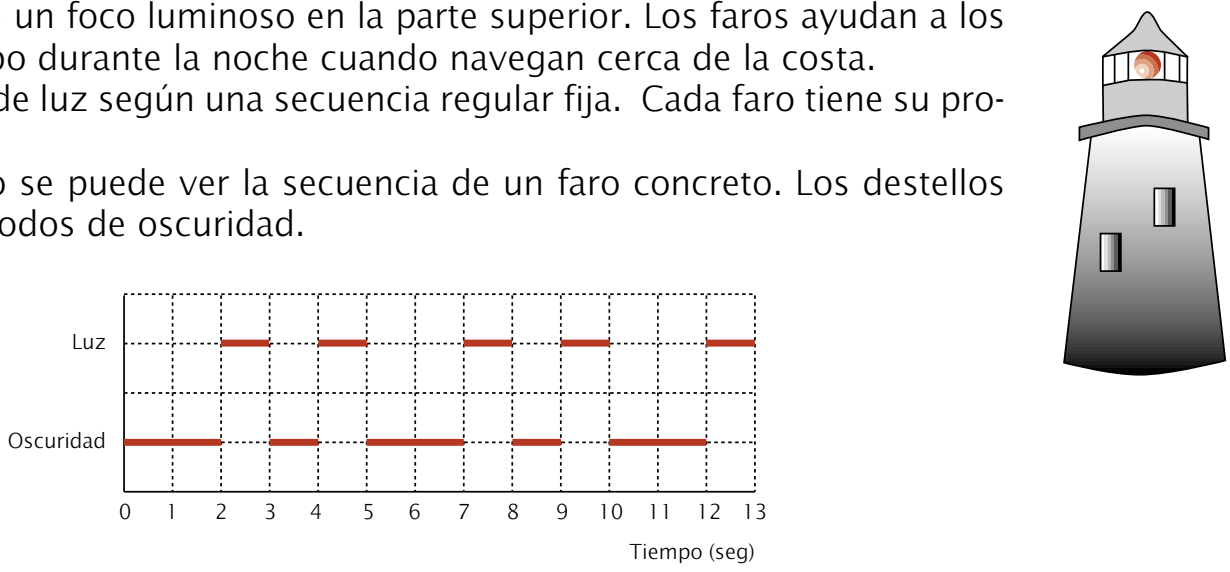

Se trata de una secuencia regular. Después de algún tiempo la secuencia se repite. Se llama período de la secuencia al tiempo que dura un ciclo completo, antes de que comience a repetirse. Cuando se descubre el período de la secuencia, es fácil ampliar el diagrama para los siguientes segundos, minutos o incluso horas. 
Matemáticas, Ejemplo 1.1:

¿Cuánto dura el período de la secuencia de este faro?

A 2 segundos.
B 3 segundos.
C 5 segundos.
D 12 segundos.

\section{Criterios de corrección y comentarios sobre el ejemplo 1.1}

Máxima puntuación

Código 1: Respuesta C: 5 segundos.

Ninguna puntuación

Código 0: $\quad$ Otras respuestas.

Tipo de pregunta: Elección múltiple

Grupo de competencia: Conexión

Idea principal: Cambio y relaciones

Situación: Pública

La manera inusual en que este problema auténtico se plantea a los estudiantes hace que el problema vaya más allá del grupo de competencia de reproducción. La representación gráfica resultará ser una novedad para la mayoría de los estudiantes, si no para todos. Ello exige movilizar destrezas de interpretación y razonamiento desde el principio. Probablemente la mayoría de los estudiantes reproducirán la situación mentalmente: oscuridad-oscuridad-luz-oscuridad-luz-oscuridadoscuridad-luz y así sucesivamente. Deberán encontrar el «ritmo», ya sea con ayuda de la representación gráfica o mediante alguna otra representación de tipo más lingüístico como la que acabamos de presentar. La acción de establecer conexiones entre diferentes representaciones hace que el problema se incluya dentro del grupo de competencia de conexión.
El concepto subyacente de periodicidad es importante tanto dentro de la disciplina de las matemáticas como en la vida diaria. La prueba piloto indica que la mayoría de los estudiantes no encontraron este problema excesivamente complicado a pesar de su aspecto no habitual.

Alguien podría argumentar que el contexto podría favorecer a los estudiantes de poblaciones costeras. No obstante, debe señalarse que la competencia matemática también engloba la capacidad de saber utilizar las matemáticas en contextos diferentes a los propios. Esto no significa necesariamente que los estudiantes de poblaciones costeras no vayan a estar, en cierto modo, en una posición privilegiada. Sin embargo, el análisis por países de la pregunta en cuestión indica que no ha sido este el caso: los países sin litoral no tuvieron resultados diferentes a los países con litoral. 
Matemáticas, Ejemplo 1.2:

¿Durante cuántos segundos emite este faro destellos de luz a lo largo de 1 minuto?
A 4
B 12
C 20
D 24

\section{Criterios de corrección y comentarios sobre el ejemplo 1.2}

Máxima puntuación

Código 1: $\quad$ Respuesta D: 24.

Ninguna puntuación

Código 0: $\quad$ Otras respuestas.

Tipo de pregunta: Elección múltiple

Grupo de competencia: Conexión

Idea principal: Cambio y relaciones

Situación: Pública

Este ejemplo es ligeramente más difícil que el Ejemplo 1.1 y el problema también es de una naturaleza algo diferente. Los estudiantes tienen que traducir y ampliar el modelo visual dado a un modelo numérico que les ayude a analizar la secuencia periódica a lo largo de un minuto. No es necesario que los estudiantes hayan contestado correctamente a la pregunta del Ejemplo 1.1, pero la utilización de este resultado es una de las estrategias posibles: dado que el período es 5 , hay 12 períodos por minuto y, puesto que cada período tiene 2 destellos de luz, la respuesta es 24 .

Otra estrategia que pueden utilizar los estudiantes de este nivel es examinar los primeros 10 ó 12 segundos en el gráfico, puesto que ambos son números por los que se puede dividir 60. Si examinan los primeros 10 segundos, verán 4 destellos de luz que deberán multiplicar por 6, y así hallarán la respuesta de 24 . De este modo, sin embargo, no contaremos con la «prueba» de que hayan entendido completa- mente el problema. Lo mismo sucede si examinan los primeros 12 segundos: 4 destellos de luz 5 veces dan un resultado de 20, que no es lo correcto. La diferencia reside en que escogiendo 10, los estudiantes obtienen exactamente 2 períodos, mientras que, escogiendo 12 , no obtienen un múltiplo del período.

Un problema auténtico, pero no demasiado difícil, asociado al grupo de conexión porque también son necesarios múltiples pasos.

La redacción del problema indica de entrada que éste es «abierto»: «En la cuadrícula de abajo traza el gráfico de una posible secuencia de destellos de luz». Aunque la pregunta parezca estar estrechamente relacionada con las dos preguntas anteriores, la tasa de respuestas correctas fue considerablemente inferior, lo que hace que esta pregunta sea "bastante difícil". 


\section{Matemáticas, Ejemplo 1.3:}

En la cuadrícula de abajo traza el gráfico de una posible secuencia de destellos de luz de un faro que emita 30 segundos de destellos de luz cada minuto. El período de esta secuencia debe ser de 6 segundos.

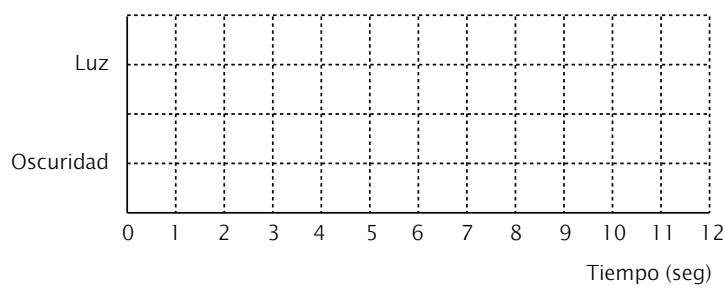

\section{Criterios de corrección y comentarios sobre el ejemplo 1.3}

Máxima puntuación

Código 2: $\quad$ El gráfico muestra una secuencia de luz y oscuridad con destellos de luz de 3 segundos por cada 6 segundos, y un período de 6 segundos. Esto se puede hacer de las siguientes maneras:

- 1 destello de un segundo y otro de dos segundos (y esto también se puede representar de diferentes maneras), o

- 1 destello de 3 segundos (lo cual puede hacerse de cuatro maneras distintas).

- Si están representados 2 períodos, la secuencia debe ser la misma para ambos.

Puntuación parcial

Código 1: $\quad$ El gráfico muestra una secuencia de luz y oscuridad con destellos de luz de 3 segundos por cada 6 segundos, pero el período no es de 6 segundos. Si se presentan 2 períodos, la pauta debe ser la misma para ambos.

- 3 destellos de un segundo alternando con 3 períodos de oscuridad de un segundo.

Ninguna puntuación

Código 0: $\quad$ Otras respuestas.

Tipo de pregunta: Pregunta de respuesta abierta

Grupo de competencia: Reflexión

Idea principal: Cambio y relaciones

Situación: Pública

Resulta interesante que a los estudiantes se les pida "construir" o "diseñar"; esto constituye un aspecto importante de la competencia matemática: utilizar las capacidades matemáticas no sólo de una manera pasiva o indirecta sino elaborando una respuesta. La solución del problema no es algo trivial, porque deben satisfacerse dos condiciones: igual cantidad de luz y de oscuridad (30 segundos por minuto) y un período de seis segundos. Esta combinación implica que los estudiantes alcancen verdaderamente un nivel conceptual de comprensión de la periodicidad, una prueba de que están trabajando con el grupo de competencias de reflexión. 


\section{Matemáticas, Unidad 2: TARIFAS POSTALES}

Las tarifas postales de Zedlandia están en basadas en el peso de los paquetes (redondeado al gramo más cercano), como se muestra en la tabla siguiente:

\begin{tabular}{l|l}
$\begin{array}{l}\text { Peso (redondeado } \\
\text { al gramo más cercano) }\end{array}$ & \multicolumn{1}{l}{ Tarifas } \\
\hline Hasta $20 \mathrm{~g}$ & 0,46 zeds \\
$21 \mathrm{~g}-50 \mathrm{~g}$ & 0,69 zeds \\
$51 \mathrm{~g}-100 \mathrm{~g}$ & 1,02 zeds \\
$101 \mathrm{~g}-200 \mathrm{~g}$ & 1,75 zeds \\
$201 \mathrm{~g}-350 \mathrm{~g}$ & 2,13 zeds \\
$351 \mathrm{~g}-500 \mathrm{~g}$ & 2,44 zeds \\
$501 \mathrm{~g}-1000 \mathrm{~g}$ & 3,20 zeds \\
$1001 \mathrm{~g}-2000 \mathrm{~g}$ & 4,27 zeds \\
$2001 \mathrm{~g}-3000 \mathrm{~g}$ & 5,03 zeds
\end{tabular}

\section{Matemáticas, Ejemplo 2.1:}

¿Cuál de los siguientes gráficos es la mejor representación de las tarifas postales en Zedlandia? (El eje horizontal muestra el peso en gramos, y el eje vertical muestra el precio en zeds.)
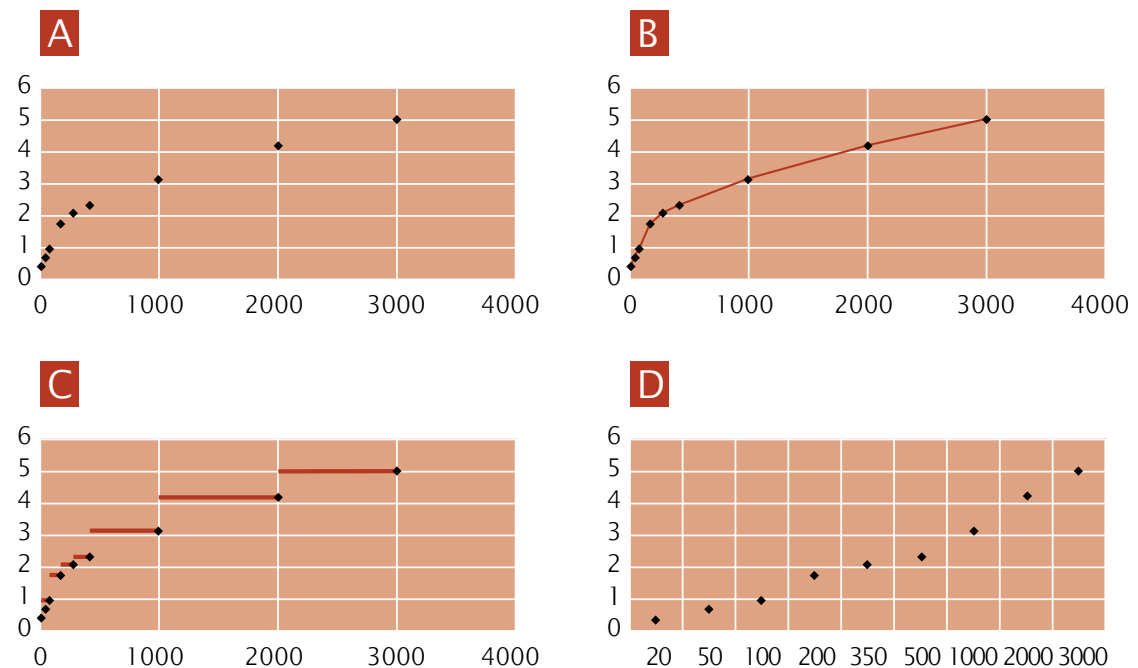


\title{
Criterios de corrección y comentarios sobre el ejemplo 2.1
}

\author{
Máxima puntuación \\ Código 1: $\quad$ Respuesta C \\ Ninguna puntuación \\ Código 0: $\quad$ Otras respuestas. \\ Tipo de pregunta: Elección múltiple \\ Grupo de competencia: Conexión \\ Idea principal: Incertidumbre \\ Situación: Pública
}

Se trata claramente de una situación pública y de un problema que se presenta con frecuencia, aunque no necesariamente de esta forma. En la vida diaria los ciudadanos sencillamente entregan el paquete y preguntan cuánto cuesta enviarlo. No obstante, se espera que los ciudadanos bien informados reflexionen mínimamente sobre la estructura del sistema de tarifas postales u otras estructuras similares. Muchas personas suelen saber que las tarifas postales aumentan muy rápidamente al principio pero que a medida que el peso es mayor el aumento se hace menor. Este tipo de estructura es muy común.

No obstante, darse cuenta de que dicha estructura pueda representarse de modo visual es algo muy distinto. El gráfico es un gráfico de tramos, que probablemente los estudiantes no hayan encontrado nunca o muy raramente en el currículum escolar. Ésta es probablemente la razón principal por la que los estudiantes encontraron difícil este problema. A los estudiantes se les ha enseñado a unir los puntos de los gráficos y, a veces, se plantean si unir los puntos mediante líneas rectas o curvas (como la alternativa B de este ejemplo). La B parece una buena respuesta, ya que da el precio por cada kilo, a diferencia de la alternativa A. El problema es que no todos los precios «existen» y que la gama de precios es muy limitada: 0,46-0,69-1,02 y así sucesivamente. Por tanto, el gráfico B no es el correcto. El gráfico $C$ es el que mejor se ajusta a la tabla de pesos y tarifas.

Otro factor de complicación a la hora de vincular la tabla al gráfico es el hecho de que los gráficos $\mathrm{A}, \mathrm{B}$ y $\mathrm{C}$ resultan complicados de interpretar para los primeros 500 gramos por las escalas utilizadas. Si el interés de los estudiantes se centra en los valores menores, entonces la alternativa D puede resultarles atractiva, porque muestra una interpretación bien legible de la tabla, y los estudiantes pueden no darse cuenta de que la escala horizontal no es lineal. Pero si se dan cuenta de que los puntos aislados del gráfico no pueden nunca representar una estructura como la de la tabla, no tendrán en cuenta esta opción.

De los comentarios realizados se deduce que el grupo de competencia es el de conexión, debido a la representación inusual y a las destrezas de interpretación necesarias para contestar la pregunta. 
Matemáticas, Ejemplo 2.2:

Juan quiere enviar a un amigo dos objetos que pesan $40 \mathrm{~g}$ y $80 \mathrm{~g}$ respectivamente.

Según las tarifas postales de Zedlandia, decide si es más barato enviar los dos objetos en un único paquete o enviar los objetos en dos paquetes separados. Escribe tus cálculos para hallar el coste en los dos casos.

\section{Criterios de corrección y comentarios sobre el ejemplo 2.2}

Máxima puntuación

Código 1: $\quad$ Será más barato enviar los objetos en dos paquetes separados. El coste será de 1,71 zeds para dos paquetes separados, y de 1,75 zeds para un único paquete que contenga los dos objetos.

Ninguna puntuación

Código 0: $\quad$ Otras respuestas.

Tipo de pregunta: Pregunta de respuesta abierta

Crupo de competencia: Conexión

Idea principal: Cantidad

Situación: Pública

Este ejemplo es más práctico que el anterior y en el estudio piloto resultó ser relativamente fácil para los alumnos.

Se podría clasificar dentro del grupo de conexión, dado que no resulta familiar para los estudiantes y requiere algo más que meras competencias de reproducción. Juan quiere enviar a un amigo dos objetos que pesan $40 \mathrm{~g}$ y $80 \mathrm{~g}$. Aunque es ligeramente contraria a la intuición, la respuesta puede hallarse con facilidad en las tablas: un envío de 40 g cuesta 0,69 zeds y uno de 80 gramos cuesta 1,02 zeds, así que dos paquetes cuestan 1,71 zeds. Enviar un paquete de 120 g costaría 1,75 zeds. Este problema no resulta complejo matemáticamente hablando, pero representa un ejemplo relevante de la competencia matemática: es un tipo de pregunta que un ciudadano llega a plantearse en diversas situaciones de su vida cotidiana. 


\section{Matemáticas, Unidad 3: LATIDOS DEL CORAZÓN}

Por razones de salud la gente debería limitar sus esfuerzos, al hacer deporte, por ejemplo, para no superar una determinada frecuencia cardiaca.

Durante años la relación entre la máxima frecuencia cardiaca recomendada para una persona y su edad se describía mediante la fórmula siguiente:

Máxima frecuencia cardiaca recomendada $=220$ - edad

Investigaciones recientes han demostrado que esta fórmula debería modificarse ligeramente. La nueva fórmula es la siguiente:

Máxima frecuencia cardiaca recomendada $=208-(0,7 \times$ edad $)$

\section{Matemáticas, Ejemplo 3.1:}

Un artículo de periódico afirma: "El resultado de usar la nueva fórmula en vez de la antigua es que el máximo número recomendado de latidos cardíacos por minuto disminuye ligeramente para los jóvenes y aumenta ligeramente para los mayores."

¿A partir de qué edad aumenta la máxima frecuencia cardiaca recomendada como resultado de introducir la nueva fórmula? Escribe tus cálculos.

\section{Criterios de corrección y comentarios sobre el ejemplo 3.1}

Máxima puntuación

Código 1: $\quad$ Se acepta 41 ó 40.

$220-$ edad $=208-0,7 \times$ edad resulta una $e d a d=40$, por lo que las personas por encima de 40 años tendrán un máximo ritmo cardiaco recomendado más alto con la nueva fórmula.

Ninguna puntuación

Código 0: $\quad$ Otras respuestas.

Tipo de pregunta: Pregunta de respuesta abierta

Crupo de competencia: Conexión

Idea principal: Cambio y relaciones

Situación: Pública/Personal

La clasificación de la situación depende obviamente de si la gente está o no interesada en la información sobre su salud y su cuerpo. Uno puede argumentar sin temor a equivocarse que la pregunta es científica (por el empleo de fórmulas), pero muchos deportistas (aficionados al footing, a la bicicleta, al remo, a pasear, etc.) sí que controlan de manera regular sus latidos durante su ejercicio. La disponibilidad de dispositivos electrónicos cada vez más baratos ha conseguido que este aspecto de la salud sea accesible para la gente corriente. Ello explica que la pregunta se clasifique como "Pública/Personal". 
Dado que tratamos aquí más con la construcción de un modelo que con la solución de un problema rutinario, se impone su clasificación dentro del grupo de conexión, así como también se impone su pertenencia a la idea principal de cambio y relaciones.

Comparar dos fórmulas que hacen referencia a la salud de una persona puede resultar una actividad que excita la curiosidad, especialmente cuando se presentan de manera verbal. Normalmente esto las hace más accesibles a los estudiantes. Incluso antes de preguntar nada, la reacción inicial de los estudiantes puede ser ver cómo su edad les conduce a resultados recomendados diferentes. Dado que los alumnos evaluados por PISA tienen 15 años, el resultado que surge de la fórmula original es de 205 latidos por minuto (y hay que caer en la cuenta de que se trata de una frecuencia por minuto, información que no se ofrece en el enunciado) y con la fórmula revisada es de 198 (ó 197). De este modo los alumnos pueden haber dado con un indicio de que la afirmación del artículo puede ser correcta.

No obstante, el ejemplo formulado es algo más complicado que todo esto. Requiere que los estudiantes averigüen a qué edad coincide el resultado de las dos fórmulas. Esto puede determinarse mediante ensayo y error (una estrategia bien asimilada por muchos estudiantes), pero es más probable que se utilice la vía algebraica: 220 - edad = 208 - $(0,7 \times$ edad $)$, que da una respuesta de unos 40 .

Desde el punto de vista de la competencia matemática y de unas matemáticas más orientadas al currículum, este problema resulta ser muy relevante e interesante. Sin embargo, los datos de la prueba piloto indican que los alumnos de 15 años encontraron este problema bastante difícil.

\section{Matemáticas, Ejemplo 3.2:}

La formula para la máxima frecuencia cardiaca recomendada $=208-(0,7 \times$ edad $)$ se usa también para determinar cuándo es más eficaz el ejercicio físico. Las investigaciones han demostrado que el ejercicio físico es más eficaz cuando los latidos cardíacos alcanzan el 80\% de la máxima frecuencia cardiaca recomendada.

Escribe una fórmula que calcule la frecuencia cardiaca recomendada para que el ejercicio físico sea más efectivo, expresada en términos de edad.

\section{Criterios de corrección y comentarios sobre el ejemplo 3.2}

Máxima puntuación

Código 1: $\quad$ Cualquier fórmula que sea el equivalente de multiplicar la fórmula del máximo ritmo cardiaco recomendado por el $80 \%$.

- frecuencia cardiaca $=166-0,56 \times$ edad.

- frecuencia cardiaca $=166-0,6 \times$ edad.

- $f=166-0,56 \times$ e.

- $f=166-0,6 \times$ e.

- frecuencia cardiaca $=(208-0,7 \times$ edad $) \times 0,8$.

Ninguna puntuación

Código 0: $\quad$ Otras respuestas.

Tipo de pregunta: Pregunta de respuesta abierta

Grupo de competencia: Conexión

Idea principal: Cambio y relaciones

Situación: Pública/Personal 
Este ejemplo parece medir exactamente las mismas competencias que el Ejemplo 3.1. El porcentaje de respuestas correctas es casi idéntico (en la prueba piloto). Pero hay una diferencia importante: en el Ejemplo 3.1 los alumnos tienen que comparar dos formulas y decidir cuándo coinciden en el resultado. En el Ejemplo 3.2 se les pide que elaboren una fórmula, algo que normalmente no se les exige en muchos países durante su formación escolar. Desde un punto de vista estrictamente matemático la pregunta no es nada difícil: se trata sencillamente de multiplicar la fórmula por 0,8. Por ejemplo, frecuencia cardiaca $=(208-0,7 \times$ edad $) \times 0,8$. Podría parecer que incluso este simple manejo de las expresiones algebraicas presentadas en un contexto práctico y real representa un reto sustancial para muchos jóvenes de 15 años.

\section{Matemáticas, Unidad 4: PAGO POR SUPERFICIE}

Los habitantes de un edificio de pisos deciden comprar el edificio. Pondrán el dinero entre todos de modo que cada uno pague una cantidad proporcional al tamaño de su piso.

Por ejemplo, una persona que viva en un piso que ocupa la quinta parte de la superficie del conjunto de pisos, deberá pagar la quinta parte del precio total del edificio.

\section{Matemáticas, Ejemplo 4.1:}

Rodea con un círculo la palabra Correcto o Incorrecto para cada una de las siguientes afirmaciones.

\section{Afirmación}

La persona que vive en el piso más grande pagará más dinero por cada metro cuadrado de su piso que la persona que vive en el piso más pequeño.

Si se conocen las superficies de dos pisos y el precio de uno de ellos, entonces se puede calcular el precio del otro.

Si se conoce el precio del edificio y cuánto pagará cada propietario, entonces se puede calcular la superficie total de todos los pisos.

Si el precio total del edificio se redujera en un $10 \%$, cada uno de los propietarios pagaría un $10 \%$ menos.
Correcto / Incorrecto

Correcto / Incorrecto

Correcto / Incorrecto

Correcto / Incorrecto

Correcto / Incorrecto

\section{Criterios de corrección y comentarios sobre el ejemplo 4.1}

Máxima puntuación

Código 1: Respuestas que especifican: Incorrecto, Correcto, Incorrecto, Correcto, en este orden.

Ninguna puntuación

Código 0: $\quad$ Cualquier otra combinación de respuestas.

Tipo de pregunta: Elección múltiple compleja

Grupo de competencia: Conexión

Idea principal: Cambio y relaciones

Situación: Pública 
Esta pregunta exige un nivel bastante alto de competencia de razonamiento proporcional y hace referencia a una situación de vida práctica en sociedad que probablemente no resulte muy familiar a los jóvenes de 15 años. El formato de elección múltiple compleja utilizado exige que los estudiantes demuestren que han comprendido ampliamente los conceptos implicados. Además, los estudiantes deben leer y entender una serie de enunciados matemáticos complejos. En la prueba piloto esta pregunta resultó muy difícil.

\section{Matemáticas, Ejemplo 4.2:}

Hay tres pisos en el edificio. El mayor de ellos, el piso 1, tiene una superficie total de $95 \mathrm{~m}^{2}$. Los pisos 2 y 3 tienen superficies de $85 \mathrm{~m}^{2}$ y $70 \mathrm{~m}^{2}$ respectivamente. El precio de venta del edificio es de 300.000 zeds.

¿Cuánto deberá pagar el propietario del piso 2? Escribe tus cálculos.

\section{Criterios de corrección y comentarios sobre el ejemplo 4.2}

Máxima puntuación

Código 2: $\quad 102.000$ zeds, con o sin cálculos. No es necesario especificar la unidad.

- Piso 2: 102.000 zeds

- Piso 2: $\frac{85}{250} \times 300.000=102.000$ zeds

- $\frac{300.000}{250}=1.200$ zeds por cada metro cuadrado, luego el apartamento 2 cuesta 102.000 .

Puntuación parcial

Código 1: Método correcto, con errores menores de cálculo.

- Piso 2: $\frac{85}{250} \times 300.000=102.000$ zeds

Ninguna puntuación

Código 0: $\quad$ Otras respuestas.

Tipo de pregunta: Pregunta de respuesta abierta

Grupo de competencia: Conexión

Idea principal: Cantidad

Situación: Pública

El Ejemplo 4.2 es un ejemplo más concreto que incluye pisos "reales" cuya superficie es "real". Los resultados de la prueba piloto confirmaron que esta pregunta resulta mucho más fácil que la primera, que es más abstracta.
La clasificación en el grupo de competencia de conexión es la adecuada dado que la resolución del problema comporta múltiples pasos y el contexto no es familiar. 
Matemáticas, Unidad 5: ESTATURA DE LOS ALUMNOS

\section{Matemáticas, Ejemplo 5.1:}

Un día, en clase de matemáticas, se mide la estatura de todos los alumnos. La estatura media de los chicos es de 160 $\mathrm{cm}$ y la estatura media de las chicas es de $150 \mathrm{~cm}$. Elena ha sido la más alta: mide $180 \mathrm{~cm}$. Pedro ha sido el más bajo: mide $130 \mathrm{~cm}$.

Dos estudiantes faltaron a clase ese día, pero fueron a clase al día siguiente. Se midieron sus estaturas y se volvieron a calcular las medias. Sorprendentemente, la estatura media de las chicas y la estatura media de los chicos no cambió.

¿Pueden las siguientes conclusiones deducirse de esta información?

Rodea con un círculo la palabra Sí o No para cada conclusión.

Conclusión

Los dos estudiantes son chicas.

Uno de los estudiantes es un chico y el otro es una chica.

Los dos estudiantes tienen la misma estatura.

La estatura media de todos los estudiantes no cambió.

Pedro sigue siendo el más bajo.
¿Puede deducirse esta conclusión?
Sí / No
Sí / No
Sí / No
Sí / No
Sí / No

\section{Criterios de corrección y comentarios sobre el ejemplo 5.1}

Máxima puntuación

Código 1: $\quad$ No en todas las conclusiones.

Ninguna puntuación

Código 0: $\quad$ Cualquier otra combinación de respuestas.

Tipo de pregunta: Elección múltiple compleja

Grupo de competencia: Reflexión

Idea principal: Incertidumbre

Situación: Educativa

La clasificación es sencilla: incertidumbre, puesto que precisa la comprensión de conceptos estadísticos; educativa, puesto que es el tipo de problema que se encuentra en un escenario escolar; y reflexión, por el importante aspecto comunicativo: los estudiantes tienen que entender el lenguaje detalladamente y los conceptos subyacentes, que son bastante sofisticados. El problema implica la habilidad de formular preguntas («icómo puedo saber...?», 
«cómo puedo hallar...?», «iqué puede pasar?»), «iqué pasaría si...?») y la habilidad de comprender y manejar conceptos matemáticos (media) en contextos complejos.

Resulta importante el aspecto de la matematización consistente en identificar la información y el contenido matemáticos relevantes. Una lectura superficial conducirá al desastre. La situación es verdaderamente compleja: varía en la clase y a lo largo del tiempo. La entidad clase se utiliza cuando se trata la media de chicos y chicas por separado, pero, posteriormente, se afirma que Elena es la persona (chica o estudiante) más alta y Pedro, la persona (chico o estudiante) más baja. Los alumnos deben realizar una lectura cuidadosa para darse cuenta de que Pedro es un chico y de que Elena es una chica. La variación en el tiempo consiste en que en un primer momento faltan dos estudiantes y en que cuando al día siguiente se les incluye en la medición, la media no se altera. La clase ha aumentado, pero no se sabe si estos dos estudiantes añadidos son dos chicas, dos chicos o un chico y una chica.

Para responder correctamente a las cinco partes de esta pregunta, los alumnos deben explorar de un modo complejo las relaciones entre los datos y los resúmenes estadísticos de dichos datos. La prueba piloto mostró que esta pregunta constituía todo un reto para los jóvenes de 15 años.

Matemáticas, Unidad 6: EL COLUMPIO

\section{Matemáticas, Ejemplo 6.1:}

Mohammed está sentado en un columpio. Empieza a columpiarse. Está intentando llegar tan alto como le sea posible. ¿Cuál de estos gráficos representa mejor la altura de sus pies por encima del suelo mientras se columpia?

Altura de los pies

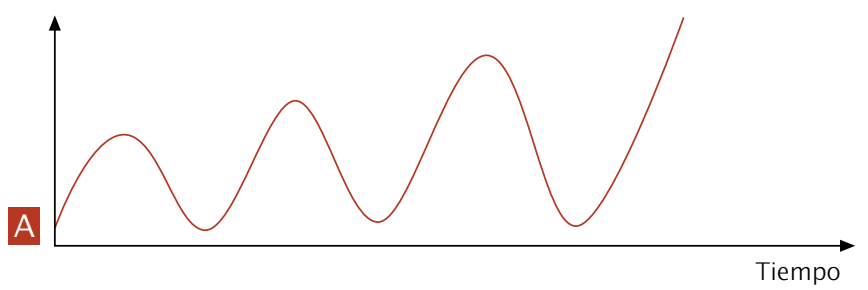

Altura de los pies

B

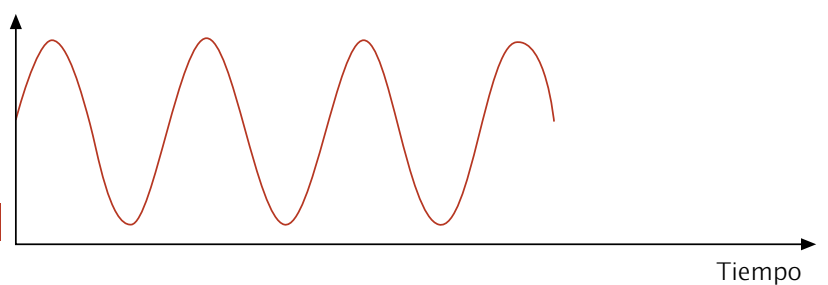



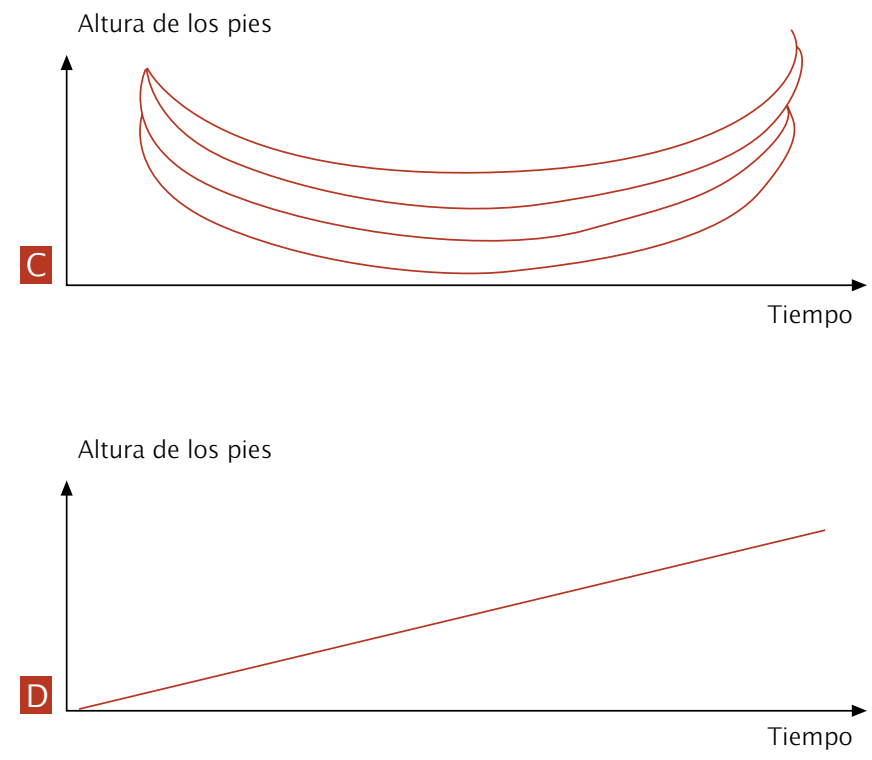

\section{Criterios de corrección y comentarios sobre el ejemplo 6.1}

Máxima puntuación

Código 1: Respuesta A.

Ninguna puntuación

Código 0: $\quad$ Otras respuestas.

Tipo de pregunta: Elección múltiple

Crupo de competencia: Conexión

Idea principal: Cambio y relaciones

Situación: Personal

Este tipo de pregunta es muy popular en ciertos países: ¿qué representación gráfica se ajusta al enunciado? En la década de los años setenta, fue el profesor de matemáticas canadiense Janvier quien promovió el formato al pedir a los estudiantes que identificaran el circuito de carreras que correspondía al gráfico de velocidad dado. En el ciclo PISA 2000 se utilizó una pregunta similar, que puede consultarse en la publicación Sample Tasks from the PISA 2000 Assessment (OCDE, París, 2002a).

En el caso del columpio, la pregunta parece más fácil que la de PISA 2000, porque aquí se pueden desechar ciertas alternativas casi inmediatamente, lo que no era el caso en el problema del circuito de carreras.
La respuesta A parece ajustarse bastante bien. La B no comienza con los pies en el suelo y no aumenta con poco balanceo; la C es una mera visualización de la acción de balanceo; y en la D no hay balanceo. Por tanto, la respuesta correcta es A, y es la que eligieron la mayor parte de los estudiantes.

La clasificación dentro del grupo de conexión es apropiada, porque los estudiantes tienen que interpretar y vincular al menos dos representaciones, textual y gráfica, y vincular el mejor gráfico al texto. La familiaridad con el contexto puede añadir un componente práctico a la evaluación de las opciones de respuesta. Los estudiantes tienen que entender el gráfico en el contexto familiar que se les presenta; no obstante, las representaciones gráficas no resultan tan familiares. 
Matemáticas, Ejemplo 7.1:

Un depósito de agua tiene la forma y dimensiones que se muestran en el dibujo.

Inicialmente el depósito está vacío. Después se llena con agua a razón de un litro por segundo.

¿Cuál de los gráficos siguientes muestra cómo va cambiando la altura del agua en la cisterna en función del tiempo?
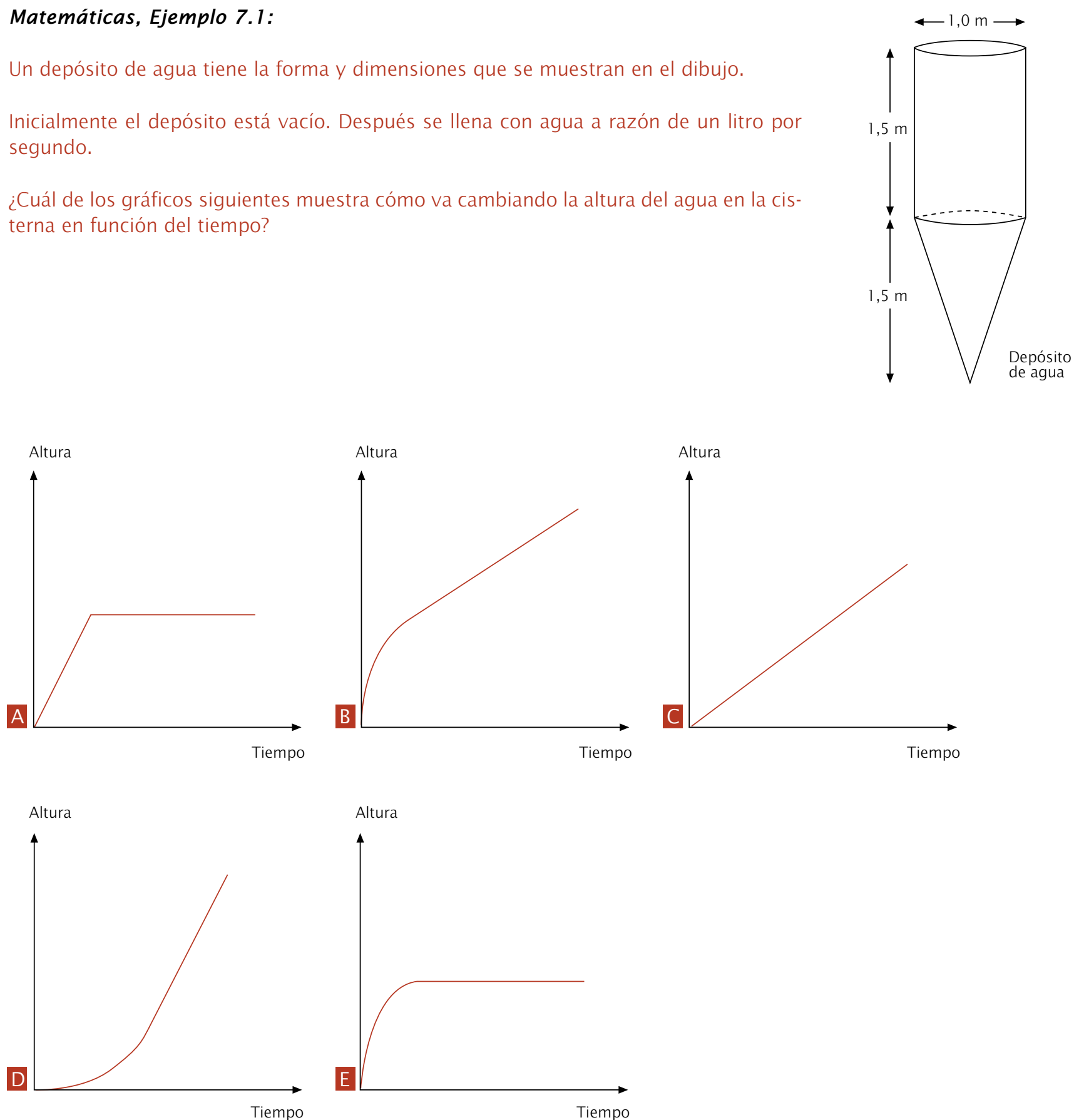


\section{Criterios de corrección y comentarios sobre el ejemplo 7.1}

Máxima puntuación

Código 1: $\quad$ Respuesta B.

Ninguna puntuación

Código 0: $\quad$ Otras respuestas.

Tipo de pregunta: Elección múltiple

Grupo de competencia: Conexión

Idea principal: Cambio y relaciones

Situación: Científica

Este ejemplo no es muy complicado de entender para los es-tudiantes: hay poco texto y un dibujo claro. Los estudiantes deben vincular el texto y el dibujo y relacionar su comprensión con las representaciones gráficas de las opciones de respuesta. Estas competencias se engloban dentro del grupo conexión.

Es interesante observar que esta pregunta contiene información superflua. Se detallan las medidas del depósito y el caudal constante que se indica es de un litro por segundo. No obstante, esta cuantificación no sirve de ayuda a los alumnos, puesto que los gráficos son únicamente "globales" o "cualitativos". Esto es interesante porque normalmente nunca se da información superflua en las preguntas de matemáticas, mientras que en los problemas del mundo real aparece continuamente. En realidad, una parte importante de cualquier proceso de matematización consiste en identificar la parte matemática importante y desechar la información superflua.

Aunque el contexto de la pregunta se ha clasificado como científico, este tipo de problemas se presentan también en situaciones personales. Llenar un vaso, un jarrón o un cubo, especialmente cuando el recipiente no es cilíndrico, puede comportar alguna sorpresa si no se tiene en cuenta que la velocidad del aumento en la altura de llenado depende de la forma del recipiente. Ser consciente de este tipo de hechos es algo que se engloba en la definición de competencia matemática.

\section{Matemáticas, Unidad 8: TIEMPO DE REACCIÓN}

En una carrera de velocidad, el tiempo de reacción es el tiempo que transcurre entre el disparo de salida y el instante en que el atleta abandona el taco de salida. El tiempo final incluye tanto el tiempo de reacción como el tiempo de carrera. En la tabla siguiente figura el tiempo de reacción y el tiempo final de 8 corredores en una carrera de velocidad de 100 metros.

\begin{tabular}{l|l|l} 
Calle & Tiempo de reacción (s) & \multicolumn{1}{l}{ Tiempo final (s) } \\
\hline 1 & 0,147 & 10,09 \\
2 & 0,136 & 9,99 \\
3 & 0,197 & 9,87 \\
4 & 0,180 & No acabó la carrera \\
5 & 0,210 & 10,17 \\
6 & 0,216 & 10,04 \\
7 & 0,174 & 10,08 \\
8 & 0,193 & 10,13
\end{tabular}

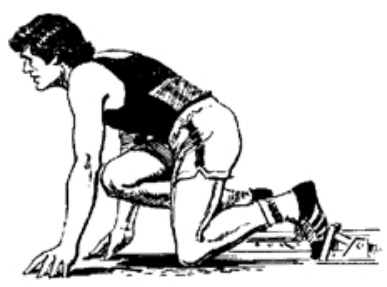


Matemáticas, Ejemplo 8.1:

Identifica a los corredores que ganaron las medallas de oro, plata y bronce en esta carrera. Completa la tabla siguiente con su número de calle, su tiempo de reacción y su tiempo final.

\begin{tabular}{l|l|l|l} 
Medalla & Calle & Tiempo de reacción (s) & Tiempo final (s) \\
\hline ORO & & & \\
\hline PLATA & & & \\
\hline BRONCE & & & \\
\hline
\end{tabular}

\section{Criterios de corrección y comentarios sobre el ejemplo 8.1}

Máxima puntuación

Código 1:

\begin{tabular}{|c|c|c|c|}
\hline Medalla & Calle & Tiempo de reacción (s) & Tiempo final (s) \\
\hline ORO & 3 & 0,197 & 9,87 \\
\hline PLATA & 2 & 0,136 & 9,99 \\
\hline BRONCE & 6 & 0,216 & 10,04 \\
\hline
\end{tabular}

Ninguna puntuación

Código 0: $\quad$ Otras respuestas.

Tipo de pregunta: Pregunta de respuesta abierta

Grupo de competencia: Reproducción

Idea principal: Cantidad

Situación: Científica

Una pregunta de reproducción que exige la comprensión de la notación decimal (cantidad) pero a la que se añade algo de información superflua y de complejidad a causa del tiempo de reacción, que no es necesario para contestar el primer ejemplo. Alrededor de las dos terceras partes de los alumnos que participaron en la prueba piloto dieron con la respuesta correcta, lo que indica que se trata de una pregunta relativamente fácil para la mayoría de los jóvenes de 15 años. 
Matemáticas, Ejemplo 8.1:

Hasta la fecha, nadie ha sido capaz de reaccionar al disparo de salida en menos de 0,1 10 segundos.

Si el tiempo de reacción registrado para un corredor es inferior a 0,1 10 segundos, entonces se considera que se ha producido una salida falsa porque el corredor tiene que haber salido antes de oír la señal.

Si el tiempo de reacción del corredor que ha ganado la medalla de bronce hubiera sido menor, ¿podría haber ganado

la medalla de plata? Justifica tu respuesta.

\section{Criterios de corrección y comentarios sobre el ejemplo 8.2}

Máxima puntuación

Código 1: Sí, con una explicación correcta. Por ejemplo:

- Sí. Si su tiempo de reacción hubiera sido 0,05 s menor, habría igualado el segundo lugar

- Sí, podría haber obtenido la medalla de plata si su tiempo de reacción hubiera sido menor o igual que $0,166 \mathrm{~s}$.

- Sí, con el tiempo de reacción más rápido posible, él habría hecho 9,93, que es suficiente para conseguir la medalla de plata.

Ninguna puntuación

Código 0: $\quad$ Otras respuestas, incluyendo sí pero sin una explicación correcta.

Tipo de pregunta: Pregunta de respuesta abierta

Crupo de competencia: Conexión

Idea principal: Cantidad

Situación: Científica

Este ejemplo precisa de un cierto nivel de razonamiento verbal y matemático. Si se ha contestado correctamente el Ejemplo 8.1, se ve claramente que el corredor de la calle 6 (Bronce) tiene un tiempo de reacción lento (es el más lento de todos) y que el de la calle 2 (Plata) tiene un tiempo de reacción muy rápido (el más rápido de todos), pero ambos acaban prácticamente con el mismo tiempo final (con una diferencia de sólo 0,05 segundos). Por tanto, el corredor de la calle 6 podría haber obtenido la medalla de plata si su tiempo de reacción hubiera sido algo más rápido, puesto que la diferencia de sus tiempos de reacción fue un bastante mayor que la diferencia en sus tiempos finales.

Dadas las destrezas de interpretación necesarias más una comparación poco habitual de decimales con diferentes grados de redondeo, esta pregunta forma parte del grupo de competencias de conexión. 
A Susana le gusta construir bloques con cubos pequeños como el que se muestra en el siguiente gráfico:

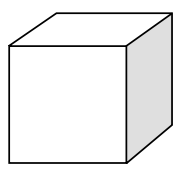

Cubo pequeño

Susana tiene muchos cubos pequeños como éste. Utiliza pegamento para unir los cubos y construir otros bloques.

Primero Susana pega ocho cubos para hacer el bloque que se muestra en el gráfico $A$ :

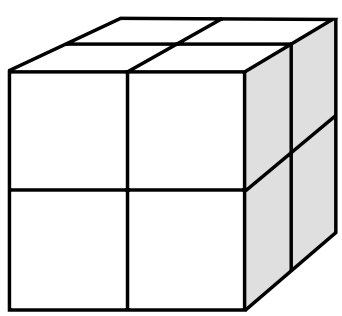

Gráfico A

Luego Susana hace los bloques macizos que se muestran en los siguientes gráficos B y C:

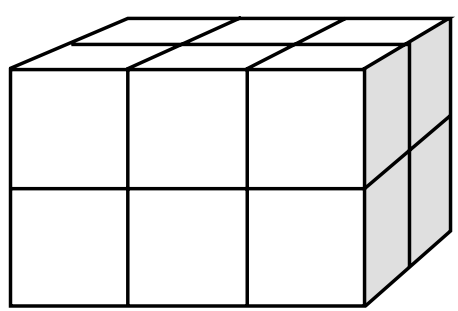

Gráfico B

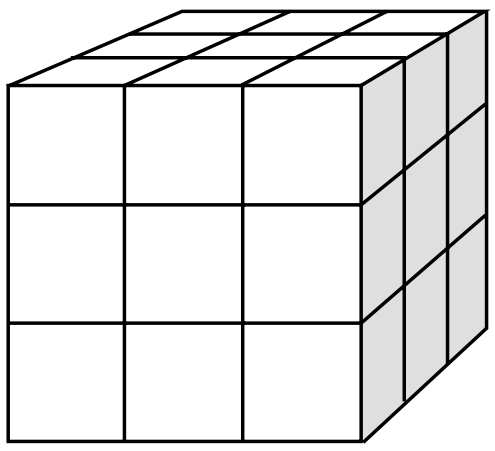

Gráfico C 
Matemáticas, Ejemplo 9.1:

¿Cuántos cubos pequeños necesitará Susana para hacer el bloque que se muestra en el gráfico B?

Respuesta: cubos.

\section{Criterios de corrección y comentarios sobre el ejemplo 9.1}

Máxima puntuación

Código 1: 12 cubos.

Ninguna puntuación

Código 0: $\quad$ Otras respuestas.

Tipo de pregunta: Pregunta de respuesta abierta

Grupo de competencia: Reproducción

Idea principal: Espacio y forma

Situación: Personal

En cada grupo de preguntas es obligatorio incluir preguntas muy fáciles y también preguntas más difíciles, medidas según los resultados de los estudiantes. Esta pregunta es realmente fácil: los estudiantes pueden imaginar el problema directamente puesto que es muy probable que hayan utilizado este tipo de bloques a menudo (Lego,
Duplo, etc.), y no habrán necesitado siquiera hacer una multiplicación para obtener la respuesta correcta. En el Gráfico B ven los seis primeros cubos y saben que hay seis cubos más detrás. Tanto por su carácter familiar como por su sencillez esta es una pregunta típica del grupo de reproducción.

\section{Matemáticas, Ejemplo 9.2:}

¿Cuántos cubos pequeños necesitará Susana para hacer el bloque macizo que se muestra en el gráfico C? Respuesta: cubos.

\section{Criterios de corrección y comentarios sobre el ejemplo 9.2}

Máxima puntuación

Código 1: 27 cubos.

Ninguna puntuación

Código 0: $\quad$ Otras respuestas.

Tipo de pregunta: Pregunta de respuesta abierta

Grupo de competencia: Reproducción

Idea principal: Espacio y forma

Situación: Personal 
El Ejemplo 9.2 se diferencia del Ejemplo 9.1 en que el número de cubos es algo mayor (27 en lugar de 12), pero conceptualmente se trata de la misma pregunta. La prueba piloto muestra que esta pregunta resultó relativamente fácil para los alumnos. Era de esperar, dado que las competencias para resolver este problema son muy básicas. Los expertos de los países participantes estuvieron de acuerdo en que las preguntas de este tipo son muy parecidas a las de sus currículos respectivos.

\section{Matemáticas, Ejemplo 9.3:}

Susana se da cuenta de que ha utilizado más cubos pequeños de los que realmente necesitaba para hacer un bloque como el que se muestra en el gráfico C. Se da cuenta de que podía haber construido un bloque como el del gráfico $\mathrm{C}$ pegando los cubos pequeños, pero dejándolo hueco por dentro.

¿Cuál es el mínimo número de cubos que necesita para hacer un bloque como el que se muestra en el gráfico C, pero hueco?

Respuesta: cubos.

\section{Criterios de corrección y comentarios sobre el ejemplo 9.3}

Máxima puntuación

Código 1: 26 cubos.

Ninguna puntuación

Código 0: $\quad$ Otras respuestas.

Tipo de pregunta: Pregunta de respuesta abierta

Grupo de competencia: Conexión

Idea principal: Espacio y forma

Situación: Personal

En el Ejemplo 9.2 se suponía que estábamos trabajando con cubos sueltos y que, por tanto, necesitábamos 27 , puesto que, de otro modo, el bloque se desmoronaría. No obstante, si se pudiera utilizar pegamento, sería posible construir un bloque como el $\mathrm{C}$ utilizando menos de 27 bloques. Aunque la respuesta "obvia" es 26 (quitando el cubo central), hay diversas consideraciones sobre este ejemplo. El problema es que la pregunta no dice explícitamente que el bloque $C$ deba verse igual desde cualquier ángulo. Esto es importante, porque si se usa pegamento y se debe conseguir algo ajustado al gráfico $C$, se puede quitar más de un cubo. Sin embargo, esto se afirma implícitamente, al decir que el bloque debe estar hueco en el interior. No obstante, desde un punto de vista lingüístico y de interpretación, esta pregunta no resulta tan directa como la anterior.

La pregunta puede clasificarse dentro del grupo de conexión por diversas razones: la matematización necesaria para captar los elementos esenciales de la pregunta, la necesidad de interpretar mentalmente el gráfico $C$ con un agujero en el centro, el razonamiento y pensamiento necesarios para obtener la respuesta correcta y la falta de un algoritmo o procedimiento estándar. 
Matemáticas, Ejemplo 9.4:

Ahora Susana quiere construir un bloque que parezca un bloque macizo y que tenga 6 cubos pequeños de largo, 5 de ancho y 4 de alto. Quiere usar el menor número posible de cubos dejando el mayor hueco posible en el interior.

¿Cuál es el mínimo número de cubos que necesitará Susana para hacer este bloque?

Respuesta: cubos.

\section{Criterios de corrección y comentarios sobre el ejemplo 9.4}

Máxima puntuación

Código 1: 96 cubos.

Ninguna puntuación

Código 0: $\quad$ Otras respuestas.

Tipo de pregunta: Pregunta de respuesta abierta

Grupo de competencia: Reflexión

Idea principal: Espacio y forma

Situación: Personal

En el Ejemplo 9.4 hay que suponer (por la forma en que se plantea el problema) que se puede utilizar pegamento. El problema ahora es: «icuál es el mínimo número de cubos necesario para construir un bloque hueco de $6 \times 5 \times 4$ ?»

Tal y como se ha apuntado antes, los estudiantes no disponen de un procedimiento heurístico estándar para contestar a esta pregunta. Tener una imagen mental del cubo que falta en una construcción de $3 \times 3 \times 3$ es algo muy diferente. En lugar de tener que extraer mentalmente un cubo, los estudiantes tienen que plantear una estrategia más generalizable que comporta un razonamiento matemático más complejo. Por tanto, tiene sentido clasificar esta pregunta dentro del grupo de competencia de reflexión.

¿Cómo pueden los alumnos dar con la respuesta correcta? Una buena estrategia sería empezar con el número máximo de cubos: 6 × $5 \times 4$ da un total de 120. Luego, mentalmente, se sacan del centro tantos como sea posible. Como hay 6 de largo, se pueden sacar 4; como hay 5 de ancho, se pueden sacar 3; como hay 4 de alto, se pueden sacar 2 . El total es $4 \times 3 \times 2$, lo que da 24 . Y $120-24=$ 96, que es la respuesta correcta. Es una buena estrategia que muestra una comprensión real. En el contexto de la clase, sería interesante pedir a los estudiantes una explicación de sus razonamientos para así descubrir técnicas de enseñanza eficaces.

Otra estrategia sería considerar todas las paredes necesarias para conseguir el bloque deseado. Un dibujo resultaría muy útil en este caso.

Para construir la pared frontal se necesitan $5 \times 4$ bloques; para la pared trasera, otros $5 \times 4$ bloques. Para la pared lateral no se necesitan $6 \times 4$, puesto que ya están cubiertas la parte delantera y la trasera. Por tanto, la longitud de las paredes laterales no es 6 , sino 4 , por lo que son necesarios 
$4 \times 4$ para cada lado. Por último, hay que cubrir la base y la parte superior sin volver a contar los cubos que ya tenemos. Esto nos da otros $3 \times 4$. Total: $5 \times 4 ; 5 \times 4 ; 4 \times 4 ; 4$ $\times 4 ; 3 \times 4 ; 3 \times 4$, lo que da un total de 96 .

Sin duda, los estudiantes utilizarán diferentes estrategias. Un estudio como PISA puede a veces utilizarse para descubrir las estrategias que los estudiantes crean o aplican al enfrentarse con una situación de esta complejidad, en la que los medios de que dispone el sujeto para formarse una representación en el sentido tradicional son limitados.

Este problema constituye un desafío, casi estrictamente intramatemático, pero que no por ello deja de movilizar competencias y destrezas, como la visualización en el espacio, que son esenciales para la competencia matemática. 
Matemáticas, Ejemplo 10.1:

A una mujer ingresada en un hospital le ponen una inyección de penicilina. Su cuerpo va eliminando gradualmente la penicilina de modo que, una hora después de la inyección, sólo el 60\% de la penicilina permanece activa.

Esta pauta continúa: al final de cada hora sólo permanece activo el 60\% de la penicilina presente al final de la hora anterior.

Supón que a la mujer se le ha administrado una dosis de 300 miligramos de penicilina a las 8 de la mañana. Completa esta tabla escribiendo el total de penicilina que permanecerá activa en la sangre de la mujer a intervalos de una hora desde las 08:00 hasta las 11:00 horas.

\begin{tabular}{l|l|l|l|l} 
Hora & $08: 00$ & $09: 00$ & $10: 00$ & $11: 00$ \\
Penicilina (mg) & 300 & & &
\end{tabular}

\section{Criterios de corrección y comentarios sobre el ejemplo 10.1}

Máxima puntuación

Código 2: $\quad$ Las tres entradas de la tabla son correctas.

\begin{tabular}{l|l|l|l|l} 
Hora & $08: 00$ & $09: 00$ & $10: 00$ & $11: 00$ \\
Penicilina (mg) & 300 & 180 & 108 & 64,8 \\
& & & & ó 65
\end{tabular}

Puntuación parcial

Código 1: $\quad$ Una o dos entradas de la tabla son correctas.

Ninguna puntuación

Código 0: $\quad$ Otras respuestas.

Tipo de pregunta: Pregunta de respuesta abierta

Grupo de competencia: Conexión

Idea principal: Cambio y relaciones

Situación: Científica 
Este primer ejemplo parece poco complicado, pero la reducción exponencial no es un asunto sencillo para muchos estudiantes. $60 \%$ del $60 \%$ del $60 \%$ del... puede parecer una regla sencilla, pero los resultados de preguntas como ésta demuestran que no es el caso. Aunque los porcentajes se tratan ampliamente en la educación primaria, a menudo los estudiantes no están preparados para trabajar con este conocimiento en una situación diferente. Identificar la información matemática pertinente significa comprender la reducción porcentual o exponencial (no necesariamente entender las expresiones, pero sí el concepto), identificar el valor inicial (300) y aplicar repetidamente el proceso.

Resulta interesante observar la gran cantidad de estudiantes (50\%) que no consiguieron dar con la respuesta correcta en la prueba piloto. Esto proporciona una indicación importante a la hora de juzgar la calidad y/o la eficacia del proceso de enseñanza/aprendizaje.

\section{Matemáticas, Ejemplo 10.2:}

Pedro tiene que tomar 80 mg de un fármaco para controlar su presión sanguínea.

El siguiente gráfico muestra la cantidad inicial del fármaco y la cantidad que permanece activa en la sangre de Pedro después de uno, dos, tres y cuatro días.

Cantidad de fármaco activo (mg)

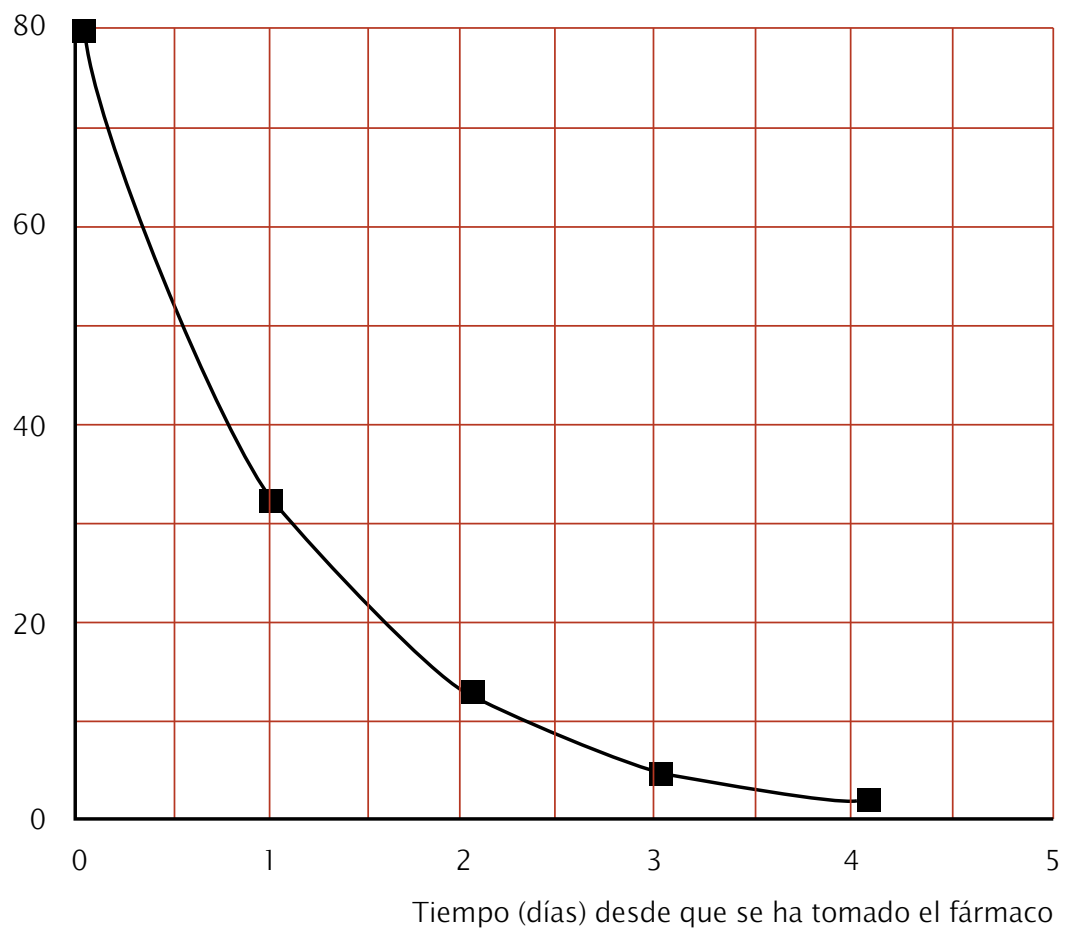


¿Cuánta cantidad de fármaco permanece activa al final del primer día?
A $6 \mathrm{mg}$
B $12 \mathrm{mg}$
C $26 \mathrm{mg}$
D $32 \mathrm{mg}$

\section{Criterios de corrección y comentarios sobre el ejemplo 10.2}

Máxima puntuación

Código 1: $\quad$ Respuesta D: $32 \mathrm{mg}$

Ninguna puntuación

Código 0: $\quad$ Otras respuestas.

Tipo de pregunta: Elección múltiple

Grupo de competencia: Reproducción

Idea principal: Cambio y relaciones

Situación: Científica

Este ejemplo es más sencillo que el anterior y únicamente requiere que se lea un gráfico, así que podemos concluir que esta pregunta presupone competencias de reproducción. No obstante, la pregunta se presenta en un contexto algo inusual, y, por tanto, requiere un cierto grado de interpretación.

\section{Matemáticas, Ejemplo 10.3:}

En el gráfico de la pregunta precedente puede verse que, cada día, permanece activa en la sangre de Pedro aproximadamente la misma proporción de fármaco con relación al día anterior.

Al final de cada día, ¿cuál de las siguientes cifras representa el porcentaje aproximado de fármaco del día anterior que permanece activo?
A $20 \%$.
B $30 \%$.
C $40 \%$.
D $80 \%$.

\section{Criterios de corrección y comentarios sobre el ejemplo 10.3}

Máxima puntuación

Código 1: $\quad$ Respuesta C: $40 \%$.

Ninguna puntuación

Código 0: $\quad$ Otras respuestas. 
Tipo de pregunta: Elección múltiple

Grupo de competencia: Conexión

Idea principal: Cambio y relaciones

Situación: Científica

El Ejemplo 10.3 remite al gráfico del Ejemplo 10.2. La pregunta en esta situación es: "¿cuál es la tasa de reducción?" Por estar presentada en un formato de elección múltiple esta pregunta permite que los estudiantes realicen una conjetura con cierta base, puesto que conocen el valor inicial, 80 , y el valor siguiente, 32 (si han contestado correctamente al Ejemplo 10.2) o uno cercano a 30 (si no utilizan el Ejemplo 10.2 y van directamente al gráfico), y 3/8 es un valor cercano a $40 \%$. Los requisitos de interpretación de esta preguntan la sitúan dentro del grupo de competencia de conexión.

\section{Matemáticas, Unidad 11: EL EDIFICIO RETORCIDO}

En la arquitectura moderna los edificios a menudo tienen formas inusuales. La imagen siguiente muestra un modelo diseñado por ordenador de un "edificio retorcido" y un plano de la planta baja. Los puntos cardinales muestran la orientación del edificio.
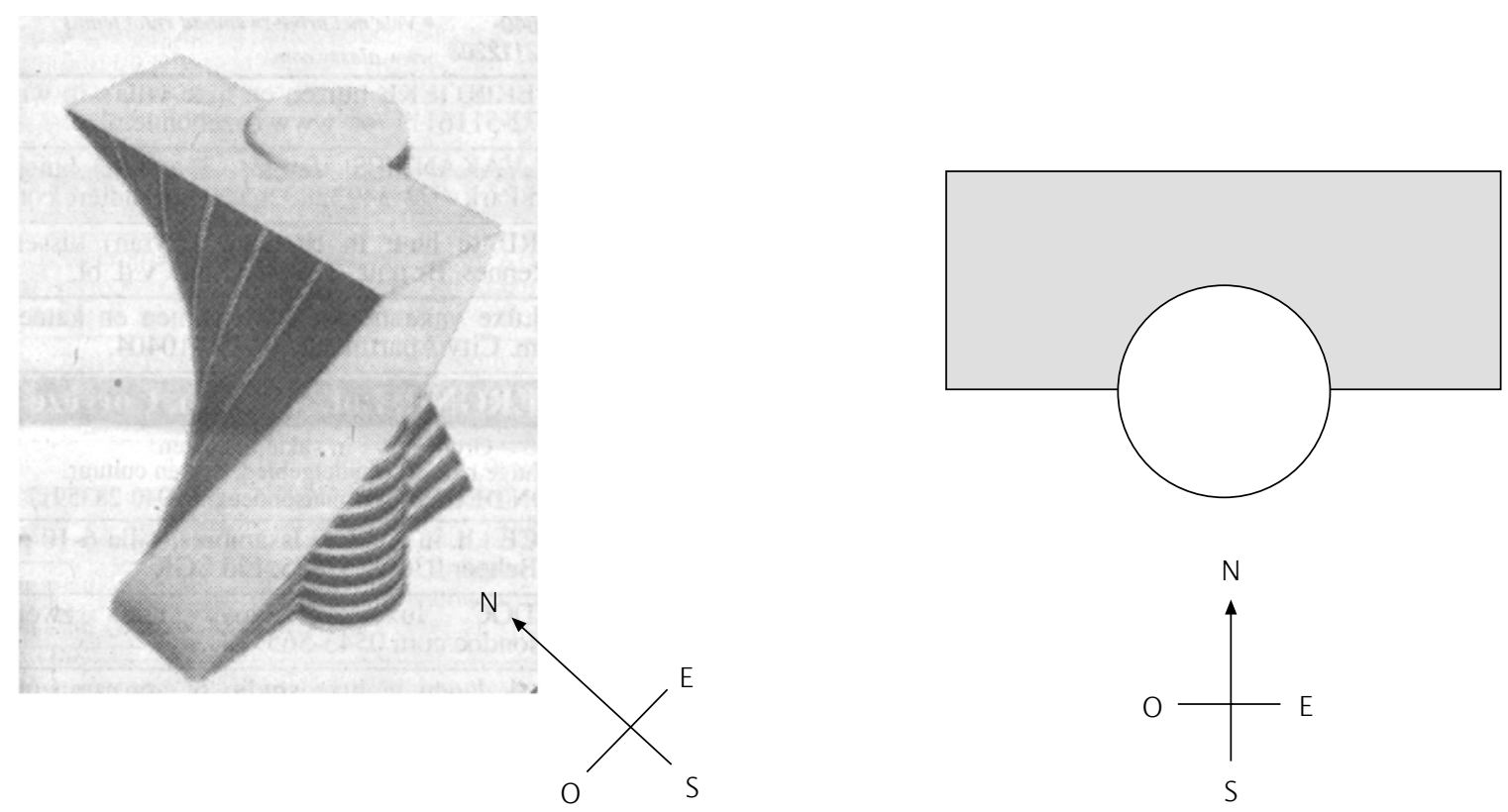

En la planta baja del edificio está la entrada principal y un espacio para tiendas. Por encima de la planta baja hay 20 plantas de viviendas.

El plano de cada planta es similar al de la planta baja, pero la orientación de cada planta es ligeramente distinta a la de la planta inmediatamente inferior. En el cilindro se encuentran el hueco del ascensor y un vestíbulo para cada planta. 
Matemáticas, Ejemplo 11.1:

Calcula la altura total del edificio en metros. Explica cómo has hallado la respuesta.

\section{Criterios de corrección y comentarios sobre el ejemplo 11.1}

Máxima puntuación

Código 2: Se aceptan respuestas entre 50 y 90 metros si se da una explicación correcta. Por ejemplo:

- La altura aproximada de un piso del edificio es 2,5 metros. Hay algo de espacio extra entre pisos. Por tanto, un cálculo aproximado es $21 \times 3=63$ metros.

- Poniendo $4 \mathrm{~m}$ para cada planta, 20 de ellas hacen un total de $80 \mathrm{~m}$, más $10 \mathrm{~m}$ por la planta baja, se obtiene un total de $90 \mathrm{~m}$.

Puntuación parcial

Código 1: Explicación y método de cálculo correctos, pero se cuentan 20 plantas en lugar de 21. Por ejemplo:

- Cada vivienda podría medir 3,5 metros de alto, 20 plantas de 3,5 metros dan un total de $70 \mathrm{~m}$ de alto.

Ninguna puntuación

Código 0: $\quad$ Otras respuestas, incluyendo una respuesta sin explicación, respuestas con un número de plantas incorrecto, y respuestas con un cálculo inadmisible sobre la altura de cada planta (4 m sería el límite máximo). Por ejemplo:

- Cada piso mide alrededor de $5 \mathrm{~m}$ de alto, así que $5 \times 21$ es igual a 105 metros

$-60 \mathrm{~m}$.

Tipo de pregunta: Pregunta de respuesta abierta

Grupo de competencia: Conexión

Idea principal: Espacio y forma

Situación: Pública

Las preguntas de esta unidad requieren imaginación y perspicacia, especialmente en lo que se refiere a la visión espacial, en un contexto público que cuenta con elementos familiares pero que puede ser novedoso para muchos estudiantes. El primer ejemplo pide que los estudiantes realicen algunos juicios razonados sobre la altura adecuada para las plantas de un edificio alto, lo que incluye tanto la altura «visible» de las habitaciones de cada planta como el espacio necesario entre plantas. Los estudiantes deben llevar construir un modelo rudimentario y traducir la representación visual a una numérica. Estas competencias se encuentran asociadas al grupo de conexión.
Muchos estudiantes fueron capaces de resolver este problema en la prueba piloto, con un porcentaje ligeramente mayor de chicos. Sin embargo, un número elevado de alumnos dejó la pregunta sin contestar, lo que indica que muchos no quisieron o no fueron capaces de emplear su imaginación de la manera necesaria.

Las imágenes siguientes son vistas laterales del edificio retorcido. 
Matemáticas, Ejemplo 11.2:

¿Desde dónde se ha obtenido la vista lateral 1?
A Desde el norte.
B Desde el oeste.
C Desde el este.
D Desde el sur.
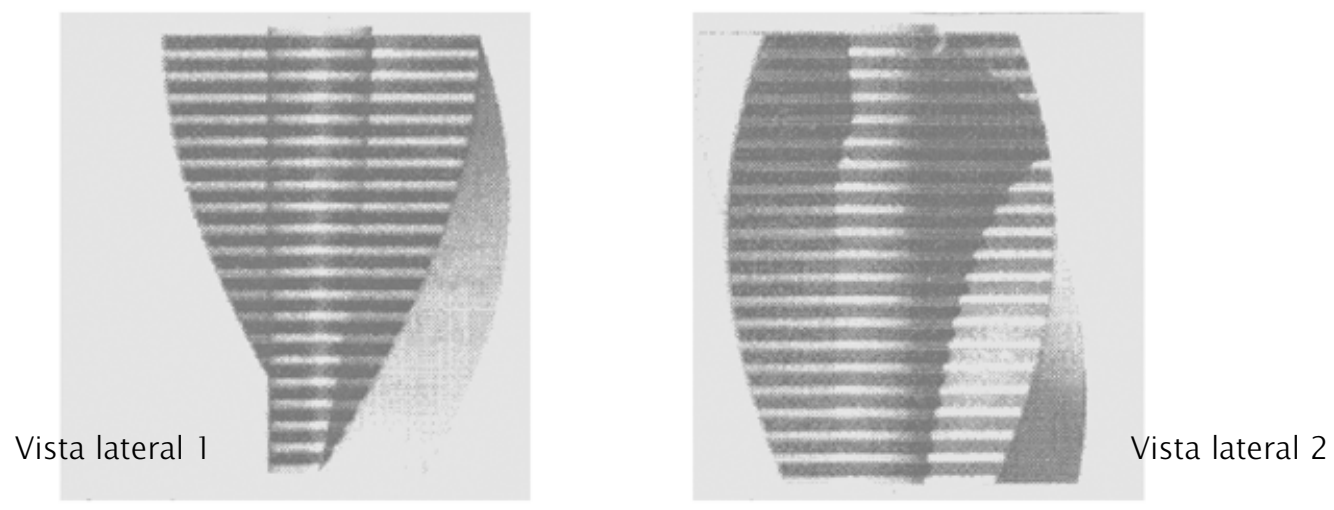

\section{Criterios de corrección y comentarios sobre el ejemplo 11.2}

Máxima puntuación

Código 1: Respuesta C: Desde el este.

Ninguna puntuación

Código 0: Otras respuestas.

Tipo de pregunta: Elección múltiple

Grupo de competencia: Conexión

Idea principal: Espacio y forma

Situación: Pública

El segundo ejemplo hace que los estudiantes comparen mentalmente diferentes representaciones visuales de un edificio y que seleccionen, de entre las opciones presentadas, la que describe la relación entre dichas representaciones. El razonamiento espacial exigido coloca la pregunta dentro del grupo de conexión.
Esta pregunta resultó mucho más fácil que la primera, pero arrojó unas características pobres de medición en varios de los países participantes. Puede que la calidad del gráfico que se utilizó en la prueba piloto no fuera la adecuada para las elevadas exigencias visuales de la pregunta. 
Matemáticas, Ejemplo 11.3:

¿Desde dónde se ha obtenido la vista lateral 2?
A Desde el noroeste.
B Desde el nordeste.
C Desde el suroeste.
D Desde el sureste.

\section{Criterios de corrección y comentarios sobre el ejemplo 11.3}

Máxima puntuación

Código 1: $\quad$ Respuesta D: Desde el sureste.

Ninguna puntuación

Código 0: Otras respuestas.

Tipo de pregunta: Elección múltiple

Grupo de competencia: Conexión

Idea principal: Espacio y forma

Situación: Pública

El tercer ejemplo es muy parecido al Ejemplo 11.2. Es interesante observar las diferentes indicaciones visuales de las dos vistas laterales de los estímulos de los Ejemplo 11.2 y
11.3. El Ejemplo 11.3 resultó algo más difícil que el Ejemplo 11.2, posiblemente a causa de las sutilezas en las sombras de la imagen y a los requisitos de interpretación que conllevan.

\section{Matemáticas, Ejemplo 11.4:}

Cada planta de viviendas tiene cierta "torsión" con respecto a la planta baja. La última planta (la 20ª por encima de la planta baja) forma un ángulo recto con la planta baja.

La figura de abajo representa la planta baja.

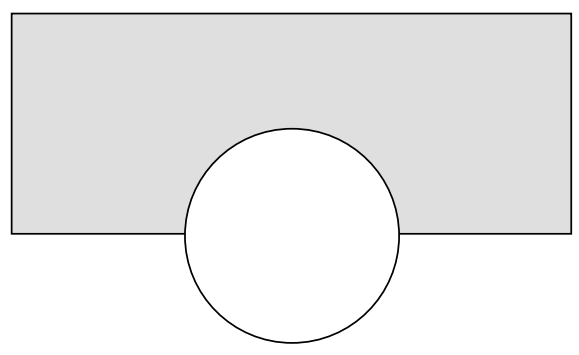


Dibuja en este mismo gráfico el plano de la $10^{a}$ planta, mostrando cómo queda situada con respecto a la planta baja.

Criterios de corrección y comentarios sobre el ejemplo 11.4

Máxima puntuación

Código 2: Un dibujo correcto, es decir, que el centro de rotación sea el correcto y el sentido de la rotación sea el contrario al de las agujas del reloj. Se aceptan ángulos de $40^{\circ}$ a $50^{\circ}$.

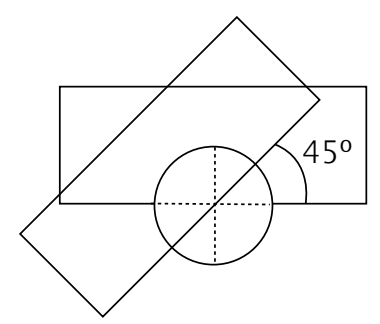

Puntuación parcial

Código 1: Una de las tres cosas siguientes es incorrecta: el ángulo de rotación, el centro de rotación o el sentido de la rotación.

Ninguna puntuación

Código 0: Otras respuestas.

Tipo de pregunta: Pregunta de respuesta abierta

Grupo de competencia: Conexión

Idea principal: Espacio y forma

Situación: Pública

El cuarto ejemplo exige a los estudiantes imaginar el efecto acumulativo del fenómeno de torsión a lo largo de un cierto número de etapas y elaborar una representación gráfica de la $10^{a}$ planta. Nuevamente, el razonamiento espacial exigido coloca la pregunta dentro del grupo de conexión.
La pregunta es relativamente difícil y un número elevado de alumnos la dejaron sin contestar en la prueba piloto. Parece que para los alumnos de 15 años este tipo de construcción geométrica representa un reto. 
Matemáticas, Unidad 12: EL CONCIERTO DE ROCK

Matemáticas, Ejemplo 12.1:

En un concierto de rock se reservó para el público un terreno rectangular con unas dimensiones de $100 \mathrm{~m}$ por $50 \mathrm{~m}$. Se vendieron todas las entradas y el terreno se llenó de fans, todos de pie.

¿Cuál de las siguientes cifras constituye la mejor estimación del número total de asistentes al concierto?
A 2.000
B 5.000
C 20.000
D 50.000
E 100.000

\section{Criterios de corrección y comentarios sobre el ejemplo 12.1}

Máxima puntuación

Código 1: $\quad$ Respuesta C: 20.000.

Ninguna puntuación

Código 0: Otras respuestas.

Tipo de pregunta: Elección múltiple

Grupo de competencia: Conexión

Idea principal: Cantidad

Situación: Pública

El marco conceptual de matemáticas destaca la importancia de las destrezas de estimación como parte del equipaje cuantitativo de un ciudadano competente en matemáticas. Esta pregunta se ubica en un contexto que debería resultar bastante familiar a muchos de los alumnos de 15 años. No obstante, después de interpretar un poco, los estudiantes tienen que desempeñar un papel activo para realizar suposi-ciones sobre cuánto espacio (por término medio) ocuparía una multitud de gente de pie. Este modo de formular el problema y el razonamiento matemático que conlleva coloca la pregunta dentro del grupo de conexión.

Se ofrecen cinco opciones de respuesta, de manera que los estudiantes sólo tienen que elegir la mejor opción. La
Opción A (2.000) implica que cada persona ocuparía una media de 2,5 metros cuadrados, lo que conllevaría una asistencia muy escasa. La Opción E (100.000) implica que la media sería de 20 personas por metro cuadrado, algo difícilmente posible y, desde luego, nada realista. Ello deja a los estu-diantes tres densidades intermedias: 1 persona, 4 personas o 10 personas por metro cuadrado. ¿Cuál es la opción más realista en las condiciones descritas (todas las entradas vendidas y el terreno lleno con todos los fans de pie)? Alrededor del 30\% de los alumnos escogieron la opción media más razonable, la opción C (20.000) en la prueba piloto. 
Matemáticas, Ejemplo 13.1:

A la derecha hay una fotografía de pasillos móviles.

El siguiente gráfico distancia-tiempo permite comparar entre "caminar sobre el pasillo móvil" y "caminar sobre el suelo junto al pasillo móvil".

Distancia desde el inicio del pasillo móvil
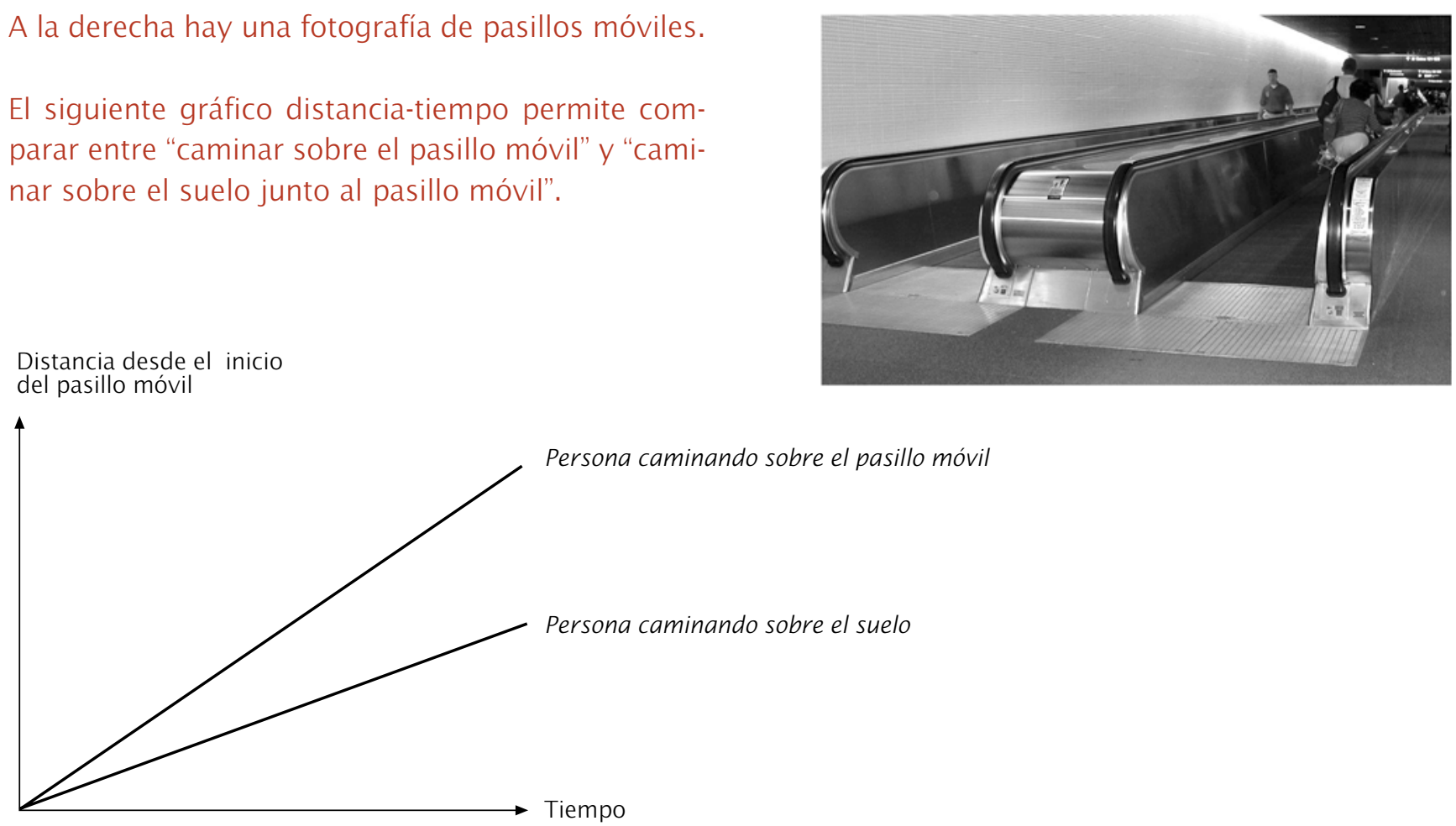

Suponiendo que, en el gráfico anterior, el ritmo del paso es aproximadamente el mismo para las dos personas, añade una línea al gráfico que represente la distancia con relación al tiempo para una persona que está quieta sobre el pasillo móvil. 


\section{Criterios de corrección y comentarios sobre el ejemplo 13.1}

Máxima puntuación

Código 1: Se acepta una línea por debajo de las dos líneas, pero debe estar más cerca de la línea de Persona caminando sobre el suelo que del eje horizontal.

Distancia desde el inicio del pasillo móvil

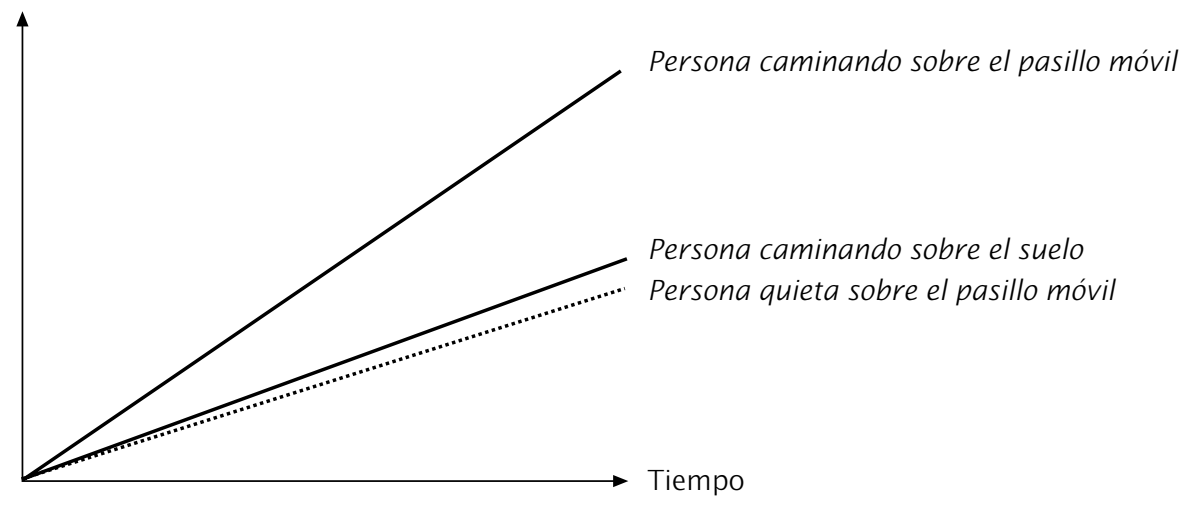

Ninguna puntuación

Código 0: Otras respuestas.

Tipo de pregunta: Pregunta de respuesta abierta

Grupo de competencia: Reflexión

Idea principal: Cambio y relaciones

Situación: Científica

El enunciado de esta pregunta presenta un objeto común en algunos lugares públicos y también recuerda a otros fenómenos similares con los que pueden estar más familiarizados los estudiantes de 15 años (como caminar al lado de unas escaleras mecánicas o bajar corriendo las escaleras al lado del ascensor). Sin embargo, la naturaleza de la pregunta la ubica en una situación científica.

Los estudiantes tienen que ocuparse de la representación matemática de la situación mostrada y deben emplear una cantidad considerable de imaginación y perspicacia para entender la representación. Por tanto, para resolver el problema y elaborar la respuesta apropiada es necesario un razonamiento matemático bastante sofisticado. Estas competencias son típicas del grupo de conexión.

En la prueba piloto esta pregunta resultó ser muy difícil; el índice de aciertos fue de un 15\%. 


\section{Elaboración de las ideas principales}

\section{CANTIDAD}

\section{Descripción}

Para organizar el mundo en que vivimos es necesario imperativamente cuantificarlo: necesitamos expresar qué es "grande" o "pequeño", "alto" o "bajo", "poco" o "mucho", "más" o "menos". Identificamos los modelos del mundo que nos rodea cuantificándolos: llamamos decena al conjunto de diez manzanas, de diez personas, diez coches o cualquier conjunto de diez elementos cualesquiera. Los números cardinales son una manera de aprehender y describir este tipo de modelos. Los números cardinales constituyen el punto de inicio de las actividades de cálculo y un origen para la búsqueda de modelos más profundos, como el de pares e impares.

Pero los números cardinales pueden no ser el primer encuentro fenomenológico para los niños pequeños. Los niños son capaces de reconocer los conceptos pequeño y grande de un modo cualitativo sin recurrir a los números, sino relacionándolos con objetos de diferentes tamaños (galleta pequeña frente a galleta grande) y a conjuntos de objetos (tres objetos frente a siete objetos).

Si se mide una magnitud, se observa una utilización de los números distinta, mucho más importante en la vida diaria. La longitud, el área, el volumen, la altura, la velocidad, la masa, la presión del aire, el valor monetario, todo ello se cuantifica mediante mediciones.

Un aspecto importante al tratar con cantidades es el razonamiento cuantitativo. Éste comporta:

- sentido numérico;

- comprensión del significado de las operaciones;

- sentido de la magnitud de los números;

- cálculos elegantes;

- cálculo mental;

- estimaciones.

El "significado de las operaciones" incluye la capacidad de realizar operaciones que implican comparaciones, proporciones y porcentajes. El "sentido numérico" se ocupa del tamaño relativo, de las diferentes representa- ciones de los números, de las formas numéricas equivalentes y del hecho de poder utilizar la comprensión de todo esto para describir las características del mundo.

La idea principal de cantidad incluye también tener un sentido para las cantidades y las estimaciones. Para poder evaluar lo razonables que son los resultados numéricos se necesita un conocimiento amplio de las cantidades (o medidas) del mundo real. ¿La velocidad media de un coche es de 5 , de 50 ó de $500 \mathrm{~km} / \mathrm{h}$ ? ¿La población del mundo es de 6 millones, 600 millones, 6.000 millones ó 60.000 millones? ¿Cuánto puede tener una torre de altura? ¿Cuánta puede ser la anchura de un río? La capacidad para estimar rápidamente el orden de magnitud es de especial importancia, especialmente a la vista de la creciente utilización de las herramientas de cálculo electrónicas. Hay que ser capaz de estimar que 33 x 613 arrojará un resultado cercano a 20.000. Para lograr esta destreza no se necesita una ejercitación intensiva en la ejecución mental de los algoritmos que tradicionalmente se calculan por escrito, sino un empleo flexible y rápido de la comprensión del valor posicional y de la aritmética de una sola cifra (Fey, 1990).

Utilizando el sentido numérico de un modo apropiado los estudiantes pueden resolver problemas que exijan un razonamiento directo, inverso y proporcional. También pueden estimar índices de variación, ofrecer criterios para seleccionar los datos pertinentes o el nivel de precisión necesario para las operaciones y modelos que utilizan. Pueden examinar algoritmos alternativos y mostrar por qué funcionan correctamente o en qué casos fallarán. Pueden desarrollar modelos que comporten operaciones y relaciones entre operaciones para aquellos problemas que utilizan datos del mundo real, así como establecer relaciones numéricas que exigen operaciones y comparaciones (Dossey, 1997).

En la idea principal de cantidad hay un lugar para el razonamiento cuantitativo «elegante», como el de Gauss que aparece en el ejemplo siguiente. La creatividad asociada a la comprensión conceptual debe ser objeto de valoración en el nivel educativo destinado a los alumnos de 15 años. 


\section{Ejemplos}

\section{Gauss}

Un profesor de Karl Friedrich Gauss (1777-1855) pidió a sus alumnos que sumaran todos los números del 1 al 100. Probablemente lo que pretendía con ello era tener a los alumnos ocupados durante un rato. Pero Gauss, que poseía un razonamiento cuantitativo excelente, descubrió un atajo. Su razonamiento fue el siguiente:

Se escribe la suma dos veces, una en orden ascendente y otra en orden descendente, del siguiente modo:

$1+2+3+\ldots \ldots \ldots . .+98+99+100$

$100+99+98+\ldots \ldots \ldots . .+3+2+1$

Ahora se suman las dos sumas, columna por columna, lo que da:

$101+101+\ldots \ldots \ldots \ldots \ldots .+101+101$

Como hay exactamente 100 copias del número 101 en esta suma, su valor es:

$100 \times 101=10100$
Dado que este producto es igual al doble de la suma original, si se divide por dos se obtiene la solución: 5050

\section{Números triangulares}

Podemos extender un poco más este ejemplo de pensamiento cuantitativo que implica regularidades numéricas para mostrar una representación gráfica de esta regularidad. Utilizaremos la fórmula que presenta el planteamiento general del problema de Gauss.

$1+2+3+\ldots+n=n(n+1) / 2$

Esta fórmula describe también un modelo geométrico conocido: los números que responden a la fórmula $\mathrm{n}(\mathrm{n}+1) / 2$ se denominan números triangulares, puesto que son exactamente los números que se obtienen al colocar bolas en un triángulo equilátero.

Los cinco primeros números triangulares, 1, 3, 6, 10, 15, se muestran en la Figura 1:

Figura 1. Los cinco primeros números triangulares

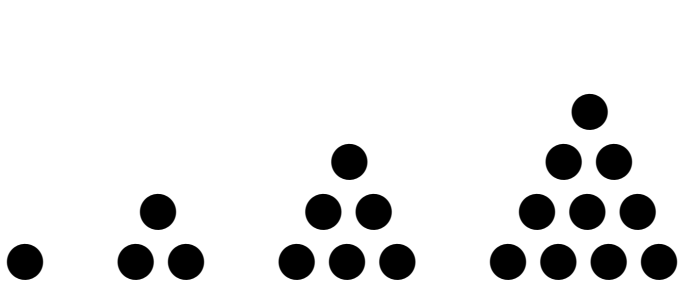

\section{Razonamiento proporcional}

Sería interesante observar cómo los estudiantes de los diferentes países resuelven problemas que se prestan a la utilización de estrategias diversas. Las diferencias serían de esperar especialmente en el área del razonamiento proporcional. En algunos países se acostumbra a utilizar fundamentalmente una estrategia por pregunta, mientras que

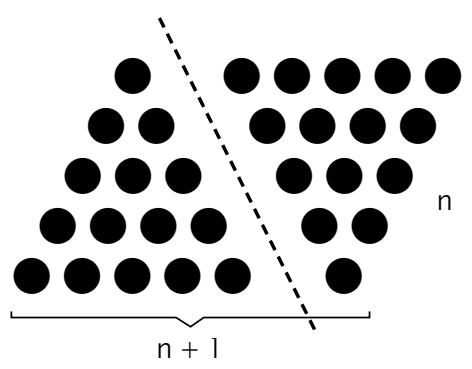

en otros se utiliza más de una estrategia. También aparecerán similitudes de razonamiento al resolver problemas que no parecen similares. Esto concuerda con los resultados de la investigación reciente de los datos TIMSS (Mitchell, J. et al., 2000). Las tres preguntas siguientes ejemplifican las diferentes estrategias y las relaciones entre ellas: 
1 Esta noche vas a dar una fiesta Quieres comprar 100 latas de refrescos ¿Cuántos paquetes de seis lastas tendrás que comprar?

2 Un ala delta con un índice de descenso en planeo de $1 \mathrm{~m}$ por cada $22 \mathrm{~m}$ recorridos empieza el vuelo desde un precipicio escarpado de 120 metros EI piloto quiere llegar hasta un punto que se encuentra a 1400 metros de distancia ¿Conseguirá llegar a ese lugar (en ausencia de viento)?

3 Un centro escolar quiere alquilar mini-buses (con asientos para ocho personas) para llevar a 98 alumnos estudiantes a un campamento escolar ¿Cuántos mini-buses necesita?

El primer problema puede considerarse un problema de división ( ) que a continuación presenta al estudiante el problema de interpretar de nuevo el contexto (icuál es el significado del resto de la divi-sión?). El segundo problema puede resolverse mediante un razonamiento proporcional (por cada metro de altura se puede volar una distancia de 22 metros, así que, partiendo de 120 metros...). El tercer problema puede resolverse también mediante una división. No obstante, los tres problemas pueden resolverse también mediante el método de la tabla de proporciones:

\begin{tabular}{lrrrrrr} 
Latas: & 1 & 10 & 5 & 15 & 2 & 17 \\
& 6 & 60 & 30 & 90 & 12 & 102 \\
\hline Volar: & 1 & 100 & 20 & 120 & & \\
& 22 & 2200 & 440 & 2640 & & \\
\hline Vehículos: & 1 & 10 & 2 & 13 & \\
& 8 & 80 & 16 & 104 & &
\end{tabular}

Dar con esta similitud constituye una destreza propia de la competencia matemática: los estudiantes con competencia matemática no necesitan buscar la herramienta apropiada o el algoritmo adecuado, sino que disponen de una amplia gama de estrategias para elegir.

\section{Porcentajes}

Carlos fue a una tienda a comprar una chaqueta que valía 50 zeds y que ahora está de oferta con un 20\% de descuento. En Zedlandia hay un impuesto sobre las ventas del 5\%. El vendedor añadió primero el 5\% del impuesto al precio de la chaqueta y luego restó el 20\%. Carlos se quejó: quería que el vendedor dedujera primero el $20 \%$ y que añadiera luego el $5 \%$ de impuesto.

\section{¿Supone esto alguna diferencia?}

Los problemas que presentan este tipo de razonamiento cuantitativo y que necesitan realizar cálculos mentales se presentan con mucha frecuencia cuando vamos de compras. La capacidad para afrontar eficazmente estos problemas es fundamental para la competencia matemática.

\section{ESPACIO Y FORMA}

\section{Descripción}

La forma constituye un objeto matemático vital, evolutivo y fascinante que está estrechamente relacionado con la geometría, pero que la supera en contenido, significado y método. La interacción con formas reales implica comprender el mundo visual que nos rodea y su descripción, y saber codificar y descodificar informaciones visuales. También significa interpretar la información visual. Para captar el concepto de forma, los estudiantes deben ser capaces de descubrir el modo en que los objetos se parecen y diferencian entre sí, de analizar los diferentes componentes del objeto y de reconocer formas en representaciones y dimensiones distintas.

Es importante no limitarse a las formas como entidades estáticas. Una forma puede modificarse como cualquier otra una entidad. Estos cambios pueden visualizarse muy bien a través de los ordenadores. Los estudiantes deberían 
ser capaces de identificar pautas y regularidades cuando las formas cambian. Un ejemplo de ello se presenta en la Figura 1.6 de la siguiente sección.

Otro aspecto dinámico importante del estudio de las formas es su posición relativa respecto a las demás, dependiendo de la posición del observador. Para conseguir esto no sólo debemos comprender la posición relativa de los objetos, sino también considerar cuestiones acerca de cómo y por qué vemos las cosas del modo en que lo hacemos, etc. La relación entre las formas o imágenes y sus representaciones en dos o tres dimensiones desempeña aquí un papel fundamental.

Hay abundantes ejemplos que precisan este tipo de razonamiento. Identificar y relacionar una fotografía de una ciudad con el mapa de esa ciudad e indicar desde qué punto se tomó la fotografía, ser capaz de dibujar un mapa, entender por qué un edificio cercano parece más grande que otro más alejado, comprender por qué las vías del tren parecen juntarse en el horizonte, todas estas cuestiones pertenecen a la idea principal de espacio y forma.

Dado que los estudiantes viven en un espacio tridimensional, deberían estar familiarizados con la visión de los objetos desde tres vistas ortogonales (por ejemplo, de frente, de lado y por encima). Deben ser conscientes del alcance y las limitaciones de las diferentes representaciones de las formas tridimensionales tal y como se observa en el ejemplo de la Figura 1.7. No sólo tienen que comprender la posición relativa de los objetos, sino también cómo pueden moverse a través del espacio y de las construcciones o formas. Un ejemplo podría ser leer e interpretar un mapa y elaborar las indicaciones de cómo ir del punto A al punto B utilizando coordenadas, el lenguaje común o un dibujo.

La comprensión conceptual de las formas también conlleva la habilidad de tomar un objeto tridimensional y plasmarlo en un plano bidimensional y viceversa, incluso cuando el objeto tridimensional se presenta en dos dimensiones. Un ejemplo de ello se presenta en la Figura 1.8.

Para resumir, a continuación se presenta una lista de aspectos clave de la idea principal espacio y forma:

- reconocer formas y modelos;

- describir, codificar y descodificar la información visual;

- comprender los cambios dinámicos de las formas;

- similitudes y diferencias;

- posiciones relativas;

- representaciones bidimensionales y tridimensionales y relaciones ente ambas;

- orientación en el espacio.

\section{Ejemplos}

La figura 1.6 muestra un ejemplo simple de la necesidad de ser flexible a la hora de ver cómo cambian las formas. Se trata de un cubo que se va seccionando (es decir, sobre el que se realizan cortes planos). Pueden plantearse preguntas como:

Figura 1.6 Un cubo con cortes planos en varios lugares
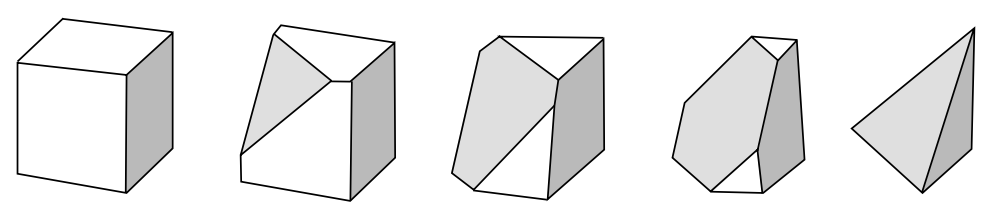

A continuación se presentan tres ejemplos de la necesidad de estar familiarizados con representaciones de formas tridimensionales. En este primer ejemplo, se dan en la Figura 1.7 las vistas lateral y frontal de un objeto elaborado con cubos. La pregunta es: 
¿Cuántos cubos se han utilizado para crear este objeto?

Figura 1.7 Vistas lateral y frontal de un objeto elaborado con cubos

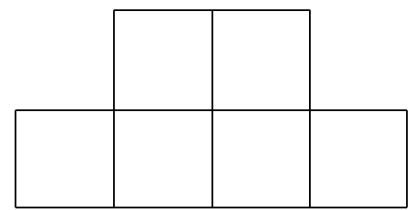

Lateral

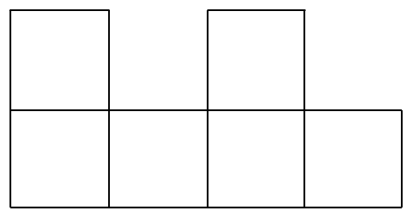

Frontal
Puede resultar una sorpresa para muchos (tanto alumnos como profesores) que el número máximo de cubos sea 20 y el mínimo sea 6 (De Lange, 1995).
El siguiente ejemplo muestra una representación bidimensional de un granero y un desarrollo incompleto del granero. El problema consiste en completar el plano del granero.

Figura 1.8 Representación bidimensional de un granero tridimensional y su desarrollo (incompleto)

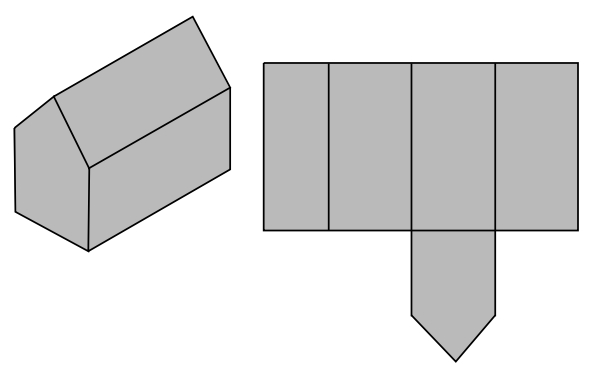

Un ejemplo final parecido al anterior es el de la Figura 1.9 (adaptada de Hershkovitz et al., 1996).

Figura 1.9 Cubo de base negra
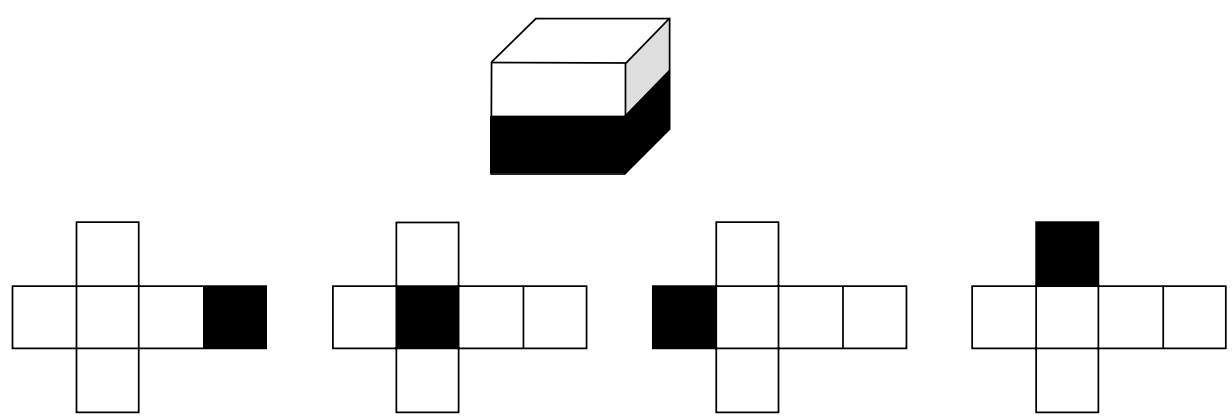

La mitad inferior del cubo se ha pintado de negro. Cada uno de los cuatro desarrollos ya tiene la base negra. Se puede pedir a los estudiantes que acaben cada desarrollo sombreando los cuadrados pertinentes. 


\section{CAMBIO Y RELACIONES}

\section{Descripción}

Para sensibilizarnos con las regularidades en ámbito del cambio, Stewart (1990) afirma que hay que:

- representar los cambios de una forma comprensible;

- comprender los tipos de cambio fundamentales;

- reconocer los diferentes tipos de cambio cuando se producen;

- aplicar estas técnicas al mundo exterior;

- controlar un universo cambiante para nuestro beneficio.

El cambio y las relaciones pueden representarse visualmente de diferentes maneras: numéricamente (en una tabla, por ejemplo), simbólicamente o gráficamente. Pasar de una a otra de estas representaciones tiene una importancia clave, así como reconocer y comprender las relaciones y los tipos de cambio fundamentales. Los alumnos deben ser conscientes de los conceptos de crecimiento lineal (proceso aditivo), crecimiento exponencial (proceso multiplicativo) y crecimiento periódico así como del crecimiento logístico, al menos de manera informal como un caso especial de crecimiento exponencial.

Los estudiantes deben poder también reconocer las relaciones entre estos modelos: las diferencias clave en-tre los procesos lineales y exponenciales, el hecho de que el crecimiento porcentual es idéntico al crecimiento exponencial, cómo y por qué se produce el crecimiento logístico tanto en situaciones continuas como discretas.

Los cambios se producen en un sistema de objetos o fenómenos interrelacionados en el que los elementos se influyen entre sí. En los ejemplos que se mencionan en el resumen, todos los fenómenos cambiaron a lo largo del tiempo. Pero hay muchos ejemplos en la vida real de asuntos en los que los objetos están interrelacionados entre sí de numerosas maneras. Por ejemplo:

Si se divide en dos la longitud de la cuerda de una guitarra, el tono nuevo que se consigue es una octava mayor que el tono original. Por tanto, el tono depende de la longitud de la cuerda.

Cuando ingresamos dinero en una cuenta bancaria sabemos que el saldo dependerá de la magnitud, la frecuencia y el número de ingresos y extracciones de dinero y de los tipos de interés.

Las relaciones conducen a la noción de dependencia. La dependencia tiene que ver con el hecho de que las propiedades y los cambios de algunos objetos matemáticos dependen de, o influyen en, las propiedades y los cambios de otros. A menudo, las relaciones matemáticas toman la forma de ecuaciones o desigualdades, pero también pueden aparecer relaciones de naturaleza más general.

La idea principal de cambio y relaciones hace uso del razonamiento funcional. Para los alumnos de 15 años esto conlleva tener una noción de tasa de cambio, de gradiente y de pendiente (aunque no necesariamente de manera formal) y de la dependencia de las variables entre sí. Deben poder realizar juicios sobre la velocidad a la que se producen los procesos, y también en términos relativos.

Esta idea principal está estrechamente relacionada con aspectos asociados a otras ideas principales. Un estudio de las regularidades en el ámbito de los números puede con- ducir al descubrimiento de relaciones sorprendentes: por ejemplo, el estudio de la sucesión de Fibonacci o del número áureo. El número áureo es un concepto que también desempeña un importante papel en geometría. En el ámbito de espacio y forma pueden hallarse muchos otros ejemplos de cambio y relaciones: por ejemplo, el crecimiento de un área en relación al crecimiento del perímetro o del diámetro. La geometría euclidiana también se presta al estudio de las relaciones. Un ejemplo conocido es la relación entre los tres lados de un triángulo. Si se conoce la longitud de dos lados, el tercero no está determinado, pero se conoce el intervalo en el que se encuentra: los extremos del intervalo son el valor absoluto de la diferencia entre los otros dos lados y de su suma, respectivamente. Entre los diversos elementos del triángulo se dan muchas otras relaciones similares.

El ámbito de la incertidumbre se presta a varios problemas que pueden observarse desde la perspectiva de la idea principal de cambio y relaciones. Si se lanzan 
dos dados y uno saca cuatro, ¿cuál es la posibilidad de que la suma de los dos sea más de siete? La respuesta (50\%) depende de la proporción de resultados poten- cialmente favorables en relación al conjunto de resultados posibles, por lo que se trata de una dependencia funcional.

\section{Ejemplos}

\section{Excursión escolar}

Una centro escolar quiere alquilar un autocar para ir de excursión y se ponen en contacto con tres empresas para informarse sobre los precios.

La Empresa A cobra una tasa inicial de 375 zeds y 0,5 zeds por kilómetro recorrido. La Empresa B cobra una tasa inicial de 250 zeds y 0,75 zeds por kilómetro recorrido. La Empresa C cobra una tasa fija de 350 zeds hasta 200 kilómetros y 1,02 zeds por kilómetro posterior a estos 200 km.

¿Qué empresa deberá elegir el centro si para ir de excursión tienen que recorrer una distancia total de entre 400 y $600 \mathrm{~km}$ ?

Aunque este contexto tiene elementos ficticios, este problema podría presentarse. Para resolverlo es preciso formular y aplicar diversas relaciones funcionales así como ecuaciones e inecuaciones. También puede resolverse a través de medios gráficos o algebraicos o de una combinación de ambos. La cuestión de que la distancia total de la excursión no está indicada con exactitud también introduce asociaciones con la idea principal de incertidumbre.

En la Figura 1.10. se muestra una representación gráfica del problema.

Figura 1.10 Tarifas de tres empresas de autocares para la excursión

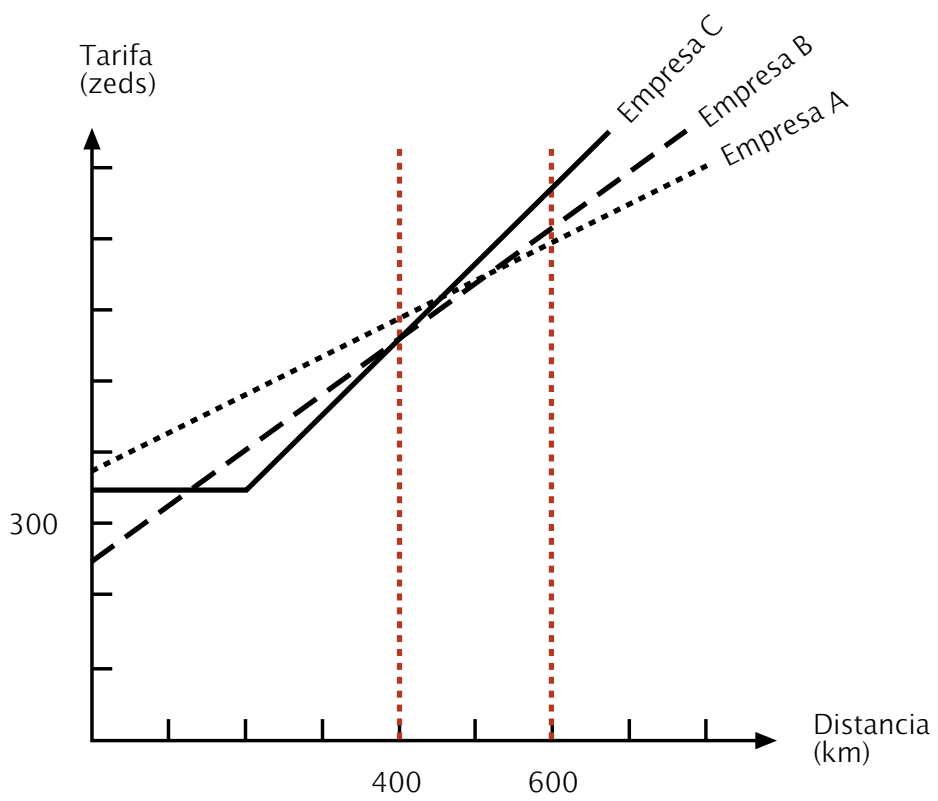




\section{Crecimiento celular}

Unos médicos están controlando la proliferación de células. Se interesan especialmente por el día en que el recuento alcance 60.000, porque es entonces cuando tienen que empezar un experimento. La tabla de resultados es la siguiente:

\begin{tabular}{l|l|l|l|l|l|l|l|l|l} 
Tiempo (días) & 4 & 6 & 8 & 10 & 12 & 14 & 16 & 18 & 20 \\
Células & 597 & 893 & 1.339 & 1.995 & 2.976 & 2.976 & 14.719 & 21.956 & 32.763
\end{tabular}

¿Cuándo llegará a 60.000 el número de células?

\section{Presa y depredador}

El gráfico siguiente muestra el crecimiento de dos organismos vivos: el paramecium y el saccharomyces:

Modelo presa y depredador

Paramecium

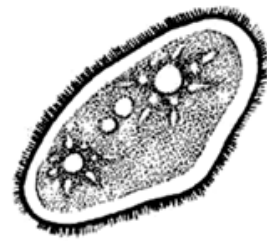

Saccharomyces
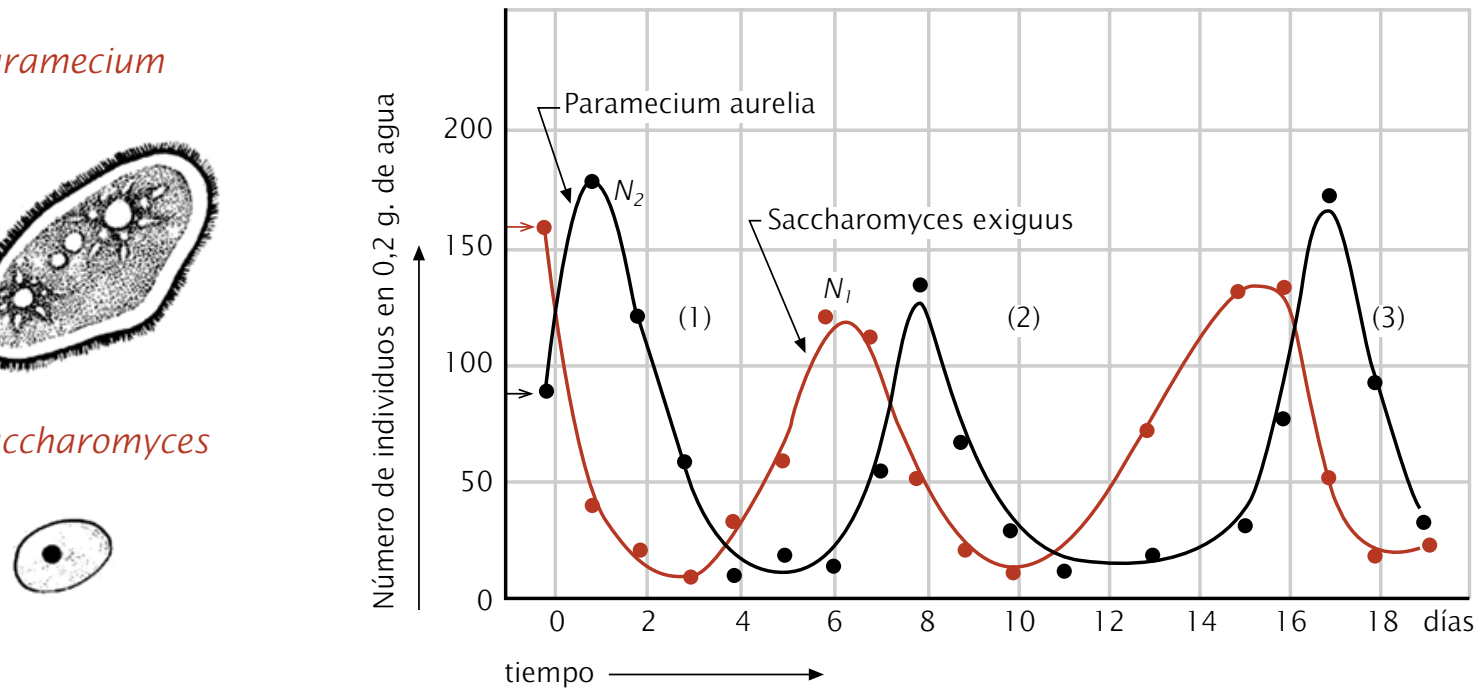

Uno de los dos seres (el depredador) se come al otro (la presa). A partir del gráfico, ¿puedes identificar quién es la presa y quién el depredador?

Una característica del fenómeno presa-depredador se define así: la tasa de crecimiento es proporcional a la cantidad de presa disponible. ¿Se aplica esta propiedad en el gráfico anterior? 


\section{INCERTIDUMBRE}

\section{Descripción}

La ciencia y la tecnología raramente tratan con hechos probados. Las ciencias se ocupan de intentar averiguar cómo funciona el mundo y el grado en que consiguen averiguarlo, del mismo modo que lo hace nuestra capacidad para describir con seguridad lo que ha ocurrido en el pasado y para predecir con precisión lo que es probable que suceda en el futuro. Sin embargo, el conocimiento científico rara vez es absoluto, eso sin contar las veces que se equivoca, de modo que siempre resta algo de incertidumbre incluso en las predicciones más científicas.

Las recomendaciones sobre el lugar que deben ocupar los datos, la estadística y la probabilidad en el currículum escolar hacen hincapié en el análisis de los datos. Como resultado de ello resulta fácil ver la estadística, en particular, como un conjunto de destrezas específicas. David S. Moore ha mostrado de qué trata realmente la idea de incertidumbre. La definición del proyecto OCDE/PISA se ajusta a sus ideas, aparecidas en On the Shoulders of Giants (Steen, 1990), y a las ideas de F. James Rutherford aparecidas en Why Numbers Count (Steen, 1997).

La capacidad para tratar de manera inteligente la variación y la incertidumbre es el objetivo de la formación sobre datos y azar. La variación es un concepto con el cual es difícil tratar: los niños que comienzan su aprendizaje la ortografía y la multiplicación piensan que el mundo es determinista; aprenden rápidamente a esperar que va a haber una respuesta correcta y que todas las demás son incorrectas, al menos cuando las respuestas tienen forma numérica. La variación es algo inesperado e incómodo.

La estadística aporta a la formación matemática algo importante y único: el razonamiento a partir de datos empíricos inciertos. Este tipo de pensamiento estadístico debería ser parte del equipamiento mental de todo ciudadano inteligente. Los elementos centrales son:

- la omnipresencia de la variación en los procesos;

- la necesidad de datos sobre procesos;
- el diseño de la elaboración de datos teniendo en cuenta la variación;

- la cuantificación de la variación;

- la explicación de la variación.

Los datos no son números únicamente, sino números en un contexto. De este modo, los datos movilizan nuestro conocimiento de su contexto para que podamos entenderlos e interpretarlos, en lugar de limitarnos a realizar meras operaciones aritméticas. La estadística no se enseña en los primeros cursos porque sí, sino porque es una manera efectiva de desarrollar el razonamiento y el entendimiento cuantitativos y de aplicar la aritmética y los gráficos a la solución de problemas.

La recogida de datos sobre asuntos importantes no es una tarea sencilla. En el estudio OCDE/PISA los datos deben ser interesantes, relevantes y prácticos y tener un significado para los estudiantes.

Los datos se obtienen a través de la medición de ciertas características, lo que significa que se representarán mediante un número. Reflexionar sobre las mediciones conduce a una comprensión madura de por qué algunos números resultan informativos y otros irrelevantes o absurdos. En primer lugar hay que definir qué se considera un modo válido de medición? Las longitudes son razonablemente sencillas: una regla servirá en muchos casos con un nivel de exactitud suficiente. Pero para las áreas puede plantearse un problema, puesto que incluso en las mediciones físicas entra en juego la incertidumbre. No sólo es importante el instrumento, sino también el grado de exactitud necesario y la variabilidad de las mediciones.

El diseño de los estudios de muestreo constituye un tema central de la estadística. El análisis de los datos se centra en la comprensión de los datos específicos disponibles asumiendo que éstos representan a una población más amplia. El concepto de muestras aleatorias simples es esencial para que los alumnos de 15 años entiendas las cuestiones relacionadas con la incertidumbre.

Un ejemplo conocido es el siguiente: 
En 1975, Ann Landers, una famosa columnista, preguntó a sus lectores;

"Si tuviera que pasar por ello otra vez, ¿tendría usted hijos?"

10.000 personas contestaron, de las cuales el 70\% dijo NO.

Se sabe que en las encuestas que son voluntarias, la mayoría de las respuestas proceden de la gente que tiene fuertes sentimientos (negativos) al respecto. Una muestra nacional aleatoria sobre la misma pregunta mostró que un 90\% de los padres volverían a tener hijos.

La esencia del análisis de datos es dejar que los datos «hablen por sí mismos»; buscar las regularidades sin pensar primero si los datos son representativos de un universo más amplio.

Los fenómenos tienen resultados particulares inciertos y, a menudo, la pauta de los resultados repetidos es aleatoria. Se ha demostrado que nuestra intuición del cambio contradice profundamente las leyes de la probabilidad (Garfield y Ahlgren, 1988; Tversky y Kahneman, 1974). Esto se debe en parte al contacto limitado que tienen los estudiantes con el azar. El estudio de los datos ofrece un escenario natural para obtener este tipo de experiencia. Esto explica por qué la prioridad del análisis de datos debería ser un principio importante para el aprendizaje y la enseñanza de la incertidumbre, por delante de la probabilidad y la deducción. Incluso en la universidad, muchos estudiantes no son capaces de entender la probabilidad y la deducción debido a ideas falsas preconcebidas que no se han subsanado mediante el estudio de las reglas formales. El concepto de probabilidad del presente estudio OCDE/PISA se basa generalmente en situaciones relativas a objetos relacionados con el azar, como monedas o dados, o en situaciones no demasiado complejas del mundo real que puedan analizarse de manera intuitiva o que puedan modelarse fácilmente con estos objetos.

\section{Ejemplos}

Los siguientes ejemplos ilustran la idea principal de incertidumbre.
La incertidumbre aparece también de fuentes como el cambio natural de la estatura de los estudiantes, la puntuación de lectura, los ingresos de un grupo de personas, etc. Un paso muy importante, incluso para los jóvenes de 15 años, es pasar a considerar el estudio de los datos y del azar como un todo coherente. Este principio comporta el avance de las ideas desde el simple análisis de datos a la recogida planificada de los datos, hasta llegar a la probabilidad y la inferencia.

Las actividades y conceptos matemáticos específicos que son importantes de esta área son los siguientes:

- Producción de datos: ¿Cuáles son los medios válidos para medir determinadas características? ¿Son los datos válidos para la utilización prevista? La actitud crítica desempeña un papel muy importante aquí al igual que el diseño del estudio estadístico.

- Análisis de datos y presentación/visualización de datos, representaciones gráficas de datos, descripciones numéricas como media y mediana.

- Probabilidad.

- La inferencia, que desempeña un papel menor para los estudiantes de este estudio porque el tratamiento formal y los métodos específicos se reservan normalmente para la educación secundaria más avanzada.

\section{Edad media}

Si el 40\% de la población de un país tiene al menos 60 años, ¿es posible que la media de edad sea de 30 años? 
¿Aumentan los ingresos?

¿Han subido o bajado los ingresos de los habitantes de Zedlandia en las últimas décadas? La media de ingresos por hogar ha descendido: en 1970 fue 34.200 zeds, en 1980 fue de 30.500 zeds y en 1990, de 31.200 zeds. Sin embargo, los ingresos por persona aumentaron: en 1970 fueron de 13.500 zeds, en 1980 fueron de 13.850 zeds y en 1990, de 15.777 zeds.

Una hogar consiste en todas las personas que viven juntas en una misma vivienda. Explica cómo es posible que los ingresos por hogar desciendan y que, al mismo tiempo, los ingresos por persona hayan crecido en Zedlandia.

\section{Aumento de la criminalidad}

El siguiente gráfico se ha extraído de la revista semanal de Zedlandia Las Noticias:

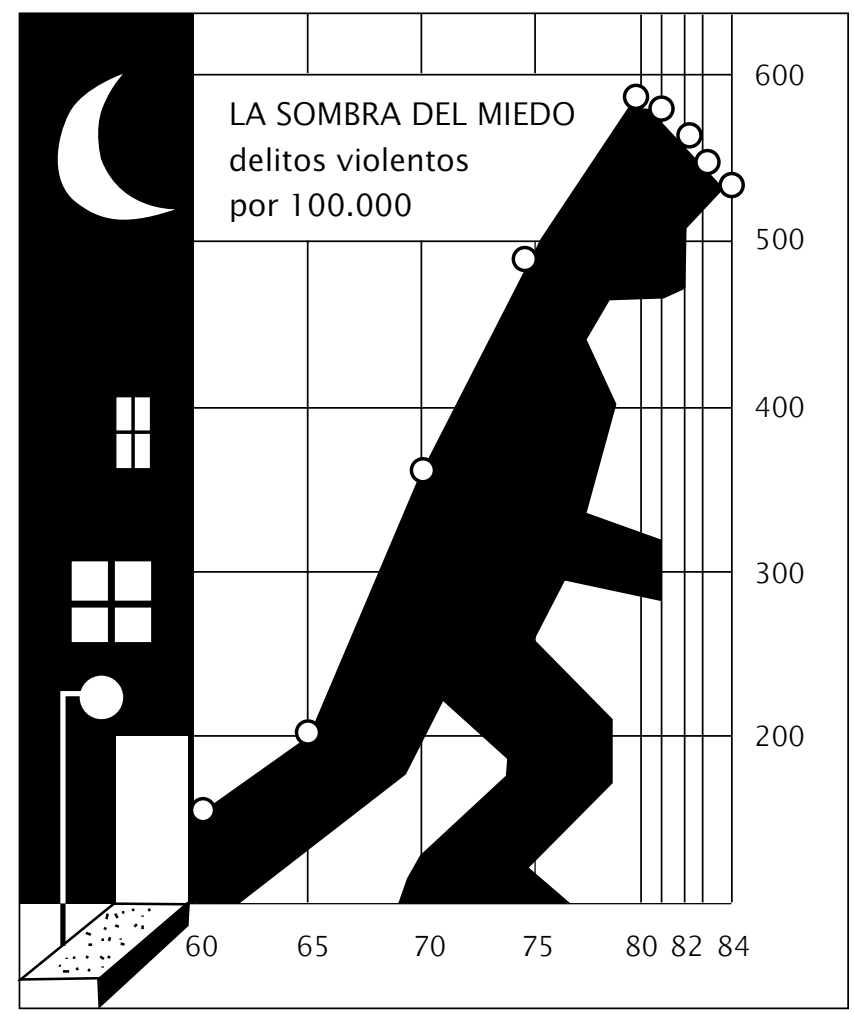

Muestra el número de delitos registrados por cada 100.000 habitantes comenzando por intervalos de cinco años y cambiando luego a intervalos de un año.

¿Cuántos delitos registrados por cada 100.000 habitantes hubo en 1960? 
Los fabricantes de sistemas de seguridad utilizaron estos mismos datos para elaborar el siguiente gráfico:

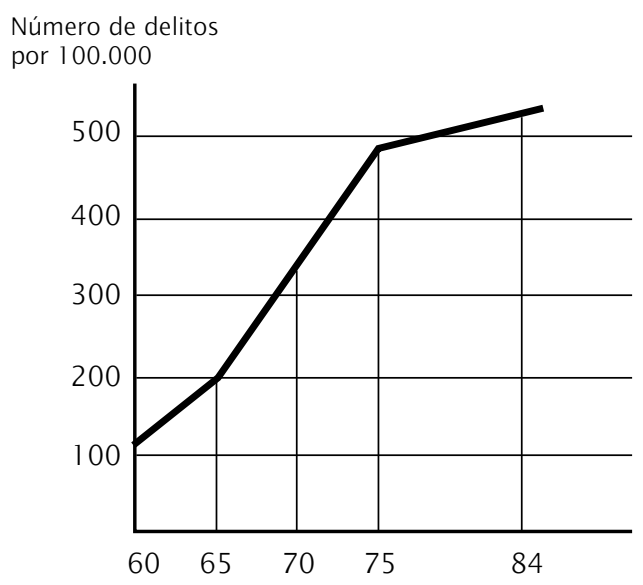

\section{¡El delito se triplica! \\ DETENGA \\ su crecimiento}

- COMPRE SISTEMAS DE ALARMA•

¿Cómo llegaron los diseñadores a elaborar este gráfico y por qué?

A la policía no le gustó el gráfico de los fabricantes de sistemas de seguridad porque la policía quería demostrar el éxito que había tenido en su lucha contra la delincuencia.

Diseña un gráfico que pueda usar la policía para demostrar que la delincuencia se ha reducido en los últimos tiempos. 


\section{ᄀ LECTURA}

\section{Definición del área de conocimiento}

Las definiciones de lectura y de competencia lectora han ido cambiando a lo largo del tiempo junto con los cambios sociales, económicos y culturales. El concepto de formación $y$, en concreto, el concepto de formación continua, han ampliado la forma de percibir la competencia lectora y sus exigencias. La competencia lectora ya no se considera una capacidad adquirida únicamente en la juventud, durante los primeros años de escolarización. Por el contrario, se ve como un conjunto en expansión de estrategias, destrezas y conocimientos que los individuos desarrollan a lo largo de la vida en diferentes situaciones y mediante la interacción con sus iguales y con las comunidades en que participan.

Mediante un proceso basado en el consenso en el que participaron expertos en lectura seleccionados por los países participantes y los grupos asesores del proyecto OCDE/PISA, se adoptó para este estudio la siguiente definición de competencia lectora:

«La competencia lectora consiste en la comprensión y el empleo de textos escritos y en la reflexión 
personal a partir de ellos con el fin de alcanzar las metas propias, desarrollar el conocimiento y el potencial personal y participar en la sociedad.»

Esta definición va más allá de la noción de competencia lectora como simple descodificación y comprensión literal e implica la comprensión y el uso de la información escrita, así como la reflexión sobre ella, para una gran variedad de fines. De este modo, la definición recalca el papel activo e interactivo del lector a la hora de generar un significado a partir de los textos escritos. Por otro lado, la definición reconoce la amplia gama de situaciones en que la competencia lectora resulta útil para los jóvenes, desde el ámbito privado al público, desde el ámbito académico al laboral y desde la participación activa en la sociedad a la formación continua. También incluye la idea de que la competencia lectora permite alcanzar las aspiraciones personales, incluyendo las aspiraciones definidas, como terminar una carrera o conseguir un empleo, y otras aspiraciones menos definidas $\mathrm{y}$ menos inmediatas que enriquecen y amplían el horizonte personal. La competencia lectora también proporciona al lector una serie de herramientas lingüísticas de creciente importancia para hacer frente a las exigencias de las sociedades modernas, con sus instituciones formales, sus grandes sistemas burocráticos y sus complejos sistemas legales.

Los lectores responden de diversas maneras a un texto dado cuando intentan utilizar y entender lo que están leyendo. En este proceso dinámico intervienen numerosos factores, algunos de los cuales son operativamente maleables dentro de un estudio de evaluación a gran escala como el proyecto OCDE/PISA. Entre ellos se cuentan la situación de lectura, la estructura del propio texto y las características de las preguntas que se plantean sobre el texto. Todos estos factores se consideran componentes importantes del proceso de lectura y se han tenido en cuenta en la creación de las preguntas usadas en la evaluación.

Para utilizar los formatos de texto, las situaciones y las características de las preguntas en la elaboración de los ejercicios y en la posterior interpretación de los resultados, ha habido que especificar los diversos valores que pueden adoptar estos factores. Esto permite clasificar los ejercicios en diversas categorías para poder tener en cuenta el peso de cada componente en el ensamblaje final de las pruebas.

\section{Formato del texto}

Uno los elementos centrales de la evaluación OCDE/PISA es la distinción entre textos continuos y discontinuos.

- Los textos continuos están normalmente formados por oraciones que, a su vez, se hallan organizadas en párrafos. Los párrafos pueden formar parte de estructuras mayores, como apartados, capítulos y libros. Los textos continuos se clasifican primordialmente por su objetivo retórico, es decir por el tipo de texto.

- Los textos discontinuos (o documentos, como también se les conoce) pueden clasificarse de dos maneras. Por un lado está el enfoque basado en la estructura formal utilizado en el trabajo de Kirsch y Mosenthal (1989-1991) que clasifica los textos por la forma en que se organizan las listas subyacentes en la elaboración de los distintos tipos de textos dis continuos. Este enfoque es útil para entender las similitudes y diferencias entre los tipos de texto discontinuo. El otro método de clasificación se basa en las descripciones habituales del formato de los textos. Este segundo enfoque es el empleado en la clasificación de textos discontinuos del proyecto OCDE/PISA.

\section{TEXTOS CONTINUOS}

Los tipos de texto son clasificaciones normalizadas de los textos continuos, basadas en los contenidos o en la intención del autor.

- La narración es el tipo de texto en el que la información hace referencia a propiedades temporales de los objetos. Los textos narrativos suelen responder a las preguntas «icuándo?»o «ien qué orden?».

- La exposición es el tipo de texto en el que la información se presenta en forma de conceptos compuestos o constructos mentales, es decir de aquellos elementos en los que se pueden analizar las concepciones o construcciones mentales. Estos textos ofrecen una explicación sobre cómo se interrelacionan los componentes en un conjunto significativo y suelen responder a la pregunta «icómo?». 
- La descripción es el tipo de texto en el que la información hace referencia a las propiedades de los objetos en el espacio. Los textos descriptivos suelen responder a la pregunta «iqué?».

- La argumentación es el tipo de texto que presenta proposiciones que tratan de relaciones entre conceptos o entre otras proposiciones. Los textos argumentativos suelen responder a la pregunta «ipor qué?». Una importante categoría dependiente de los textos argumentativos son los textos persuasivos.

- La instrucción (que a veces se denomina mandato) es el tipo de texto que aporta indicaciones sobre lo que hay que hacer y puede consistir en procedimientos, reglas, normas y directivas que especifican los requisitos de ciertos comportamientos.

- Un documento, o registro, es un texto que ha sido diseñado para estandarizar y conservar la información. Se caracteriza por unos rasgos textuales y de formato altamente formalizados.

- Un hipertexto es una serie de fragmentos de texto unidos de modo que las unidades puedan ser leídas en diferente orden, lo que permite que los lectores sigan distintos recorridos para acceder a la información.

\section{TEXTOS DISCONTINUOS}

Los textos discontinuos se organizan de un modo distinto al de los textos continuos y por ello requieren distintos enfoques de lectura. En el trabajo de Kirsch y Mosenthal (1989-1991), el lector encontrará una descripción del enfoque estructural. Según este trabajo, las listas son los textos discontinuos más elementales. Las listas constan de cierto número de elementos que comparten una o varias propiedades. La propiedad compartida se puede usar como etiqueta o título de la lista. Las listas pueden tener sus elementos ordenados (p. ej., los nombres de los alumnos de una clase, ordenados alfabéticamente) o desordenados (p. ej., una lista de la compra).

La clasificación de textos discontinuos por el formato, como se ha indicado, ofrece una perspectiva conocida para describir los tipos de textos discontinuos que se pueden incluir en la evaluación.

- Los cuadros y gráficos son representaciones icónicas de datos. Se emplean en la argumentación científica y también en periódicos y revisas para mostrar información de tipo numérico y tabular en un formato visual.

- Las tablas y matrices. Las tablas son matrices formadas por filas y columnas. Normalmente, las entradas de cada columna y cada fila comparten algunas propiedades y, por ello, las etiquetas de la columna y de la fila forman parte de la estructura de información del texto. Algunos ejemplos de tablas son los horarios, las hojas de cálculo, los formularios de pedidos y los índices.

- Las ilustraciones suelen acompañar a las descripciones técnicas (p. ej., para identificar visualmente las piezas de un electrodoméstico), a los textos expositivos y a las instrucciones (p. ej., para mostrar cómo se instala un electrodoméstico). Es útil efectuar una distinción entre ilustraciones de procedimiento (cómo hacer algo) y de proceso (cómo funciona algo).

- Los mapas son textos discontinuos que indican las relaciones geográficas entre lugares. Existen muchos tipos de mapas, como los mapas de carreteras, que marcan las distancias y vías de comunicación existentes entre lugares concretos, o los mapas temáticos, que indican las relaciones existentes entre lugares y carac terísticas sociales o físicas.

- Los formularios son textos con una estructura y formato específicos, que requieren que el lector responda de determinada manera a preguntas concretas. Los formularios se emplean en numerosas organizaciones para recopilar datos y suelen contener formatos de respuesta estructurados o precodificados. Algunos ejemplos típicos de este tipo de textos son los impresos para las declaraciones de Hacienda, los formularios de inmigración, los formularios de visado o de solicitud, los cuestionarios estadísticos, etc.

- Las hojas informativas, al contrario que los formularios, ofrecen información en lugar de solicitarla. Presentan la información de forma resumida y estructurada, con 
un formato pensado para que el lector pueda encontrar fácil y rápidamente datos específicos. Las hojas informativas pueden contener varias disposiciones del texto, junto con listas, tablas, cifras y características de formato complejas (encabezados, fuentes, sangría, márgenes, etc.), para resumir y destacar la información. Los horarios, listas de precios, catálogos y programas son ejemplos de este tipo de texto discontinuo.

- Los avisos y anuncios son documentos diseñados para invitar al lector a hacer algo, p. ej., adquirir bienes o servicios, asistir a encuentros o reuniones, elegir un candidato para un cargo público, etc. La intención de estos documentos es persuadir al lector. Ofrecen algo y requieren tanto la atención como la acción del lector. Entre los documentos con este tipo de formato se encuentran los anuncios, invitaciones, convocatorias, advertencias y notas.

- Los vales y cupones certifican que su propietario tiene derecho a ciertos servicios. La información que contienen debe ser suficiente para mostrar si el compro- bante es válido o no. Entre los textos de este tipo se encuentran los tickets, facturas, etc.

- Los certificados son reconocimientos escritos de la validez de un acuerdo o contrato. Su formalización atañe más al contenido que al formato. Normalmente requieren la firma de una o más personas autorizadas y con competencia para atestiguar la veracidad de lo que se declara. Las garantías, expedientes académicos, diplomas, contratos, etc. son documentos que presentan estas propiedades.

La distribución y variedad de los textos que los estudiantes deben leer para el proyecto OCDE/PISA constituyen características importantes de esta evaluación. El Cuadro 2.1 muestra la distribución de los ejercicios con textos continuos y discontinuos en el ciclo PISA 2000 (en el que la lectura era el área principal) y en el ciclo PISA 2003 (en el que la lectura será un área secundaria). Como se puede comprobar, tanto en el ciclo 2000 como en el 2003, los textos continuos representan dos tercios de los ejercicios o preguntas incluidos en la evaluación. Dentro de esta categoría, en los dos ciclos, el porcentaje mayor corresponde a los textos expositivos.

Cuadro 2.1. Distribución de los ejercicios de lectura según el formato y el tipo de texto

Formato y tipo de texto

Continuo
Narrativo
Expositivo
Descriptivo
Argumentativo/Persuasivo
Instruccional
TOTAL' (Textos continuos)
Discontinuo
Diagramas y gráficos
Tablas
Esquemas
Mapas
Formularios
Anuncios
TOTAL' (Textos discontinuos)

- Continuo

Narrativo

Argumentativo/Persuasivo

Instruccional

A

\section{Discontinuo}

Tablas

Esquemas

Formularios

TOTAL' (Textos discontinuos)

1) Las sumas no son exactas por causa de los redondeos.
$\%$ de ejercicios

por formato $y$ tipo de texto

\begin{tabular}{|r|r|}
\hline 21 & 17 \\
\hline 36 & 67 \\
14 & 17 \\
20 & - \\
10 & - \\
100 & 100 \\
\hline & \\
\hline 37 & \\
29 & 20 \\
12 & 40 \\
10 & - \\
10 & 10 \\
2 & 30 \\
100 & - \\
\hline
\end{tabular}

Lectura como área principal (PISA 2000)

Lectura como área secundaria (PISA 2003)
$\%$ de ejercicios por formato y tipo de texto en relación al total de la prueba 


\section{Características de las preguntas}

Se emplean tres conjuntos de variables para describir las características de las preguntas: los procesos (aspectos) de lectura, que describen el ejercicio que debe realizar el alumno; los tipos de pregunta, que establecen la manera en que los alumnos deben demostrar su competencia con el ejercicio; y los criterios de corrección, que especifican la forma en que deben valorarse las respuestas de los estudiantes. Se describirán a continuación cada uno de estos conjuntos de variables, aunque el primero exige una consideración más extensa.

\section{CINCO PROCESOS (ASPECTOS)}

En un intento de propiciar situaciones de lectura auténticas, la evaluación de la lectura del proyecto OCDE/PISA mide los siguientes cinco aspectos de la lectura, necesarios para asegurar la plena comprensión de un texto, sea continuo o discontinuo. Los estudiantes deben demostrar su competencia en todos los procesos siguientes:

- extracción de información;

- desarrollo de una comprensión general amplia;

- desarrollo de una interpretación;

- reflexión sobre el contenido de un texto y valoración del mismo;

- reflexión sobre la forma de un texto y valoración de la misma.

La comprensión plena de los textos implica todos estos procesos. Se espera que todos los lectores, independientemente de su competencia global, sean capaces de demostrar cierto grado de capacidad en cada uno de ellos (Langer,
1995). Si bien existe una interrelación entre los cinco aspectos — cada uno exige aproximadamente las mismas destrezas básicas-, el hecho de lograr dominar uno de ellos no garantiza que se dominen los demás. Algunos consideran que estos aspectos forman parte del repertorio de todo lector en cada etapa de su desarrollo, y no de una jerarquía ordenada o un conjunto secuencial de destrezas.

El Cuadro 2.2 identifica las principales características distintivas de los cinco procesos de lectura medidos en el proyecto OCDE/PISA. Aunque el cuadro simplifica inevitablemente cada uno de los procesos, ofrece un esquema útil para organizar y describir las relaciones existentes entre ellos. Según se aprecia en el cuadro, los cinco procesos se pueden diferenciar a partir de cuatro características. La primera depende de si el lector se limita a usar información extraída del propio texto o bien debe recurrir a algún tipo de conocimiento externo. Una segunda característica tiene que ver con el hecho de que el lector se centre en partes independientes del texto o bien recurra a las relaciones entre la información contenida en el texto. A veces se espera que los lectores busquen datos importantes mientras que, en otras ocasiones, se les pide que demuestren su comprensión de las relaciones existentes entre los apartados del texto. La tercera característica distintiva depende de si el lector se centra en el texto como conjunto o en las relaciones entre sus partes. La cuarta característica depende de que el lector deba trabajar con el contenido básico del texto o bien con su estructura. Los cinco procesos de lectura se representan en la última línea del Cuadro 2.2, en los extremos de las ramas. Empezando en la parte superior del cuadro y a lo largo de cada rama, se muestran las características asociadas con cada proceso. 
Cuadro 2.2. Características distintivas de los cinco procesos (aspectos) de la lectura

\section{Competencia lectora}

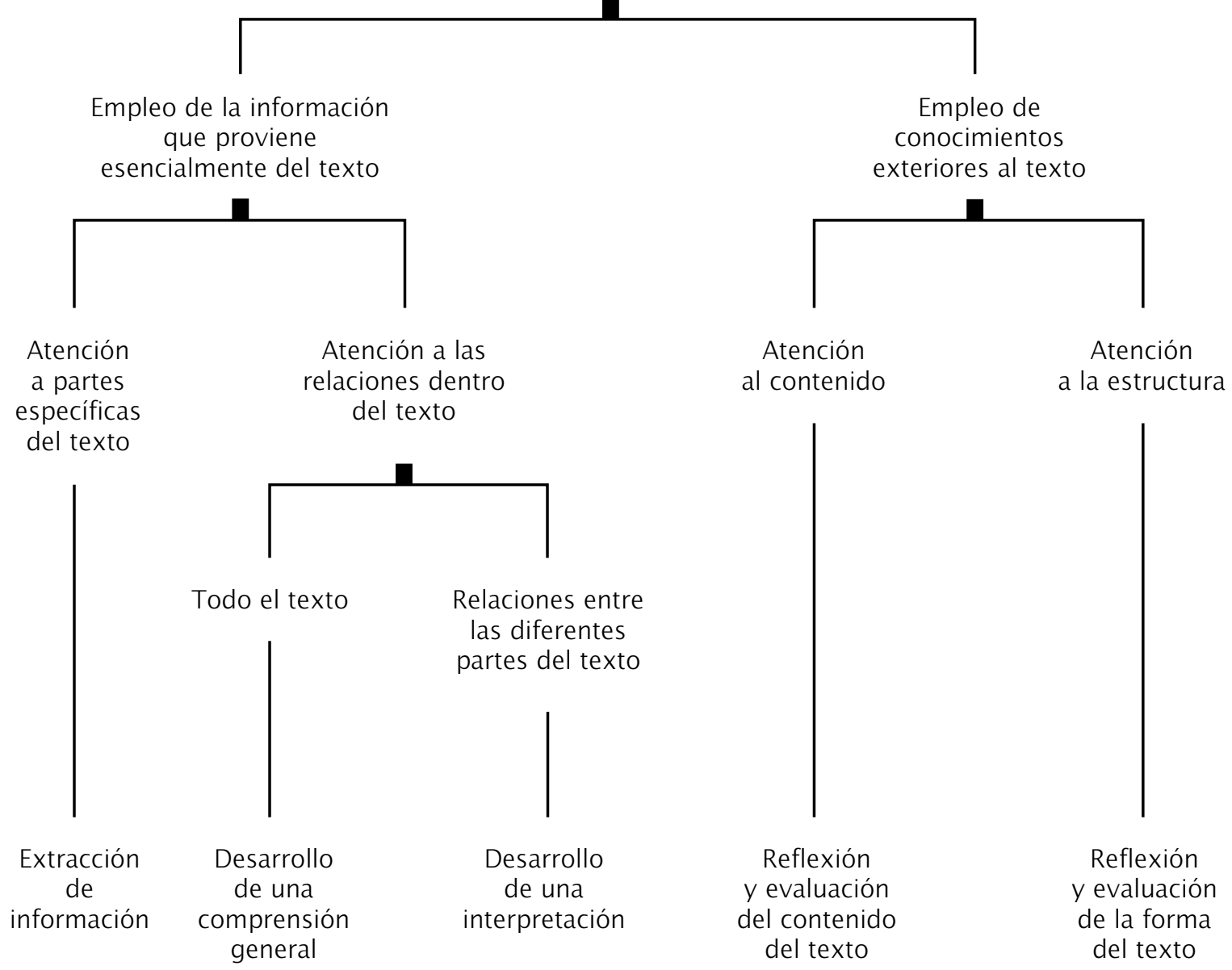

La siguiente descripción trata de definir los procesos de forma operativa y relacionarlo con ciertos tipos de pregunta. Aunque cada proceso se describe partiendo de un solo texto, puede aplicarse también a múltiples textos cuando constituyen una única unidad en el seno de la prueba. La descripción de cada proceso consta de dos partes. La primera ofrece una visión general, mientras que la segunda describe la forma concreta en que puede evaluarse el proceso.

\section{Extracción de información}

En el curso de la vida diaria, es habitual que los lectores necesiten una información concreta, como un número de teléfono o el horario de salida de un autobús o de un tren. También pueden estar buscando un hecho concreto que apoye o refute una afirmación de otra persona. En situaciones como éstas, a los lectores les interesa poder encontrar datos aislados. Para ello, deben analizar el texto buscando, localizando y seleccionando la información relevante. La 
mayoría de las veces, lo que se procesa implícitamente son las oraciones, aunque, en algunos casos, la información puede encontrarse en dos o más oraciones o en distintos párrafos.

En los ejercicios de la evaluación que requieren buscar información, el alumno debe comparar la información aportada en la pregunta con la información que se expresa en el texto con las mismas palabras o con sinónimos, y debe partir de ésta para obtener la nueva información que se le pide. En estos ejercicios, la extracción de información se basa en el propio texto y en la información explicitada en el mismo. Los ejercicios de extracción de información requieren que el alumno localice datos a partir de las restricciones o características detalladas en las preguntas. El alumno tiene que detectar o identificar uno o más elementos esenciales de una pregunta: personajes, lugar/tiempo, escenario, etc. Y, posteriormente, buscar un fragmento de texto literal o sinónimo.

Los ejercicios de extracción de información pueden implicar varios grados de ambigüedad. Por ejemplo, puede que se solicite al estudiante que seleccione información explícita, como una indicación temporal o espacial en un texto o tabla. Una versión más difícil de este mismo tipo de ejercicio puede implicar la búsqueda de información expresada mediante sinónimos. Ello puede implicar el uso de destrezas de clasificación, o bien puede exigir que el alumno sepa diferenciar entre dos datos similares. Los distintos niveles de capacidad asociados al proceso pueden medirse variando sistemáticamente los elementos que determinan la dificultad del ejercicio.

\section{Desarrollo de una comprensión general}

Para desarrollar una comprensión general de lo que se ha leído, el lector debe considerar el texto como un conjunto o bien observarlo desde una perspectiva global. Hay varios ejercicios de evaluación en los que los lectores deben desarrollar una comprensión general. Puede que se pida a los alumnos que demuestren su comprensión inicial identificando el tema principal o mensaje del texto, o bien su intención o uso general. Por ejemplo, algunos ejercicios exigen que el lector seleccione o idee un título o tema para el texto, que explique el orden de unas instrucciones sencillas o que identifique las dimensiones principales de un gráfico o tabla. Otros ejercicios exigen que el alumno examine o describa al personaje principal, la situación o el ambiente de una historia, que identifique un tema o un mensaje en un texto literario o que explique la intención o el uso de un mapa o de un cuadro.

En relación con este proceso, algunos ejercicios pueden exigir que el alumno compare determinados elementos del texto con la pregunta. Por ejemplo, se plantea esta exigencia cuando el tema o la idea principal aparecen explicitados en el texto. Otros ejercicios pueden exigir que el alumno se centre en más de una referencia concreta del texto: por ejemplo cuando el lector tiene que deducir el tema a partir de la repetición de cierta categoría de información. Seleccionar la idea principal implica establecer una jerarquía de ideas y elegir la más general y la más dominante. Este tipo de ejercicio indica si el alumno es capaz de distinguir entre las ideas principales y los detalles secundarios o si es capaz de reconocer el resumen de un tema principal en una frase o título.

\section{Desarrollo de una interpretación}

El desarrollo de una interpretación exige que los lectores amplíen sus impresiones iniciales para desarrollar una comprensión más específica o completa sobre lo leído. Los ejercicios de esta categoría exigen desarrollar una comprensión lógica, ya que los lectores deben procesar la organización de la información en el texto. Para ello, los lectores deben demostrar que han entendido la cohesión del texto, aunque no puedan explicitar en qué consiste. En algunos casos, el desarrollo de una interpretación puede requerir que el lector procese una secuencia de sólo dos oraciones dotadas de cohesión, lo cual puede facilitarse todavía más con la presencia de marcas de cohesión, como el uso de en primer lugar y en segundo lugar para indicar una secuencia. En casos más difíciles, (p. ej., para indicar las relaciones de causa y efecto), puede que no existan marcas específicas.

Algunos de los ejercicios que pueden usarse para evaluar este proceso implican, entre otras cosas, comparar y contrastar información, deducir inferencias e identificar y relacionar pruebas. Los ejercicios consistentes en "comparar y contrastar" exigen que el alumno obtenga dos o más datos a partir del texto. En este tipo de ejercicios, para procesar la información explícita o implícita procedente de una o 
más fuentes, el lector suele tener que inferir una relación o categoría determinadas. Este proceso interpretativo se evalúa también en otros ejercicios donde se exige que el alumno infiera la intención del autor y que identifique las pruebas que apoyan su deducción.

\section{Reflexión sobre el contenido} de un texto y valoración del mismo

La reflexión sobre el contenido de un texto exige que el lector relacione la información contenida en él con conocimientos procedentes de otras fuentes. Además, los lectores deben contrastar las afirmaciones del texto con su propio conocimiento del mundo. A menudo se pide a los lectores que articulen y defiendan su propio punto de vista. Para ello, los lectores deben ser capaces de desarrollar una comprensión de lo que se ha dicho y de lo que se pretende decir con el texto. Acto seguido deben contrastar su representación mental con lo que saben y creen partiendo bien de informaciones previas o bien de informaciones localizadas en otros textos. Los lectores deben basarse en las pruebas contenidas en el texto y contrastarlas con otras fuentes de información recurriendo a conocimientos generales y especializados, así como a su capacidad para llevar a cabo razonamientos abstractos.

Los ejercicios que evalúan este tipo de proceso implican, entre otras cosas, aportar pruebas o argumentos externos al texto, valorar la importancia de determinados datos o pruebas o establecer comparaciones con reglas morales o estéticas (normas). Es posible que se pida al alumno que proporcione o identifique datos alternativos que puedan reforzar un argumento del autor, o que evalúe la suficiencia de las pruebas o datos contenidos en el texto.

Los conocimientos externos con los que se debe relacionar la información textual pueden proceder del propio conocimiento del estudiante, de otros textos facilitados en la evaluación o de las ideas explicitadas en la pregunta.

\section{Reflexión sobre la forma}

de un texto y valoración de la misma

Los ejercicios de esta categoría exigen que los lectores se distancien del texto, lo consideren objetivamente y valoren su calidad y adecuación. El conocimiento de elementos tales como la estructura textual, el género o el registro del texto tiene un papel importante en estos ejercicios. Estas características, que forman la base del oficio de un autor, tienen una importancia esencial para comprender los estándares inherentes a tareas de esta naturaleza. Analizar si un autor ha logrado retratar con éxito algunas características o convencer al lector sobre su punto de vista no requiere sólo un conocimiento sustantivo, sino también cierta capacidad para detectar matices lingüisticos: por ejemplo, hay que captar cuándo la elección de un adjetivo puede influir en una interpretación.

Cuadro 2.3. Distribución de los ejercicios según los procesos (aspectos) de la lectura

Proceso de lectura (aspecto)

\begin{tabular}{lcc}
\hline & $\begin{array}{c}\text { Como área principal } \\
\text { (PISA 2000) }\end{array}$ & $\begin{array}{c}\text { Como área secundaria } \\
\text { (PISA 2003 y 2006) }\end{array}$ \\
Extracción de la información & 29 & 29 \\
Interpretación de los textos & 49 & 50 \\
Reflexión y evaluación & 22 & 21 \\
TOTAL & 100 & 100
\end{tabular}


Algunos de los ejercicios que evalúan la capacidad para reflexionar sobre la forma de los textos pueden exigir que se determine la utilidad de un texto o el uso que hace un autor de determinadas características textuales para conseguir un propósito concreto. También pueden pedir al alumno que describa o comente el estilo del autor o que identifique su intención o su actitud.

El Cuadro 2.3 muestra la distribución de los ejercicios de lectura según los cinco procesos (aspectos) de la lectura definidos más arriba. La categoría más extensa, con aproximadamente el $50 \%$ de los ejercicios, se corresponde con las dos ramas del Cuadro 2.2 que piden a los estudiantes concentrarse en las relaciones internas de un texto. Estos ejercicios exigen a los estudiantes que desarrollen una comprensión global o una interpretación. A efectos de presentación de la información, se han agrupado en un solo proceso denominado "interpretación de textos". En los ciclos PISA 2000 y PISA 2003, la siguiente categoría en extensión está compuesta por el 29\% de los ejercicios, donde se requiere que los estudiantes demuestren su capacidad para recuperar datos aislados. Todos estos pro- cesos — desarrollar una comprensión global, extraer una información y desarrollar una interpretación- tratan de medir si el lector es capaz de entender y de utilizar informaciones contenidas en el texto. Los ejercicios restantes, que corresponden aproximadamente al $20 \%$, piden a los estudiantes que reflexionen sobre el contenido o la información inserta en el texto o sobre la estructura y forma del propio texto.

\section{TIPOS DE PREGUNTA}

El Cuadro 2.4 muestra que, en los ciclos PISA 2000 y 2003, aproximadamente el $43 \%$ de los ejercicios de lectura correspondían a preguntas de respuesta construida abierta que exigían cierto trabajo de valoración por parte del corrector. El resto de los ejercicios consistía en preguntas de respuesta construida cerrada que el corrector podía puntuar más fácilmente, así como en preguntas de elección múltiple sencilla, donde los alumnos eligen una entre varias respuestas alternativas, y preguntas de elección múltiple compleja, en las que el estudiante elige más de una respuesta.

Cuadro 2.4. Distribución de los ejercicios de lectura según proceso (aspecto) y tipo de pregunta

Proceso (aspecto)

\begin{tabular}{|c|c|c|c|c|c|c|c|c|}
\hline & \multicolumn{2}{|c|}{$\begin{array}{c}\text { \% de preguntas } \\
\text { de elección } \\
\text { múltiple }\end{array}$} & \multicolumn{2}{|c|}{$\begin{array}{l}\text { \% de preguntas } \\
\text { complejas de } \\
\text { elección múltiple }\end{array}$} & \multicolumn{2}{|c|}{$\begin{array}{l}\% \text { de preguntas } \\
\text { construidas } \\
\text { cerradas }\end{array}$} & \multicolumn{2}{|c|}{$\begin{array}{c}\% \text { de preguntas } \\
\text { construidas } \\
\text { abiertas }^{1}\end{array}$} \\
\hline Recuperación de información & 8 & & 2 & 4 & 6 & 14 & 13 & 11 \\
\hline Interpretación de los textos & 32 & 29 & 2 & 4 & 2 & 7 & 13 & 11 \\
\hline Reflexión y evaluación & 2 & & 2 & & & & 18 & 21 \\
\hline TOTAL ${ }^{2}$ & 42 & 29 & 6 & 7 & 9 & 21 & 44 & 43 \\
\hline \multicolumn{9}{|c|}{ Lectura como área principal (PISA 2000) } \\
\hline \multicolumn{9}{|c|}{ Lectura como área secundaria (PISA 2003) } \\
\hline
\end{tabular}

1. Esta categoría incluye preguntas de respuesta concisa

2. Los datos pueden no sumar exactamente el total indicado debido al redondeo.

\section{Tipos de pregunta}

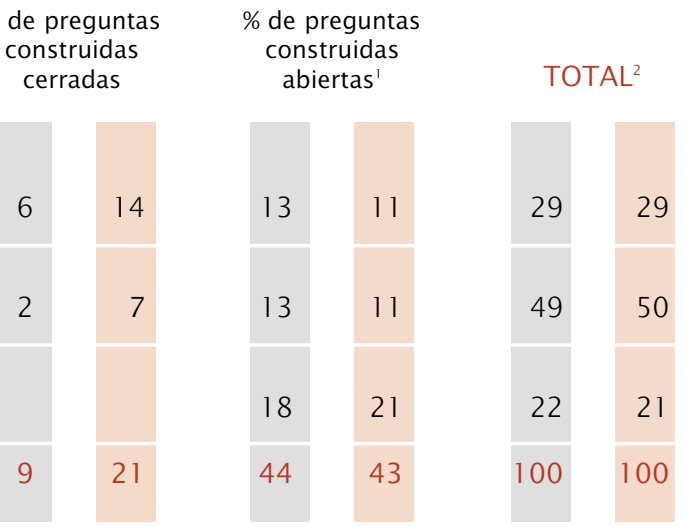


Este cuadro revela también que, si bien las preguntas de elección múltiple y las de respuesta construida abierta están representadas en todos los procesos, no siguen una distribución uniforme. Hay un porcentaje mayor de preguntas de elección múltiple asociado a los dos procesos que tienen que ver con la interpretación de las relaciones existentes en un texto, como se aprecia en la segunda fila del Cuadro 2.4. Por el contrario, si bien los ejercicios de reflexión y valoración corresponden aproximadamente al 20\% de los utilizados en los ciclos PISA 2000 y 2003, sólo el 2\% son preguntas de elección múltiple en la evaluación del 2000. De los ejercicios de reflexión y valoración, un $20 \%$ aproximadamente son preguntas de respuesta construida abierta que requieren cierto trabajo de valoración por parte del corrector.

\section{LA PUNTUACIÓN}

La puntuación es relativamente sencilla en las preguntas de elección múltiple, puntuadas de modo dicotómico: el alumno ha elegido la respuesta correcta o no. Los modelos de puntuación parcial permiten efectuar una corrección más matizada de las preguntas. Como algunas de las respuestas incorrectas son más completas que otras, los alumnos que dan una respuesta "casi correcta" obtienen una puntuación parcial. Los modelos psicométricos de este tipo de puntuación politómica están contrastados y en algunos sentidos son preferibles a una puntuación dicotómica, ya que utilizan en mayor medida la información de las respuestas. Sin embargo, la interpretación de la puntación parcial es más compleja, ya que cada ejercicio ocupa más de una posición en la escala de dificultad: una para la respuesta totalmente correcta y otras para cada una de las respuestas parcialmente correctas. La puntuación parcial se emplea en algunas de las preguntas de respuesta construida más compleja.

\section{Situaciones}

La manera en que se define la situación procede del trabajo del Consejo de Europa (2001) sobre el lenguaje. Se identifican cuatro variables de situación: la lectura para uso personal, la lectura para uso público, la lectura para uso laboral y la lectura para uso educativo. Como la evaluación de la competencia lectora del proyecto
OCDE/PISA pretende medir aquellos tipos de lectura que se dan tanto den-tro como fuera de las aulas, la forma en que se define la situación no puede basarse simplemente en el lugar donde se lleva a cabo la lectura. Por ejemplo, los libros de texto se leen tanto en los centros educativos como en los hogares, pero tanto el proceso como el propósito de la lectura de estos textos difiere ligeramente de un escenario al otro. Además, la lectura también se ve afectada por la utilidad pretendida por el autor, por los distintos tipos de contenido y por el hecho de que otras personas (p. ej., profesores o patrones) deciden a veces qué se debe leer y con qué objetivo.

Por ello, para el objeto de esta evaluación, la situación puede entenderse como una clasificación general de los textos basada en la utilidad pretendida por el autor, en la relación con otras personas relacionadas implícita o explícitamente con el texto y en el contenido general. Los textos de ejemplo se han extraído de una serie de situaciones diferentes para maximizar la diversidad de contenidos incluidos en la evaluación de la competencia lectora. Así mismo se ha prestado una especial atención al origen de los textos seleccionados. El objetivo ha sido conseguir un equilibrio entre la definición global de competencia lectora utilizada en el proyecto OCDE/PISA y la diversidad lingüística y cultural de los países participantes. Esta diversidad contribuye a garantizar que ningún grupo se encuentre en ventaja o en desventaja en relación al contenido evaluado.

Las cuatro variables de situación tomadas del trabajo del Consejo de Europa pueden describirse de la forma que sigue:

- Lectura para uso personal (particular): Este tipo de lectura se lleva a cabo para satisfacer los propios intereses, tanto prácticos como intelectuales. Se incluye la lectura realizada para mantener o desarrollar víncu los personales con otras personas. Los contenidos suelen incluir cartas personales, narraciones de ficción, biografías o textos informativos leídos por curiosidad, como parte de una actividad de ocio o recreo.

- Lectura para uso público. Este tipo de lectura se lleva a cabo para participar en actividades sociales más 
amplias. Incluye el uso de documentos oficiales e informativos sobre acontecimientos públicos. En general, estos ejercicios están asociados con un contacto más o menos anónimo con otras personas.

- Lectura para uso laboral (profesional). Aunque sólo algunos de los jóvenes que ahora tienen 15 años tienen que emplear la lectura para un uso laboral, es importante evaluar su aptitud para introducirse en el mundo del trabajo ya que, en la mayor parte de los países, más del $50 \%$ de los jóvenes de 15 años se integrará en la población activa en un plazo de uno o dos años. Se suele hacer referencia a la actividad típica de esta modalidad como "lectura para actuar" (Sticht, 1975; Stiggins, 1982), ya que tiene relación con el cumplimiento de determinada tareas.
- Lectura para uso educativo. Este tipo de lectura suele estar relacionado con la adquisición de información dentro de una tarea de aprendizaje más amplia. No suele ser el alumno quien elige los materiales, sino que los impone un profesor. El contenido suele estar diseñado específicamente para el objeto de la instrucción. Se suele hacer referencia a la actividad típica de esta modalidad como "lectura para aprender" (Sticht, 1975; Stiggins, 1982).

El Cuadro 2.5 muestra la distribución de los ejercicios de lectura en la evaluación teniendo en cuenta las cuatro situaciones según que la lectura sea era el área principal de evaluación (PISA 2000) o un área secundaria (PISA 2003). La distribución de ejercicios entre las situaciones es más homogénea en el ciclo de 2003.

\section{Cuadro 2.5. Distribución de los ejercicios de lectura según la situación}

\begin{tabular}{lcc} 
Situación & \multicolumn{2}{c}{ Porcentaje de ejercicios } \\
\hline & $\begin{array}{c}\text { Como área principal } \\
\text { (PISA 2000) }\end{array}$ & $\begin{array}{c}\text { Como área secundaria } \\
\text { (PISA 2003) }\end{array}$ \\
Personal & 20 & 21 \\
Pública & 38 & 25 \\
Laboral & 14 & 25 \\
Educativa & 28 & 29 \\
TOTAL & 100 & 100
\end{tabular}

\section{Presentación de los resultados}

\section{ESCALAS PARA LOS EJERCICIOS DE LECTURA}

Para garantizar la cobertura más amplia posible de la competencia lectora tal como ha sido definida en este texto, los ejercicios de lectura se aplican a muestras re-presentativas de los estudiantes de 15 años de los países participantes. Sin embargo, ningún estudiante deberá responder a todo el conjunto de ejercicios. El estudio ha sido diseñado para que cada uno de los alumnos participantes responda a un determinado subconjunto del total de ejercicios procurando al mismo tiempo que cada uno de los ejercicios se aplique a muestras nacionalmente representativas de los estudiantes. Sintetizar la competencia de los estudiantes en todo el conjunto de ejercicios posibles plantea, pues, una cierta dificultad.

Podemos imaginar que los ejercicios de lectura se distribuyen a lo largo de un continuum, según la dificultad que plantean a los estudiantes y el nivel de destreza necesario para contestar correctamente a cada pregunta. El procedimiento utilizado por OCDE/PISA para reflejar este continuum de dificultad y destreza es la TRI, Teoría de Respuesta al Item (Item Response Theory). La TRI es un 
modelo matemático que se emplea para calcular la probabilidad de que una persona responda correctamente a un ejercicio determinado dentro de un grupo concreto de ejercicios. Esta probabilidad se distribuye a lo largo de un continuum que representa tanto la competencia de una persona (entendida como su capacidad) como la complejidad de una pregunta (entendida como su dificultad). Este continuum de dificultad y competencia se conoce como una "escala".

\section{PRESENTACIÓN DE LOS RESULTADOS}

PISA 2003 seguirá el esquema de presentación de los resultados usado en el ciclo PISA 2000, que presentaba los resultados según una escala de competencia con base teórica e interpretable en términos de política educativa. Los resultados de la evaluación de la competencia lectora se presentaron inicialmente por medio de una sola escala compuesta, donde la media equivalía a
500 y la desviación típica a 100. Además, el rendimiento de los estudiantes se representó mediante cinco subescalas: tres subescalas de proceso (aspecto) (extracción de información, interpretación de textos y reflexión y evaluación; OCDE, 2001a) y dos subescalas de formato de texto (texto continuo y discontinuo; OCDE, 2002). Estas cinco subescalas permiten comparar los valores medios y la distribución de los diferentes subgrupos y países en los distintos componentes que integran la competencia lectora. Aunque existe una correlación elevada entre las subescalas, la presentación de los resultados en cada una ella de ellas puede revelar interacciones interesantes entre los países participantes. En los casos en que se da una interacción de este tipo, se puede observar y relacionar con el currículum y con la metodología educativa utilizada. En algunos países, lo importante es saber cómo enseñar mejor el currículum escolar en vigor. En otros países, puede que lo importante no sea sólo saber cómo enseñar, sino también qué enseñar.

Cuadro 2.6. Relaciones entre el marco conceptual de competencia lectora y las subescalas de proceso (aspecto)

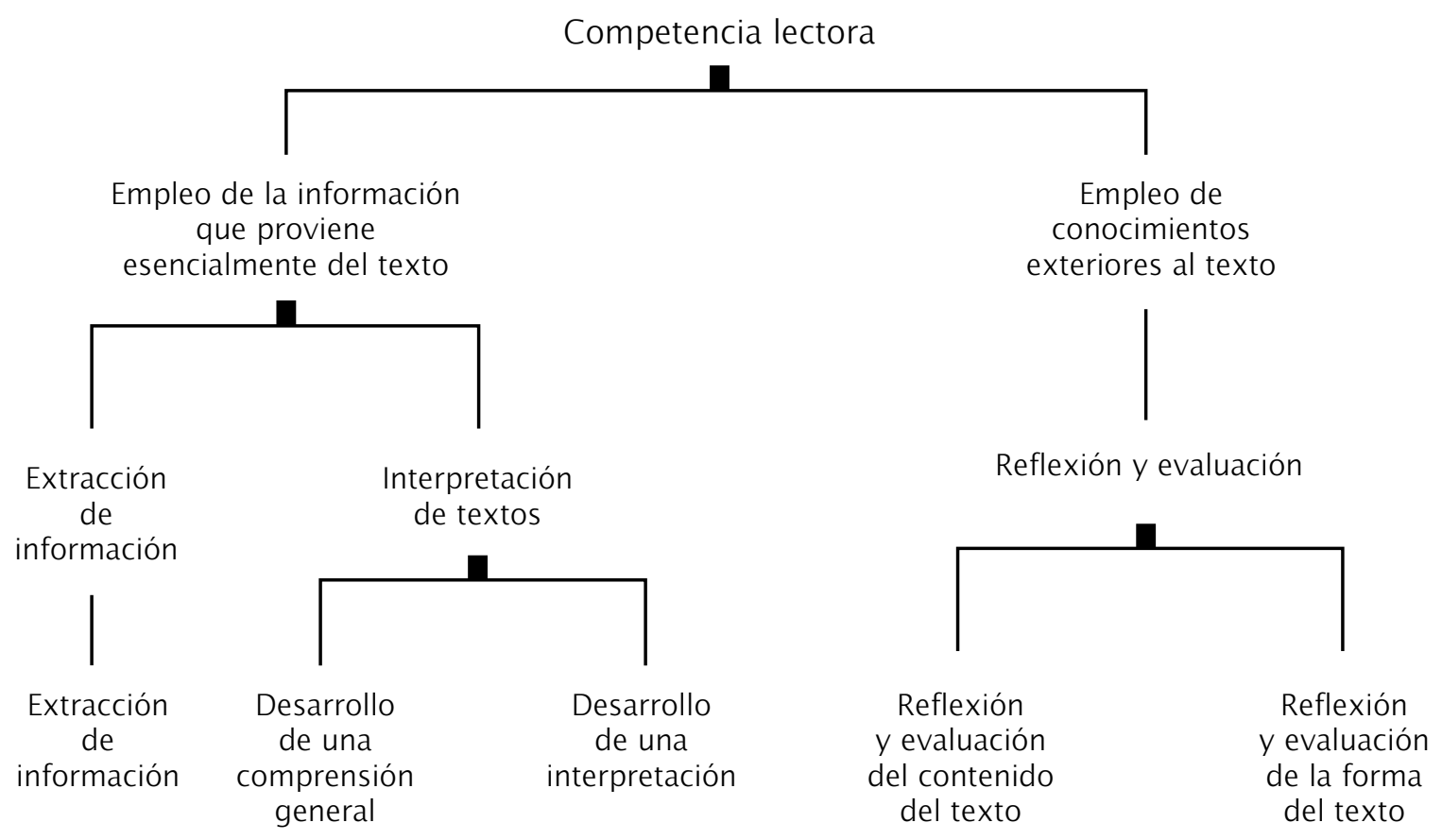




\section{Las subescalas de proceso (aspecto)}

El Cuadro 2.6 presenta los ejercicios de lectura de acuerdo con tres procesos. Hay dos razones para utilizar tres en lugar de cinco subescalas de proceso. La primera es pragmática: en la evaluación de 2003 y 2006, la lectura es un área secundaria y estará limitada a unas 30 preguntas en lugar de las 141 empleadas en el ciclo PISA 2000, cuando la lectura era el área principal; por tanto, la información recopilada será insuficiente para informar sobre las tendencias producidas en las cinco escalas de proceso. La segunda razón es conceptual: estos tres procesos parten del conjunto de cinco procesos mostrado en el Cuadro 2.2. El desarrollo de una comprensión y el desarrollo de una interpretación se han agrupado en una sola subescala denominada "interpretación de textos" porque, en ambos casos, el lector procesa la información existente en el texto: en el caso del desarrollo de una comprensión, en el conjunto del texto, y en el caso del desarrollo de una interpretación, en la interrelación entre las partes del texto. La reflexión sobre el contenido de un texto y la reflexión sobre la forma de un texto se han agrupado en una sola subescala denominada "reflexión y valoración" porque la distinción entre la reflexión y valoración sobre el contenido y la reflexión y valoración sobre la forma, resultaba, en la práctica, un poco arbitraria.

\section{La subescalas relativas al formato del texto}

El ciclo PISA 2003 ofrecerá también la posibilidad de mostrar los resultados basándose en subescalas relativas al formato del texto, tal como se indicó en Reading for change: Performance and engagement across countries (OCDE, 2002). El Cuadro 2.7 presenta los diversos formatos de texto correspondientes a las dos subescalas de formato y a sus ejercicios respectivos. Esta forma de organizar los datos permite observar las diferencias existentes entre los países en relación con la capacidad de sus estudiantes para trabajar con textos de formato distinto. En la presentación de resultados de PISA 2000, se emplearon dos tercios de los ejercicios para crear la subescala de texto continuo, y un tercio para crear la subescala de texto discontinuo. En el proyecto de 2003, los ejercicios se distribuyen de forma similar entre los dos formatos de texto.

Cuadro 2.7. Relación entre el marco conceptual de competencia lectora y las subescalas relativas al formato del texto

Competencia lectora

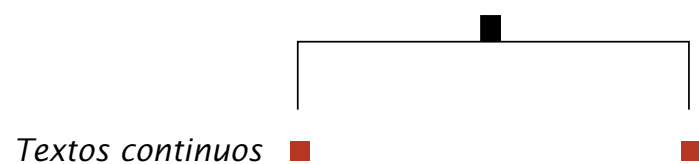

Narrativo

Expositivo

Descriptivo

Argumentativo

y persuasivo

Instruccionales

\section{Textos discontinuos}

Diagramas

y gráficos

Tablas

Esquemas

Mapas

Formularios

Anuncios 
Los valores de la escala compuesta, así como los de las cinco subescalas, representan distintos grados de competencia. Un valor bajo indica que el estudiante tiene destrezas y conocimientos muy limitados, mientras que un valor alto indica que el estudiante tiene destrezas y conocimientos avanzados. Utilizando la Teoría de Respuesta al Item es posible no sólo sintetizar los resultados de varios subgrupos de estudiantes sino también determinar la dificultad relativa de los ejercicios de lectura incluidos en el estudio. Es decir, al igual que cada individuo obtiene un valor concreto en la escala según su capacidad para resolver los ejercicios de la evaluación, cada ejercicio obtiene un valor específico según su dificultad, que se determina a partir de los resultados alcanzados por los estudiantes en los diferentes países que participan en la evaluación.

\section{ELABORACIÓN DE UNA PLANIFICACIÓN DE PREGUNTAS}

El conjunto completo de ejercicios de lectura usado en el proyecto OCDE/PISA presenta una amplia variedad de formatos de texto, de situaciones y de exigencias y, por consiguiente, de grados de dificultad. Esta variedad se representa mediante lo que se conoce como una planificación de preguntas. La planificación de preguntas ofrece una representación visual de las destrezas de lectura mostradas por los estudiantes en las diferentes escalas. La planificación debe incluir una breve descripción de los ejercicios de evaluación hechos públicos junto con los valores que ocupan en las diferentes escalas. Estas descripciones incluyen las destrezas específicas para cuya evaluación se ha diseñado cada ejercicio y, en el caso de ejercicios de respuesta abierta, los criterios empleados para evaluar correctamente la pregunta. El examen de las descripciones permite entender los diferentes procesos que deben efectuar los estudiantes y las competencias que deben demostrar en los distintos puntos de las escalas de lectura.
En el Cuadro 2.8 se muestra una planificación de preguntas de la evaluación PISA 2000. Es importante dar una pequeña explicación sobre la forma de interpretarlo. El valor asignado a cada pregunta parte de la asunción de que una persona situada en determinado punto de la escala muestra la misma capacidad para resolver todos los ejercicios de ese punto de la escala. Para los efectos de la evaluación OCDE/PISA, se decidió que el concepto capacidad significa que los estudiantes, en determinado punto de la escala de lectura, tienen una probabilidad del $62 \%$ de responder correctamente a las preguntas de ese punto. Por ejemplo, en el Cuadro 2.8, hay una pregunta que ocupa el punto 421 de la escala compuesta. Esto significa que los estudiantes que obtengan un valor de 421 en la escala compuesta de competencia lectora tendrán una probabilidad del $62 \%$ de responder correctamente las preguntas que han obtenido el valor 421 de esa escala. Ello no significa que los estudiantes que obtengan un valor inferior a 421 respondan siempre incorrectamente. Lo que significa es que se espera que los estudiantes que han obtenido un valor inferior a 421 respondan correctamente a una pregunta de este nivel de dificultad menos del $62 \%$ de las veces. Y a la inversa, los estudiantes que han obtenido una puntuación superior a 421 tendrán una probabilidad de más del 62\% de responder correctamente. No hay que olvidar que la pregunta aparecerá también en una de las subescalas de proceso y en una de las subescalas de formato, además de en la escala compuesta de competencia lectora. En este ejemplo, la pregunta que ocupa el valor 421 de la escala compuesta exige que los estudiantes identifiquen la intención común de dos textos breves comparando las ideas principales de cada uno de ellos. Se trata de una pregunta de interpretación, que, por lo tanto, aparecerá en la escala de textos interpretativos, así como en la escala de textos continuos. 
Figura 2.8. Ejemplo de planificación de preguntas del ciclo PISA 2000

Tipos de proceso (aspecto)

Formato de texto

Planificación de pregunta compuesta

822: REALIZAR UNA HIPÓTESIS sobre un hecho inesperado teniendo en cuenta el conocimiento externo junto con toda la información relevante de una TABLA COMPLEJA sobre un tema que resulte poco familiar. (puntuación 2)

727: ANALIZAR diversos casos descritos y ASIGNARLOS a las categorías dadas en un DIACRAMA DE ÁRBOL, donde una parte de la información importante se encuentra en notas a pie de página. (puntuación 2)

705: REALIZAR UNA HIPÓTESIS sobre un hecho inesperado teniendo en cuenta el conocimiento externo junto con toda la información relevante en una TABLA COMPLEJA sobre un tema que resulte poco familiar. (puntuación 1)

652: EVALUAR la conclusión de una NARRACIÓN LARGA en relación a su tema o atmósfera implícitos (puntuación 2)

645: RELACIONAR LOS MATICES LINGÜÍSTICOS de una NARRACIÓN LARGA en relación al tema principal con la presencia de ideas opuestas. (puntuación 2)

631: LOCALIZAR información en un DIAGRAMA DE ÁRBOL a través de una información que se encuentra en una nota a pie de página. (puntuación 2)

603: INTERPRETAR el significado de una frase relacionándola con el contexto general de una NARRACIÓN LARGA.

600: REALIZAR UNA HIPÓTESIS sobre una decisión del autor relacionando las pruebas de un gráfico con el tema principal deducido a partir de VARIAS PRESENTACIONES GRÁFICAS.

581: COMPARAR Y EVALUAR el estilo de dos CARTAS abiertas.

567: EVALUAR la conclusión de una NARRACIÓN LARGA en relación al argumento. (puntuación 1)

542: INFERIR UNA RELACIÓN ANÁLOGA entre dos hechos descritos en una CARTA abierta.

540: IDENTIFICAR la fecha de inicio implícita de un GRÁFICO.

539: INTERPRETAR EL SIGNIFICADO de citas breves de una NARRACIÓN LARCA en relación a la atmósfera o situación inmediata. (puntuación 1)

537: RELACIONAR los hechos de una NARRACIÓN LARGA con las propias ideas para justificar puntos de vista opuestos. (puntuación 2)

\begin{tabular}{|c|c|c|c|c}
\multicolumn{3}{|c|}{$\begin{array}{c}\text { Tipos de proceso } \\
\text { (aspecto) }\end{array}$} & \multicolumn{2}{c}{ Formato } \\
de texto
\end{tabular}


Figura 2.8. Ejemplo de planificación de preguntas del ciclo PISA 2000

Tipos de proceso (aspecto)

Formato de texto

\section{Planificación de pregunta compuesta}

529: EXPLICAR la motivación de un personaje relacionando Ios hechos de una NARRACIÓN LARCA.

508: INFERIR LA RELACIÓN entre DOS PRESENTACIONES GRÁFICAS con convenciones diferentes.

486: EVALUAR la adecuación de un DIAGRAMA DE ÁRBOL para diferentes propósitos específicos.

485: LOCALIZAR la información numérica de un DIAGRAMA DE ÁRBOL. (puntuación 1)

480: RELACIONAR los hechos de una RELACIÓN LARGA con las propias ideas para justificar un único punto de vista. (puntuación 1)

478: LOCALIZAR Y COMBINAR información de un GRÁFICO DE LÍNEA y de su introducción para deducir un valor que falta.

477: COMPRENDER la estructura de un DIAGRAMA DE ÁRBOL.

473: ASIGNAR categorías dadas en un DIAGRAMA DE ÁRBOL para describir casos cuando parte de la información importante se encuentra en notas a pie de página. (puntuación 1)

447: INTERPRETAR la información de un único párrafo para comprender el escenario de una NARRACIÓN

445: DIFERENCIAR entre las variables y las CARACTERÍSTICAS ESTRUCTURALES de un DIAGRAMA DE ÁRBOL.

421: IDENTIFICAR el OBJETIVO común de DOS TEXTOS CORTOS.

405: LOCALIZAR elementos de información explícita de un TEXTO con organizadores contundentes.

397: Inferir la IDEA PRINCIPAL de un simple GRÁFICO DE BARRAS a partir del título.

392: LOCALIZAR un elemento de información literal de un texto con una estructura de texto clara.

367: LOCALIZAR información explícita de una sección corta y especificada de una NARRACIÓN

363: LOCALIZAR un elemento de información expresada de manera explícita en un TEXTO con encabezados.

356: RECONOCER EL TEMA de un artículo que contenga un subtítulo claro y una redundancia considerable.

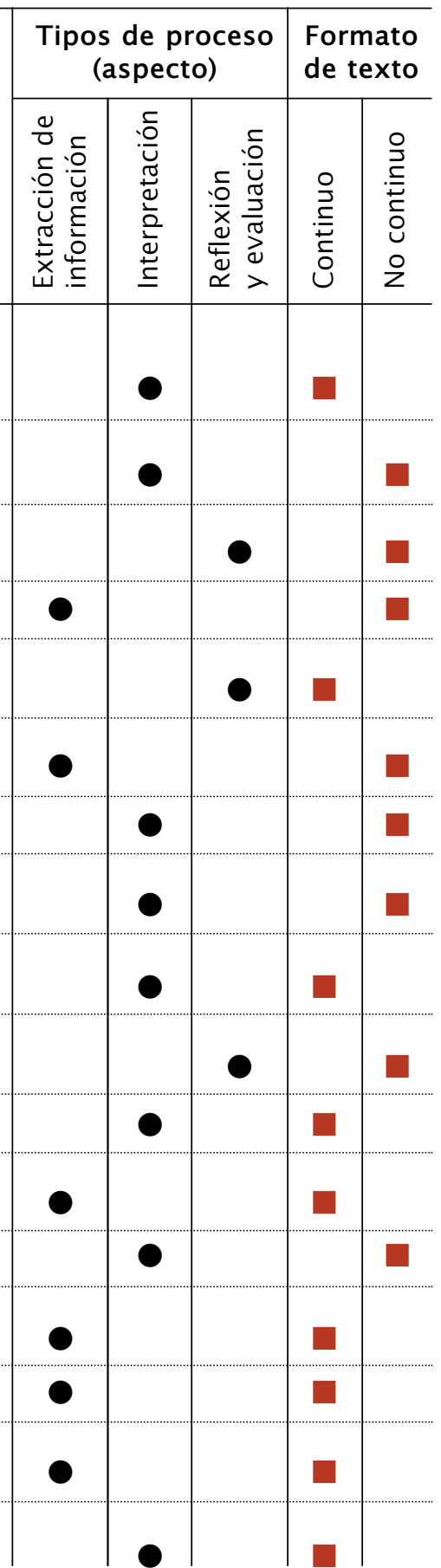




\section{NIVELES DE CAPACIDAD LECTORA}

Al igual que la muestra de alumnos participantes de cada país se elige de forma que represente a la población nacional de estudiantes de 15 años, cada ejercicio de lectura representa una clase de ejercicios dentro del ámbito de la lectura. Por tanto, representa las capacidades que deberían haber adquirido los estudiantes de 15 años al manejar y procesar textos escritos. Puede preguntarse qué diferencia hay entre los ejercicios del nivel inferior de la escala y los situados en las franjas central y superior de la escala. Y también si los ejercicios que caen más o menos en el mismo punto de la escala tienen características en común por el hecho de presentar niveles de dificultad similares. Una inspección somera de la planificación presentada revela que los ejercicios de la parte inferior de la escala son distintos a los de la parte superior. Y un análisis más detenido de la gama de ejercicios representada en cada escala proporciona indicaciones sobre un conjunto ordenado de destrezas y estrategias para el procesamiento de la información. Los miembros del grupo de expertos en lectura analizaron cada ejercicio para identificar un conjunto de variables que pudieran influir en su dificultad. Descubrieron que la dificultad está determinada en parte por la extensión, la estructura y la complejidad del propio texto. Sin embargo, también observaron que en la mayoría de las unidades de lectura (entendiendo por unidad un texto y un conjunto de preguntas), las preguntas se situaban a lo largo de toda la escala de competencia lectora. Esto significa que, mientras que la estructura de un texto tiene que ver con la dificultad de una pregunta, lo que el lector tiene que hacer con este texto, tal como se define en la pregunta o instrucción, interactúa con el texto y afecta a la dificultad global.
Los expertos identificaron cierto número de variables que pueden influir en la dificultad de cualquier ejercicio de lectura. Uno de los factores más importantes es el proceso utilizado, que está relacionado con la extracción de información, con el desarrollo de una interpretación o con la reflexión sobre lo que se ha leído. Los procesos difieren en complejidad y sofisticación: desde la búsqueda de relaciones sencillas entre datos concretos, pasando por la clasificación de las ideas de acuerdo con unos criterios dados, hasta la valoración crítica y la formación de hipótesis sobre una parte del texto. Además de por los procesos utilizados, la dificultad de los ejercicios de extracción de información varía según el número de datos que se deben incluir en la respuesta, el número de criterios que debe satisfacer la información y el hecho de que la información extraída deba ordenarse o no de determinada manera. En el caso de los ejercicios de interpretación y reflexión, la cantidad de texto que se debe asimilar es un factor importante que afecta a la dificultad. En las preguntas que exigen reflexión por parte del lector, la dificultad del ejercicio se ve influida por el carácter familiar o específico de los conocimientos externos al texto a los que se debe recurrir. En todos los procesos de lectura, la dificultad del ejercicio depende de la "visibilidad" de la información solicitada, de la cantidad de información alternativa presente y del hecho de que el lector tenga o no instrucciones explícitas sobre las ideas o la información necesarias para completar el ejercicio.

En un intento de representar esta progresión de la complejidad y la dificultad en el ciclo PISA 2000, la escala compuesta de lectura y cada una de las subescalas se dividieron en cinco niveles:

$\mid$\begin{tabular}{cl} 
Nivel & Valores de la escala PISA \\
\hline 1 & 335 a 407 \\
2 & 408 a 480 \\
3 & 481 a 552 \\
4 & 553 a 625 \\
5 & Más de 625
\end{tabular}


Los comités de expertos decidieron que los ejercicios situados en cada nivel de lectura compartían muchas de las características y limitaciones y diferían de manera sistemática de los ejercicios de los niveles superiores o infe- riores. Por consiguiente, estos niveles pueden constituir un método útil para investigar la progresión de las exigencias de competencia lectora en cada escala. Esta progresión se representa en el Cuadro 2.9.

Cuadro 2.9. Mapa de niveles de competencia lectora

\section{Extracción de información}

5

Localizar y posiblemente secuenciar o combinar múltiples elementos de información profundamente insertada, algunos de los cuales pueden hallarse fuera del cuerpo principal del texto. Inferir qué información del texto es importante para el ejercicio. Tratar con diferente información extremadamente verosímil y/o que desempeña un papel fundamental.
Interpretación de textos

O interpretar el significado de un lenguaje con matices o demostrar un entendimiento completo y detallado de un texto.

\section{Reflexión y evaluación}

Realizar hipótesis o evaluar de manera crítica recurriendo al conocimiento especializado. Tratar con conceptos opuestos a las expectativas o recurrir a un entendimiento de textos largos o complejos.

Textos continuos: Tratar con textos cuya estructura discursiva no es obvia o no está claramente marcada para discernir la relación de las diferentes partes del texto con su intención o tema implícito.

Textos discontinuos: Identificar las pautas entre muchos elementos de información presentados de una manera visual que puede ser extensa y detallada, a veces haciendo referencia a información de fuera de la presentación visual. El lector puede tener que darse cuenta de manera independiente de que para una comprensión completa de la sección del texto es necesario consultar una parte independiente de dicho documento, como, por ejemplo, una nota a pie de página.

4 Localizar y posiblemente secuenciar o combinar múltiples elementos de información profundamente insertada, elementos que pueden necesitar cumplir numerosos criterios, en un texto de contexto o forma familiares. Inferir qué información del texto es importante para el ejercicio.
Utilizar un alto grado de deducción del texto para comprender y aplicar categorías en un contexto no familiar y para interpretar el significado de una sección de texto teniendo en cuenta el texto en su totalidad. Ocuparse de las ambigüedades, las ideas contrarias a lo esperado y las ideas expresadas en negativo.
Utilizar el conocimiento formal o conocido para realizar hipótesis sobre un texto o valorarlo de manera crítica. Demostrar una comprensión precisa de textos largos o complejos.

Textos continuos: Seguir vínculos lingüísticos o temáticos a lo largo de varios párrafos, a menudo sin marcadores discursivos claros, para localizar, interpretar o evaluar información bien insertada en el texto o para inferir un significado psicológico o metafísico.

Textos discontinuos: Escudriñar un texto largo y detallado para hallar la información relevante, a menudo con poca o ninguna ayuda de organizadores tales como tablas o formato especial, para localizar los diferentes elementos de información a analizar o combinar. 
Cuadro 2.9. Mapa de niveles de competencia lectora

Extracción de información

3 Localizar, y, en algunos caos, reconocer la relación entre los elementos de información, elementos que pueden tener que cumplir múltiples criterios. Tratar con diferente información que desempeñe un papel fundamental.
Interpretación de textos

Integrar diferentes partes de un texto para identificar la idea principal, comprender una relación o interpretar el significado de una palabra o frase. Comparar, contrastar o categorizar teniendo en cuenta muchos criterios. Tratar con diferente información que desempeñe un papel importante.
Reflexión y evaluación

Establecer conexiones o comparaciones, dar explicaciones o evaluar una característica de un texto. Demostrar una comprensión detallada del texto en relación al conocimiento familiar diario o recurrir a un conocimiento menos habitual.

Textos continuos: Utilizar convenciones de organización textual, si se encuentran presentes, y seguir los vínculos lógicos explícitos o implícitos, tales como las relaciones de causa-efecto a lo largo de las frases o párrafos, para localizar, interpretar o valorar la información.

Textos discontinuos: Considerar una presentación en vista de una segunda presentación o documento aparte, posiblemente en un formato diferente, o combinar diferentes elementos de información espacial, verbal y numérica de un gráfico o mapa para extraer conclusiones sobre la información representada.

2 Localizar uno o más elementos de información que pueden tener que cumplir múltiples criterios. Tratar con diferente información que desempeñe un papel importante.
Identificar la idea principal de un texto, comprender las relaciones, elaborar o aplicar categorías simples o interpretar el significado de una parte delimitada de un texto cuando la información no está destacada y resulta necesario inferir a bajo nivel.
Establecer una comparación o vínculos entre el texto y el conocimiento exterior o explicar una característica del texto recurriendo a las posiciones y experiencias personales.

Textos continuos: Seguir las conexiones lógicas y lingüísticas de dentro de un párrafo para localizar o interpretar información, o sintetizar información de varios textos o partes de dentro de un texto para inferir el objetivo del autor.

Textos discontinuos: Demostrar la comprensión de la estructura subyacente de una presentación visual, como una tabla o diagrama de árbol simple, o combinar dos elementos de información de un gráfico o tabla.

Localizar uno o más elementos independientes de información explícita, que tenga que cumplir un único criterio generalmente, con poca o ninguna información importante en el texto.
Reconocer el tema principal o el objetivo del autor de un texto que trate un tema familiar y en el que la información necesaria no esté destacada en el texto.

Textos continuos: Valerse de la redundancia, los encabezados de párrafo o de las convenciones tipográficas comunes para adquirir la visión de la idea principal del texto o para localizar la información explícita de dentro de una sección corta del texto.

Textos discontinuos: Atender a elementos diferenciados de información, normalmente de dentro de una presentación individual, como un mapa sencillo, un gráfico de línea o barra que presente únicamente una pequeña cantidad de información de modo simple, y en el que la mayor parte del texto verbal esté limitado a un pequeño número de palabras o frases. 
Interpretación de los niveles de competencia lectora Cada nivel, además de representar una serie de ejercicios y de los conocimientos y destrezas relacionados, representa una serie de capacidades mostradas por los estudiantes. Como se ha dicho, los miembros del comité de expertos establecieron inicialmente estos niveles para representar un conjunto de ejercicios con características compartidas. Además, los diferentes niveles comparten propiedades estadísticas. Dentro de cada nivel, se puede esperar que el estudiante que ha obtenido el valor medio resuelva correctamente el ejercicio puntuado con el valor medio de ese nivel en un $62 \%$ de las veces. Además, la amplitud de cada nivel está determinada en parte por la expectativa de que un estudiante del extremo inferior obtenga una puntuación del $50 \%$ en cualquier ejercicio hipotético compuesto por preguntas seleccionadas aleatoriamente dentro de ese mismo nivel.

Como cada escala de lectura representa un continuo en los conocimientos y destrezas, los estudiantes de un nivel concreto, además de mostrar que han obtenido los conocimientos y destrezas asociados con ese nivel, muestran también haber obtenido los resultados asociados con los niveles inferiores. Por ello, los conocimientos y destrezas supuestos para cada nivel parten de las competencias conseguidas en el nivel inferior y las engloban. Esto significa que un estudiante que haya sido calificado dentro del Nivel 3 de la escala de competencia lectora tiene la capacidad necesaria para resolver los ejercicios del Nivel 3, pero también para resolver los ejercicios del Nivel 1 y del Nivel 2. Esto significa también que se espera que el estudiante que está en los Niveles 1 y 2 responda correctamente menos del 50\% de las veces a preguntas del Nivel 3. Dicho de otra manera, se espera que responda con corrección menos del $50 \%$ de un ejercicio compuesto exclusivamente por preguntas pertenecientes al Nivel 3.

El Cuadro 2.10 muestra la probabilidad de que los alumnos que hayan obtenido determinadas puntuaciones en la escala compuesta de lectura den una respuesta correcta a ejercicios de distinta dificultad. Uno es un ejercicio del Nivel 1, otro es un ejercicio del Nivel 3 y el tercero recibe dos calificaciones: una en el Nivel 4 y la otra en el Nivel 5. Como puede apreciarse, un estudiante con una puntuación de 298, por debajo el Nivel 1, tiene sólo un $43 \%$ de probabilidades de responder correctamente al ejercicio del Nivel 1, que ocupa el valor 367 en la escala de competencia lectora. Esta persona tiene una probabilidad de sólo el 14 por ciento de responder a la pregunta del Nivel 3 y una probabilidad casi nula de responder correctamente al ejercicio del Nivel 5. Una persona con un resultado de 371 , en el centro del Nivel 1, tiene una probabilidad del $63 \%$ de responder a la pregunta situada en el valor 367, pero una probabilidad sólo levemente superior a la de uno entre cuatro de responder correctamente a la pregunta del valor 508, y una probabilidad de sólo el $7 \%$ de responder correctamente al ejercicio seleccionado en el Nivel 5. Por el contrario, se puede esperar que una persona clasificada en el Nivel 3 responda correctamente el $89 \%$ de las veces a los ejercicios puntuados con el valor 367 en la escala de lectura, y un 64\% de las veces a los ejercicios del valor 508, cerca del punto central del Nivel 3. Sin embargo, esta persona tendría apenas una probabilidad de cada cuatro (27\%) de responder correctamente a las preguntas de la parte central del Nivel 5. Por último, se espera que un estudiante del Nivel 5 responda correctamente la mayoría de las veces a la mayoría de los ejercicios. Como se muestra en el Cuadro 2.10, un estudiante con una puntuación de 662 en la escala compuesta de lectura tiene una probabilidad del 98\% de responder correctamente al ejercicio puntuado con el valor 367, un 90\% de probabilidades de responder correctamente a la pregunta del Nivel 3 (508), y una probabilidad del $65 \%$ de responder correctamente el ejercicio próximo al centro del Nivel 5 (652).

El cuadro 2.10 suscita implícitamente varias cuestiones sobre el nivel máximo y mínimo. Aunque nadie ha alcanzado el valor superior de la escala de competencia lectora, puede asegurarse con cierto grado de certeza que los estudiantes con una competencia muy elevada pueden resolver ejercicios clasificados dentro del nivel superior de capacidad. Para los estudiantes que se encuentran en la base de la escala de lectura se plantea más de un problema. El Nivel 1 empieza en el valor 335, aunque se estima que en cada país hay un determinado porcentaje de estudiantes que se sitúa por debajo de este punto de la escala. Aunque no existen ejercicios de lectura puntuados con un valor inferior al 335 de la escala, no es correcto decir que estos estudiantes no cuentan con destrezas de lectura o que son «totalmente incompetentes». Sin embargo, partiendo de sus resultados en el conjunto de ejercicios 
Cuadro 2.10. Probabilidad (en porcentaje) de responder correctamente

a ejercicios de diversa dificultad por parte de estudiantes

con diferentes niveles de competencia

\begin{tabular}{|c|c|c|c|c|}
\hline & $\begin{array}{l}\text { Pregunta de } \\
\text { Nivel } 1 \text { a } 367 \\
\text { puntos }\end{array}$ & $\begin{array}{l}\text { Pregunta de } \\
\text { Nivel } 3 \text { a } 508 \\
\text { puntos }\end{array}$ & $\begin{array}{l}\text { Pregunta de } \\
\text { Nivel } 4 \text { a } 567 \\
\text { puntos }\end{array}$ & $\begin{array}{l}\text { Pregunta de } \\
\text { Nivel } 5 \text { a } 652 \\
\text { puntos }\end{array}$ \\
\hline $\begin{array}{l}\text { Por debajo del Nivel } 1 \\
\text { (competencia de } 298 \text { puntos) }\end{array}$ & 43 & 14 & 8 & 3 \\
\hline $\begin{array}{l}\text { Nivel } 1 \\
\text { (competencia de } 371 \text { puntos) }\end{array}$ & 63 & 27 & 16 & 7 \\
\hline $\begin{array}{l}\text { Nivel } 2 \\
\text { (competencia de } 444 \text { puntos) }\end{array}$ & 79 & 45 & 30 & 14 \\
\hline $\begin{array}{l}\text { Nivel } 3 \\
\text { (competencia de } 517 \text { puntos) }\end{array}$ & 89 & 64 & 48 & 27 \\
\hline $\begin{array}{l}\text { Nivel } 4 \\
\text { (competencia de } 589 \text { puntos) }\end{array}$ & 95 & 80 & 68 & 45 \\
\hline $\begin{array}{l}\text { Nivel } 5 \\
\text { (competencia de } 662 \text { puntos) }\end{array}$ & 98 & 90 & 82 & 65 \\
\hline
\end{tabular}

empleado en la evaluación, se espera que obtengan una puntuación correcta menos del 50\% de las veces en un conjunto de ejercicios seleccionados dentro del Nivel 1. Por ello, se clasifican como estudiantes con un resultado inferior al Nivel 1.

Dado que, comparativamente, en nuestras sociedades hay pocos jóvenes sin ninguna destreza lectora, el marco no mide si los estudiantes de 15 años son o no capaces de leer en un sentido técnico. Es decir, el proyecto OCDE/PISA no estima la fluidez de lectura de los estudiantes de 15 años ni su competencia en la resolución de ejercicios de ortografía o de identificación de palabras. Sin embargo, se hace eco de la idea contemporánea de que los estudiantes, al final de la escolarización obligatoria, deberían ser capaces de elaborar y ampliar el significado de lo leído y reflexionar sobre ello, con toda una gama de textos continuos y discontinuos que se suelen asociar con diversas situaciones de dentro y de fuera del ámbito escolar. Si bien no es posible decir qué conocimientos y destrezas lectoras poseen los estudiantes que han obtenido puntuaciones inferiores al Nivel 1, su nivel de capacidad indica que no es probable que sean capaces de usar la lectura como una herramienta más para la adquisición de conocimientos y destrezas en otras áreas. 



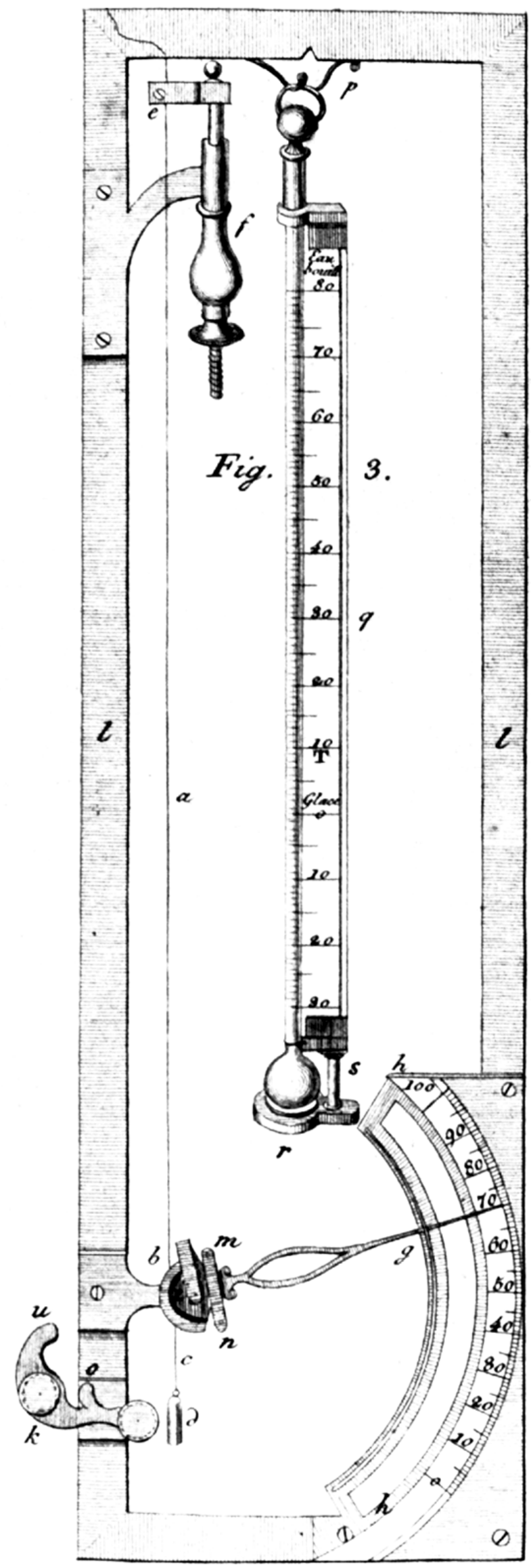

Una destreza importante para los jóvenes es la capacidad de extraer conclusiones apropiadas a partir de hechos y datos recibidos, de criticar los argumentos de otros con base factual y de distinguir entre una mera opinión y una afirmación sustentada por hechos. Las ciencias desempeñan aquí un papel importante dada su relación con la racionalidad, al contrastar ideas y teorías con la información factual del mundo que nos rodea. Esto no quiere decir que las ciencias prescindan de la creatividad y de la imaginación, ya que éstas han ocupado siempre un lugar relevante en el proceso de comprensión del mundo por parte del hombre. Las ideas que a veces parecen haber salido de la nada han sido cazadas al vuelo gracias a un mecanismo que Einstein describió como «la vía de la intuición, que es capaz de sentir el orden que se esconde tras la apariencia» (Einstein, 1933). Qué ideas se aprovechan es algo que depende de su aceptabilidad social en el momento histórico, de manera que los avances del conocimiento científico dependen no sólo de la creatividad de los individuos, sino también de la cultura en la que se proponen. No obstante, una vez se ha realizado el salto creativo y se ha articulado un nuevo marco teórico para el conocimiento, éste ha de comprobarse 
concienzudamente frente a la realidad. Como afirma Hawking (1988):

«Una teoría es buena si satisface dos requisitos: debe describir fielmente un gran número de observaciones a partir de un modelo que contenga sólo unos pocos elementos arbitrarios y debe realizar predicciones precisas de los resultados de las observaciones futuras» (Hawking, 1988, pág. 9).

Las teorías que no cumplen estos requisitos, o que no pueden comprobarse, no son teorías científicas. Es importante que cualquier ciudadano cultivado sepa distinguir entre las preguntas que la ciencia puede responder y las que no, así como entre lo científico y lo pseudo-científico.

\section{Definición del área de conocimiento}

El pensamiento actual sobre los resultados deseados de una educación en ciencias para todos los ciudada-nos hace hincapié en el desarrollo de una comprensión global de los conceptos fundamentales y de los marcos explicativos de la ciencia, de los métodos mediante los cuales ésta consigue que los hechos apoyen sus afirmaciones y del poder y las limitaciones de la ciencia en el mundo real. Se valora en especial la capacidad para aplicar estos conocimientos a situaciones reales en las hay que valorar afirmaciones y tomar decisiones. Por ejemplo, Millar y Osborne (1998) han identificado el enfoque de un currículum científico contemporáneo como «la capacidad para leer y asimilar información científica y técnica y valorar su importancia». Su informe prosigue:

«En este enfoque, la atención no se centra en cómo "hacer ciencia". Tampoco en cómo crear conocimientos científicos ni en recordarlos brevemente en un examen final. [...] Asi pues, en ciencias, se debería pedir a los estudiantes que fueran capaces de evaluar pruebas factuales, de distinguir entre teorías $y$ observaciones y de valorar el grado de confianza que hay que conceder a las explicaciones proporcionadas» (Millar y Osborne, 1998).

Éstos deberían ser los resultados de la formación en ciencias para todos los estudiantes. Para algunos alumnos, los pocos que se convertirán en los científicos del mañana, esto se ampliará a un estudio en profundidad de las ideas científicas y al desarrollo de la capacidad de «hacer ciencia».

Si se tienen en cuenta estos puntos, el objetivo principal de la educación científica, que deberá ser el punto central del proyecto OCDE/PISA, es que los alumnos lleguen a obtener una competencia científica. Este término se ha empleado en diversos contextos. Por ejemplo, el International Forum on Scientific and Technological Literacy for All (Foro internacional sobre competencia científica y tecnológica para todos, UNESCO, 1993) ofreció varias definiciones, tales como:

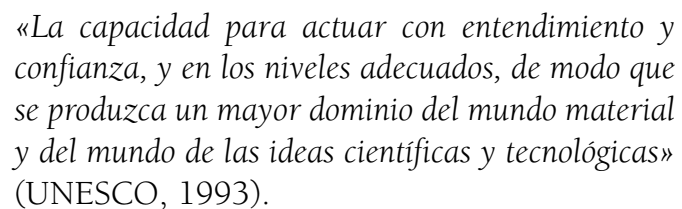

Entre los muchos y diferentes puntos de vista sobre la competencia científica (estudiados por Shamos, 1995; Laugksch, 2000; véase también Braeber y Bolte, 1997), se encuentran las ideas sobre los niveles de competencia científica. Por ejemplo, Bybee (1997) ha propuesto cuatro niveles, de los cuales los dos inferiores son la "competencia científica nominal", que consiste en el conocimiento de los nombres y los términos, y la "competencia funcional", que se aplica a quienes son capaces de emplear el vocabulario científico en contextos limitados. Estos niveles se consideran demasiado bajos para incluirlos dentro del marco OCDE/PISA. El nivel más alto identificado por Bybee es la "competencia científica multidimensional", que conlleva el entendimiento de la naturaleza de la ciencia, de su historia y de su papel dentro de la cultura, en un nivel más adecuado para la élite científica que para la mayoría de los ciudadanos. Quizá es la asunción de que la competencia científica comporta un razonamiento en este nivel de especialización lo que precisamente dificulta la divulgación una idea más asequible sobre ella. De acuerdo a los objetivos del marco conceptual de ciencias del estudio OCDE/PISA, lo más apropiado se encuentra más próximo al tercer nivel descrito por Bybee, la "competencia científica conceptual y de procedimiento". 
Tras considerar las descripciones existentes, el proyecto OCDE/PISA define la competencia científica del siguiente modo:

\section{La competencia científica es la capacidad de emple- ar el conocimiento científico para identificar pre- guntas y extraer conclusiones basadas en hechos con el fin de comprender y de poder tomar decisio- nes sobre el mundo natural y sobre los cambios que ha producido en él la actividad humana.}

Las siguientes observaciones amplían el significado que se condensa en esta afirmación.

\section{La competencia científica}

Es importante destacar que, para la competencia científica, el conocimiento científico (en el sentido de conocimiento de la ciencia) y los procesos mediante los cuales éste se desarrolla no sólo resultan esenciales, sino que también están estrechamente relacionados en la misma acepción del término. Tal y como se explicará más adelante, los procesos sólo son científicos si se aplican a empeños científicos. De este modo, la utilización de los procesos científicos comporta necesariamente cierta comprensión de los temas científicos. La idea de competencia científica aquí adoptada tiene en cuenta esta combinación de maneras de pensar y comprender los aspectos científicos del mundo.

\section{emplear el conocimiento científico para identifi-} car preguntas y extraer conclusiones basadas en hechos

En la definición anterior se emplea el término conocimiento científico para englobar algo más que el conocimiento de los hechos, nombres y términos. Incluye también la comprensión de los conceptos científicos fundamentales, de las limitaciones del conocimiento científico y de la naturaleza de la ciencia como actividad humana. Las preguntas que hay que identificar son aquellas que pueden responderse mediante la investigación científica, lo que implica tanto el conocimiento de la ciencia como los aspectos científicos de temas específicos. Extraer conclusiones basadas en hechos conlleva conocer y aplicar procesos de selección y evaluación de la información o de los datos, al mismo tiempo que se reconoce que, a menudo, no se cuenta con la información suficiente para extraer conclusiones definitivas y que, por tanto, se hace necesario especular de manera cauta y consciente sobre la información disponible.

\section{comprender y tomar decisiones}

En primer lugar esta afirmación indica que la comprensión del mundo natural se valora como un fin en sí mismo y como un requisito necesario para tomar decisiones. En segundo lugar indica que puede ayudar a tomar decisiones, aunque rara vez las determina. Las decisiones prácticas siempre tienen lugar en situaciones de dimensiones sociales, políticas o económicas, y el conocimiento científico se emplea en el contexto de los valores humanos referentes a estas dimensiones. Cuando hay un consenso sobre estos valo-res, el empleo de datos científicos no resulta controvertido. Sin embargo, cuando no hay consenso, la selección y el empleo de los datos científicos serán más polémicos en la toma de decisiones.

\section{el mundo natural y los cambios que ha produci-} do en él la actividad humana

La expresión "mundo natural" se utiliza como una abreviatura para designar al medio físico, a los seres vivos y a las relaciones que se establecen entre ellos. Las decisiones sobre el mundo natural incluyen aque-llas relacionadas con la ciencia y relativas a la persona y a la familia, a la comunidad y a los asuntos del mundo. Los cambios producidos por la actividad humana se refieren a la adaptación planificada o no del mundo natural a los propósitos humanos (tecnologías sencillas y complejas) y a sus consecuencias.

Aquí es importante tener en cuenta (y esta idea se ampliará más adelante) que la competencia científica no es una dicotomía. Es decir, que no se pretende categorizar a las personas como competentes o incompetentes en ciencias, sino constatar la existencia de una progresión desde una competencia menos desarrollada hasta otra más desarrollada. Por ejemplo, el estudiante con una competencia científica menos desarrollada puede ser capaz de evocar un conocimiento científico simple y objetivo (p. ej., nombres, hechos, terminología, reglas simples) y de utilizar el conocimiento científico común a la hora de extraer o evaluar conclusiones. Una competencia científica más desarrollada se demostrará a través de la capacidad de crear o utilizar modelos conceptuales simples para realizar predicciones o dar explicaciones, de realizarlas y transmitirlas con precisión, de analizar las 
investigaciones científicas en relación con un diseño experimental, de utilizar datos como referencias factuales para valorar diferentes puntos de vista o perspectivas y sus implicaciones, y para transmitir esas valoraciones con precisión.

\section{Organización del área}

La definición de competencia científica del proyecto OCDE/PISA comprende tres aspectos:

- conocimiento y conceptos científicos, que se evaluarán a través de su empleo en materias específicas,

- procesos científicos, que, dado que son científicos, conllevan el conocimiento de la ciencia; no obstante, en la evaluación, este conocimiento no deberá constituir la dificultad mayor para poder contestar correctamente a las preguntas,

- situaciones o contexto en los que se evalúan el conocimiento y los procesos y que adoptan la forma de problemas de contenido científico.

Aunque estos aspectos de la competencia científica se tratarán separadamente, hay que precisar que en la evaluación de esta competencia siempre aparecerá una combinación de los tres.

Los dos primeros aspectos se utilizan tanto para la elaboración de las preguntas de prueba como para la descripción del rendimiento de los alumnos. El tercer aspecto garantiza que, a la hora de elaborar las pruebas, se haga intervenir un abanico suficientemente amplio de situaciones pertinentes en términos de competencia científica.

Los siguientes apartados desarrollan los tres aspectos que organizan las pruebas. Al plantearse en torno a estos aspectos, el marco conceptual del proyecto OCDE/PISA se ha asegurado que el enfoque de la evaluación se centre en el producto de la educación científica considerada como un todo.

\section{CONOCIMIENTO O CONCEPTOS CIENTÍFICOS}

Sólo puede evaluarse una muestra de las ideas científicas. Además, el objetivo del proyecto OCDE/PISA no es contabilizar todo el conocimiento que puedan tener los alumnos, sino describir en qué grado son capaces de aplicar su conocimiento en contextos importantes para su vida presente y futura. No se ha pretendido por tanto identificar una lista de posibles conocimientos evaluables, sino de definir los criterios de selección. Así, el conocimiento que será evaluado ha sido seleccionado a partir de los grandes dominios de la física, la química, la biología y las ciencias de la Tierra y el espacio, de acuerdo a los tres criterios siguientes:

- El primero de ellos es su importancia en las situaciones cotidianas. Los conocimientos científicos se diferencian en el grado en que resultan útiles en la vida diaria. Por ejemplo, aunque la teoría de la relatividad ofrece una descripción más detallada de las relaciones entre longitud, masa, tiempo y velocidad, las leyes de Newton son más útiles en asuntos relacionados con la comprensión de las fuerzas y el movimiento en la vida diaria.

- El segundo criterio es que el conocimiento y las áreas de aplicación seleccionadas deberían tener una importancia para la vida que se mantuviera a lo largo de, al menos, la próxima década. Dado que está previsto que la prueba final de ciencias tenga lugar en el año 2006, el ciclo 2003 del pro-yecto OCDE/PISA se centrará en el conocimiento que probablemente vaya a continuar siendo importante en las ciencias y la política educativa pública durante un número significativo de años.

- El tercer criterio es que el conocimiento necesario pueda combinarse con algunos procesos científicos. Esto no sería así si lo único que se exigiera fuera recor dar nombres o definiciones.

El Cuadro 3.1 muestra el resultado de la aplicación de estos criterios al contenido de las áreas científicas principales. Enumera los temas científicos principales, con algunos ejemplos del conocimiento que abarcan. Este conocimiento es necesario para entender el mundo natural y para dar sentido a las nuevas experiencias. Dicho conocimiento depende y deriva del estudio de los hechos y fenómenos específicos, pero no va más allá del conocimiento detallado que procede el estudio de estas cuestiones. Los ejemplos del Cuadro 3.1 se presentan para expresar el sentido de los temas; con ello no se pretende enumerar exhaustivamente todos los conocimientos que engloba cada tema. 
Cuadro 3.1. Principales temas científicos para la evaluación de ciencias

- Estructura y propiedades de la materia (conductividad térmica y eléctrica)

- Cambio atmosférico (radiación, transmisión, presión)

- Cambios físicos y químicos (estados de la materia, tasas de reacción, descomposición)

- Transformación de la energía (conservación de la energía, degradación de la energía, fotosíntesis)

- Fuerzas y movimiento (fuerzas en equilibrio y desequilibrio, velocidad, aceleración, momento)

- Forma y función (célula, esqueleto, adaptación)

- Biología humana (salud, higiene, nutrición)

- Cambio fisiológico (hormonas, electrólisis, neuronas)

- Biodiversidad (especies, patrimonio genético, evolución)

- Control genético (dominancia, herencia)

- Ecosistemas (cadenas tróficas, sostenibilidad)

- La Tierra y su lugar en el universo (sistema solar, cambios diurnos y estacionales)

- Cambio geológico (deriva continental, meteorización)

\section{PROCESOS CIENTÍFICOS}

Los procesos son acciones mentales (y a veces físicas) que se emplean al concebir, obtener, interpretar y utilizar pruebas o datos con el objetivo de lograr un conocimiento o comprensión. Los procesos deben emplearse en relación con alguna materia; un proceso libre de contenido no tiene sentido. Pueden aplicarse a una amplia gama de materias y se convierten en procesos científicos cuando la materia procede de aspectos científicos del mundo y el resultado de su aplicación es ampliar la comprensión científica.

Lo que normalmente se describe como procesos científicos cubre un amplio conjunto de destrezas y saberes necesarios para recopilar e interpretar los hechos del mundo que nos rodea y extraer conclusiones de ellos. Los procesos relativos a la recopilación de hechos incluyen los relativos al ejercicio de la investigación científica: planificar y montar situaciones experimentales, tomar mediciones y realizar observaciones con los instrumentos necesarios, etc. El desarrollo de estos procesos figura entre en los objetivos de la formación escolar en ciencias de modo que los estudiantes puedan experimentar y comprender cómo se crea el conocimiento científico y, idealmente, captar la naturaleza de la investigación científica. Pocos serán los estudiantes que necesiten hacer uso de estas destrezas prácticas con posterioridad a su vida escolar; no obstante, sí necesitarán haber entendido los procesos y conceptos desarrollados mediante las manipulaciones y las experiencias prácticas. Además, hay razones sólidas para creer que lo que tradicionalmente se ha considerado como el «proceso científico» -mediante el cual se extraen conclusiones de manera inductiva a partir de las observaciones y que aún prevalece en el modo en que aún se enseñan las ciencias en la escuela- es contrario al modo en que se desarrolla el conocimiento científico (p. ej., Ziman, 1980).

La competencia científica, tal y como se presenta aquí, otorga una mayor prioridad al hecho de utilizar el conocimiento científico para "extraer conclusiones basadas en hechos" que a la habilidad de recopilar los hechos relevantes por uno mismo. La habilidad para relacionar 
los hechos y datos con afirmaciones y con-clusiones se considera esencial, y todos los ciudadanos deben saber realizar juicios sobre los aspectos de sus vidas que se ven afectados por las ciencias. Todo ciudadano necesita saber cuándo resulta pertinente el conocimiento científico y discernir entre las preguntas que la ciencia es capaz de responder y las que no. Los ciudadanos tienen que poder juzgar cuándo una prueba es válida, tanto en lo referente a su pertinencia como al modo en que se ha obtenido. Sin embargo, lo más importante de todo es que los ciudadanos nece-sitan ser capaces de relacionar las pruebas factuales con las conclusiones extraídas de ellas y de sopesar las pruebas a favor y en contra de determinadas acciones que afecten a la vida personal, social o global.
Las distinciones que acabamos de hacer se resumen brevemente diciendo que se da prioridad a los procesos sobre la ciencia en lugar de a los procesos internos a la ciencia. Es importante que los procesos del Cuadro 3.2 se entiendan como procesos sobre la ciencia principalmente y no como destrezas que hay que emplear dentro de la ciencia. Todos los procesos del Cuadro 3.2 comportan conocimiento científico. En el primer proceso el conocimiento científico es el factor esencial; en los procesos segundo y tercero este conocimiento es necesario, pero no suficiente, porque es imprescindible el conocimiento sobre la recopilación y el empleo de las pruebas científicas.

Cuadro 3.2. Los procesos científicos del proyecto PISA 2003

\section{Ciencias}

- Describir, explicar y predecir fenómenos científicos

- Entender la investigación científica

- Interpretar las pruebas y conclusiones científicas

A continuación se detallan con más detalle estos procesos.

\section{Describir, explicar y predecir los fenómenos científicos}

En este proceso los estudiantes demuestran su comprensión a través de la aplicación a una situación dada del conocimiento científico apropiado. Deben poder describir o explicar los fenómenos y predecir los cambios y, en algunos casos, reconocer o identificar las descripciones, explicaciones o predicciones que resulten pertinentes.

\section{Comprender la investigación científica}

La comprensión de la investigación científica comporta reconocer y comunicar preguntas que pueden ser investigadas científicamente y saber lo que forma parte de tales investigaciones. Comporta especialmente reconocer de manera científica las preguntas susceptibles de investigación o formular una pregunta susceptible de ser investi- gada de manera científica en una situación dada. También engloba la identificación o el reconocimiento de los hechos necesarios para subyacer a una investigación científica: por ejemplo, los datos que deben compararse, las variables que deben ser modificadas o controladas, las informaciones adicionales necesarias o las acciones que deben realizarse para poder recopilar los datos relevantes.

\section{Interpretar las pruebas y conclusiones científicas}

Esto significa dar sentido a los hallazgos científicos de modo que prueben determinadas afirmaciones o conclusiones. Puede conllevar la evaluación de la información científica y la extracción de conclusiones basadas en pruebas científicas y su posterior comunicación. También puede comportar elegir una conclusión alternativa en relación con las pruebas disponibles y comunicarla, dar argumentos a favor o en contra de una conclusión dada a través de los datos proporcionados, identificar los supuestos de los que se ha partido para llegar a una conclusión 
o reflexionar sobre las implicaciones sociales de las conclusiones científicas.

Para todos estos procesos es necesario cierto conocimiento científico. No obstante, en el caso de los procesos segundo y tercero, el conocimiento no constituye la principal dificultad, puesto que se trata de evaluar los procesos mentales que forman parte de la recopilación, evaluación y comunicación de las pruebas científicas válidas. Por el contrario, en el primer proceso lo que se evalúa es la comprensión de las ideas científicas involucradas, y, por tanto, constituye la dificultad mayor.

Es importante señalar que para cada uno de los procesos enumerados existe un amplio abanico de dificultad en las preguntas de la prueba, que dependerá del conocimiento científico y de las áreas de aplicación correspondientes. La elaboración de las pruebas OCDE/PISA garantiza, a través de las reacciones de los países y de la prueba piloto, que las preguntas seleccionadas para la prueba final posean el nivel de dificultad adecuado para los jóvenes de 15 años.

\section{SITUACIONES O CONTEXTO: ÁREAS DE APLICACIÓN}

Tal y como se ha mencionado anteriormente, el proyecto OCDE/PISA evalúa conocimientos científicos importan-tes y relevantes para los planes de estudios de ciencias de los países participantes, sin verse limitado por el denominador común de los currículos nacionales. De acuerdo con su enfoque de la competencia científica, el proyecto requiere la aplicación de determinados conocimientos científicos y el empleo de procesos científicos en situaciones que reflejan el mundo real y que movilizan ideas científicas.

El Cuadro 3.3 enumera las áreas de aplicación de la ciencia que suscitan cuestiones que los ciudadanos de hoy y de mañana necesitan comprender para tomar las decisiones que correspondan. Son estas áreas de aplicación las que promueven la selección del contenido de las unidades y de sus correspondientes preguntas. El Cuadro 3.3 indica las áreas de aplicación en que se evaluarán los procesos y los conocimientos científicos.

Cuadro 3.3. Áreas de aplicación de la evaluación de ciencias

\section{La ciencias de la vida y la salud}

- Salud, enfermedad y nutrición

- Preservación y uso sostenible de las especies

- Interdependencia de los sistemas físicos y biológicos

\section{Las ciencias de la Tierra y el medio ambiente}

- Contaminación

- Producción y pérdida de suelo

- Tiempo y clima

\section{Las ciencias aplicadas a la tecnología}

- Biotecnología

- Empleo de materiales y eliminación de residuos

- Utilización de la energía

- Transporte 
A la hora de elegir las preguntas de prueba es importante considerar no sólo el área de aplicación sino tam-bién el contexto en el que se plantearán los ejercicios. Al hacer la selección del contexto, es importante tener en cuenta que el propósito del proyecto OCDE/PISA es evaluar la capacidad de los alumnos para aplicar las destrezas y los conocimientos adquiridos al término de la enseñanza obligatoria. El proyecto OCDE/PISA requiere que las preguntas de evaluación se enmarquen en situaciones de la vida en general, sin limitarse a la vida en el centro educativo. En el escenario del centro educativo, se pueden limitar los conocimientos y procesos científicos al ámbito de la clase o del laboratorio; sin embargo, cada vez más se están intentando aplicar al mundo extraescolar, incluso en los currículos de ciencias de los diferentes países participantes.

Las situaciones del mundo real conllevan problemas que nos afectan como individuos (p. ej., la alimentación y la utilización de la energía), como miembros de una comunidad local (p. ej., el tratamiento del abastecimiento de agua o la ubicación de una central eléctrica) o como ciudadanos del mundo (p. ej., el calentamiento global o la pérdida de biodiversidad). Todo ello debe estar representado en el abanico de preguntas de las pruebas del proyecto OCDE/PISA. Otro tipo de contexto apropiado para algunos temas es el histórico, donde puede evaluarse la comprensión de los avances del conocimiento científico. En el marco del proyecto OCDE/PISA, el en-foque de las preguntas se centra en asuntos relativos al individuo y la familia (personal), a la comunidad (público), a la vida en el mundo (global) y aquellos que muestran la manera en que el conocimiento científico evoluciona e influye en las decisiones sociales asociadas a la ciencia (importancia histórica).

En un estudio internacional es importante que las áreas de aplicación empleadas para las preguntas de las pruebas se seleccionen según su importancia en relación a los intereses y la vida de los alumnos de todos los países. Dichas preguntas deben ser apropiadas para evaluar el conocimiento y los procesos científicos. En el desarrollo y selección de las preguntas hay una preocupación especial por las diferencias culturales, no sólo en aras de la validez de la evaluación, sino por el respeto a los diferentes valores y tradiciones de los países participantes. Las áreas de aplicación seleccionadas para las preguntas del estudio son pertinentes y apropiadas para los diferentes países al tiempo que comportan la combinación deseada de conocimiento científico y de aplicación de procesos científicos.
Mediante la selección de estas áreas de aplicación y estas situaciones, el proyecto OCDE/PISA pretende evaluar la aplicación del conocimiento que probablemente se ha adquirido a través del currículum de ciencias (aunque parte del conocimiento puede haberse obtenido también a través de otras asignaturas o de fuentes extraescolares). Sin embargo, aunque el conocimiento exigido sea el curricular, para averiguar si éste ha traspasado el aprendizaje de los hechos aislados y sirve al desarrollo de la competencia científica el proyecto OCDE/PISA evalúa la aplicación de este conocimiento en preguntas que reflejan situaciones de la vida real. Algunos de los ejemplos que se presentan más adelante ayudan a explicar este punto.

\section{Características de la prueba y ejemplos}

De acuerdo con la definición de competencia científica del proyecto OCDE/PISA, cada pregunta requerirá la utilización de uno de los procesos del Cuadro $3.2 \mathrm{y}$, como ya se ha apuntado, cierto conocimiento científico. Tal y como demuestran los ejemplos que se incluyen más abajo, Lo que se denomina una unidad comprenderá varias preguntas vinculadas a un estímulo inicial. Cada una de las preguntas de una unidad ha sido concebida para evaluar principalmente uno de los procesos científicos del Cuadro 3.2., sin embargo, algunas puede evaluar también otros procesos y poner en juego otros conceptos científicos.

Una razón para utilizar esta estructura es elaborar las unidades de un modo tan realista como sea posible y reflejar en ellas una parte de la complejidad de las situaciones de la vida real. Otra razón tiene que ver con una utilización eficiente del tiempo de prueba, puesto que reduce el tiempo que el estudiante necesita para introducirse en el tema de la unidad al presentar menos situaciones formulando varias preguntas sobre ellas en lugar de plantear preguntas aisladas sobre un mayor número de situaciones diferentes. Sin embargo, hay que tener en cuenta que ninguna puntuación sea dependiente de las demás. También se reconoce lo importante que es reducir el posible sesgo que se introduce cuando se utiliza un número de situaciones reducido.

Ayudarán a explicar este significado operacional los siguientes ejemplos de preguntas que evalúan algunos de los procesos evaluados. 


\section{Ciencias, Unidad 1: ¡DETENGAN A ESE GERMEN!}

El Proceso 2 se evalúa en dos preguntas de esta unidad. Los estudiantes tienen que leer un texto breve sobre la historia de la vacunación.

Ya en el siglo XI, los médicos chinos manipulaban el sistema inmunitario. Al soplar polvo de costras de un enfermo de viruela en los orificios nasales de sus pacientes, a menudo podían provocar una enfermedad leve que evitaba un ataque más grave posterior. Hacia 1700, la gente se frotaba la piel con costras secas para protegerse de la enfermedad. Estas prácticas primitivas se introdujeron en Inglaterra y en las colonias americanas. En 1771 y 1772, durante una epidemia de viruela, un médico de Boston Ilamado Zabdiel Boylston puso a prueba una idea que tenía. Arañó la piel de su hijo de seis años y de otras 285 personas y frotó el pus de las costras de viruela en las heridas. Sobrevivieron todos sus pacientes a excepción de seis.

\section{Ciencias, Ejemplo 1.1:}

\section{¿Qué idea estaba tratando de poner a prueba Zabdiel Boylston?}

\section{Criterios de corrección y comentarios sobre el ejemplo 1.1}

Máxima puntuación

Código 2: Respuestas que hagan referencia tanto a:

- la idea de que inocular a alguien con viruela le proporciona cierta inmunidad.

$\mathrm{Y}$ a:

- la idea de que al arañar la piel la viruela pasa al flujo sanguíneo.

Puntuación parcial

Código 1: Respuestas que hacen referencia a una sola de las dos ideas anteriores.

Ninguna puntuación

Código 0: Otras respuestas.

Tipo de pregunta: Pregunta de respuesta construida abierta

Proceso: Comprensión de la investigación científica (Proceso 2)

Concepto: Biología humana

Situación: Ciencias de la vida y la salud 


\section{Ciencias, Ejemplo 1.2:}

Enumera otras dos de informaciones que necesitarías para determinar el grado de éxito del método de Boylston.

\section{Criterios de corrección y comentarios sobre el ejemplo 1.2}

Máxima puntuación

Código 2: Respuestas que incluyen las DOS informaciones siguientes:

- el índice de supervivencia sin el tratamiento de Boylston;

Y:

- si los pacientes estuvieron expuestos a la viruela al margen del tratamiento.

Puntuación parcial

Código 1: Respuestas que indican solo una de las dos ideas anteriores.

Ninguna puntuación

Código 0: Otras respuestas.

Tipo de pregunta: Pregunta de respuesta construida abierta

Proceso: Comprensión de la investigación científica (Proceso 2)

Concepto: Biología humana

Situación: Ciencias de la vida y la salud 
Las cuatro preguntas siguientes forman parte de una unidad cuyo estímulo es un fragmento sobre Peter Cairney, quien trabaja para el Australian Road Research Board (Consejo Australiano de Investigación Vial). A continuación se presenta el estímulo.

...Otra manera que tiene Peter de obtener información para mejorar la seguridad de las carreteras es el uso de una cámara de televisión colocada sobre un poste de 13 metros para filmar el tráfico de una carretera estrecha. Las imágenes muestran a los investigadores cosas tales como la velocidad del tráfico, la distancia entre los coches y qué parte de la carretera utilizan. Después de algún tiempo se pintan líneas divisorias en la carretera. Los investigadores pueden utilizar la cámara de televisión para observar si el tráfico es ahora diferente. ¿Es el tráfico ahora más rápido o más lento? ¿Van los coches más o menos distanciados entre sí que antes? ¿Los automovilistas circulan más cerca del margen de la carretera o más cerca del centro ahora que hay líneas? Cuando Peter conozca todo esto podrá recomendar sobre si hay que pintar o no pintar líneas en carreteras estrechas.

\section{Ciencias, Ejemplo 2.1:}

Si Peter quiere estar seguro de que está recomendando lo correcto, quizá deba obtener más información además de sus filmaciones. De las afirmaciones siguientes, ¿cuál o cuales le ayudarían a estar más seguro de su recomendación sobre los efectos de pintar líneas en carreteras estrechas?
A. Hacer lo mismo en otras carreteras estrechas
Sí / No
B. Hacer lo mismo en otras carreteras anchas
Sí / No
C. Comprobar el número de accidentes un tiempo antes y después de pintar las líneas
Sí / No
D. Comprobar el número de coches que utilizan
la carretera antes y después de pintar las líneas Sí / No

\section{Criterios de corrección y comentarios sobre el ejemplo 2.1}

Máxima puntuación

Código 2: Sí, No, Sí, No, en este orden.

Puntuación parcial

Código 1: Sí, No, No, No, en este orden.

Ninguna puntuación

Código 0: Cualquier otra combinación de respuestas.

Tipo de pregunta: Elección múltiple compleja

Proceso: Comprensión de la investigación científica (Proceso 2)

Concepto: Fuerzas y movimiento

Situación: Ciencias y tecnología 


\section{Ciencias, Ejemplo 2.2:}

Supón que Peter se da cuenta de que, tras haber pintado líneas divisorias en un cierto tramo de carretera estrecha, el tráfico cambia tal y como se indica a continuación.
Velocidad
El tráfico va más rápido
Posición
El tráfico se mantiene más cerca de los márgenes de la carretera
Distancia de separación
Ningún cambio

A la vista de estos resultados se decidió que deberían pintarse líneas en todas las carreteras estrechas. ¿Crees que ésta fue la mejor decisión? Explica tus razones para estar a favor o en contra.

Estoy a favor

Estoy en contra

Razón:

\section{Criterios de corrección y comentarios sobre el ejemplo 2.2}

Máxima puntuación

Código 1: Respuestas que están de acuerdo o en desacuerdo con la decisión por razones coherentes con la información dada. Por ejemplo:

- de acuerdo porque hay menos posibilidad de chocar si el tráfico se mantiene cerca de los márgenes de la carretera, incluso aunque vaya más rápido;

- de acuerdo porque si el tráfico va más rápido, hay menos necesidad de adelantar;

- en desacuerdo porque, si el tráfico va más rápido y se mantiene la misma distancia entre los coches, esto significa que los conductores no tienen espacio suficiente para detenerse en caso de emergencia.

Ninguna puntuación

Código 0: $\quad$ Respuestas a favor o en contra pero que no especifican las razones o dan razones que no tienen relación con el problema.

Tipo de pregunta: Pregunta de respuesta construida abierta

Proceso: Interpretación de las pruebas científicas y conclusiones (Proceso 3)

Concepto: Fuerzas y movimiento

Situación: Ciencia y tecnología 
Ciencias, Ejemplo 2.3:

Se aconseja a los conductores que dejen más espacio entre su vehículo y el de delante cuando viajan a mayor velocidad que cuando viajan a menor velocidad, porque los coches que van más rápido necesitan más tiempo para frenar.

Explica por qué un coche que va más rápido necesita más distancia para detenerse que un coche que va más lento.

Razones:

\section{Criterios de corrección y comentarios sobre el ejemplo 2.3}

Máxima puntuación

Código 2: Respuestas que mencionan que:

- La mayor inercia de un vehículo que va más rápido significa que, dada la misma fuerza, avanzará más mientras reduce su velocidad que un vehículo que va más lento.

Y:

- Cuanto mayor es la velocidad, más tiempo se necesita para reducirla a cero, así que el coche avanzará más en este tiempo.

Puntuación parcial

Código 1: Respuestas que indican sólo una de las dos ideas anteriores.

Ninguna puntuación

Código 0: $\quad$ Otras respuestas, o repetición de la afirmación, p. ej., que necesita más tiempo para detenerse debido a su velocidad.

Tipo de pregunta: Pregunta de respuesta construida abierta

Proceso: Descripción, explicación y predicción de los fenómenos científicos (Proceso 1)

Concepto: Fuerzas y movimiento

Situación: Ciencia y tecnología 
Ciencias, Ejemplo 2.4:

Al ver la televisión, Peter ve un coche (A) que va a $45 \mathrm{~km} / \mathrm{h}$ que es adelantado por otro coche (B) que va a $60 \mathrm{~km} / \mathrm{h}$. ¿A qué velocidad le parece que va el coche B a alguien que va viajando en el coche A?
A. $\quad 0 \mathrm{~km} / \mathrm{h}$
B $\quad 15 \mathrm{~km} / \mathrm{h}$
C. $\quad 45 \mathrm{~km} / \mathrm{h}$
D. $\quad 60 \mathrm{~km} / \mathrm{h}$
E. $\quad 105 \mathrm{~km} / \mathrm{h}$

\section{Criterios de corrección y comentarios sobre el ejemplo 2.4}

Máxima puntuación

Código 1: Respuesta B: $15 \mathrm{~km} / \mathrm{h}$

Ninguna puntuación

Código 0: Otras respuestas.

Tipo de pregunta: Elección múltiple

Proceso: Descripción, explicación y predicción de los fenómenos científicos (Proceso 1)

Concepto: Fuerzas y movimiento

Situación: Ciencia y tecnología 


\section{Ciencias, Unidad 3: MAÍZ}

Las siguientes tres preguntas se han extraído de una unidad llamada Maíz. El estímulo es un artículo de periódico sobre un agricultor, Auke Ferweda, que quema maíz en su estufa a modo de combustible.

...Ferwerda señala que el maíz que se utiliza como pienso para el ganado es, en realidad, un tipo de combustible. Las vacas comen maíz para conseguir energía. Pero, según explica Ferwerda, la venta del maíz como combustible en lugar de como pienso podría ser mucho más rentable para los granjeros.

Ferwerda sabe que el medio ambiente recibe cada vez más atención y que la legislación estatal para proteger el medio ambiente cada vez es más compleja. Lo que Ferwerda no acaba de entender es la cantidad de atención que se está dedicando al dióxido de carbono. Se le considera la causa del efecto invernadero. También se dice que el efecto invernadero es la causa principal del aumento de la temperatura media de la atmósfera de la Tierra. Sin embargo, desde el punto de vista de Ferweda no hay nada malo en el dióxido de carbono. Al contrario, él aduce que las plantas y los árboles lo absorben y lo convierten en oxígeno para los seres humanos.

Él afirma: "Ésta es un área agrícola y los agricultores cultivan maíz. Tiene una etapa larga de crecimiento, absorbe mucho dióxido de carbono y emite mucho oxígeno. Hay muchos científicos que dicen que el dióxido de carbono no es la causa principal del efecto invernadero".

\section{Ciencias, Ejemplo 3.1:}

Ferwerda compara el uso del maíz como combustible con el maíz que se usa como alimento.

La primera columna de la tabla siguiente contiene una lista de fenómenos que pueden producirse cuando se quema maíz como combustible.

¿Se producen también esos fenómenos cuando el maíz actúa como combustible en el cuerpo de un animal?

Rodea con un círculo Sí o No para cada una de ellos.

Cuando se quema maíz:

Se consume oxígeno.

Se produce dióxido de carbono.

Se produce energía.
¿Tiene también esto lugar cuando el maíz actúa como combustible en el cuerpo de un animal?
Sí / No

Sí / No

Sí / No 


\section{Criterios de corrección y comentarios sobre el ejemplo 3.1}

Máxima puntuación

Código 1: Sí, Sí, Sí, en este orden. (Todas las partes deben haber sido contestadas correctamente, dado que cualquier error indicaría algún fallo de comprensión del proceso de transforma-ción de alimentos en el cuerpo de un animal.)

Ninguna puntuación

Código 0: Cualquier otra combinación de respuestas.

Tipo de pregunta: Elección múltiple compleja

Proceso: Descripción, explicación y predicción de los fenómenos científicos (Proceso 1)

Concepto: Cambios químicos y físicos

Situación: Ciencias de la vida y la salud

\section{Ciencias, Ejemplo 3.2:}

En el artículo se describe la transformación del dióxido de carbono: “...las plantas y los árboles lo absorben y lo convierten en oxígeno...".

Hay más sustancias que participan en esta transformación aparte del dióxido de carbono y el oxígeno. La transformación puede representarse de la siguiente manera:

dióxido de carbono + agua $\longrightarrow$ oxígeno +

Escribe en el cuadro el nombre de la sustancia que falta.

\section{Criterios de corrección y comentarios sobre el ejemplo 3.2}

Máxima puntuación

Código 1: Respuestas que indiquen cualquiera de las opciones siguientes: glucosa, azúcar, hidrato(s) de carbono, sacárido(s), almidón.

Ninguna puntuación

Código 0: Otras respuestas.

Tipo de pregunta: Pregunta de respuesta constuida abierta

Proceso: Descripción, explicación y predicción de los fenómenos científicos (Proceso 1)

Concepto: Transformaciones de la energía

Situación: Ciencias de la vida y la salud 
Ciencias, Ejemplo 3.3:

Al final del artículo, Ferwerda se refiere a los científicos que dicen que el dióxido de carbono no constituye la causa principal del efecto invernadero.

Carolina encuentra la siguiente tabla, en la que se muestran ciertos resultados de las investigaciones sobre los cuatro gases principales causantes del efecto invernadero.

Efecto invernadero relativo por molécula de gas

\begin{tabular}{c|c|c|c}
\hline Dióxido de carbono & Metano & Óxido nitroso & Clorofluorocarbonos \\
1 & 30 & 160 & 17.000
\end{tabular}

A partir de esta tabla, Carolina concluye que el dióxido de carbono no es la causa principal del efecto invernadero. No obstante, esta conclusión es prematura. Estos datos deben combinarse con otros datos para poder concluir si el dióxido de carbono es o no la causa principal del efecto invernadero.

¿Qué otros datos debe conseguir Carolina?
A. Datos sobre el origen de los cuatro gases.
B. Datos sobre la absorción de los cuatro gases que realizan las plantas.
C. Datos sobre el tamaño de cada uno de los cuatro tipos de moléculas.
D. Datos sobre la cantidad de cada uno de los cuatro gases en la atmósfera.

\section{Criterios de corrección y comentarios sobre el ejemplo 3.3}

Existe una relación estrecha entre saber que la concentración de una sustancia influye en su capacidad de acción y reconocer que no puede extraerse una conclusión válida sin esta información adicional.

Máxima puntuación

Código 1: Respuesta D: Datos sobre la cantidad de cada uno de los cuatro gases en la atmósfera.

Ninguna puntuación

Código 0: Otras respuestas.

Tipo de pregunta: Elección múltiple

Proceso: Interpretación de las pruebas científicas y conclusiones (Proceso 3)

Concepto: Estructura y propiedades de la materia

Situación: Ciencias de la Tierra y el medio ambiente 
Para contestar todas estas preguntas, el alumno necesita emplear el conocimiento adquirido a través del currículum de ciencias y aplicarlo en una situación nueva. Cuando la evaluación de los conocimientos científicos no es el objetivo principal de la pregunta, el conocimiento necesario no representa el obstáculo (o impedimento) principal, de modo que la resolución debe depender de la capacidad para realizar el proceso implicado. Al contrario, cuando la evaluación del conocimiento científico es el objetivo principal (como en los Ejemplos 2.3, 2.4, $3.1 \mathrm{y}$ 3.2 ), el proceso que se requiere del alumno lo constituye la comprensión de conocimiento referenciado.

\section{Estructura de las pruebas}

Las unidades de prueba contienen hasta ocho preguntas que se puntúan de manera independiente. En la mayor parte de las unidades, si no en todas, hay unas preguntas que implican conocimiento y comprensión de los conceptos científicos a los que se hace referencia (como en los Ejemplos 2.3 2. 2.4 3.1 y 32.) y otras que piden al alumno la aplicación de uno o varios procesos de recopilación de datos y de utilización de pruebas factuales en una investigación científica, como en los Ejemplos 1.1, 1.2, 2.1, 2.2 y 3.3. Tal y como se ha indicado anteriormente, el proyecto OCDE/PISA no incluye unidades que requieran manipulación práctica, al menos en los ciclos 2000 y 2003 en los que las ciencias constituyen un área de evaluación secundaria.

En el Cuadro 3.4 se presenta el reparto deseado en la evaluación para los procesos en porcentajes de pun-tuación. Éste deberá revisarse para el ciclo de 2006, cuando las ciencias sean el área de conocimiento principal del proyecto OCDE/PISA.

Cuadro 3.4. Distribución recomendada de la puntuación en los procesos científicos

Procesos científicos

Proceso 1: Describir, explicar

y predecir fenómenos científicos

Proceso 2: Entender la investigación científica

Proceso 3: Interpretar las pruebas

y conclusiones científicas

TOTAL
\% de puntuación de las unidades de ciencias del proyecto OCDE/PISA
Puede suceder perfectamente que los temas de ciertas unidades tiendan más hacia la evaluación del conocimiento (Proceso 1) y que con otros ocurra precisamente lo contrario. Siempre que sea posible deberá haber en todas las unidades preguntas que evalúen los Procesos 2 y 3 y preguntas que evalúen el Proceso 1. Esto se hace con el objeto de cubrir el conocimiento científico relevante que los estudiantes probablemente han desarrollado a través del currículum de ciencias o fuera de la escuela, y también porque la habilidad para emplear los procesos depende en gran medida de la situación en que se utilizan. Los objetivos del proyecto OCDE/PISA establecen que el conocimiento científico y la combinación de dicho conocimiento con la capacidad para extraer conclusiones basadas en hechos son resultados de formación valiosos. El objetivo recomendado de asignar una cifra similar de puntos a estos dos tipos de resultados debería servir a estos objetivos. 
Tal y como se ha indicado anteriormente, todas las preguntas tendrán en cuenta el uso del conocimiento científico que los alumnos hayan desarrollado probablemente a lo largo del currículum de ciencias escolar. Las preguntas de ciencias del proyecto OCDE/PISA se diferencian de otras evaluaciones de ciencias - pero no de todas - en que exigen que el conocimiento se aplique a situaciones de la vida real. De manera análoga, entre los objetivos de muchos currículos de ciencias se encuentra la capacidad para extraer conclusiones basadas en hechos.
La evaluación OCDE/PISA exige la aplicación de procesos en situaciones que traspasan el escenario del aula o del laboratorio escolar. El grado en que esto resulte novedoso para los estudiantes dependerá de lo apartadas que se encuentren las aplicaciones del mundo real del currículum que hayan tratado.

En relación a las áreas de aplicación, el Cuadro 3.5 muestra que el reparto de puntos será lo más igualitario posible entre los tres grupos principales.

Cuadro 3.5. Distribución recomendada de la puntuación por áreas de aplicación

Áreas de aplicación

Ciencias de la vida y la salud

Ciencias de la Tierra y el medio ambiente

Ciencias aplicadas a la tecnología

TOTAL
\% de puntuación de las unidades de ciencias del proyecto OCDE/PISA
Cada unidad de prueba se define mediante un estímulo determinado, que puede ser un pasaje corto o un escrito acompañado de una tabla, cuadro, gráfico o diagrama. Las preguntas forman un conjunto de pre-guntas puntuadas de manera independiente, que deben elaborarse conforme a un formato de elección múl-tiple, respuesta abierta breve o respuesta abierta larga. La diferencia entre una respuesta abierta breve y una larga es que esta última precisa ser puntuada por varios correctores, mientras que la primera puede ser puntuada de manera fiable por un único corrector.

Hasta ahora, dado que las ciencias han sido un área de conocimiento secundaria en los estudios PISA, el número de unidades y preguntas desarrolladas y evaluadas en las pruebas piloto ha sido limitado. No obs-tante, a partir de esta experiencia podemos resumir el formato de las pruebas para 2003:
- Con sólo una excepción, las unidades constan de varias preguntas; estas preguntas evalúan uno o más conocimientos científicos o contextos (Cuadro 3.1), procesos científicos (Cuadro 3.2) y conocimientos relativos a una o más áreas de aplicación de la ciencia (Cuadro 3.3); y requieren respuestas sobre papel, escritas o dibujadas.

- En el ciclo 2003, al igual que en el 2000, las unidades se presentan por escrito, aunque se está investigando la utilización de estímulos presentados de distinta forma para el ciclo 2006, en el las ciencias constituirán el área de evaluación principal.

- Algunas unidades conllevan aspectos ligados a la lectura o a las matemáticas, pero no hay ninguna pregunta que requiera sólo una identificación de la información del estímulo sin necesidad de algún otro tipo 
de procesamiento científico adicional, ni preguntas que conlleven únicamente recordar información aislada.

Para cubrir el abanico de destrezas y comprensión definido en este marco conceptual se necesitan diferentes formatos de respuesta. Pueden elaborarse, por ejemplo, preguntas de elección múltiple para evaluar de manera válida los procesos que conlleven una identificación o selección. Sin embargo, para evaluar la capacidad de evaluación y comunicación, un formato de respuesta abierta ofrecerá probablemente una validez y autenticidad mayores. En muchos casos, sin embargo, el formato más adecuado dependerá del contenido particular de la pregunta.

\section{Escalas de presentación de resultados}

Para cumplir los objetivos del proyecto OCDE/PISA es esencial el desarrollo de escalas del rendimiento de los alumnos. El proceso de obtención de una escala debe ser iterativo para que las descripciones iniciales —que se basan en los resultados de las pruebas piloto y final del estudio del año 2000 y en la experiencia de evaluar el rendimiento en ciencias y los hallazgos derivados de la investigación del aprendizaje y del desarrollo cognitivo en ciencias- puedan modificarse a medida que se vayan obteniendo más datos de otros estudios y pruebas.

El proyecto PISA 2000 (en el que las ciencias eran un área menor y por tanto proporcionaba una información limitada) presentó la competencia en ciencias según una escala de media 500 y desviación típica 100. Aunque no se identificaron niveles de competencia, fue posible describir lo que los estudiantes pueden hacer en tres de los puntos de esta escala:

- En la parte superior de la escala (en torno a 690 puntos) los estudiantes son capaces de crear o emplear modelos conceptuales para realizar predicciones o dar explicaciones, analizar investigaciones científicas para captar, por ejemplo, el diseño de un experimento o identificar una de las ideas examinadas, comparar datos para evaluar puntos de vista o perspectivas dife- rentes, y comunicar argumentos científicos y/o descripciones de manera detallada y precisa.

- En torno a los 550 puntos, por lo general los alumnos son capaces de emplear el conocimiento científico para realizar predicciones o dar explicaciones, reconocer preguntas a las que puede responderse mediante la investigación científica y/o identificar detalles de lo que está implicado en una investigación científica y seleccionar información importante a partir de datos contrarios o razonamientos encadenados a la hora de extraer o evaluar conclusiones.

- Hacia la parte inferior de la escala (unos 400 puntos) los alumnos son capaces de recordar un conocimiento científico simple y objetivo (p. ej., nombres, hechos, terminología, reglas simples) y de utilizar el conocimiento científico común a la hora de extraer o evaluar conclusiones.

En el ciclo PISA 2003 probablemente se seguirá un formato similar para la presentación de los resultados de ciencias. No obstante, en el año 2006, cuando el tiempo de prueba disponible permita una mayor cobertura del conocimiento y de las áreas de aplicación en ciencias, será posible presentar subescalas para los procesos incluidos en el Cuadro 3.2 (además de la inclusión de puntos de corte específicos que identifiquen los niveles de competencia). Ello incluirá, por tanto, una subescala referente al conocimiento científico (Proceso 1) que debe evaluarse a través de su aplicación en las situaciones presentadas.

En 2006 se contará con información suficiente de los procesos científicos enumerados en el Cuadro 3.2 como para considerar la presentación del rendimiento en las principales áreas de conocimiento de ciencias. Esto dependerá de consideraciones estadísticas, conceptuales y de política educativa. Si resultase factible la presentación de subescalas, los países contarían con la ventaja de poder comparar detalladamente los resultados de su formación en ciencias con los resultados que consideraran deseables.

Informar sobre el contenido de las diferentes preguntas, y de las respuestas incorrectas a las mismas, es un complemento 
importante a los resultados estadísticos. Se espera que esta categorización de los contenidos se apoye sobre los resultados de la prueba piloto y se relacione con los tipos de respuestas dadas por los estudiantes. También será necesario presentar algunos tipos de respuestas a preguntas específicas para ilustrar las escalas y para poderles asignar etiquetas descriptivas. Esto implicará hacer públicas algunas de las preguntas utilizadas en las pruebas OCDE/PISA.

También resultarían convenientes otros tipos de presentación, lo que podría convertirse en realidad tras el estudio principal de ciencias en 2006. Uno de ellos sería el del rendimiento por grupos de preguntas de diversas unidades con relación a distintas áreas de aplicación de las ciencias. Esta información sería útil para considerar si se ha prestado la atención precisa y suficiente a temas que son objeto de preocupación actual.

\section{Otras cuestiones}

Cuando la información para una unidad de evaluación de ciencias se presenta como un pasaje escrito, pueden evaluarse aspectos relativos a la lectura. De manera análoga, cuando la información se presenta en forma de tablas, diagramas, gráficos, etc., puede evaluarse la capacidad de leer información, y cuando se precisa cierto manejo numérico, se pueden evaluar diversos aspectos de matemáticas. Este tipo de unidades formará parte de la secciones combinadas de las pruebas. Otras unidades evaluarán únicamente procesos científicos que comporten extraer conclusiones basadas en hechos y mostrar que se comprenden los conceptos científicos.

Los estudios de ciencias de los años 2000 y 2003, en los que la ciencia es un área secundaria, serán la base de futuras comparaciones temporales. La limitación del número de las unidades de evaluación en los años 2000 y 2003 (incluso dentro de un diseño que permite que los distintos conjuntos de preguntas sean respondidos por varias submuestras de alumnos) supone que hay menos unidades relativas a cada área de aplicación de la ciencia de las que habrá en 2006. Por tanto, los estudios secundarios de la competencia en ciencias conllevan la evaluación de todos los procesos enumerados en el Cuadro 3.2 y algunos de los conocimientos científicos (conceptos) y áreas de aplicación de los que se presentan en los Cuadros 3.1 y 3.3. En 2006, el año principal para las ciencias, se hará posible tener una cobertura mucho mayor de los conocimientos científicos y las áreas de aplicación. 


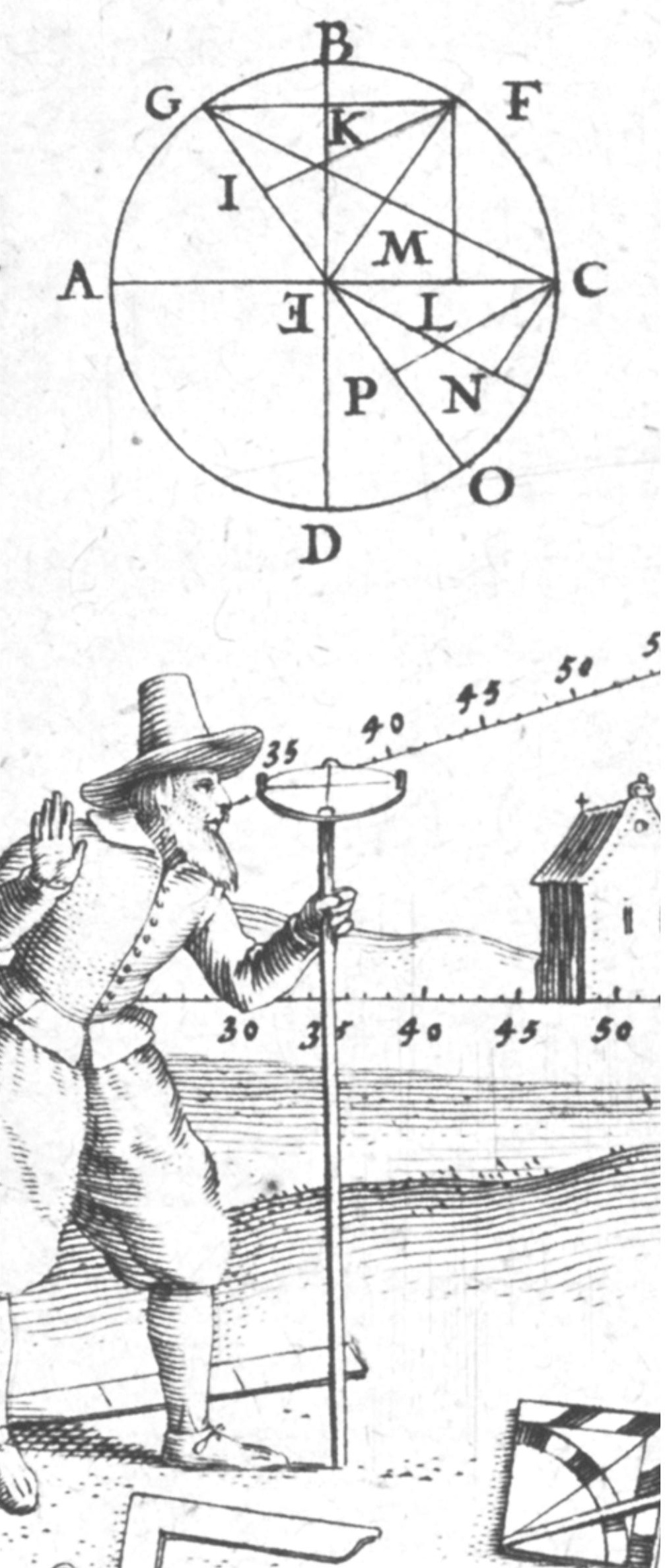

\section{ᄀ SOLUCIÓN DE PROBLEMAS}

\section{Introducción}

La solución de problemas constituye un objetivo educativo central en los programas escolares de todos los países. Los educadores y encargados de elaborar la política educativa están especialmente preocupados por la competencia de los estudiantes a la hora de resolver problemas en contextos reales. Ello comporta que sean capaces de comprender la información dada, identificar las características más importantes y sus interrelaciones, elaborar o aplicar una representación externa, resolver el problema y evaluar, justificar y comunicar sus soluciones. Los procesos de solución de problemas, entendidos según esta definición, se encuentran a lo largo de todo el currículum, en matemáticas, en ciencias, en ciencias humanas, en ciencias sociales y en muchas otras áreas de contenido. La solución de problemas ofrece una base para el aprendizaje futuro, para una participación efectiva dentro de la sociedad y para la realización de las actividades personales.

A pesar de que la solución de problemas es una actividad humana omnipresente, no resulta fácil desarrollar un marco que ponga de manifiesto sus componentes y que 
establezca mediciones del rendimiento de los alumnos. Algunos autores han observado la falta de una definición consensuada y exhaustiva de la solución de problemas (p. ej., Frensch y Funke, 1995; O’Neil, 1999). Sin embargo, existe una amplia colección de textos sobre el aprendizaje y otros temas relacionados (Bransford, Brown y Cocking, 1999; PEG, 2001) que tratan la solución de problemas, pero a menudo lo hacen sin explicitar una definición del término en su contexto.

El programa de evaluación OCDE/PISA desarrolla, administra e interpreta a escala internacional estudios sobre la competencia de los alumnos. El objetivo de este programa es informar sobre los niveles de competencia de los estudiantes en diferentes áreas de conocimiento. No obstante, el programa no se centra en informar sobre el grado de conocimiento curricular que han adquirido los estudiantes, sino más bien en describir las capacidades de los estudiantes en situaciones del mundo real, que exijan la aplicación de sus conocimientos de lectura, ciencias y matemáticas. Además de recopilar datos sobre el rendimiento de los estudiantes en estas áreas, la evaluación OCDE/PISA también recoge datos relativos a la capacidad interdisciplinar de los estudiantes para la solución de problemas.

\section{Antecedentes}

Para preparar el marco de solución de problemas del proyecto OCDE/PISA se analizaron los programas de investigación existentes que evaluaban las capacidades de los estudiantes para resolver problemas en entornos diferentes y novedosos. Se identificaron diversos estudios con resultados interesantes o formatos innovadores, entre los cuales pueden citarse los siguientes:

- la clinical reasoning test (prueba de razonamiento clínico) basada en estudios de casos de tratamiento de pacientes (Boshuizen et al., 1997);

- la overall-test (prueba global), sobre la toma de decisiones reales en la formación empresarial (Seger, 1997);

- la what if - test (prueba «y si...»), que estudia el conocimiento intuitivo que se utiliza al examinar simulacio nes de fenómenos científicos (Swaak y de Jong, 1996).
En una revisión más general de la investigación, se encontraron también iniciativas importantes. Por ejemplo, en matemáticas existe una larga tradición de estudio del aprendizaje y del razonamiento orientados a los problemas (Hiebert et al., 1996; Schoenfeld, 1992) y de las correspondientes estrategias de evaluación (Charles, Lester y O'Daffer, 1987; Dossey, Mullis y Jones, 1993). Los estudios de psicología detallan la importancia de que los alumnos conozcan el razonamiento analógico (Vosniadou y Ortony, 1989) y el razonamiento inductivo (Csapó, 1997). Klieme (1989) ofrece un estudio integrado sobre cómo evaluar la solución de problemas desde una perspectiva educativa, psicológico-cognitiva y psicométrica. Collis, Romberg y Jurdak (1986) elaboraron una prueba para evaluar la solución de problemas que utilizaba «super preguntas», cada una de las cuales estaba compuesta de una serie de subpreguntas dirigidas a niveles sucesivos de complejidad cognitiva. Otros estudios abordan la diferenciación entre los diversos niveles de complejidad de las tareas. Muchos se basan en el influyente trabajo de Bloom, Hasting y Madaus (1971). Otros tratan las expectativas de rendimiento del estudio TIMSS (Robitaille y Garden, 1996) y los diversos marcos conceptuales de evaluación PISA (OCDE, 1999 y 2000).

En los últimos años ha crecido el interés por evaluar la solución de problemas como una competencia interdisciplinar, pero los estudios sobre la evaluación de esta capacidad (Klieme, 2000; Mayer, 1992) no ofrecen marcos conceptuales para ello. Durante los últimos cinco años ha habido varios intentos de aplicar la solución de problemas interdisciplinar en algunas evaluaciones a gran escala. Trier y Peschar, participantes de la Red A de la OCDE (1995), trataron la solución de problemas como una de las cuatro competencias interdisciplinares importantes y elaboraron una prueba de viabilidad para dicha evaluación. Su ejercicio de ejemplo consistía en una tarea de planificación de tipo ensayo en la que los individuos tenían que programar el viaje de un club juvenil. Si bien pudieron recopilar datos, se toparon con dificultades al puntuar las respuestas.

De manera independiente, Frensch y Funke (1995) idearon diversas variantes experimentales de las pruebas de planificación, mientras que Klieme et al. (en prensa) desarrollaron una prueba de respuestas múltiples para medir 
la competencia en la solución de problemas, destinada a un programa de evaluación de un estado federal alemán. En esta evaluación, el ejercicio de planificación se descompuso en diversos pasos de acción: clarificación de objetivos, recopilación de información, planificación, toma de decisiones, ejecución del plan y evaluación del resultado. Cada tarea se trató mediante una serie de preguntas que exigían que los individuos juzgaran la coherencia de los objetivos, analizaran mapas, planificaciones y otros documentos, razonaran sobre el orden de actividades, detectaran posibles errores en la realización de las actividades y llevaran a cabo otras acciones relacionadas con la solución de problemas. Se está considerando incluir un sistema similar para medir la competencia de los alumnos en la solución de problemas en el estudio ISA (International Study of Adults, Estudio Internacional de la Población Adulta), antes llamado Adult Literacy and Life Skills Survey (ALLS, Estudio de la Competencia y Destrezas para la Vida de la Población Adulta) (Binkley et al., 1999).

En una variante nacional alemana realizada con 650 alumnos de 15 años dentro del proyecto PISA 2000, se puso en práctica y validó una serie de ocho evaluaciones interdisciplinares de solución de problemas (Klieme, 2000). El propósito era utilizar tantos datos de investigación cognitiva básica sobre solución de problemas como fuera posible para el desarrollo y la validación de nuevos instrumentos. Los resultados demostraron la viabilidad de la evaluación de solución de problemas interdisciplinares tanto por ordenador como sobre papel. Algunas de las conclusiones fueron las siguientes:

- las competencias de solución de problemas de tipo interdisciplinar se distinguen de las competencias relacionadas con otras áreas de conocimiento (matemáticas, ciencias y lectura);

- varios indicadores de la competencia analítica para la solución de problemas, entre ellos el ejercicio Bomba de bicicleta elaborado por Harry O'Neill (1999), el «enfoque por proyecto» y una prueba con problemas de transferencia analógicos, tenían un factor en común.

El objetivo del marco conceptual de evaluación de problemas OCDE/PISA ha sido el de ampliar los prototipos desarrollados en los estudios de investigación y viabilidad para llegar a un modelo que pudiera aplicarse a una evaluación a gran escala como parte del ciclo PISA 2003.

\section{Definición del área de conocimiento}

Al tratar las evaluaciones de la competencia de solución de problemas, Richard Mayer (1992) afirmó que los encargados de su diseño debían procurar que el alumno:

- se viera inmerso en procesos de razonamiento (o cognitivos) de orden superior con objeto de obtener soluciones de ejercicios realistas y auténticos que precisaran la integración de destrezas, y

- se vea expuesto a problemas no rutinarios que requirieran que éste invente una nueva estrategia de solución.

La evaluación de la solución de problemas debería ampliarse a situaciones no rutinarias que recurrieran a los conocimientos anteriores, combinaran áreas de conocimiento y requirieran que los sujetos evaluados integrasen conceptos, representaciones y procesos.

La mayoría de las personas implicadas en el estudio de la solución de problemas en ámbitos de investigación o prácticos y que usan una u otra noción del campo coincide en que, para describir la solución de problemas por parte de los alumnos, el punto principal está en describir los actos cognitivos que los estudiantes realizan para tratar y resolver los problemas y para comunicar las soluciones. Así, para el ciclo PISA 2003 se adopta la siguiente definición de solución de problemas:
La solución de problemas es la capacidad que tiene una persona de emplear los procesos cognitivos para enfrentarse a y resolver situa- ciones interdisciplinares reales en las que la vía de solución no resulta obvia de modo inmediato y en las que las áreas de conoci- miento o curriculares aplicables no se enmar- can dentro de una única área de matemáti- cas, ciencias o lectura 
Algunos de los términos de esta definición necesitan explicarse más detalladamente:

\section{procesos cognitivos}

Este aspecto de la solución de problemas tiene que ver con los diferentes elementos implicados en el acto de resolver un problema y los procesos cognitivos que subyacen a ellos, entre ellos los procesos de comprensión, descripción, representación, resolución, reflexión y comunicación. Estos procesos se tratarán con mayor profundidad en la sección siguiente.

\section{interdisciplinares}

Las evaluaciones OCDE/PISA actuales estudian principalmente el grado en que la solución de problemas se aplica a las distintas áreas de conocimiento. Los marcos conceptuales de lectura, matemáticas y ciencias evalúan destrezas de solución de problemas dentro de cada una de estas áreas. La evaluación de la solución de problemas del proyecto OCDE/PISA amplía el examen de las competencias de los estudiantes incluyendo una gama mayor de ejercicios de resolución de problemas que traspasa las fronteras entre las áreas curriculares tradicionales.

\section{reales}

La anterior definición de la solución de problemas centra su atención en la resolución de problemas de la vida real. Estos problemas exigen que los individuos aúnen conocimientos y estrategias para enfrentarse y resolver problemas característicos de situaciones reales. Tales problemas exigen que las personas se muevan entre diferentes representaciones, a veces relacionadas, y que muestren un cierto grado de flexibilidad en el modo en que recuerdan y aplican el conocimiento que poseen. Estos problemas exigen que los estudiantes tomen decisiones que puedan tener repercusiones inmediatas para las personas implicadas.

\section{Organización del área de conocimiento}

La definición de solución de problemas utilizada en el proyecto OCDE/PISA impone que los ejercicios deben depender necesariamente de estrategias y conocimientos específicos de los contextos o áreas de conocimiento. Por tanto, los contextos, áreas y situaciones en los que se evalúe la solución de problemas deben seleccionarse cuidadosamente. Deben tenerse en cuenta los siguientes elementos:

- Los tipos de problemas. Una definición general de la solución de problemas tiene que englobar una amplia gama de tipos. Para la evaluación PISA 2003 se han seleccionados tres tipos de problemas: toma de decisiones, análisis y diseño de sistemas y tratamiento de disfunciones. En el siguiente apartado se tratan estos tipos de problemas con detalle. Estos tres tipos engloban la mayor parte de los procesos de solución de problemas identificados hasta ahora. La evaluación de solución de problemas de la evaluación OCDE/PISA no incluye tipos como la solución de problemas inter personales o el análisis de textos argumentativos.

- El contexto del problema. Este componente trata de ubicar los problemas con relación a la experiencia de los estudiantes en materia de solución de problemas. Los contextos seleccionados deben encontrarse a una cierta distancia de las situaciones escolares y del currículum educativo de los estudiantes. Por consiguiente, los problemas del proyecto PISA 2003 deben emplear contextos de la vida personal, laboral, del tiempo libre, y de la comunidad y sociedad. Estos contextos abarcan un continuo que va desde el espacio personal a la conciencia cívica, e incluye contextos tanto curriculares como extracurriculares.

- Las disciplinas asociadas. Para reflejar el acento puesto en la vida real, la solución de problemas de este ciclo PISA engloba una amplia gama de disciplinas, entre ellas las matemáticas, las ciencias, la literatura, las ciencias sociales, la tecnología y el comercio. Como tal, la solución de problemas complementa las áreas de conocimiento principales, matemáticas, ciencias y lectura, del proyecto OCDE/PISA. Las destrezas y conocimientos asociados a un ejercicio de solución de problemas no quedarán limitados a ninguna de estas áreas de conocimiento, de manera que se evita una posible repetición.

- Los procesos de solución de problemas. ¿En qué grado es capaz el alumno de enfrentarte a un problema determinado y avanzar en el camino hacia la solución? 
¿Cómo podrá saberse si el estudiante ha comprendido la naturaleza de un problema, ha caracterizado el problema mediante la identificación de variables y relaciones, ha seleccionado y adaptado las representaciones de un problema, ha avanzado hacia una solución, ha reflexionado sobre el trabajo y, por último, ha comunicado los resultados?

- Las capacidades de razonamiento. Cada uno de estos procesos de solución de problemas requiere no sólo conocimientos, sino también destrezas o capacidades. Por ejemplo, a la hora de entender la situación de un problema, el alumno puede tener que distinguir entre lo que son hechos y lo que es únicamente una opinión. Para formular una solución, el alumno puede tener que identificar las relaciones entre las variables. Para seleccionar una estrategia, el alumno puede tener que considerar las causas y los efectos. Para comunicar los resultados, el alumno puede tener que organizar la información de manera lógica. Estas acciones precisan a menudo capacidades de razonamiento analítico, cuantitativo, analógico y combinatorio. Estas capacidades o destrezas constituyen las principales competencias implicadas en la solución de problemas.

\section{Cuadro 4.1. Tipos de destrezas de razonamiento}

El razonamiento analítico se caracteriza mediante situaciones en las que el alumno debe aplicar principios de la lógica formal para determinar las condiciones necesarias y suficientes o para determinar si las condiciones y limitaciones que se enuncian en el estímulo del problema implican una relación de causalidad.

El razonamiento cuantitativo se caracteriza mediante situaciones en las que, para resolver un problema dado, el alumno debe aplicar propiedades y procedimientos relativos al sentido numérico y a las operaciones numéricas propias de las matemáticas.

El razonamiento analógico se caracteriza mediante situaciones en las que el alumno debe resolver un problema en un contexto similar al de otro con el cual ya está familiarizado o cuyos elementos de base ya ha resuelto alguna vez. Los parámetros o el contexto del nuevo estímulo han sido modificados, pero los factores inductores o el mecanismo causal son los mismos. El alumno debe poder resolver el nuevo problema interpretándolo a partir de su anterior experiencia con una situación análoga.

El razonamiento combinatorio se caracteriza mediante situaciones en las que el alumno debe examinar diferentes factores, considerar todas sus combinaciones posibles, evaluar las combinaciones relativas a alguna limitación objetiva y realizar una elección entre las combinaciones establecer un orden de prioridad entre ellas.

Por tanto, la actividad de solución de problemas es una amalgama de muchos procesos cognitivos diferentes, organizados para alcanzar un determinado objetivo que no podría alcanzarse, al menos de manera obvia, mediante la simple aplicación de un procedimiento, proceso, rutina o algoritmo conocidos y propios de una única área temática. La competencia para la solución de problemas puede describirse en términos de la capacidad de los alumnos para crear y supervisar cierto número de procesos dentro de una determinada gama 
de tareas y situaciones. La evaluación de la solución de problemas intenta identificar los procesos utilizados en diversas situaciones y áreas de contenido para describir y cuantificar, si es posible, la calidad de los resultados del trabajo de los alumnos.

Cuadro 4.1. Visualización de los elementos clave del marco conceptual de solución de problemas
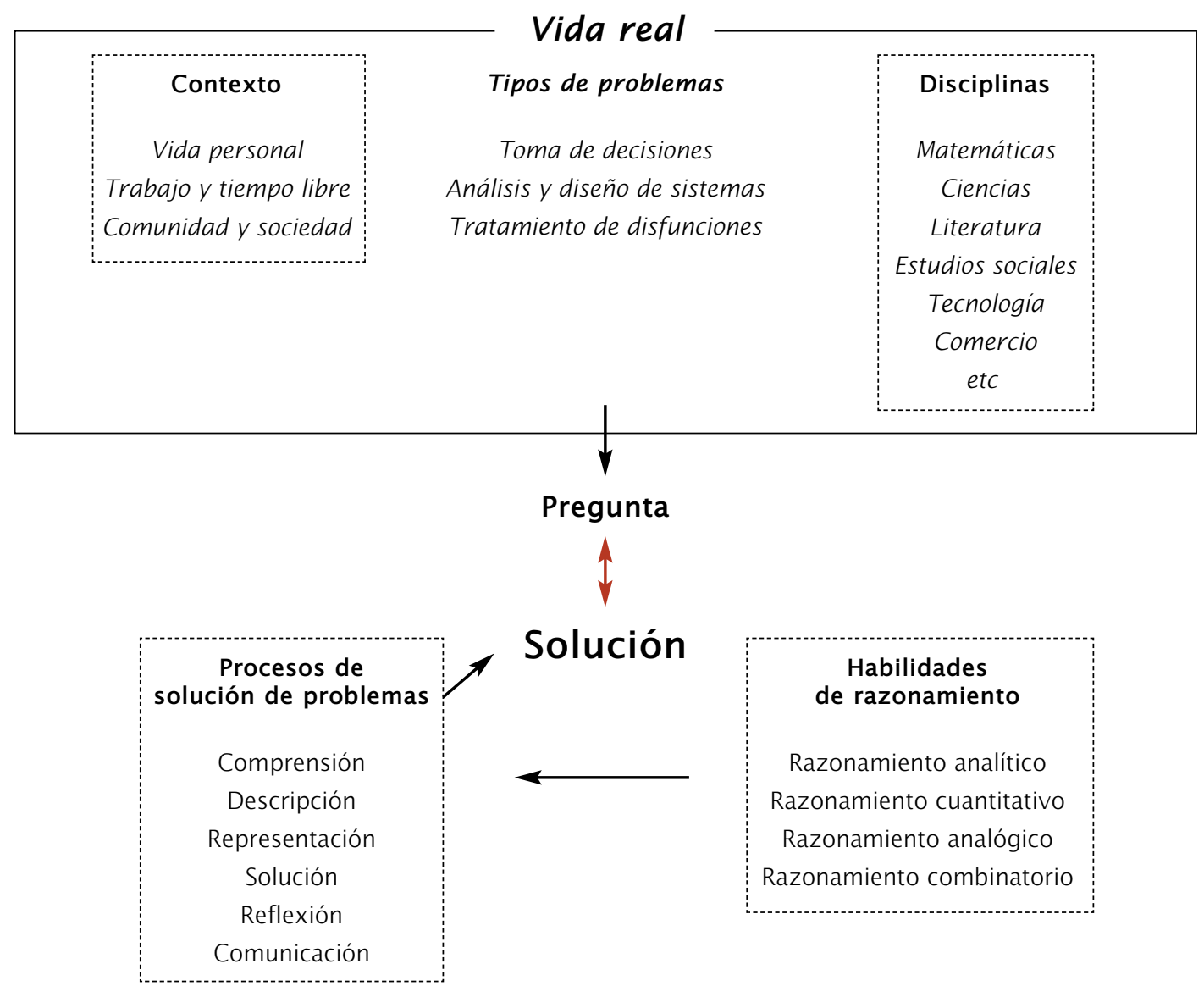

Habilidades de razonamiento

Razonamiento analítico Razonamiento cuantitativo Razonamiento analógico Razonamiento combinatorio
En el Cuadro 4.1 se presentan los elementos de la evaluación del área de solución de problemas del proyecto PISA 2003. Estas relaciones ilustran cómo la evaluación recurre al conocimiento sobre el contenido y el contexto de diversos campos, así como a las competencias propias de las áreas de contenido y de la solución de problemas entendida como área de conocimiento.

\section{TIPOS DE PROBLEMAS}

Para la evaluación interdisciplinar de la solución de problemas dentro del proyecto PISA 2003 se ha decidido limitar la evaluación de la capacidades de los alumnos a tres grandes dominios que denominamos "tipos de problemas". Estos tres tipos de problemas son: la toma de 
decisiones, el análisis y diseño de sistemas y el tratamiento de disfunciones.

Estos tres tipos de problemas corresponden a estructuras genéricas de solución de problemas que capturan aspectos importantes del razonamiento analítico propio del día a día y de la vida real, perspectiva buscada por el programa de evaluación. Constituyen una alternativa a las evaluaciones de la lectura, las matemáticas y las ciencias, en las que hay un área de conocimiento bien definida que proporciona la estructura necesaria para delimitar la evaluación. En la evaluación de la solución de problemas la atención se centra en el proceso y no en el conocimiento. Sin embargo, los procesos no pueden evaluarse si no van vinculados a algún tipo de estructura. Los tres tipos de problemas propuestos proporcionan las estructuras genéricas para poder evaluar los procesos de solución de problemas.

\section{Toma de decisiones}

Los problemas de toma de decisiones exigen que los estudiantes entiendan una situación que comporta diferentes alternativas y restricciones para que terminen tomando una decisión que se ajuste a las restricciones. Por ejemplo, en la Unidad 1 de solución de problemas: "No al dolor", se pide a los estudiantes que decidan cuál es el calmante más adecuado según la edad del paciente, los síntomas y otras condiciones de salud.

Los ejercicios de toma de decisiones como el anterior conllevan por lo general que se comprenda la información dada y lo que se pide en el ejercicio, que se identifiquen las limitaciones o características relevantes, que se elabore una representación del problema o se establezcan alternativas, que se tome una decisión que observe las limitaciones, que se compruebe que la solución cumpla las limitaciones y, finalmente, que se comunique o justifique la decisión. En los ejercicios de este tipo, el estudiante debe seleccionar una alternativa entre las que se le presentan. Al hacerlo debe combinar informaciones que provienen de diferentes fuentes (razonamiento combinatorio) y seleccionar la mejor solución.

Un problema de toma de decisiones resultará más difícil cuanto mayor sea su complejidad. Por ejemplo, la decisión de comprar un coche se complica a medida que aumenta la cantidad de información analizada, cuando la información trae consigo diferentes representaciones que hay que relacionar o cuando debe tenerse en cuenta un gran número de limitaciones. Hay estudiantes que son capaces de realizar tareas fáciles de toma de decisiones pero que no lo consiguen cuando la complejidad de la tarea aumenta.

Cuando la complejidad de un ejercicio de toma de decisiones es elevada, las representaciones externas pueden ser de gran ayuda. En la Unidad 1 de solución de problemas: "No al Dolor", se ofrece una representación en forma de tabla. En otros ejercicios de toma de decisiones son los estudiantes los que deben elaborar este tipo de representaciones, en forma de tablas, diagramas, gráficos, etc. La capacidad de los estudiantes para elaborar representaciones o aplicar una representación dada, como al realizar o interpretar un gráfico, son factores que determinan su rendimiento en este tipo de ejercicios. Una vez elaborada o aplicada la representación, el estudiante debe seleccionar, relacionar y comparar la información a partir de cómo está organizada en la representación y seleccionar la mejor alternativa. 
No resulta fácil elegir el calmante apropiado para los dolores ocasionales, debido a la gran cantidad de marcas de calmantes que hay en el mercado, afirmando todas que son la más adecuada.

La asociación "Cuidados Médicos" ofrece la información siguiente acerca de los siguientes cuatro calmantes:

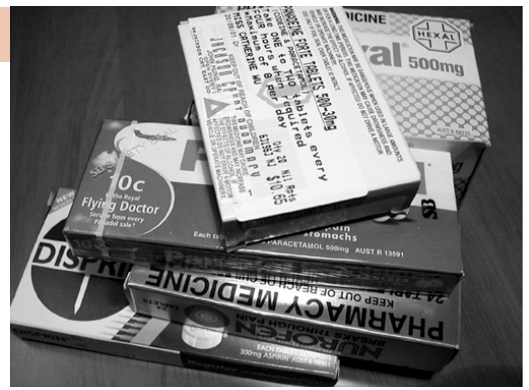

Nombre

del calmante

Descripción

Síntomas que alivia

Dosificación

Precauciones

Acuaspirina

Comprimido de aspirina $100 \%$ soluble. Ideal para personas que no llegan a ingerir los comprimidos.
Dolores de cabeza, musculares, dentales, de espalda, de garganta. Reduce la inflamación y la fiebre.
Adultos y niños mayores

de 12 años: 1 a 2 comprimidos disueltos en medio vaso de agua cada 4 horas según sea necesario. No más de 8 comprimidos cada $24 \mathrm{~h}$. Niños menores de 12 años: No administrar Acuaspirina a niños menores de 12 años
El uso prolongado puede ser perjudicial. No deben tomarlo las personas que sigan una dieta baja en sodio.
Paracem
100\% paracetamol. Adecuado para madres que amamantan y asmáticos. No produce irritación de estómago como la aspirina.
Dolores de cabeza, de espalda, de muelas, dolor muscular, artritis. Reduce la fiebre.
Adultos y niños mayores de 12 años: 1 a 2 comprimidos cada 4 horas según sea necesario.

Niños menores de 12 años: 0,5 a 1 comprimidos cada 4 horas según sea necesario.
El uso prolongado puede ser perjudicial.
Adultos y niños mayores de 14 años: 1 a 2 comprimidos cada 8 horas. No más de 6 comprimidos al día. Niños de 14 años o menos: Los niños de 14 años o menos no deben tomar NoAx.
No tomar NoAx con el estómago vacío. Consulte a su médico si sufre asma o si está tomando alguna otra medicación. Posibles efectos secundarios: mareos, hinchazón de pies. normalmente entre los 15 y 30 minutos.

Reliefen
Cada comprimido contiene 200 mg de ibuprofeno. Es más suave para el estómago que la aspirina.
Dolores de cabeza, musculares y reumáticos, dolor dental, síntomas del resfriado, dolor de espalda; reduce la fiebre y la inflamación.
Adultos y niños mayores de 12 años: 1 a 2 comprimidos cada $4-6$ horas. No más de 6 comprimidos cada $24 \mathrm{~h}$. Niños de 12 años o menos: El Reliefen no es adecuado para niños de 12 años o menos.
Si sufre de asma o disfunción renal, es alérgico a la aspirina o está embarazada, debe consultar a su médico antes de tomar Reliefen. 
Solución de problemas, Ejemplo 1.1:

A partir de la información dada, clasifica los cuatro calmantes del más suave al más fuerte. (Escribe los números 1 a 4 en las casillas; el 4 corresponde al más fuerte).

$\square \quad$ Acuaspirina

$\square \quad$ Paracem

$\square \quad$ NoAx

$\square \quad$ Reliefen

\section{Puntuación}

Máxima puntuación

Código 1: Respuestas de 2, 1, 4, 3 en ese orden.

Ninguna puntuación

Código 0: Otras respuestas.

\section{Solución de problemas, Ejemplo 1.2:}

Identifica dos de los calmantes que puedan provocar más irritación de estómago que los otros dos.
A. Acuaspirina
B. Paracem
C. NoAx
D. Reliefen

\section{Puntuación}

Máxima puntuación

Código 1: Respuestas que indican A y C como los dos calmantes que pueden provocar irritación de estómago.

Ninguna puntuación

Código 0: Otras respuestas. 
Solución de problemas, Ejemplo 1.3:

La madre de Miguel tomó algunos comprimidos de Reliefen para el resfriado y el dolor de cabeza. Tomó dos comprimidos a las 8 a.m., un comprimido a la 1 p.m. y dos comprimidos a las 6 p.m. Antes de irse a la cama a las 11 p.m., ¿cuántos comprimidos podría tomar de acuerdo a las instrucciones de dosificación?

\section{Puntuación}

Máxima puntuación

Código 1: Un comprimido, de manera que el total no sobrepase los seis comprimidos en 24 horas.

Ninguna puntuación

Código 0: Otras respuestas.

\section{Solución de problemas, Ejemplo 1.4:}

Selecciona el calmante más adecuado para cada uno de los siguientes pacientes a partir de la información dada.

PACIENTE

Inma, una niña de 10 años

con resfriado y fiebre.

Jorge, un chico asmático de 13 años con esguince en el tobillo que necesita un calmante para reducir el dolor y la inflamación.

Guillermo, un operario de maquinaria de 45 años que necesita un calmante duradero para el dolor de espalda mientras continúa con su trabajo.

Susana, una madre que amamanta, y que tiene dolor de cabeza.
RODEA CON UN CÍRCULO EL CALMANTE MÁS ADECUADO

Acuaspirina / Paracem / NoAx / Reliefen

Acuaspirina / Paracem / NoAx / Reliefen

Acuaspirina / Paracem / NoAx / Reliefen

Acuaspirina / Paracem / NoAx / Reliefen

\section{Puntuación}

Máxima puntuación

Código 1: Paracem, Acuaspirina, Reliefen, Paracem, en este orden.

Ninguna puntuación

Código 0: Cualquier otra combinación de respuestas. 
Tras tomar una decisión los estudiantes deben ser capaces de evaluar, justificar y comunicar la decisión a una audiencia externa. La habilidad para justificar y comunicar la solución de un problema constituye un aspecto importante de sus capacidades de toma de decisión.

En resumen, los ejercicios de toma de decisiones requieren que se comprenda la información dada, que se identifiquen las limitaciones y alternativas relevantes, que se elaboren o apliquen representaciones externas, que se seleccione la mejor solución de entre varias alternativas y que se evalúe, justifique o comunique la decisión.

\section{Análisis y diseño de sistemas}

Los problemas de análisis y diseño de sistemas requieren que el estudiante analice una situación compleja para así entender su lógica y/o diseñar un sistema que funcione y logre ciertos objetivos, dada la información sobre la relación entre los distintos aspectos del contexto del problema. Por ejemplo, en la Unidad 2: "Gestión de ventas de CD", se pide al alumno que analice el sistema de registro de la gestión de ventas de $\mathrm{CD}$ de una tienda.

Los problemas de análisis y diseño de sistemas difieren de los problemas de toma de decisiones en al menos dos aspectos cruciales: i) al estudiante se le pide que analice un sistema o diseñe la solución a un problema en lugar de seleccionar una alternativa entre varias, y ii) la situación descrita normalmente es un sistema complejo de variables interrelacionadas en el que una variable afecta a las otras y, por tanto, la solución a veces no está claramente definida. Dicho de otro modo, los problemas de análisis y diseño de sistemas se caracterizan por la naturaleza dinámica de las relaciones entre las variables involucradas y una posible falta de univocidad de la solución. Estos tipos de problemas aparecen a menudo en disciplinas como las ciencias medioambientales o económicas. En los ejercicios de toma de decisiones, las variables normalmente no interactúan de manera tan compleja, las limitaciones son más claras y las decisiones son más fáciles de justificar.

Los ejercicios de análisis y diseño de sistemas requieren, por lo general, que se identifiquen las variables relacionadas y que se determine el modo en que interactúan. En tales escenarios, los estudiantes deben ser capaces de analizar situaciones complejas y determinar las relaciones que definen los sistemas o diseñar uno que satisfaga la relaciones dadas y que logre ciertos objetivos importantes. La habilidad para evaluar, justificar y comunicar la solución de un problema constituye también una parte esencial del proceso.

Al igual que se vio al tratar los problemas de toma de decisiones, la dificultad de un problema de análisis y diseño de sistemas resulta también afectada por su complejidad. Cuanto más compleja es una situación (por lo que se refiere al número de variables, pero también a las interrelaciones), mayor es la dificultad del ejercicio. La elaboración de una representación o la aplicación de una representación dada o ya conocida constituye parte obligada del proceso de resolución de un problema.

En la Unidad 2: "Gestión de ventas de CD", el estudiante tiene que identificar las variables importantes para las ventas de CD y analizar las relaciones entre ellas para establecer el mejor modo de organizar la información. Esta tarea requiere también que los alumnos desarrollen métodos para extraer información mediante razonamiento lógico. 


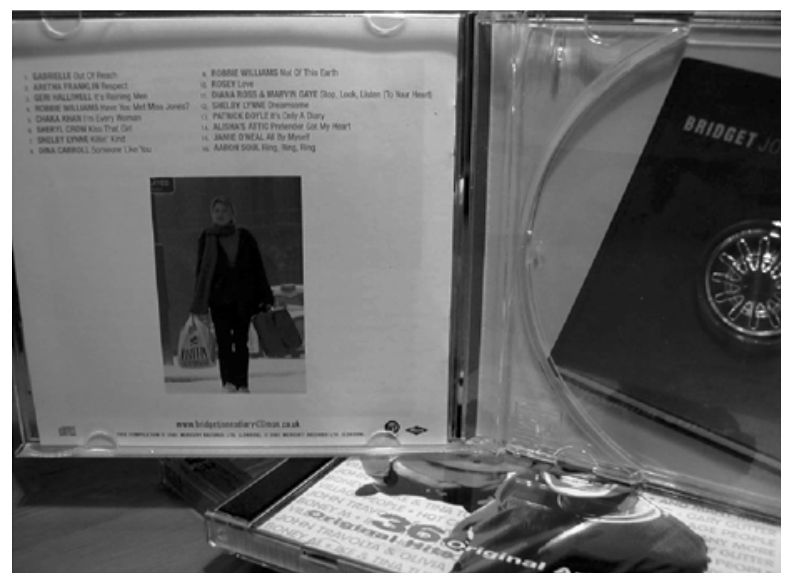

La tienda de discos Melodía está elaborando un sistema para registrar los CD de música que vende. La dirección ha preparado dos fichas de registro en el ordenador tal y como se muestra a continuación:

Ficha de registro 1: Características de cada CD (una línea por CD)

\begin{tabular}{|c|c|c|}
\hline $\mathrm{N}^{0}$ serie $\mathrm{CD}$ & Título del CD & Compañía discográfica \\
\hline 14339 & Carnaval de primavera & NAXA \\
\hline 10292 & Éxitos de los 90 & FineStudio \\
\hline 00551 & Arias para amantes de la ópera & DigiRec \\
\hline
\end{tabular}

Ficha de registro 2: Características de cada pista del CD (una línea por pista)

\begin{tabular}{l|l|l}
$N^{0}$ serie CD & Número de pista & Nombre de la pista \\
\hline 14339 & 1 & Fiebre de primavera \\
14339 & 2 & Salto a la primavera \\
14339 & 3 & Ritmo de medianoche \\
10292 & 1 & El mejor baile
\end{tabular}


Solución de problemas, Ejemplo 2.1:

¿A qué hoja de registro (1 ó 2) debe añadirse cada uno de las siguientes características?

$\begin{array}{ll}\text { CARACTERÍSTICA } & \text { DATOS DE EJEMPLO } \\ & \text { FICHA } 1 \text { O FICHA 2 }\end{array}$

\begin{tabular}{l|l|l}
\hline Artista/Grupo/Orquesta & Faye Weber; Filarmónica de Berlín & Ficha $1 /$ Ficha 2 \\
Precio & 15 zeds; 25 zeds el CD doble. & Ficha $1 /$ Ficha 2 \\
Existencias & Pedido; En almacén & Ficha $1 /$ Ficha 2 \\
Compositor & Warren Jones; Li Yuan & Ficha 1 / Ficha 2:
\end{tabular}

\section{Puntuación}

Máxima puntuación

Código 1: Ficha 2, Ficha 1, Ficha 1, Ficha 2, en este orden.

Ninguna puntuación

Código 0: Cualquier otra combinación de respuestas

\section{Solución de problemas, Ejemplo 2.2:}

Añade dos características a la Ficha 1 y otras dos características a la Ficha 2, y añade datos de ejemplo. No incluyas características que ya hayan sido mencionadas.

\section{Puntuación}

Lista de características para la Ficha 1:

- año de publicación del CD, p. ej., (C)1998.

- duración total del CD, p. ej., 78 minutos.

- categoría del CD: clásico, popular, folklórico.

Lista de atributos para la Ficha 2:

- duración de la pista, p. ej., 5’32".

- año/lugar de grabación, p. ej., marzo de 1998, Praga.

Máxima puntuación

- autor de la letra, p. ej., Sharon Green.

Código 2: Respuestas que incluyan:

- dos características de la Ficha 1, de la lista anterior.

Y

- dos características de la Ficha 2, de la lista anterior. 
Puntuación parcial

Código 1: Respuestas incompletas, tales como mencionar:

- únicamente dos características para la Ficha 1,

O

- únicamente dos características para la Ficha 2,

O

- una característica para la Ficha 1 y una característica para la Ficha 2,

$\mathrm{O}$

- dos características para cada ficha, pero sin entradas de ejemplo.

Ninguna puntuación

Código 0: Otras respuestas.

\section{Solución de problemas, Ejemplo 2.3:}

El sistema permite a los usuarios realizar búsquedas entre los CD previamente registrados. A continuación se muestra cómo se escriben las órdenes de búsqueda mediante paréntesis ( ) y palabras clave: "Y" y "O":

(1) Para localizar todos los CD de menos de 15 zeds con grabaciones realizadas por la solista Irene Emilia, escribe la siguiente orden de búsqueda:

$($ Precio $<15)$ Y $($ Artista $=$ Irene Emilia $)$

(2) Para localizar todos los CD con grabaciones de la Quinta Sinfonía de Beethoven grabadas por las Orquestas Sinfónicas de Boston o Chicago, escribe la siguiente orden de búsqueda:

(Nombre de la pista $=$ Quinta Sinfonía de Beethoven) Y (Orquesta = Boston O Chicago)

Escribe una orden de búsqueda para localizar todos los CD producidos y registrados por las compañías discográficas NAXA o DigiRec de las grabaciones de la canción "Anoche tuve un sueño".

\section{Puntuación}

Máxima puntuación

Código 1: Respuestas que incluyan:

(Pista $=$ Anoche tuve un sueño) Y (compañía = NAXA O DigiRec).

Tenga en cuenta que el énfasis se hace en la colocación de AND, OR y en los paréntesis. El texto y el orden de los paréntesis no son importantes. Tampoco es importante la formulación exacta de las palabras clave, como pista y compañía. Se puede aceptar título es lugar de nombre de pista; productor en lugar de compañía, etc.

Ninguna puntuación

Código 0: Otras respuestas. 
Evaluar, justificar y comunicar la solución son partes muy importantes del proceso de resolución de problemas de un ejercicio de análisis y diseño de sistemas. La solución de un ejercicio de este tipo a menudo no es única ni obvia y se presentan ventajas y desventajas asociadas a cada solución posible.

En resumen, un ejercicio de análisis y diseño de sistemas normalmente requiere que se comprendan las relaciones complejas que se producen entre diferentes variables interdependientes, que se identifiquen sus características fundamentales, que se elabore o aplique una representación dada, que se analice una situación compleja o que se diseñe un sistema para conseguir determinados objetivos. Ello implica normalmente que el alumno compruebe y evalúe su trabajo a medida que va siguiendo los diferentes pasos que conducen a un análisis o diseño.

\section{Tratamiento de disfunciones}

Los problemas de tratamiento de disfunciones precisan que el alumno comprenda las características principales de un sistema y que pueda detectar un defecto o un malfuncionamiento en una característica del sistema o mecanismo. Por ejemplo, en la Unidad 3: "Bomba de bicicleta", a Juana se le pide que determine por qué no sale aire de la bomba de inflar las ruedas. A pesar de que ha accionado repetidamente hacia arriba y hacia abajo el mango de la bomba, no ha salido nada de aire. Juana no podrá llegar a diagnosticar lo que pasa a menos que entienda el funcionamiento de la bomba y, más exactamente, el de las válvulas interior y exterior, y el del pistón para impulsar el aire desde el exterior de la bomba hasta el tubular de la bicicleta y su válvula de inflado.

Los ejercicios de tratamiento de disfunciones se distinguen de manera clara de los ejercicios de toma de decisiones y de los de análisis y diseño de sistemas, puesto que no implican seleccionar la mejor opción entre las demás ni diseñar el sistema que mejor se adapte a unos requisitos dados, sino que requieren comprender la lógica de un mecanismo causal, como, por ejemplo, el funcionamiento de un proceso o sistema físico. Véase, por ejemplo, el caso de una empresa minorista que debe hallar las razones del descenso de sus cifras de ventas o el de un programador que tiene que encontrar el error de un programa.

A pesar de las diferentes estructuras de los tres tipos de problemas, el alumno que se enfrenta a un ejercicio de tratamiento de disfunciones debe también entender el funcionamiento del dispositivo o proceso (es decir, entender el mecanismo), identificar las características importantes para diagnosticar el problema específico que se le pide arreglar, crear o aplicar las representaciones pertinentes, formular un diagnóstico, proponer una solución y, si la situación lo precisa, poner en práctica la solución.

La representación es muy importante en los problemas de tratamiento de disfunciones, porque a menudo exigen la integración de información verbal y gráfica. En la Unidad 3: "Bomba de bicicleta", Juana debe combinar la información gráfica y verbal para llegar a comprender el mecanismo de la bomba. En otras situaciones puede que el alumno necesite crear una representación gráfica a partir de una descripción verbal o describir verbalmente una ilustración que presente el funcionamiento del dispositivo. La capacidad para cambiar de manera flexible entre uno y otro tipo de representación constituye un aspecto importante del proceso de resolución de problemas que a menudo interviene en los problemas de tratamiento de disfunciones. Por último, la evaluación, justificación y comunicación resultan tan importantes en este tipo de problemas como en los demás. Por ejemplo, en el Ejemplo 3.2, deben aportarse razones que apoyen las afirmaciones.

En resumen, los ejercicios de tratamiento de disfunciones comportan detectar el problema, proponer una solución y, a veces, llevar a cabo esta solución. En estos ejercicios el estudiante tiene que llegar a entender el funcionamiento de un dispositivo o proceso, identificar los aspectos importantes del ejercicio y crear una representación o aplicar una representación dada. 
Juana tuvo ayer algunos problemas con su bomba de inflar ruedas de bicicleta. Accionaba hacia arriba y hacia abajo repetidamente el mango de la bomba pero no salía aire por el latiguillo. Ella quería saber por qué no funcionaba, así que miró en la caja donde se guardaba la bomba y encontró un pedazo de papel con la siguiente información.

Cuando se estira hacia arriba el mango del pistón, el aire pasa a través de la válvula interior y llena el espacio entre el pistón y la válvula exterior. Cuando se empuja hacia abajo el mango del pistón, la válvula inte-rior se cierra y el pistón expulsa el aire que se encuentra por debajo del pistón a través de la válvula exterior.
Bomba de bicicleta

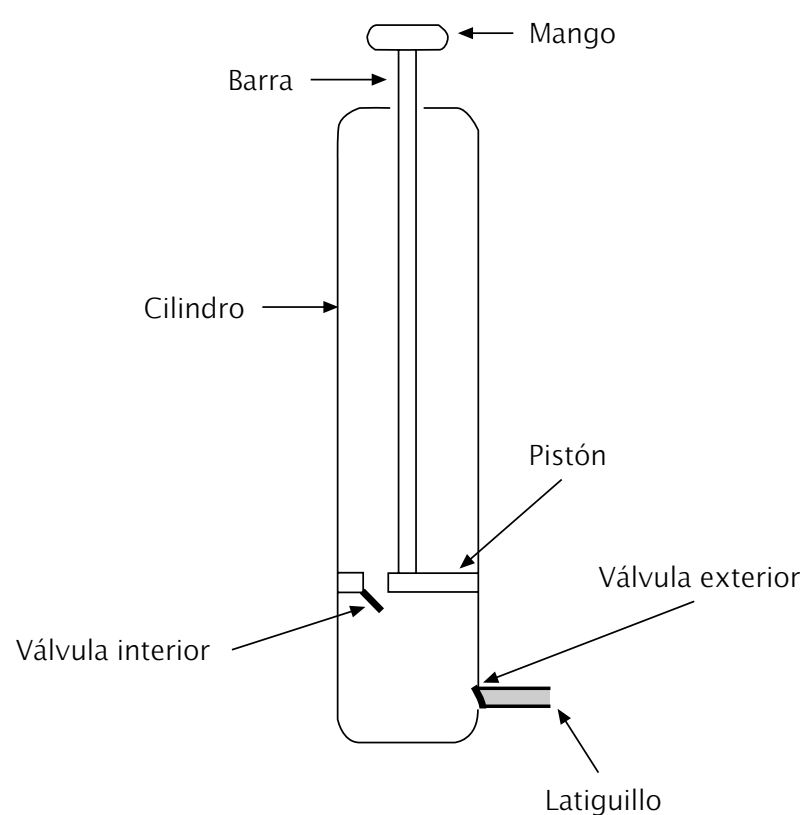

Solución de problemas, Ejemplo 3.1:

Explica cómo el movimiento de las válvulas posibilita el funcionamiento de la bomba de bicicleta cuando el pistón se encuentra en posiciones diferentes.

\section{Puntuación}

Máxima puntuación

Código 2: Respuestas que describen qué sucede con los DOS movimientos del mango del pistón.

- Cuando el mango del pistón se empuja hacia abajo, la válvula interior se cierra y la válvula exterior se abre. Y

- Cuando el mango del pistón se estira hacia arriba, la válvula interior se abre y la válvula exterior se cierra.

Puntuación parcial

Código 1: Respuestas que describen qué sucede con el movimiento del mango del pistón en una sola dirección.

- Cuando el mango del pistón se empuja hacia abajo, la válvula interior se cierra y la válvula exterior se abre. $\mathrm{O}$

- Cuando el mango del pistón se estira hacia arriba, la válvula interior se abre y la válvula exterior se cierra.

Ninguna puntuación

Código 0: Otras respuestas. 


\section{Solución de problemas, Ejemplo 3.2:}

Identifica dos posibles causas de que no salga aire por el latiguillo. Da una explicación para sostener cada una de ellas.

\section{Puntuación}

Posibles causas y explicaciones:

- la válvula interior está atascada y, por tanto, no puede pasar el aire a la parte inferior del cilindro, por debajo del pistón;

- la válvula exterior está atascada y no permite que el aire salga por el latiguillo;

- el pistón está desgastado y no se produce suficiente compresión para que el aire salga por el latiguillo;

- hay una fuga en la pared del cilindro por debajo del pistón que anula, por tanto, la compresión;

- hay una fuga en el latiguillo que hace que se escape el aire;

- no hay toma de aire hacia el cilindro.

Máxima puntuación

Código 2: Respuestas que mencionan DOS razones con explicaciones.

Puntuación parcial

Código 1: Respuestas que mencionan sólo UNA razón con una explicación.

Ninguna puntuación

Código 0: Otras respuestas.

\section{PROCESOS DE SOLUCIÓN DE PROBLEMAS}

El desarrollo de un marco conceptual para la solución de problemas precisa identificar los procesos implicados en el trabajo del alumno a la hora de resolver problemas. Esto no es fácil, puesto que los modos a través de los cuales diferentes personas resuelven los problemas no encajan en un formato estándar. Los procesos propuestos más abajo se basan en el análisis cognitivo de los tres tipos de problemas descritos anteriormente, inspirados en el trabajo sobre el razonamiento y la solución de problemas de psicólogos cognitivos (p. ej., Mayer y Wittrock, 1996; Bransford et al, 1999; Baxter y Glaser, 1997; Vosniadou y Ortony, 1989), así como en el trabajo fundamental de Polya (1945). El modelo propuesto consta de varios procesos que proporcionan una estructura organizativa para examinar el trabajo del alumno y organizar los ejercicios de evaluación de la solución de problemas. Obsérvese que no se parte del supuesto de que estos procesos hayan de ser jerárquicos o necesarios para la solución de un problema determinado. Cuando los individuos acometen, representan y resuelven problemas en tiempo real y de manera dinámica, pueden llegar a una solución de un modo que trascienda la estrecha linealidad de este modelo. De hecho, en la actualidad, la mayor parte de la información sobre el funcionamiento del sistema cognitivo de los seres humanos respalda la idea de que se trata de un sistema de procesamiento de información paralelo, más que lineal.

- Comprensión del problema. Implica la forma en que los estudiantes entienden un texto, diagrama, fórmula o tabla y formulan deducciones basadas en ellos; cómo relacionan la información procedente de varias fuentes; cómo demuestran la comprensión de conceptos relevantes; y cómo utilizan sus conocimientos propios para entender la información dada. 
Tabla 4.1: Características de los diversos tipos de solución de problemas

Toma de decisiones

Objetivo

Escoger entre las

diferentes alternativas

con restricciones

\section{Análisis y diseño de sistemas}

Identificar las relaciones

entre las partes del sistema

y/o diseñar un sistema

para establecer las relacio-

nes entre las partes

\section{Tratamiento de disfunciones}

Diagnosticar y corregir un mecanismo o sistema estropeado o defectuoso

\section{Procesos implicados}

Comprender una situación cuando se dan diferentes alternativas y restricciones y una tarea específica
Entender la información que caracteriza un sistema dado y los requisitos asociados a una tarea específica
Comprender las características principales de un sistema o mecanismo y su mal funcionamiento así como las exigencias de una tarea específica

Identificar los enlaces causales entre variables

\begin{tabular}{|c|c|c|}
\hline $\begin{array}{l}\text { Identificar las restricciones } \\
\text { relevantes }\end{array}$ & $\begin{array}{l}\text { Identificar las partes rele- } \\
\text { vantes del sistema }\end{array}$ & $\begin{array}{l}\text { Identificar los enlaces causa- } \\
\text { les entre variables }\end{array}$ \\
\hline $\begin{array}{l}\text { Presentar las alternativas } \\
\text { posibles }\end{array}$ & $\begin{array}{l}\text { Presentar las relaciones } \\
\text { entre las partes del sistema }\end{array}$ & $\begin{array}{l}\text { Representar el funcionamien- } \\
\text { to del sistema }\end{array}$ \\
\hline $\begin{array}{l}\text { Tomar una decisión entre } \\
\text { las alternativas }\end{array}$ & $\begin{array}{l}\text { Analizar o diseñar un siste- } \\
\text { ma que reproduzca las rela- } \\
\text { ciones entre las partes }\end{array}$ & $\begin{array}{l}\text { Diagnosticar el mal funciona- } \\
\text { miento del sistema y/o pro- } \\
\text { poner una solución }\end{array}$ \\
\hline $\begin{array}{l}\text { Comprobar y valorar la } \\
\text { decisión }\end{array}$ & $\begin{array}{l}\text { Comprobar y valorar el } \\
\text { análisis o el diseño del sis- } \\
\text { tema }\end{array}$ & $\begin{array}{l}\text { Comprobar y evaluar el diag- } \\
\text { nóstico y la solución }\end{array}$ \\
\hline $\begin{array}{l}\text { Comunicar o justificar la } \\
\text { decisión }\end{array}$ & $\begin{array}{l}\text { Comunicar el análisis o jus- } \\
\text { tificar el diseño propuesto }\end{array}$ & $\begin{array}{l}\text { Comunicar o justificar la con- } \\
\text { clusión y la solución }\end{array}$ \\
\hline Número de restricciones & $\begin{array}{l}\text { Número de variables inte- } \\
\text { rrelacionadas y naturaleza } \\
\text { de las relaciones }\end{array}$ & $\begin{array}{l}\text { Número de partes interrela- } \\
\text { cionadas en el sistema o } \\
\text { mecanismo y modo en que } \\
\text { estas partes interaccionan }\end{array}$ \\
\hline $\begin{array}{l}\text { Número y tipo de represen- } \\
\text { taciones utilizadas (verbal, } \\
\text { gráfica, numérica) }\end{array}$ & $\begin{array}{l}\text { Número y tipo de represen- } \\
\text { taciones utilizadas (verbal, } \\
\text { gráfica, numérica) }\end{array}$ & $\begin{array}{l}\text { Número y tipo de represen- } \\
\text { taciones utilizadas (verbal, } \\
\text { gráfica, numérica) }\end{array}$ \\
\hline
\end{tabular}


- Descripción del problema. Implica la forma en que los estudiantes identifican las variables del problema y sus interrelaciones; cómo deciden qué variables son relevantes o irrelevantes; cómo elaboran hipótesis, y cómo extraen, organizan, consideran y evalúan de manera crítica la información contextual.

- Representación del problema. Implica la forma en que los estudiantes elaboran representaciones tabulares, gráficas, simbólicas o verbales o en que aplican una representación externa a la solución del problema, y cómo cambian entre los diferentes formatos de representación.

- Resolución del problema. Implica tomar una decisión (en el caso del tipo toma de decisiones), analizar o diseñar un sistema para alcanzar ciertos objetivos (en el caso del tipo análisis y diseño de sistemas) o diagnosticar y proponer una solución (en el caso del tipo tratamiento de disfunciones).

- Reflexión sobre el problema. Implica la forma en que los estudiantes examinan su solución y buscan una aclaración o información adicional; cómo evalúan su solución desde diferentes perspectivas en un intento de reestructurar las soluciones y hacerlas más aceptables técnica o socialmente; y cómo justifican sus soluciones.

- Transmisión de la solución del problema. Implica la forma en que los estudiantes seleccionan los medios y representaciones adecuados para expresar y comunicar sus soluciones a una audiencia externa.

\section{RESUMEN DE LOS TIPOS DE PROBLEMAS}

Las entradas de la Tabla 4.1 resumen las características básicas de los tres tipos de problemas en relación con el objetivo, los procesos implicados y los factores de complejidad creciente asociados a los problemas.

\section{SITUACIONES}

La evaluación de la solución de problemas en el proyecto OCDE/PISA debería exigir a los estudiantes que aplicaran sus conocimientos y destrezas de un modo nuevo, que trasladaran sus capacidades de un escenario a otro y que emplearan sus conocimientos para tratar los problemas de toma de decisiones, análisis y diseño de sistemas y tratamiento de disfunciones. Como tal, el trabajo interdisciplinar de resolución de problemas abarcará en muchos casos la noción de "destrezas para la vida". Por lo general, los problemas se insertarán en situaciones de la vida real asociadas a la vida personal, al trabajo y ocio y a la comunidad y sociedad.

\section{El lugar de la solución de problemas en el ciclo PISA 2003}

A pesar de que la lectura, las matemáticas y las ciencias sean tres áreas de conocimiento fundamentales de cualquier sistema educativo, no proporcionan a los alumnos todas las destrezas que necesitan para prepararse para la vida adulta. Un examen de los nuevos conocimientos y destrezas que se esperan de los ciudadanos y de la población activa del siglo XXI indica que dichas expectativas cambian tan rápidamente como avanza la tecnología. Al igual que las diferentes formas de la tecnología han reemplazado a las formas de trabajo manual, los nuevos conocimientos y destrezas han ocupado el lugar de un contenido más tradicional como requisitos de entrada al trabajo y a la vida adulta. Las evaluaciones OCDE/PISA deben medir las capacidades de los estudiantes para adaptar, modificar y resolver problemas que precisan nuevas y emergentes competencias clave.

\section{COMPETENCIAS CLAVE}

El desarrollo de listas de aptitudes o de competencias clave ha sido un objetivo primordial de diversas acciones de la OCDE, y, de manera más visible, en el proyecto DeSeCo (Definición y Selección de Competencias; Rychen y Salganik, 2000). Este trabajo llegó a la conclusión de que las competencias clave son multifuncionales y multidimensionales por naturaleza y permiten que una persona traspase dominios y maneje órdenes superiores de complejidad mental. Las competencias claves permiten que los individuos manejen situaciones complejas de modo activo y reflexivo. En especial, ayudan a los individuos a pasar de las visiones dualistas de sus entornos o coyunturas a posiciones de visión estratégica que revelan interpretaciones diversas, y a veces conflictivas, de los hechos y contextos. Las competencias clave requieren numerosos procesos 
mentales. Entre los procesos enumerados en el informe DeSeCo se cuentan los siguientes:

- reconocer y analizar modelos, establecer analogías entre las situaciones vividas y las nuevas (manejar la complejidad);

- percibir las situaciones, discriminando entre las características irrelevantes y las relevantes (dimensión perceptiva);

- seleccionar los medios apropiados para alcanzar determinados objetivos, valorar las diferentes posibilidades que se ofrecen, realizar juicios y aplicarlos (dimensión normativa);

- desarrollar una orientación social, confiar en los demás, escuchar y entender las posiciones de los demás (dimensión cooperativa);

- dar sentido a lo que nos pasa a nosotros mismos y a los demás en la vida, percibir y describir el mundo, nuestro lugar en él y el lugar en el que nos gustaría estar (dimensión narrativa).

El examen de estos procedimientos demuestra que la solución de problemas considerada como una actividad interdisciplinar constituye el núcleo de las competencias clave. El reconocimiento, la abstracción, la generalización y la evaluación de regularidades y la elaboración de los planes de acción subsiguientes representan una parte central de lo que la solución de problemas aporta a la toma de decisiones en un contexto educativo, técnico y profesional. Percibir las situaciones dentro de contextos complejos y definir las características y limitaciones relevantes resulta fundamental para analizar sistemas y estructuras y elaborar planes de acción para hacer frente a los problemas en todas las vertientes de la actividad humana. Lo que la solución de problemas aporta para hacer frente a las dificultades que aparecen en la vida o en el trabajo es la capacidad de seleccionar los medios apropiados para alcanzar los objetivos que se persiguen o desean.

\section{EL PAPEL DE LA SOLUCIÓN DE PROBLEMAS EN LAS TENDEN- CIAS DEL EMPLEO Y EN LA DEMANDA DE DESTREZAS}

Los actuales alumnos de 15 años se incorporarán a la población activa a lo largo de los próximos 10 años. Para evaluar si están preparados para la vida es importante identificar las características del mercado laboral que se encontrarán. Los estudios de tendencias del empleo y de las exigencias de destrezas relacionadas indican que en los últimos 20 años han tenido lugar cambios importantes en el mercado laboral (OIT, 1998; OCDE, 2001b). Los rápidos avances tecnológicos y la globalización de los negocios y la industria han generado una demanda creciente de técnicos y profesionales altamente cualificados. Esta demanda ha provocado a su vez la necesidad de una reforma educativa, tanto en la enseñanza formal como en la formación en el puesto de trabajo. En los Estados Unidos, el informe SCANS (Secretary's Comission on Achieving Necessary Skills, Comisión del Secretario sobre la consecución de las destrezas necesarias, Departamento de Trabajo de EE.UU., 1991) propuso un método para que los centros educativos concibieran las destrezas y el conocimiento necesarios de un modo que fuera más allá de las disciplinas académicas tradicionales. El marco conceptual de la SCANS consiste en tres destrezas fundamentales acompañadas de cinco competencias generales (Stern, 1999). Los fundamentos de las destrezas consisten en:

- destrezas básicas: lectura, escritura, aritmética y matemáticas, comprensión auditiva y expresión oral;

- destrezas de razonamiento: pensamiento creativo, toma de decisiones, solución de problemas, visión mental de las cosas, saber cómo aprender y cómo razonar;

- aptitudes personales: responsabilidad, autoestima, sociabilidad, autonomía e integridad y honradez.

Entre las competencias asociadas se cuentan:

- recursos: saber gestionar el tiempo, el dinero, los materiales, las instalaciones y los recursos humanos;

- interpersonales: participar en un equipo, ayudar a que los demás aprendan, servir a clientes/consumidores, liderar y dirigir, negociar y trabajar con la diversidad;

- información: adquirirla y evaluarla, organizarla y man tenerla, interpretarla y comunicarla, y utilizar ordenadores para procesarla;

- sistemas: comprender los sistemas, controlar y corregir su rendimiento, y mejorar o diseñar sistemas;

- tecnología: elegir una tecnología, aplicarla a una tarea, mantener y arreglar equipos y dispositivos.

Así, mientras las asignaturas académicas principales de lectura, escritura y matemáticas destacan en la línea de 
destrezas básicas de la SCANS, los diseñadores del informe SCANS, al igual que los del informe DeSeCo, han ubicado las destrezas de solución de problemas y razonamiento crítico como un área de estudio separada. Ello no indica que no se dé una actividad de solución de problemas o razonamiento crítico en lectura, matemáticas o ciencias, pero sí indica que hay una tendencia creciente a considerar la resolución de problemas como un área de la actividad humana independiente y reconocida, que se sitúa al margen de las áreas de conocimiento tradicionales.

Los informes SCANS y DeSeCo son sólo dos ejemplos de los análisis de los conocimientos y destrezas que precisan las concepciones actuales y emergentes de las necesidades de la población activa. Muchos otros análisis han proporcionado también visiones similares de las destrezas genéricas y relacionadas con la vida laboral que necesitarán los alumnos de hoy. McCurry (2002) ofrece un análisis de estos informes en el que muestra que, al margen de los conocimientos y aptitudes asociados a las áreas de conocimiento tradicionales, las destrezas de resolución de problemas o el razonamiento general representan una competencia central para la vida y el trabajo del mañana.

\section{Diferencias entre solución de problemas y otras} áreas de competencia del proyecto PISA

La evaluación de la solución de problemas interdisciplinares en el proyecto PISA 2003 se diferencia en varios e importantes aspectos de los estudios de solución de problemas incluidos en las tres evaluaciones de áreas de competencia del proyecto PISA y en estudios sociológicos existentes. En primer lugar, en las evaluaciones OCDE/PISA de lectura, matemáticas y ciencias, la solución de problemas se utiliza para evaluar el conocimiento y la comprensión de las diferentes áreas, mientras que en solución de problemas la atención se centra en los procesos de resolución de problemas por sí mismos. En segundo lugar, la solución de problemas del proyecto OCDE/PISA se diferencia de las evaluaciones de las otras áreas de conocimiento en que enfatiza la integración de la información de diferentes áreas en lugar de recurrir a una sola área de conocimiento. Por último, las evaluaciones del proyecto OCDE/PISA son diferentes por el hecho de tener soluciones abiertas y por la complejidad de las destrezas de razonamiento crítico que conllevan.
En este intento de medir las capacidades de solución de problemas, la evaluación OCDE/PISA comparte el planteamiento del proyecto y la centralidad del razonamiento analítico propios del ISA (International Survey of Adults, Estudio internacional de la población adulta) y de algunas partes de las opciones alemanas del ciclo PISA 2000. Por otro lado, la evaluación OCDE/PISA se centra únicamente en tres tipos de problemas definidos, lo que permite efectuar una evaluación dotada de mayor claridad y profundidad de los procesos que emplean los estudiantes en estos planteamientos. Pero quizá lo más importante es que la evaluación OCDE/PISA se diferencia de otros estudios de evaluación educativa a gran escala en que no se basa en el currículum, sino que evalúa la preparación para la vida que poseen los estudiantes de 15 años. Mientras que los marcos concepturales de lectura, matemáticas y ciencias hacen hincapié en la competencia y especifican el papel que las destrezas y los conceptos clave tienen en las áreas de conocimiento para preparar a los alumnos para la vida adulta, la solución de problemas OCDE/PISA se centra en destrezas de razonamiento genéricas y complejas de orden superior que trascienden las tradicionales áreas de conocimiento.

\section{Evaluar procesos en lugar de conocimientos}

Puesto que la evaluación OCDE/PISA de la solución de problemas se centra en el razonamiento genérico y en los procesos de resolución, es importante reconocer que la solución de problemas no es un área propia de una asignatura temática, sino que tiene que ver con la aplicación de los procesos de los que se valen las personas cuando se enfrentan a situaciones problemáticas (NCTM, 2000). Por tanto, la solución de problemas OCDE/PISA examina el trabajo del alumno centrándose en la forma en que los alumnos consiguen:

- comprender la naturaleza del problema;

- caracterizar el problema identificando las variables y relaciones inherentes al problema;

- seleccionar y refinar las representaciones del problema;

- solucionar el problema;

- reflexionar sobre la solución dada;

- comunicar la solución del problema.

Centrarse en los procesos en lugar de hacerlo únicamente en las soluciones finales permite entender el 
modo en que la gente aborda la resolución de los problemas. Mayer (1985) puntualiza que este enfoque propio del procesamiento de información para examinar la solución de problemas se basa en el análisis de tareas. De este modo, proporciona una descripción independiente de lo que aporta la solución de problemas, más allá de la puntuación obtenida en una prueba. Comprender los procesos que tienen lugar puede también ayudar a los profesores en su preparación de actividades formativas de resolución de problemas.

\section{Tipos de problemas}

Como ya se ha explicado, los tres tipos de problemas empleados en la evaluación PISA 2003 son la toma de decisiones, el análisis y diseño de sistemas y el tratamiento de disfunciones. Estos tipos de problemas se ajustan bien tanto a las recomendaciones del SCANS como del DeSeCo. La razón principal para restringir la cantidad de tipos es que el tiempo disponible para la evaluación de la solución de problemas es limitado. Aunque hubiera sido posible seleccionar ejercicios de solución de problemas de entre una muy extensa gama de exigencias, así como identificar estrategias similares y desarrollar contextos para situar los problemas, se decidió limitar los tipos y exigencias de los problemas estudiados.

Muchos de los ejercicios empleados en el análisis de los tres tipos contienen problemas que comportan planificar, asignar recursos, localizar las causas de los problemas, evaluar y organizar la información y hallar las mejores opciones. Aunque ninguno de estos ejercicios precisa un conocimiento profundo de lectura, matemáticas o ciencias, todos requieren un pensamiento lógico y un razonamiento analítico. Estos ejercicios no forman parte de las áreas de lectura, matemáticas o ciencias, sino que se centran en las importantes destrezas de base para la solución de problemas que se han identificado en los informes citados anteriormente.

Para medir adecuadamente los aspectos interdisciplinares de la solución de problemas es importante que:

- la evaluación se centre con igual intensidad tanto en los procesos que los estudiantes emplean a la hora de solucionar problemas como en la corrección de las soluciones;
- se espera que el alumno pueda movilizar competencias de resolución de problemas relacionadas con las áreas de conocimiento del proyecto OCDE/PISA, pero cuidando de que los problemas utilizados para evaluar la solución de problemas en tanto que competencia interdisciplinar desborden el marco de una única área de conocimiento, estableciendo vínculos a la vez con aspectos que quedan fuera de las áreas curriculares y con otros que quedan a caballo sobre las fronteras que delimitan diversas áreas;

- las competencias interdisciplinares de solución de problemas sean evaluadas mediante ejercicios que desborden el área temática en términos de contenido (centrándose en situaciones de la vida real que impliquen una transferencia de aprendizajes curriculares) y de contexto (centrándose en ambientaciones complejas, dinámicas y realistas, así como en ejercicios de razonamiento).

Está claro que la solución de problemas interdisciplinar constituye una parte integral de las destrezas necesitadas por la población activa actual y futura, y que el elemento de solución de problemas del proyecto OCDE/PISA cubre algunos vacíos al evaluar la preparación de los alumnos que no cubren las áreas de conocimiento más académicas. Sin embargo, el marco conceptual de solución de problemas actual no contempla todas las áreas de solución de problemas, por ejemplo, la solución de problemas interpersonales y de grupo, que muchas empresas consideran algo importante.

\section{Características de la evaluación}

\section{ACCESIBILIDAD Y EQUIDAD}

La evaluación debe ser accesible para todos los alumnos sean cuales sean los programas educativos de los países participantes. Esto significa que las preguntas tienen que poder ser entendidas y resueltas por alumnos de 15 años independientemente del currículum que sigan. Las preguntas deben elaborarse con diferentes representaciones (gráficos, tablas, palabras, símbolos, dibujos, etc.) que todos puedan interpretar fácilmente. Además, se procurará evitar cualquier sesgo en el diseño y la elaboración de las preguntas. Por ejemplo, debe evitarse un vocabulario 
excesivamente técnico, unos requisitos de lectura difícil y el uso de preguntas que recurran a experiencias vitales personales.

\section{CALCULADORAS}

La evaluación de la solución de problemas no se centra en la capacidad de los estudiantes para realizar cálculos. Por tanto, deberá permitirse que todos los alumnos participantes en la evaluación de problemas del proyecto OCDE utilicen las calculadoras que normalmente emplean en clase. El usar o no calculadora deberá ser decisión de cada uno de los estudiantes, dependiendo de cuándo consideren apropiado usar una calculadora y de cómo piensen que puede contribuir a solucionar un problema. No se deberá elaborar ninguna pregunta cuya solución dependa únicamente del empleo o no empleo de una calculadora, y la extensión de las preguntas no deberá impedir que los estudiantes que no usen calculadora puedan encontrarse en desventaja a la hora de realizar los cálculos requeridos.

\section{Tipos de pregunta}

En anteriores evaluaciones de solución de problemas a gran escala, las preguntas empleadas fueron de los siguientes tipos: elección múltiple, verdadero o falso, o respuesta breve. Se utilizaron estos tipos de preguntas porque se consideraba que contribuían a una mayor fiabilidad, proporcionaban mayor objetividad, reducían los costes de corrección y facilitaban los requisitos administrativos en comparación con las evaluaciones que contaban con respuestas elaboradas por los estudiantes. No obstante, para determinar adecuadamente la capacidad de los estudiantes para razonar, para resolver problemas y para comunicar los resultados de tales actividades, se necesitan datos más extensos sobre su trabajo. Además, para describir y medir adecuadamente el trabajo de los estudiantes es importante poder examinar diversos tipos de procesos de reflexión que emplean en situaciones problemáticas. Por todo ello, en la evaluación de la solución de problemas interdisciplinar del proyecto PISA 2003, se requiere una mayor variedad de tipos de preguntas. Además de las preguntas de elección múltiple, la evaluación contará con preguntas de respuesta construida tanto cerrada como abierta. A continuación se describen cada uno de los tipos de pregunta.

\section{PREGUNTAS DE ELECCIÓN MÚLTIPLE}

Las preguntas de elección múltiple resultan apropiadas para determinar de manera rápida y económica si los estudiantes dominan ciertas aptitudes, conocimientos o capacidades para reunir la información. Unas preguntas de elección múltiple bien diseñadas pueden medir el conocimiento y la comprensión de los alumnos, así como su elección y la aplicación de estrategias de solución de problemas. Estas preguntas pueden diseñarse para ver más allá de la capacidad de los estudiantes de utilizar alternativas o descartar opciones para determinar una respuesta correcta. No obstante, las preguntas de elección múltiple tienen una capacidad limitada para determinar la amplitud y profundidad de las capacidades de solución de problema de los alumnos en un buen número de contextos.

Las preguntas de elección múltiple empleadas en la evaluación de solución de problemas del proyecto OCDE/PISA deben ceñirse a los siguientes puntos:

- no deben poderse contestar mediante el mero procedimiento de seleccionar valores o efectuar mediciones o comparaciones de tamaño a partir de los gráficos que acompañan a la unidad;

- deben poseer alternativas o distractores diseñados para establecer el modo en que los estudiantes consiguen o no hacer frente a la situación que plantea la pregunta y proporcionar información sobre sus procesos de razonamiento, pero no inducirlos a caer en errores comunes;

- deben utilizarse cuando un modelo de pregunta alternativo requeriría que los estudiantes dibujaran un gráfico o elaboraran un cuadro que fuera a llevarles mucho tiempo o resultarles complicado.

\section{PREGUNTAS DE RESPUESTA CONSTRUIDA CERRADA}

Las preguntas de respuesta construida cerrada permiten que los examinadores evalúen objetivos de mayor importancia y procesos más complejos en un formato de respuesta controlado. Las preguntas de respuesta construida cerrada son parecidas a las preguntas de elección múltiple, pero en ellas se pide a los estudiantes que produzcan una respuesta cuya corrección o incorrección ven 
rápidamente los examinadores. La posibilidad de acertar por casualidad se da menos en las preguntas de respuesta cerrada, y este tipo de pregunta permite a los examinadores observar qué son capaces de producir los estudiantes en una situación que no requiere una corrección experta y donde la puntuación parcial no tiene lugar.

Las preguntas de respuesta construida cerrada empleadas en la evaluación de la solución de problemas del proyecto OCDE/PISA deben ceñirse a los siguientes puntos:

- deben utilizarse cuando sea importante ver que los estudiantes son capaces de elaborar una respuesta a la pregunta por sí mismos;

- deben formular de manera explícita qué es lo que los estudiantes tienen que hacer para responder a la pregunta;

- deben suscitar un número limitado de respuestas posibles para así poder ser corregidas rápidamente con un alto grado de fiabilidad.

\section{PREGUNTAS DE RESPUESTA CONSTRUIDA ABIERTA}

Las preguntas de respuesta construida abierta permiten que los examinadores determinen lo que los estudiantes son capaces de producir a partir de su comprensión de una pregunta y lo que son capaces de explicar sobre cómo la han resuelto. Las preguntas de respuesta construida abierta breve precisan respuestas breves por parte de los estudiantes: resultados numéricos, la clasificación o el nombre correcto de un grupo de objetos, un ejemplo de un concepto dado, etc.

Las preguntas de respuesta construida abierta breve empleadas en la evaluación de la solución de problemas del proyecto OCDE/PISA deben ceñirse a los siguientes puntos:

- deben utilizarse cuando sea importante determinar si los estudiantes son capaces de elaborar una respuesta a la pregunta por sí mismos;

- deben formular de manera explícita qué es lo que los estudiantes tienen que hacer para responder a la pregunta;

- deben permitir examinar el grado en que los estudiantes entienden el problema.
Las preguntas de respuesta construida abierta extensa requieren que los estudiantes aporten resultados más completos de su trabajo o que demuestren que han utilizado procesos de razonamiento más complejos al resolver un problema. En cualquier caso, se espera que los estudiantes transmitan claramente sus procesos de toma de decisiones en el contexto del problema (p. ej., por escrito, mediante dibujos, diagramas o pasos bien ordenados).

Las preguntas de respuesta construida abierta extensa empleadas en la evaluación de la solución de problemas del proyecto OCDE/PISA deben ceñirse a los siguientes puntos:

- deben exigir a los estudiantes que integren la información o los conceptos, y que muestren el modo en que estos conducen a la solución del problema propuesto;

- deben cubrir múltiples conceptos; las respuestas de los estudiantes deberán poner en evidencia su comprensión y capacidad de establecer conexiones entre esos conceptos;

- deben utilizarse cuando la situación requiera varios pasos para llegar a una solución y posea componentes diversos;

- deben exigir a los estudiantes que expliquen o justifiquen el trabajo realizado;

- deben ser susceptibles de ser corregidas mediante guías, de modo que los correctores formados puedan puntuar las preguntas de manera eficaz y fiable.

\section{GRUPOS O UNIDADES DE PREGUNTAS}

Para ayudar a los estudiantes a implicarse mejor en algunos problemas (y probablemente luchar contra las dificultades de motivación a la hora de responder), la mayoría de las preguntas de las pruebas de solución de problemas deben elaborarse en grupos o unidades, es decir en conjuntos que tratan un mismo tema o una misma situación articulada en torno a un proyecto. Estas unidades están formadas por grupos de dos o más preguntas, a menudo de tipo diferente y que implican representaciones distintas, que estén relacionadas por un tema o por un contexto común. En cualquier caso, las preguntas de las unidades deben ser independientes, al menos en la medida en que la respuesta correcta a una pregunta no sea necesaria para contestar correctamente a la siguiente. 


\section{GUÍAS DE CORRECCIÓN}

Las guías de corrección para evaluar las respuestas de los estudiantes deben elaborarse dentro de un marco general que valore los aspectos principales de la solución de problemas. Deberán permitir determinar si los estudiantes alcanzan los niveles siguientes:

- comprender la información dada;

- identificar o describir las características fundamentales del problema y sus interrelaciones;

- elaborar o producir una representación del problema;

- resolver el problema;

- comprobar, evaluar o justificar aspectos del problema;

- comunicar la solución del problema.

En las correcciones, la mayor puntuación debe otorgarse cuando se detecte una comprensión completa del problema, una solución correcta, una perspicacia considerable y un desarrollo claro, apropiado y completo de la respuesta. Además, dichas respuestas deben parecer lógicas, estar claramente redactadas y no contener errores. Los ejemplos que incluyan deben estar bien escogidos y desarrollados completamente.

En un nivel de puntuación algo inferior, el trabajo del alumno debe presentar una comprensión clara del problema, algo de perspicacia y un planteamiento aceptable, pero algún punto débil en su desarrollo. Se dan ejemplos, pero sin estar del todo desarrollados.

En un nivel aún más bajo, el trabajo presenta signos de haber entendido el problema en el plano conceptual, patentes a través de la representación o del planteamiento lógico adoptados. No obstante, en conjunto, la respuesta no está bien desarrollada. Aunque aparecen varios errores de lógica o de razonamiento, la respuesta tiene alguna parte correcta. Los ejemplos dados son incorrectos o están incompletos.

Por último, hay un nivel sin puntuación que se otorga a las preguntas totalmente incorrectas o irrelevantes. En la puntuación a este nivel, debe realizarse alguna diferenciación adicional para distinguir entre los estudiantes que han intentado resolver el problema y aquellos que lo han dejado en blanco. Esto último puede deberse a la falta de tiempo o a un problema de motivación.
Debe tenerse en cuenta que no todas las preguntas contarán con los tres niveles positivos de puntuación descritos, pero el conjunto de la prueba de solución de problemas incluirá preguntas apropiadas para evaluar globalmente los distintos niveles en los resultados de los estudiantes.

\section{PUNTUACIÓN DE DOS CIFRAS}

Además de puntuar las respuestas de los alumnos, las guías de corrección deberán proporcionar una base para puntuar las estrategias empleadas por los estudiantes al resolver un problema dado o para mostrar las ideas falsas que han impedido que los estudiantes dieran con la solución correcta. Esta forma de puntuación es útil para intentar captar la naturaleza del razonamiento del alumno y el grado en que los estudiantes controlan destrezas de razonamiento de orden superior, y puede llevarse a cabo mediante la utilización de los métodos de puntuación de código dual utilizados en las evaluaciones TIMSS y PISA 2000. Esta aproximación utiliza un código de dos cifras a la hora de puntuar las preguntas. La primera cifra indica si se otorga alguna puntuación (total o parcial) al alumno, si el trabajo ha sido incorrecto, si tiene una letra ininteligible o está en blanco. La segunda cifra proporciona información sobre el tipo de planteamiento utilizado por el alumno en caso de que la pregunta se haya abordado correctamente. Si el estudiante no ha recibido puntuación ninguna, este segundo dígito procura información sobre los tipos de error o las falsas ideas que caracterizan el trabajo del alumno.

\section{ESTRUCTURA GENERAL DE LA EVALUACIÓN}

La evaluación de la solución de problemas interdisciplinar consta de dos bloques de unidades, de 30 minutos cada uno. Están representados los tres tipos de problemas (toma de decisiones, análisis y diseño de sistemas y tratamiento de disfunciones) en una proporción de 2:2:1 respectivamente.

Las preguntas de cada bloque se agrupan en cuatro o cinco unidades diferentes. Hay un 50\% de preguntas que valorará un único corrector y otro $50 \%$ de preguntas que requiere la evaluación de varios correctores. Cada unidad cuenta al menos con una pregunta que exija a los alumnos resolver o evaluar una estrategia de solución del problema central de la unidad. 
La información de los ejercicios puede ser más o menos explícita. Algunos ejercicios pueden contener información preestructurada con ciertas restricciones, mientras que otros pueden exigir que los estudiantes extraigan la información y elaboren las restricciones por sí mismos. Cuando resulte apropiado, debe plantearse claramente el problema o ejercicio al principio de cada unidad. Cada unidad debe tener una introducción en la que se exponga claramente a los alumnos el tipo de ejercicio que deben hacer y el tipo de trabajo que tendrán que realizar.

En ninguna unidad debe haber más de tres documentos de referencia, para evitar la confusión de los alumnos; no obstante, en general se debe utilizar información proveniente de más de una disciplina dentro de cada unidad.

\section{Análisis y presentación de los resultados}

Se desarrollará una escala para presentar los resultados de la evaluación de solución de problemas interdisciplinares, independiente de las elaboradas para otras áreas de conocimiento principales y secundarias del ciclo PISA 2003.

La presentación de los resultados de la evaluación interdisciplinar de la solución de problemas se diseñará de manera que proporcione una imagen clara de las competencias de los estudiantes en esta área a los responsables de la política educativa, administradores, profesores, padres y alumnos. En especial, la presentación de resultados debe proporcionar:

- una escala de competencia acompañada de un texto explicativo sobre la naturaleza de las capacidades de los alumnos para la resolución de problemas en diversos puntos a lo largo de dicha escala;

- una planificación de preguntas similar a las utilizadas en otras áreas del proyecto OCDE/PISA para tratar su dificultad relativa y comparar las capacidades del estudiante a lo largo de las diferentes preguntas, contextos y otras características del diseño;

- datos sobre las relaciones existentes entre el rendimiento de los estudiantes en la solución de problemas y otras áreas de las evaluaciones OCDE/PISA;
- tablas y gráficos que reflejen el rendimiento de subgrupos específicos de estudiantes: por sexo, estatus socioeconómico o diferentes vertientes curriculares.

\section{Ampliaciones potenciales del marco conceptual para futuros ciclos OCDE/PISA}

Deben tenerse en cuenta dos opciones para futuras evaluaciones interdisciplinares de la solución de problemas dentro del proyecto OCDE/PISA. Estas opciones hacen referencia a la evaluación de la solución de problemas resueltos mediante trabajo en grupo y al empleo de pruebas administradas por ordenador y diseñadas según las líneas del trabajo de Klieme y sus colegas (en prensa).

\section{SOLUCIÓN DE PROBLEMAS RESUELTOS EN GRUPO}

Una opción centrada en la solución de problemas resueltos en grupo podría consistir en un bloque separado de preguntas, que los alumnos completarían en grupos de tres. Las preguntas de esos bloques podrían elaborarse a partir de preguntas de la evaluación interdisciplinar habitual. Esto permitiría comparar el trabajo realizado por cada estudiante en un escenario individual con el trabajo realizado en escenarios de colaboración. Estos bloques de evaluación deberían proporcionar tiempo para la generación y formulación de ideas y para el desarrollo de los roles de grupo.

Los programas Pacesetter del College Board (2000) cuentan con modelos operativos de evaluaciones de la solución de problemas en grupo. Las expectativas sobre la competencia de los estudiantes en el terreno de la solución de problemas y en el de la educación globalmente considerada exigen el desarrollo de estas competencias en un entorno que valore los aspectos sociales y el trabajo en grupo y, por tanto, también deben ser evaluadas. Dada la relación de la solución de problemas en grupo con los objetivos específicos de los diferentes países respecto a los estudiantes, una evaluación de este tipo debería desarrollarse como una opción internacional dentro de la evaluación interdisciplinar de solución de problemas en futuros ciclos del proyecto OCDE/PISA. 


\section{PRUEBAS ADMINISTRADAS POR ORDENADOR}

El interés internacional en las capacidades de los estudiantes para la solución de problemas en tiempo real y en entornos dinámicos exige el desarrollo de opciones de evaluación que puedan permitir la administración de pruebas por ordenador según las líneas desarrolladas por Klieme (2000). Estas pruebas proporcionarían una fuente de información muy rica sobre las competencias de resolución de problemas de los estudiantes en un entorno dinámico. También permitirían examinar cómo los estudiantes ordenan y desarrollan su trabajo en situaciones complejas, de un modo imposible de obtener a través de una evaluación realizada sobre papel. Este enfoque permite estudiar la interacción de los elementos de información con la selección de estrategias de resolución de problemas y la formulación de soluciones. Al igual que en la evaluación de la solución de problemas en grupo, esta evaluación por ordenador debería considerarse como una opción internacional en futuros estudios.

\section{Ejemplos adicionales}

Las siguientes unidades ilustran una amplia gama de unidades, preguntas y ejercicios de la evaluación de la solución de problemas interdisciplinar del proyecto OCDE/PISA. Estas unidades se utilizaron en la prueba piloto del ciclo
2003, pero, por una u otra razón, no fueron seleccionadas para la prueba final. No obstante, se han subsanado las deficiencias observadas y, a menos que se indique lo contrario, estas unidades se presentan aquí como ejemplo de cómo son las unidades y preguntas de las pruebas. Dado que la evaluación PISA 2003 no había finalizado aún cuando se elaboró esta publicación, no se han incluido aquí preguntas de esa evaluación por razones de seguridad.

Las tres unidades que aquí se presentan complementan a las tres unidades de solución de problemas presentadas más arriba (unidades de solución de problemas 1, 2 y 3). Estas seis unidades proporcionan una imagen bastante completa de las diversas situaciones incluidas en la evaluación de solución de problemas del proyecto PISA 2003. Hay dos unidades de toma de decisiones, dos unidades de análisis y diseño de sistemas (una de análisis y una de diseño) y dos unidades de tratamiento de disfunciones (una en el contexto de un sistema y otra en el de un mecanismo). Las diversas preguntas de las unidades ponen de manifiesto toda la variedad de formatos de pregunta y de tipos de respuesta requeridos.

Las preguntas de las unidades se presentan en recuadros con algunas notas y comentarios explicativos para ilustrar lo que se pretende con la pregunta y las respuestas comunes que dieron los alumnos en la prueba piloto. Tras cada pregunta, aparece su guía de corrección. 


\section{Solución de problemas, Unidad 4: PILAS}

La Unidad 4 de solución de problemas plantea a los estudiantes un contexto en el que deben decidir qué clase de pila es la mejor opción para un radiocasete estéreo. Virginia ha pedido a cuatro de sus amigos que la ayuden en un experimento: cada uno probará dos marcas de pilas y luego anotará el tiempo que cada pila ha durado en sus propios radiocasetes. Los datos registrados por Virginia y sus amigos aparecen en forma de tabla para que los alumnos los utilicen a la hora de responder a dos de las preguntas de esta unidad.

Este problema trata de cómo decidir qué pilas son las mejores del mercado.

Virginia se da cuenta de que unas marcas de pilas duran más que otras en su radiocasete estéreo. En el mercado hay cuatro marcas distintas de pilas que le vayan bien a su radiocasete. Pide a algunos amigos que la ayuden a decidir cuál de ellas es la mejor.

Cada uno de sus amigos prueba dos marcas de pilas distintas en su propio radiocasete estéreo. La Figura 1 muestra los datos que le entregan. (Usan las pilas de una marca hasta que se agotan del todo y entonces prueban las pilas de otra hasta que también se agotan.) Todas las pilas son del mismo tamaño.

Figura 1: Duración de las distintas marcas de pilas

\begin{tabular}{l|ll|ll}
\multicolumn{2}{c}{} & \multicolumn{2}{c}{$\begin{array}{l}\text { Primera marca } \\
\text { de pilas }\end{array}$} & \multicolumn{2}{c}{$\begin{array}{l}\text { Segunda marca } \\
\text { de pilas }\end{array}$} & Duración \\
\hline Virginia & Energplus & 5 días & Durabat & 5 días \\
Marcos & BaterX & 4 días & Elect-L & 5 días \\
Kike & Durabat & 6 días & Elect-L & 5 días \\
Pablo & Elect-L & 3 días & Energplus & 4 días \\
Isabel & Energplus & 7 días & BaterX & 4 días
\end{tabular}

\section{Solución de problemas, Ejemplo 4.1:}

Virginia examina los resultados y dice: "Esta investigación demuestra que Durabat es la marca de pilas que dura más tiempo".

Escribe una razón, basándote en los resultados de la investigación anterior, por la que se pueda concluir que "Durabat es la marca de pilas que dura más tiempo". 


\section{Criterios de corrección y comentarios sobre el ejemplo 4.1}

Máxima puntuación

Código 1: Respuestas que dicen que Durabat es la que tiene una media de duración mayor: $(6+5) / 2=5$, 5 . Las demás marcas de pilas tienen una media inferior (Energplus $=5,33$, BaterX $=4$, Elect- $L=4,33$ )

Nota: Para dar esta puntuación no es necesario que los estudiantes escriban sus cálculos.

$\mathrm{O}$

Durabat duró 5 días o más. Las otras pilas duraron menos (4, 4 y 3 días).

Ninguna puntuación

Código 0: Otras respuestas.

Tipo de pregunta: Pregunta de respuesta construida abierta

Tipo de problema: Toma de decisiones

Situación: Vida personal/Científica

Esta pregunta incita a los alumnos a comprender la naturaleza de la puesta a prueba de un producto como las pilas, así como el papel que los datos pueden desempeñar en un tipo de comprobación de ese estilo. Dados los datos de la tabla, parece que un plan de respuesta posible es algún tipo de comparación de la duración de las pilas. Para ello, es preciso que los estudiantes se den cuenta de lo que se les está pidiendo, que establezcan una comparación y que den algún tipo de justificación en su respuesta.

Si los estudiantes abordan la pregunta tratando de establecer la duración media de las pilas y concluyen que Durabat es la más duradera puesto que su duración media es la mayor, quiere decir que han examinado la información, han comparado las diferentes alternativas, han establecido una generalización y han comunicado sus resultados.
Algunos estudiantes no supieron determinar bien lo que se les pedía. Interpretaron que la pregunta les pedía una explicación sobre la necesidad de energía de los radiocasetes o se centraron únicamente en la primera o segunda marca de pilas que los estudiantes probaron. Algunos estudiantes aportaron razones ajenas al experimento, del tipo «No se puede deducir de los anuncios de la televisión».

Esta pregunta es de algún modo similar a las que se pueden plantear cuando se comporten como consumidores. No obstante, para la mayoría de los alumnos esta pregunta no será habitual y les hará pensar de una forma inédita así como elaborar la manera de comunicar sus conclusiones.

\section{Solución de problemas, Ejemplo 4.2:}

Escribe DOS razones diferentes por las que es posible que los resultados de esta prueba no sean fiables. 


\section{Criterios de corrección y comentarios sobre el ejemplo 4.2}

Posibles razones:

- No se especifica el uso diario ni en términos de tiempo ni de función (reproducir, rebobinar, volumen, etc.).

- La muestra que se utiliza para esta investigación es pequeña.

- Las mediciones no son precisas. ¿Qué se entiende por un día?

- No hay que fiarse del resultado ya que, unas veces, la misma marca de pilas dura 7 días y, otras veces, 4 días.

- Cuando los radiocasetes son diferentes pueden tener diferentes necesidades eléctricas.

Máxima puntuación

Código 2: Respuestas que mencionan claramente DOS posibles razones de la lista anterior.

Nota: se debe tener en cuenta que los dos razonamientos deben ser diferentes y no simplemente dos maneras de decir lo mismo.

Puntuación parcial

Código 1: Respuestas que mencionan claramente sólo UNA posible razón de la lista anterior.

Ninguna puntuación

Código 0: Otras respuestas.

Tipo de pregunta: Pregunta de respuesta construida abierta

Tipo de problema: Toma de decisiones

Situación: Vida personal/Científica

Esta pregunta exige que los estudiantes examinen las limitaciones con las que se realiza el experimento, que observen los factores que podrían ser fuente de diferencias en la vida de las pilas y que consideren diferentes explicaciones para los resultados de la prueba.

Algunos alumnos no llegaron a entender el ejercicio y trataron de explicar por qué el resultado del Ejemplo 4.1 de solución de problemas era verdadero. Otros estudios se centraron en un aspecto particular de la situación y dieron una única razón, o dos razones equivalentes, de por qué los resultados no eran fiables. Por ejemplo, dos de las razones de un alumno fueron que algunos radiocasetes podían haberse ido encendiendo y apagando y que los radiocasetes podían no haber estado funcionando durante la misma cantidad de tiempo.
Para responder bien a esta pregunta, los alumnos deben comprender perfectamente el ejercicio de comprobación de la duración de una pila. Ello conlleva ser capaz de enumerar posibles factores relacionados con la duración de una pila, examinar las interrelaciones entre estos factores, comparar y contrastar estos factores con los utilizados para responder al anterior Ejemplo 4.1 de solución de problemas y transmitir detenidamente dos explicaciones alternativas que invalidar la opinión de Virginia.

La capacidad para resolver correctamente este ejercicio puede estar relacionada con la experiencia de los alumnos en la metodología científica. Por esta razón no se incluyó esta unidad en la prueba final sino que se reservó como unidad de ejemplo. 


\section{Solución de problemas, Unidad 5: RODILLOS}

Esta unidad plantea a los alumnos dos situaciones en las que tienen que analizar cómo gira un sistema de rodillos, y luego una situación en la que deben diseñar un sistema de correas de transmisión que hará girar el conjunto de rodillos en determinadas direcciones.

El material introductorio presenta un sistema de rodillos sencillo y proporciona información gráfica de cómo giran los rodillos en el sistema, partiendo del sentido en que gira el rodillo motor.

Este problema trata sobre el diseño de un conjunto de rodillos que tienen que girar de una forma concreta.

Se puede hacer girar un conjunto de rodillos colocándolos unos en contacto con otros y girando luego uno de ellos. El rodillo que se hace girar recibe el nombre de rodillo motor.

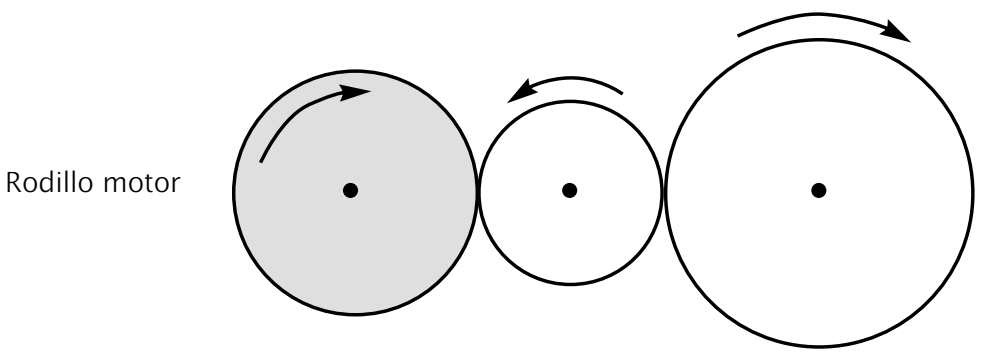

\section{Solución de problemas, Ejemplo 5.1:}

\section{A continuación se presenta un determinado acoplamiento de rodillos.}

Rodillo motor

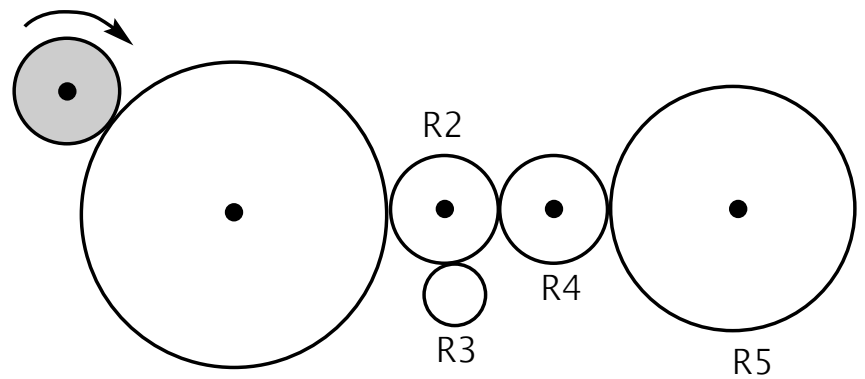

R 1 
¿Qué rodillo o rodillos girarán en el mismo sentido que el del rodillo motor, y cuáles girarán en sentido opuesto?

\begin{tabular}{|c|c|}
\hline RODILLO & $\begin{array}{l}\text { ¿GIRARÁ EN EL MISMO SENTIDO QUE } \\
\text { EL RODILLO MOTOR O EN EL SENTIDO OPUESTO? }\end{array}$ \\
\hline R1 & Mismo sentido / Sentido opuesto \\
\hline & Mismo sentido / Sentido opuesto \\
\hline & Mismo sentido / Sentido opuesto \\
\hline & Mismo sentido / Sentido opuesto \\
\hline & Mismo sentido / Sentido opuesto \\
\hline
\end{tabular}

\section{Criterios de corrección y comentarios sobre el ejemplo 5.1}

Máxima puntuación

Código 1: Opuesto, Mismo, Opuesto, Opuesto, Mismo, en este orden. (R2 y R5 girarán en el mismo sentido que el del rodillo motor.)

Ninguna puntuación

Código 0: Cualquier otra combinación de respuestas.

Tipo de pregunta: Elección múltiple compleja

Tipo de problema: Análisis y diseño de sistemas

Situación: Vida personal/Trabajo y ocio

Para contestar correctamente a esta pregunta los estudiantes deben entender la relación entre los rodillos y la forma en que se produce el movimiento en los rodillos contiguos como resultado del movimiento del rodillo motor. Para ello deben concebir por inducción, a partir del ejemplo, una regla sobre el sentido de la rotación de los rodillos en contacto, y quizá también comprender la relación entre rodillos contiguos en disposiciones similares que les sean familiares.

A partir de la comprensión intuitiva de la situación, los alumnos llegan a una generalización que viene a decir que los rodillos en contacto se mueven en sentidos opuestos. Esta generalización por sí sola no es suficiente para contestar del todo a la pregunta que se plantea. Los estudiantes tienen que darse cuenta de que ésta es una relación transitiva: si A-B-C es una cadena de rodillos contiguos y A se mueve en el sentido de las agujas del reloj, entonces B se mueve en sentido contrario a las agujas del reloj y $\mathrm{C}$, otra vez en el sentido de las agujas del reloj. Esta comprensión de la transitividad permite a los estudiantes aplicar la explicación a todos los componentes de una secuencia de rodillos, quizá colocando flechas que apunten a un sentido diferente al pasar de una a otra rueda. Este tipo de comprensión es de naturaleza analógica.

Las capacidades de los estudiantes para contestar a las preguntas de esta unidad se basan en parte en la comprensión de los sistemas mecánicos y en el razonamiento espacial. Por esta razón no se incluyó esta unidad en la prueba final sino que se reservó como unidad de ejemplo. 
Solución de problemas, Ejemplo 5.2:

Algunos acoplamientos de rodillos no girarán al girar la rueda motora. Explica por qué no girará el acoplamiento siguiente.

\section{Criterios de corrección y comentarios sobre el ejemplo 5.2}

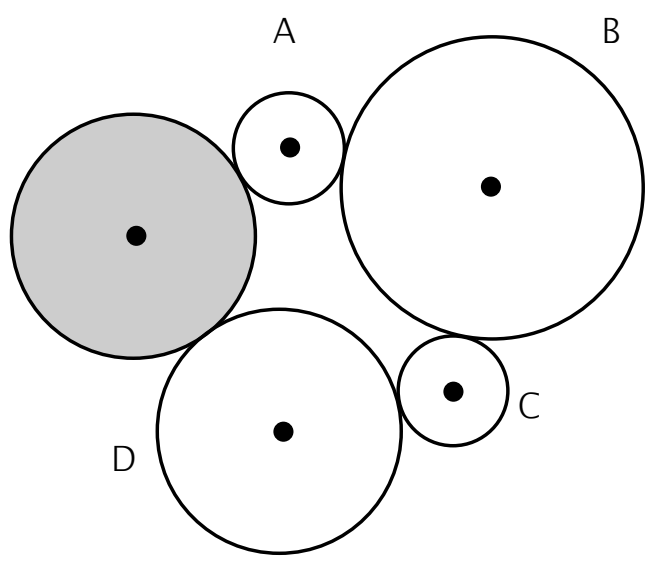

Máxima puntuación

Código 1: Respuestas que indican que si el rodillo motor gira a derechas o en el sentido de las agujas del reloj, la rueda A girará a izquierdas o en sentido contrario al de las agujas, la B a derechas, la C a izquierdas y la $\mathrm{D}$ a derechas. La rueda $\mathrm{D}$ obligará a la rueda motora a girar a izquierdas pero como ya se está moviendo a derechas, entonces se llega a la conclusión de que no es posible el movimiento del conjunto.

$\mathrm{O}$

Una explicación parecida (compruebe que las marcas que los estudiantes hagan en sus dibujos concuerden con las explicaciones que redacten).

- Al estar todas las ruedas en contacto, cada rueda será movida en un sentido por una rueda y en el sentido contrario por otra rueda.

- Porque la rueda motora y una de las próximas a ella intentan girar en el mismo sentido.

- Las ruedas entrechocarán, p. ej., B y C van a moverse en el mismo sentido.

- La rueda $A$ mueve la rueda $B$ en el sentido contrario al de la rueda C, y por lo tanto no se moverá.

Ninguna puntuación

Código 0: Otras respuestas, por ejemplo:

- Porque están unidas, pero no en línea recta.

- Porque no están pegadas las unas a las otras.

- Todas se mueven en sentidos opuestos.

Tipo de pregunta: Pregunta de respuesta construida abierta

Tipo de problema: Análisis y diseño de sistemas

Situación: Vida personal/Trabajo y ocio 
Al igual que el Ejemplo 5.1, esta pregunta requiere que los estudiantes comprendan las relaciones que se dan en un juego secuencial de rodillos y que sean capaces de trasladar esa comprensión a los sucesivos pares de rodillos en este acoplamiento "en anillo".

Aquí los estudiantes tienen que aplicar la regla derivada relativa a la rotación alterna de los rodillos contiguos. Se trata de una actividad de análisis de sistemas. Esta pregunta exige a los alumnos que comprueben la compatibilidad de casos específicos, en un contexto de problema determinado, respecto a la regla derivada en relación al comportamiento de rotación en un sistema desarrollado espacialmente.

El razonamiento de esta pregunta resulta novedoso para muchos estudiantes. Pocos de ellos tienen experiencia en enfrentarse a una situación definida espacialmente y en buscar pruebas de que no se produzca un resultado determinado. Analizar un sistema para hallar lo que no se produce es algo que difiere de la mayoría de ejercicios escolares similares. Las «explicaciones» de muchos estudiantes consistieron únicamente en las flechas que indicaban que se producía un conflicto en el sentido rotacional a medida que se avanzaba por el sistema.

Esta pregunta implica comprender el giro de los rodillos en relación al rodillo motor y el contacto entre los rodillos y la correa de transmisión. En este caso, los estudiantes deben deducir una regla sobre el funcionamiento de la correa de transmisión y la rotación de los rodillos según se hallen en el mismo lado de la correa o en lados opuestos.

Una vez que los estudiantes han establecido la relación, deben verificarla y elaborar un diseño (en este caso la colocación de la cinta de transmisión en el juego de rodillos dado), y a continuación "construir el sistema" que producirá el efecto rotatorio deseado. Una vez los estudiantes hayan elaborado el diseño, deberán comprobarlo de nuevo para asegurarse de que produce la rotación deseada en los distintos rodillos.

Este problema tiene más de una solución correcta. Sin embargo, entre las respuestas de los estudiantes prácticamente no se encontraron diseños asimétricos.

\section{Solución de problemas, Ejemplo 5.3:}

Otro sistema para que los rodillos giren es mediante una correa de transmisión que conecte el rodillo motor con los otros. A continuación se presentan dos ejemplos:

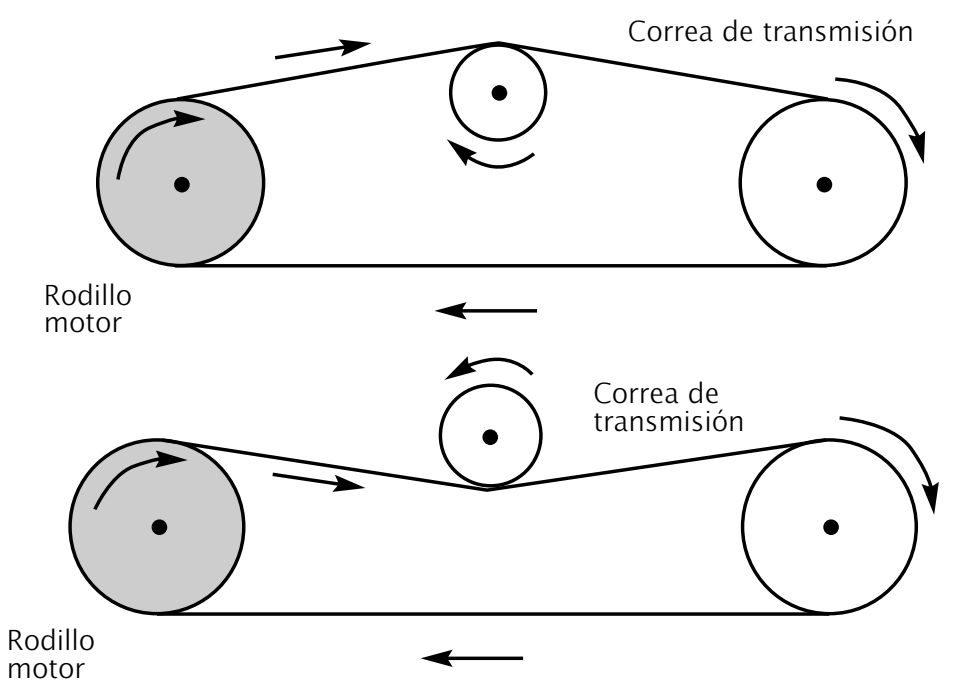


Dibuja una correa de transmisión alrededor del siguiente conjunto de rodillos de tal manera que todos los rodillos mayores giren a derechas, en el sentido de las agujas del reloj, y todos los rodillos pequeños giren a izquierdas, en el sentido contrario a las agujas del reloj. La correa no debe pasar sobre sí misma.
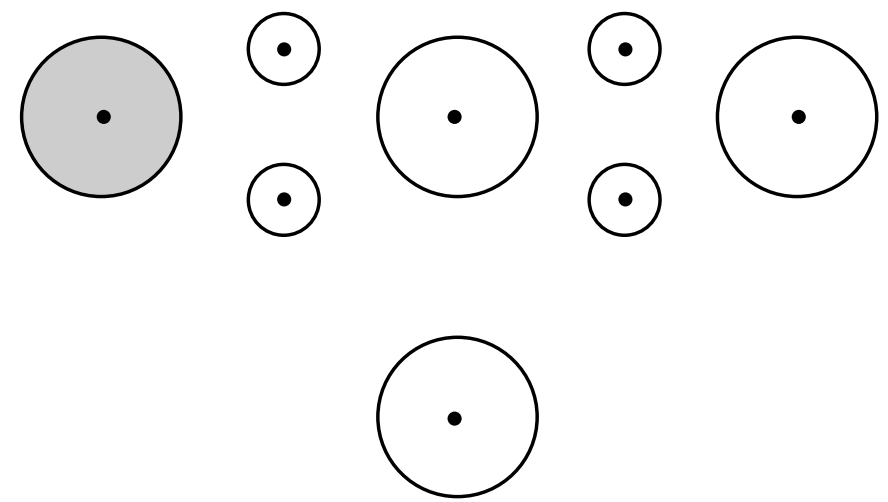

\section{Criterios de corrección y comentarios sobre el ejemplo 5.3}

Máxima puntuación

Código 1: Respuestas conforme al siguiente ejemplo.

Nota: Se debe puntuar con el Código 1 aunque en el dibujo la correa no toque las ruedas.

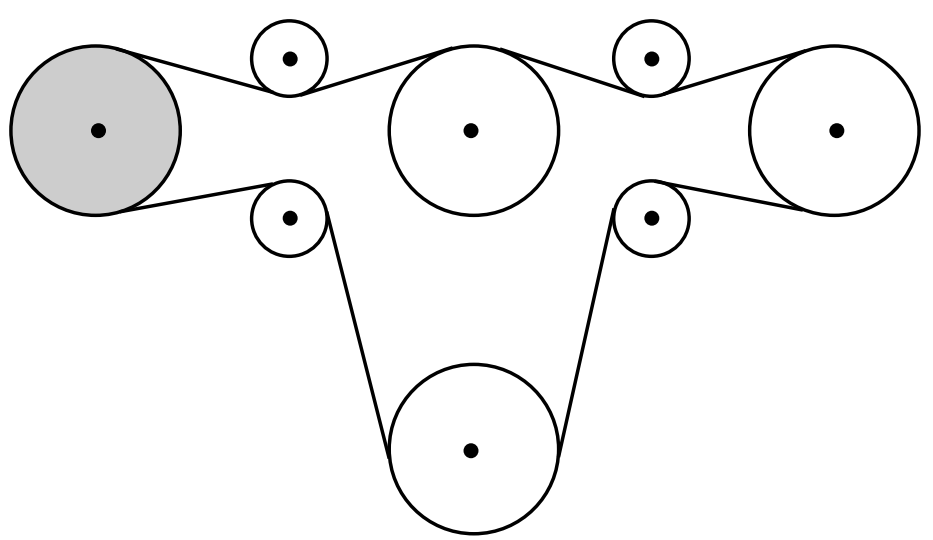

Ninguna puntuación

Código 0: Otras respuestas.

Tipo de pregunta: Pregunta de respuesta construida abierta

Tipo de problema: Análisis y diseño de sistemas

Situación: Vida personal/Trabajo y ocio 


\section{Solución de problemas, Unidad 6: VENTA DE LIBROS}

La Unidad 6 plantea a los estudiantes una situación referente al sistema de ventas a través de Internet de una librería. El problema consiste en analizar el sistema de ventas de libros, encontrar un arreglo para los problemas que puedan aparecer con la dirección postal del cliente y modificar el programa de ventas mediante la adición de un subproceso que verifique la tarjeta de crédito del cliente y cargue en ella el precio de su compra.

La unidad empieza con la presentación de un diagrama de flujo que muestra los pasos del procesamiento de la venta de un libro a través de Internet.

\section{VENTA DE LIBROS}

La librería EDILIBRO vende libros a través de Internet. El siguiente diagrama muestra los pasos para dar curso al pedido de un libro:

\section{Figura A: Pasos para dar curso al pedido de un libro}

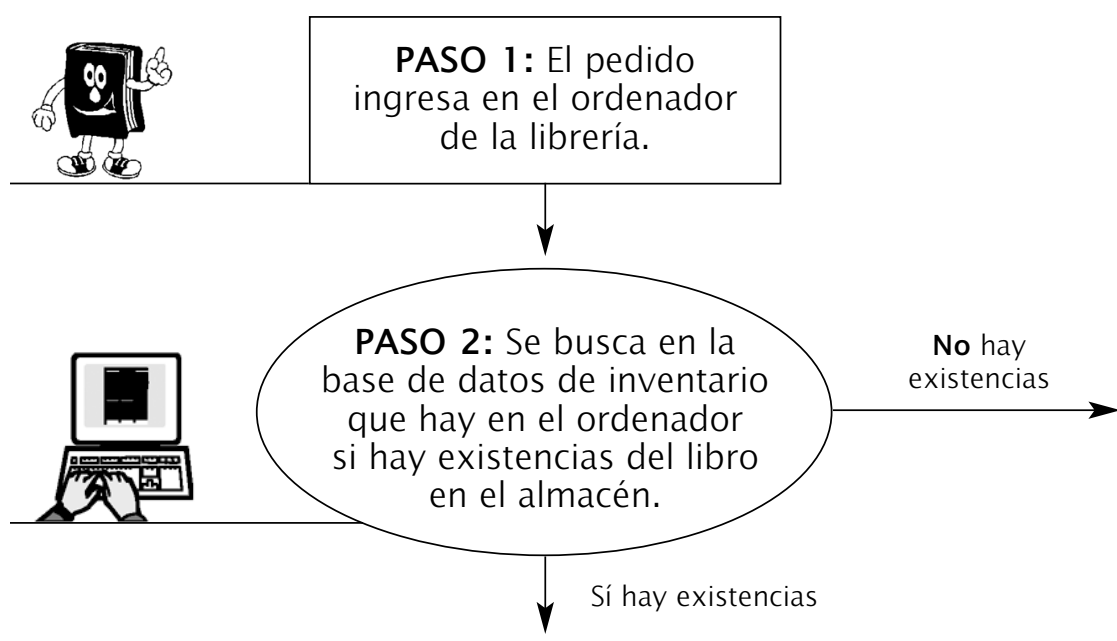

PASO 2a: Se informa al cliente de que el libro no está disponible ahora. Se pregunta al cliente si, de todos modos, quiere hacer el pedido del libro para el futuro.

PASO 3: Se empaqueta y se envía el libro al cliente junto con la factura.

\begin{tabular}{|c|c|}
\hline \multicolumn{1}{c|}{} & $\begin{array}{c}\text { PASo 4: Se actualiza } \\
\text { la base de datos } \\
\text { del ordenador añadiendo } \\
\text { la venta del libro. }\end{array}$ \\
\hline
\end{tabular}


Solución de problemas, Ejemplo 6.1:

Un libro enviado a un cliente fue devuelto porque la dirección postal no era correcta. ¿En qué paso o pasos del proceso se ha podido cometer este error?

\begin{tabular}{l|l} 
Paso & ¿Podría haberse cometido el error en este paso? \\
\hline 1 & Sí / No \\
2 & Sí / No \\
$2 a$ & Sí / No \\
3 & Sí / No \\
4 & Sí / No
\end{tabular}

\section{Criterios de corrección y comentarios sobre el ejemplo 6.1}

Máxima puntuación

Código 1: Sí, No, No, Sí, No, en este orden.

Ninguna puntuación

Código 0: Cualquier otra combinación de respuestas.

Tipo de pregunta: Elección múltiple compleja

Tipo de problema: Tratamiento de disfunciones

Situación: Trabajo y ocio

Para dar una respuesta correcta al Ejemplo 6.1, los alumnos deben comprender la relación entre los diferentes pasos del procedimiento y las instrucciones asociadas con cada uno. Entender un diagrama de flujo resulta crucial para el análisis y la depuración de muchos procedimientos empresariales de carácter secuencial, en los que el orden temporal de las decisiones tomadas es de gran importancia para el éxito de un procedimiento como éste.

\section{Solución de problemas, Ejemplo 6.2:}

La librería EDILIBRO tiene dificultades en cobrar los libros que han comprado algunos clientes. En consecuencia, la librería quiere exigir a los clientes que indiquen el número de su tarjeta de crédito cuando hagan algún pedido de libros.

Para ello, la librería desea añadir los siguientes pasos al proceso de la Figura A. 

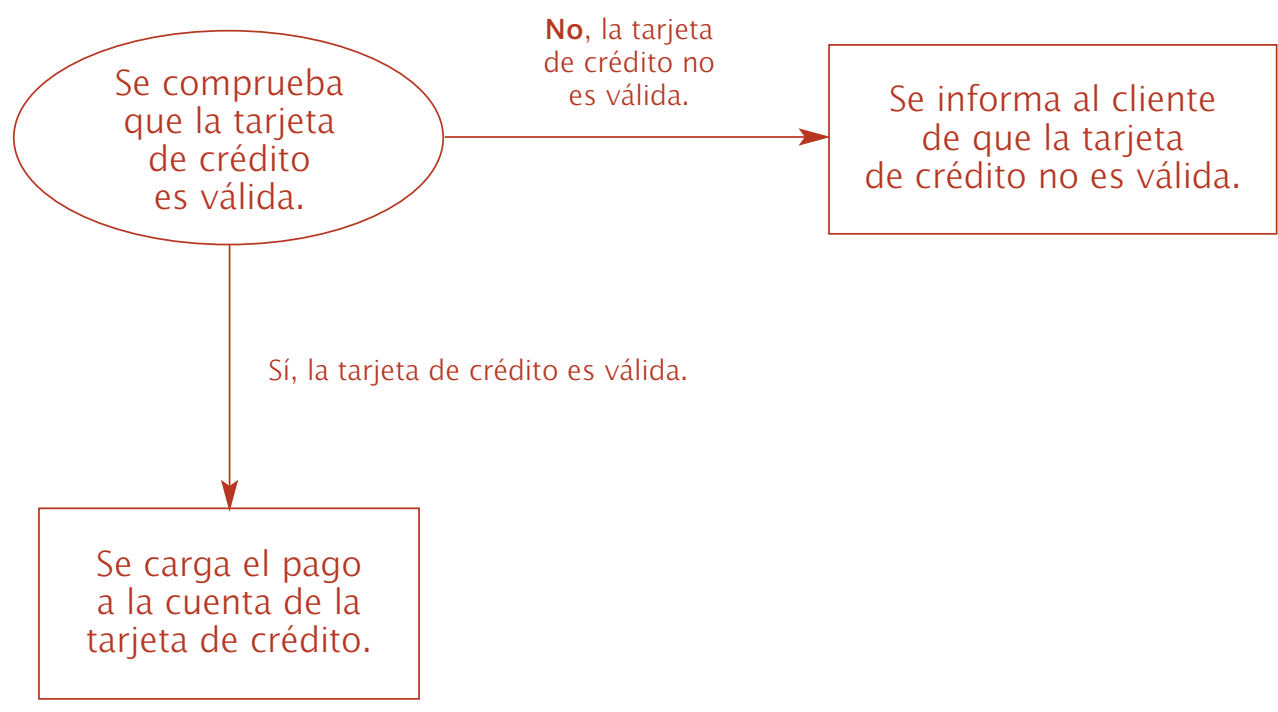

En la Figura A, ¿dónde introducirías estos pasos destinados a comprobar y procesar la información de la tarjeta de crédito?
A. Entre los pasos 1 y 2.
B. Entre los pasos 2 y 3.
C. Entre los pasos 2 y $2 \mathrm{a}$
D. Entre los pasos 3 y 4.
E. Después del paso 4.

\section{Criterios de corrección y comentarios sobre el ejemplo 6.2}

Máxima puntuación

Código 1: $\quad$ Respuesta B. Entre los pasos 2 y 3.

Nota: El cargo no se debe realizar hasta que la editorial sepa que puede suministrar el producto al cliente.

Ninguna puntuación

Código 0: Otras respuestas.

Tipo de pregunta: Elección múltiple

Tipo de problema: Tratamiento de disfunciones

Situación: Trabajo y ocio 
Una vez los estudiantes han analizado el procedimiento deben formular un diagnóstico del problema que aparece en el enunciado. En este caso, el proceso conlleva realizar una serie de comprobaciones que implican razonamiento de tipo condicional, algo así como: "Si aquí aparece este tipo de error, ¿cómo afecta entonces al envío del paquete o carta en lo siguientes pasos del sistema?" Para realizar correctamente los pasos de la depuración, el estudiante debe ser capaz de razonar en situaciones que contengan información tanto verbal como gráfica.

$\mathrm{Al}$ igual que en el Ejemplo 6.1, en esta pregunta los estudiantes deben razonar a partir de información verbal y gráfica para entender los aspectos secuenciales del procedimiento. Pero, además, deben diseñar un sistema identificando, mediante un análisis concienzudo de la lógica utilizada, dónde se puede añadir un subproceso que compruebe la tarjeta de crédito del cliente y transfiera a ésta el cargo como parte del procedimiento de pedido. La ubicación correcta del subproceso (es decir, entre los pasos 2 y 3) exige darse cuenta de que no se debe cargar el importe al cliente a no ser que haya existencias del libro.

Muchos estudiantes eligieron la opción A (entre los pasos 1 y 2), algo que puede corresponderse con la práctica de algunas editoriales. Por esta razón, y por el hecho de que la experiencia en realizar pedidos vía Internet varía considerablemente entre los estudiantes, no se incluyó esta unidad en la prueba final el estudio principal sino que se reservó como unidad de ejemplo. 



\section{$\boldsymbol{ᄀ}$ REFERENCIAS}

Baxter, G.P. y R. Glaser (1997), An Approach to Analysing the Cognitive Complexity of Science Performance Assessments (Technical Report 452), National Center for Research on Evaluation, Standards and Student Testing (CRESST), Los Ángeles, California, EE. UU.

Binkley, M.R. y R. Sternberg, S. Jones, D. Nohara (1999), An Overarching Framework for Understanding and Assessing Life Skills, Unpublished International Life Skills Survey (ILSS) Frameworks, (inédito), National Center for Education Statistics, Washington, Distrito de Columbia, EE. UU.

Bloom, B.S., J.T. Hasting y G.F. Madaus (1971), Handbook on Formative and Summative Evaluation of Student Learning, McGraw-Hill, Nueva York, Nueva York, EE. UU.

Blum, W (1996), "Anwendungsorientierter Mathematikunterricht Trends und Perspektiven", en G. Kadunz et al. (eds.), Trends und Perspektiven. Schriftenreihe Didaktik der Mathematik, vol. 23, HoelderPichler-Tempsky, Viena, Austria, pág. 15-38.

Boshuizen, H.P.A., C.P.M. van Der Vleuten, H.G. Schmidt y M. Machiels-Bongaerts (1997), "Measuring Knowledge and Clinical Reasoning Skills in a Problem-based Curriculum", Medical Education, 31, 
Department of Educational Research and Development University of Limburg, Limburgo, Países Bajos, pág. 115-121.

Bransford, J.D., A.L. Brown y R.R. Cocking (eds.) (1999), How People Learn: Brain, Mind, Experience, and School, National Academy Press, Washington, Distrito de Columbia, EE. UU.

Bybee, R.W. (1997), "Towards an Understanding of Scientific Literacy", en W. Grabe y C. Bolte (eds.), Scientific Literacy -- An International Symposium, IPN, Kiel, Alemania.

Charles, R., F. Lester y P. O'Daffer (1987), How to Evaluate Progress in Problem Solving, National Council of Teachers of Mathematics, Reston, Virginia, EE. UU.

College Board (2000), véanse documentos en la Web: http://www.collegeboard.com/about/association/pace/pacemath.html

Collis, K.F., T.A. Romberg y M.E. Jurdak (1986), "A Technique for Assessing Mathematical Problem Solving Ability", Journal for Research in Mathematics Education, 17(3), pág. 206-221.

Committee of Inquiry into the Teaching of Mathematics in Schools (1982), Mathematics Counts (the Cockcroft report), Her Majesty's Stationery Office, Londres, Reino Unido.

Consejo Europeo (2001), Common European Framework of Reference for Languages: Learning, Teaching, Assessment, Cambridge University Press, Cambridge, Reino Unido.

de Corte, E., B. Greer y L. Verschaffel (1996) "Mathematics Teaching and Learning", en D. C Berliner y R. C. Calfee (eds.), Handbook of Educational Psychology, Macmillan, Nueva York, Nueva York, EE. UU., pág. 491-549.

Csapó, B. (1997), "The Development of Inductive Reasoning: Crosssectional Assessments in an Educational Context", International Journal of Behavioral Development, 20(4), pág. 609-626.

Departamento de Trabajo de EE. UU. (1991), The Secretary's Commission on Achieving Necessary Skills (SCANS): What Work Requires of Schools, U.S. Department of Labor, Washington, Distrito de Columbia, EE. UU.

Devlin, K. (1994, 1997), Mathematics, the Science of Patterns, Scientific American Library, Nueva York, EE. UU.
Dossey, J.A. (1997), "Defining and Measuring Quantitative Literacy", in L.A. Steen, (ed.), Why Numbers Count: Quantitative Liferacy for Tomorrow's America, The College Board, Nueva York, EE. UU, pág. 173-186.

Dossey, J.A., I.V.S. Mullis y C.Q. Jones (1993), Can Our Students Problem Solve?, National Center for Educational Statistics, Washington, Distrito de Columbia, EE. UU..

Einstein, A. (1933), "Preface to M. Plank", Where is Science Going?, Allen and Unwin, Londres, Reino Unido.

Fey, J. (1990), "Quantity", in L.A. Steen (ed.), On the Shoulders of Giants: New Approaches to Numeracy, National Academy Press, Washington, Distrito de Columbia, EE. UU.

Frensch, P. y J. Funke (1995), "Definitions, Traditions, and a General Framework for Understanding Complex Problem Solving", en P. Frensch y J. Funke (eds.), Complex Problem Solving: The European Perspective, Lawrence Erlbaum Associates, Hillsdale, Nueva Jersey, EE. UU, pág. 3-25.

Freudenthal, H. (1973), Mathematics as an Educational Task, D. Reidel, Dordrecht, Países Bajos.

Freudenthal, H. (1983), Didactical Phenomenology of Mathematical Structures, D. Reidel, Dordrecht, Países Bajos.

Garfield, J. y Ahlgren, A. (1988), "Difficulties in Learning Basic Concepts in Probability and Statistics: Implications for Research", Journal for Research in Mathematics Education, 19(1), pág. 44-63.

Gee, J. (1998), Preamble to a Literacy Program, Department of Curriculum and Instruction, Madison, Wisconsin, EE. UU.

Graeber, W. y C. Bolte (eds.) (1997), Scientific Literacy - An International Symposium, IPN, Kiel, Alemania.

Grünbaum, B. (1985), "Geometry Strikes Again", Mathematics Magazine, 58 (1), pág 12-18.

Hawking, S.W. (1988), A Brief History of Time, Bantam Press, Londres, Reino Unido.

Hiebert, J., T.P. Carpenter, E. Fennema, L. Fuson, P. Human, H. Murray, A. Olivier y D. Wearne (1996), "Problem Solving as a Basis for Reform in Curriculum and Instruction: The case of Mathematics", Journal for Research in Mathematics Education, 25(4), pág. 12-21. 
Oficina Internacional del Trabajo (OIT) (1998), World Employment Report 1998-1999: Employability in the Global Economy - How Training Matters, OIT, Ginebra, Suiza.

Kirsch, I.S. y P.B. Mosenthal (1989-1991), "Understanding Documents. A Monthly Column", Journal of Reading, International Reading Association, Newark, Delaware, EE. UU.

Klieme, E. (1989), Mathematisches Problemlösen als Testleistung, Lang, Fráncfort del Meno, Alemania.

Klieme, E. (2000), Assessment of Cross-disciplinary Problem Solving Competencies, obra inédita para Network A, OCDE-OCDE/PISA, París, Francia.

Klieme, E., J. Ebach, H.J. Didi, A. Hensgen, K. Heilmann y H.K. Meisters (en prensa), Problemlösetest für Sechste und Siebente Klassen, Hogrefe, Goettingen, Alemania.

De Lange, J. (1987), Mathematics, Insight and Meaning, OW and OC, Utrecht University, Utrecht, Países Bajos.

De Lange, J. (1995), "Assessment: No Change Without Problems", en T.A. Romberg (ed.), Reform in School Mathematics and Authentic Assessment, Suny Press, Albany, Nueva York, EE. UU.

De Lange, J. y H. Verhage (1992), Data Visualization, Sunburst, Pleasantville, Nueva York, EE. UU.

Langer, J. (1995), Envisioning Literature, International Reading Association, Newark, Delaware.

Laugksch, R. C. (2000), "Scientific Literacy: A Conceptual Overview", Science Education, 84 (1) 71 -94.

LOGSE (1990), Ley de Ordenacion General del Sistema Educativo, Madrid, España.

Masters, G., R. Adams y M. Wilson (1999), "Charting Student Progress", en G. Masters y J. Keeves (eds.), Advances in Measurement in Educational Research Assessment, Elsevier Science, Amsterdam, Países Bajos.

Masters G. y M. Forster (1996), Progress Maps, Australian Council for Educational Research, Melbourne, Australia.

Mathematical Association of America (MAA) (1923), The Reorganization of Mathematics in Secondary Education; a Report of the National Committee on
Mathematical Requirements, The Mathematical Association of America, inc, Oberlin, Ohio, EE. UU.

Mathematical Sciences Education Board (MSEB) (1990), Reshaping School Mathematics: A Philosophy and Framework of Curriculum, National Academy Press, Washington, Distrito de Columbia, EE. UU.

Mayer, R.E. (1985), "An Information-processing Analysis of Mathematical Ability", en R.J. Sternberg (ed.), Human Abilities - An Information-processing Approach, Freeman, Nueva York, Nueva York, EE. UU.

Mayer, R.E. (1992), Thinking, Problem Solving, Cognition (2 ${ }^{\mathrm{a}}$ Ed.), Freeman, Nueva York, Nueva York, EE. UU.

Mayer, R.E. y M.C. Wittrock (1996), "Problem Solving Transfer", en D. C. Berliner y R. C. Clafee (eds.), Handbook of Educational Psychology, Macmillan, Nueva York, Nueva York, EE. UU, pág. 45-61.

McCurry, D. (2002), Notes towards an Overarching Model of Cognitive Abilities, Unpublished report (inédito), Australian Council for Educational Research, Melbourne, Australia.

Millar, R. y J. Osborne (1998), Beyond 2000: Science Education for the Future, King's College London School of Education, Londres, Reino Unido.

Mitchell, J., E. Hawkins, P. Jakwerth, F. Stancavage y J. Dossey (2000), StudentWork and Teacher Practice in Mathematics, National Center for Education Statistics, Washington, Distrito de Columbia, EE. UU.

National Council of Teachers of Mathematics (NCTM) (1989), Curriculum and Evaluation Standards for School Mathematics, NCTM, Reston, Virginia, EE. UU.

National Council of Teachers of Mathematics (NCTM) (2000), Principles and Standards for Mathematics, NCTM, Reston, Virginia, EE. UU.

Neubrand, M., R. Biehler, W. Blum, E. Cohors-Fresenborg, L. Flade, N. Knoche, D. Lind, W. Löding, G. Möller y A. Wynands (grupo de expertos de matemáticas del proyecto OCDE/PISA) (2001), "Grundlagen der Ergänzung des Internationalen OECD/PISAMathematik-Tests in der Deutschen Zusatzerhebung", Zentralblatt für Didaktik der Mathematik 33(2), págs. 33 - 45.

Newton, I. (168), Philosophiae naturalis principia mathematica Auctore Is. Newton, Trin. Coll. Cantab. Soc. Matheseos Professore Lucasiano, \& 
Societatis Regalis Sodali. Imprimatur. S. Pepys, Reg. Soc. Praeses. Julii 5. 1686. Londoni, Jussu Societatis Regiae ac Typis Josephi Streater. Prostat apud plures Bibliopolas. Anno MDDCLXXXVII. (English Translation: Mathematical Principles of Natural Philosophy, published by University of California Press, Berkeley, 1934).

Niss, M. (1999), "Kompetencer og Uddannelsesbeskrivelse", Uddanneise, 9, pág. 21-29.

OCDE (1999), Measuring Student Knowledge and Skills - A New Framework for Assessment, OCDE, París, Francia.

OCDE (2000), Measuring Student Knowledge and Skills - The PISA 2000 Assessment of Reading, Mathematical, and Scientific Literacy, OCDE, París, Francia.

OCDE (2001a), Knowledge and Skills for Life - First Results from PISA 2000, OCDE, París, Francia.

OCDE (2001b), The New Economy - Beyond the Hype: The OECD Growth Project, OCDE, París, Francia.

OCDE (2002a), Sample Tasks from the PISA 2000 Assessment: Reading, Mathematical, and Scientific Literacy, OCDE, París, Francia.

OCDE (2002b), Reading for Change - Performance and Engagement across Countries, OECD, París, Francia.

O'Neil, H. (1999), A Theoretical Basis for Assessment of Problem Solving, (obra inédita presentada en el encuentro anual de la American Education Research Association), University of Southern California, Montreal, Canadá.

PEG (Grupo de expertos en solución de problemas) (2001), Problem Solving and OECD/PISA 2003, inédito, OCDE/PISA, París, Francia.

Polya, G. (1945), How to Solve It, Princeton University Press, Princeton, Nueva Jersey, EE. UU.

Robitaille, D. y R. Garden (eds.) (1996), Research Questions and Study Design, Pacific Educational Press, Vancouver, Canadá.

Romberg, T. (1994), "Classroom Instruction that Fosters Mathematical Thinking and Problem Solving: Connections between Theory and Practice", en A. Schoenfeld (ed.), Mathematical Thinking and Problem Solving, Lawrence Erlbaum Associates, Hillsdale, Nueva Jersey, EE. UU., pág. 287-304.
Ryjchen, D. y L.H. Salganik (2000), Definition and Selection of Key Competencies (DeSeCo), OCDE, París, Francia.

Schoenfeld, A.H. (1992), "Learning to Think Mathematically: Problem Solving, Metacognition, and Sense-making in Mathematics", en D. A. Grouws (ed.), Handbook of Research on Mathematics Teaching and Learning, Macmillan, Nueva York, Nueva York, EE. UU., pág 334-370.

Schupp, H. (1988), "Anwendungsorientierter Mathematikunterrricht en "Sekundarstufe I Zwischen Tradition und Neuen Impulsen", Der Mathematikunterricht, 34(6), pág. 5-16.

Seger, M.S.R. (1997), "An Alternative for Assessing Problem Solving Skills: The Overall Test", Studies in Educational Evaluation, 23(4), pág. 373-398

Shamos, M.H. (1995), The Myth of Scientific Literacy, Rutgers University Press, New Brunswick, Nueva Jersey, EE. UU.

Steen, L.A. (1990), On the Shoulders of Giants: New Approaches to Numeracy, National Academy Press, Washington, Distrito de Columbia, EE. UU.

Steen, L.A. (ed.) (1997), Why Numbers Count: Quantitative Literacy for Tomorrow's America, The College Board, Nueva York, EE. UU.

Stern, D. (1999), "Improving Pathways in the United States from High School to College and Career", Preparing Youth for the 21st Century - The Transition from Education to the Labour Market, OCDE, París, Francia.

Stewart, K. (1990), "Change", In L.A. Steen (ed.), On The Shoulders of Giants: New Approaches to Numeracy, National Academy Press, Washington, Distrito de Columbia, EE. UU.

Sticht, T.G. (ed.) (1975), Reading for Working: A Functional Literacy Anthology, Human Resources Research Organization, Alexandria, Virginia, EE. UU.

Stiggins, R.J. (1982), "An Analysis of the Dimensions of Job-related Reading”, Reading World, 82, pág. 237-247.

Swaak, J. y T. de Jong (1996), "Measuring Intuitive Knowledge in Science: The Development of the What-if Test", Studies in Educational Evaluation, 22(4), pág. 341-362. 
Trier, U. y J. Peschar (1995), "Cross-Curricular Competencies: Rational and Strategy for Developing a New Indicator", Measuring What Students Learn, OCDE, París, Francia, pág. 99-109.

Tversky, A. y D. Kahneman (1974), "Judgements under Uncertainty: Heuristics and Biases", Science, 185, pág. 1124-1131.

UNESCO (1993), International Forum on Scientific and Technological Literacy for All, Final Report, UNESCO, París, Francia.

Vosniadou, S. y A. Ortony (1989), Similarity and Analogical Reasoning, Cambridge University Press, Nueva York, Nueva York, EE. UU.

Ziman, J. M. (1980), Teaching and Learning about Science and Society, Cambridge University Press, Cambridge, Reino Unido. 



\section{$\neg$ GRUPO DE EXPERTOS DEL PROYECTO PISA 2003}

Grupo de expertos en matemáticas (MEG)

Jan de Lange, director

Universidad de Utrecht

Utrecht, Paises Bajos

Werner Blum, subdirector

Universidad de Kassel

Kassel, Alemania

Mary Lindquist, subdirectora

Columbus, Georgia, Estados Unidos

Vladimír Burjan

EXAM

Eslovaquia

Sean Close

St Patricks College

Dublín, Irlanda 
John Dossey

Illinois State University

Normal, Illinois, Estados Unidos

Zbigniew Marciniak

Universidad de Varsovia

Varsovia, Polonia

Mogens Niss

IMFUFA, Universidad de Roskilde

Roskilde, Dinamarca

Kyungmee Park

Universidad de Hongik

Seúl, Corea del Sur

Luis Rico

Universidad de Granada

Granada, España

Yoshinori Shimizu

Universidad Gakugei de Tokyo

Tokio, Japón
Grupo de expertos en lectura (REG)

Irwin Kirsch, director

Educational Testing Service

Princeton, Nueva Jersey, Estados Unidos

Marilyn Binkley

National Center for Education Statistics

Washington, Distrito de Columbia, Estados Unidos

Alan Davies

University of Edinburgh

Escocia, Reino Unido

Stan Jones

Statistics Canada

Nueva Escocia, Canadá

John de Jong

CITO, Instituto Nacional Holandés

de Investigación Educativa

Arnhem, Países Bajos

Dominique Lafontaine

Université de Liège

Lieja, Bélgica

Pirjo Linnakylä

Universidad de Jyväskylä

Jyväskylä, Finlandia

Martine Rémond

Institut National de Recherche Pédagogique

París, Francia 


\section{Grupo de expertos en ciencias (SEG)}

Wynne Harlen, director

University of Bristol, Reino Unido

Peter Fensham

Monash University

Melbourne, Australia

Raul Gagliardi

Ginebra, Suiza

Svein Lie

Universidad de Oslo

Oslo, Noruega

Manfred Prenzel

Instituto de Educación Científica Leibnitz

de la Universidad de Kiel

Kiel, Alemania

Senta A. Raizen

National Center for Improving Science Education

Washington, Distrito de Columbia, Estados Unidos

Donghee Shin

Universidad de Dankook

Seúl, Corea del Sur

Elizabeth Stage

University of California

Oakland, California, Estados Unidos

\section{Grupo de expertos}

en solución de problemas (PEG)

John Dossey, director

Illinois State University

Normal, Illinois, Estados Unidos

Beno Csapo

Universidad de Szeged

Szeged, Hungría

Wynne Harlen

Berwickshire, Reino Unido

Ton de Jong

Universidad de Twente

Twente, Países Bajos

Irwin Kirsch

Educational Testing Service

Princeton, Nueva Jersey, Estados Unidos

Eckhard Klieme

Instituto Alemán

de Investigación Educativa Internacional

Fráncfort del Meno, Alemania

Jan de Lange

Universidad de Utrecht

Utrecht, Países Bajos

Stella Vosniadou

Universidad de Atenas

Atenas, Grecia 